\title{
EXPLORING THE OPPORTUNITY FOR AN ENVIRONMENTAL CERTIFICATION PROGRAM FOR AIRBNB HOMEOWNER HOSTS
}

by

\author{
Geoffrey Fudurich \\ Bachelor of Commerce, University of Guelph, 2010
}

\author{
A thesis \\ presented to Ryerson University \\ in partial fulfillment of the \\ requirements for the degree of \\ Master of Applied Science \\ in the program of \\ Environmental Applied Science and Management
}

Toronto, Ontario, Canada 2017

(C) Geoffrey Fudurich 2017 


\begin{abstract}
Author's Declaration
I hereby declare that I am the sole author of this thesis. This is a true copy of the thesis, including any required final revisions, as accepted by my examiners.

I authorize Ryerson University to lend this thesis to other institutions or individuals for the purpose of scholarly research.

I further authorize Ryerson University to reproduce this thesis by photocopying or by other means, in total or in part, at the request of other institutions or individuals for the purpose of scholarly research.

I understand that my thesis may be made electronically available to the public.
\end{abstract}




\begin{abstract}
Exploring the Opportunity for an Environmental Certification Program

for Airbnb Homeowner Hosts

Master of Applied Science, 2017

Geoffrey Fudurich

Environmental Applied Science and Management, Ryerson University
\end{abstract}

This exploratory, qualitative study was focused on answering three research questions: 1) Would Airbnb homeowner hosts be willing to participate in an environmental certification program? 2) What would motivate Airbnb homeowner hosts to participate in an environmental certification program? 3) What program design elements would enhance the likelihood of their participation in the program? The study used semi-structured face-to-face and telephone interviews to collect data from Airbnb hosts. Only hosts in the Greater Toronto Area whose property was a freehold, detached or semi-detached house were eligible for participation. Results indicated a willingness to participate in an environmental certification program, with two unique motivations revealed, specifically the ability to attract like-minded guests and measure household impacts. A number of program design elements were also reviewed, with hosts' concerns focusing on cost and guest comfort. Hosts also expressed a preference for a program that leveraged the existing Airbnb review system. 


\section{Acknowledgements}

The successful completion of this thesis would not have been possible without the support I received from a number of individuals. Firstly, I would like to thank my faculty supervisor, Dr. Kelly MacKay, for her guidance through this process. Since my transition to Dr. MacKay as my supervisor I have benefitted greatly from her experience and encouragement, which significantly improved the thoroughness and rigour of my research and thesis.

I would also like to thank Dr. Sonya Graci, my original thesis supervisor and someone I could continually rely on for advice and feedback. Additionally, I would like to thank Dr. Chris Gibbs for assisting me with the development of my thesis topic and for sharing his knowledge and experiences regarding research similar to my own. Both Dr. Graci and Dr. Gibbs are also members of my thesis committee, for which I am also extremely grateful.

I have also greatly depended on the assistance of Elias Chu and Dr. Cory Searcy since my admission to the program. Thank you both for ensuring that all students in the Environmental Applied Science and Management program are aware of all events, significant dates, and program-related requirements that affect us.

A debt of gratitude is also owed to the participants in this study, whose generous sacrifice of time allowed me to investigate the topic under study.

Finally, I would like to thank my close family and friends whose support during this process has been unwavering and who were always willing to assist me in my academic pursuits.

Thank you. 


\section{Table of Contents}

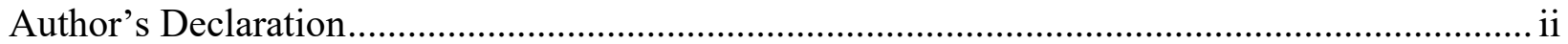

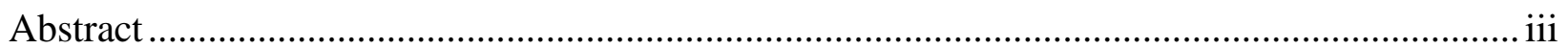

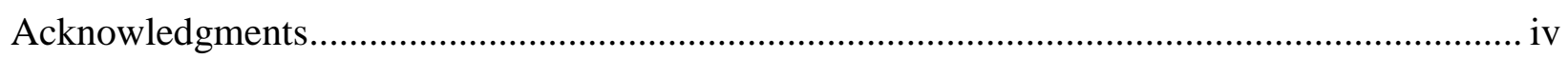

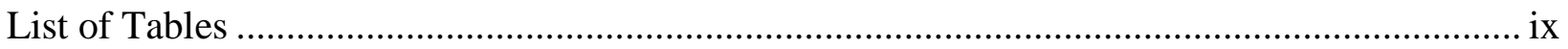

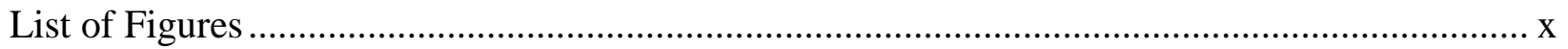

List of Appendices ........................................................................................................

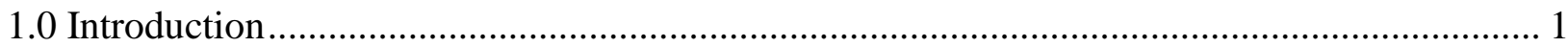

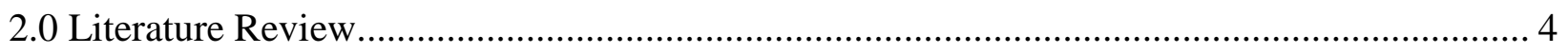

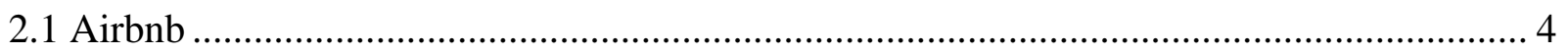

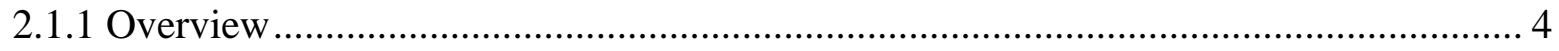

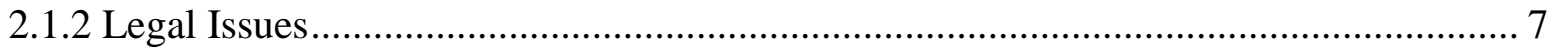

2.1.3 Airbnb in the Greater Toronto Area..................................................................... 9

2.1.4 Airbnb Environmental Branding Initiatives.......................................................... 11

2.1.5 Airbnb Environmental Impact Report ............................................................... 14

2.1.6 Airbnb and Collaborative Consumption .............................................................. 16

2.1.7 Motivations and Barriers for Choosing Airbnb ……….............................................. 19

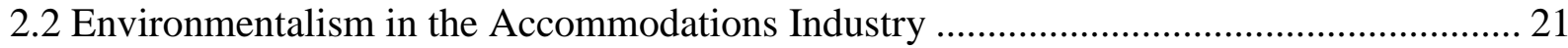

2.3 Environmental Certification in the Tourism Industry ..................................................... 25

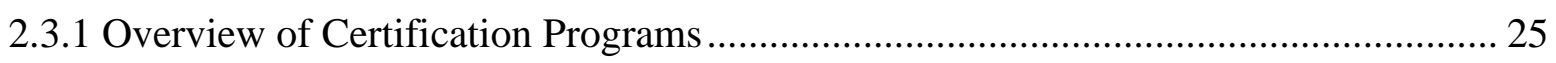

2.3.2 History and Growth of Certification Programs.......................................................... 27

2.4 Environmental Certification in the Hospitality Industry ……………............................ 28

2.5 Adoption of Environmental Certification ........................................................................ 29

2.6 Core Components of Environmental Certification Programs ……………………............. 31

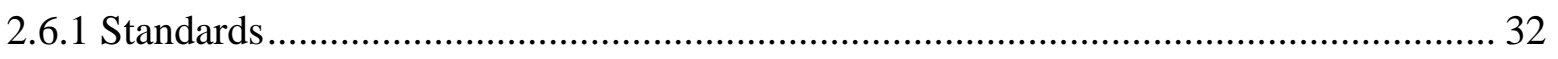

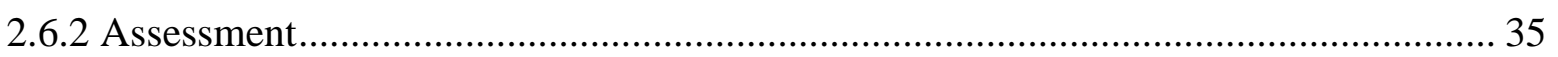

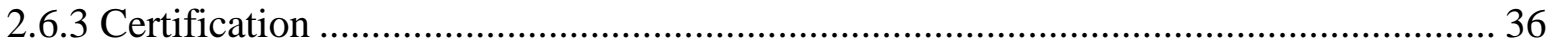

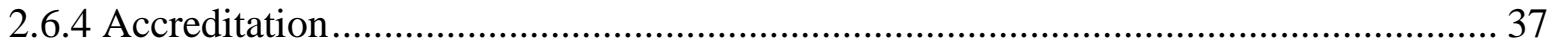

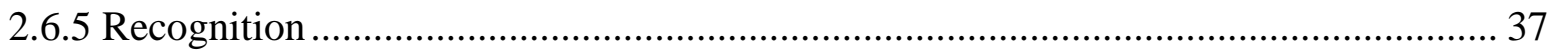

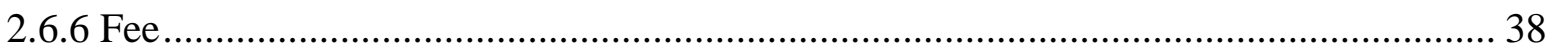

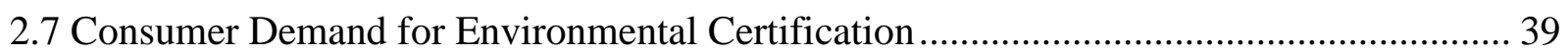

2.8 Consumer Behaviour Regarding Environmental Products ................................................ 43

2.9 Awareness of Environmental Certification Programs ......................................................... 47 
2.10 Motivations for Pursuing Environmental Certification ................................................... 49

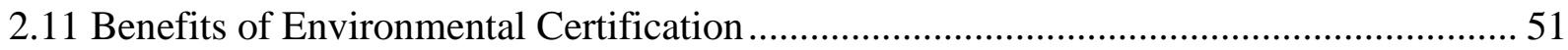

2.12 Motivations of Small Businesses for Pursuing Environmental Certification ................... 53

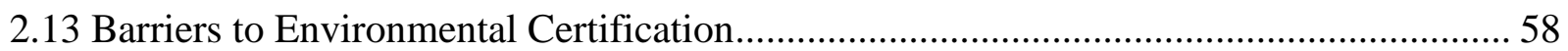

2.14 Development of Environmental Certification Programs ................................................... 61

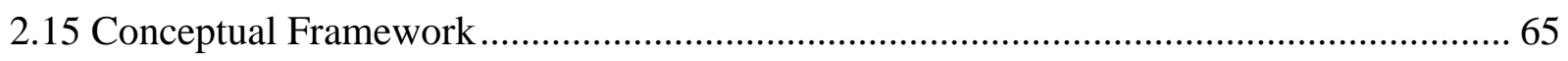

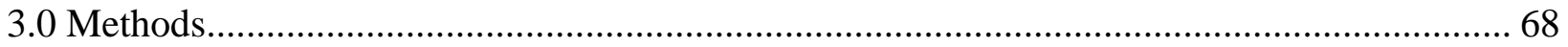

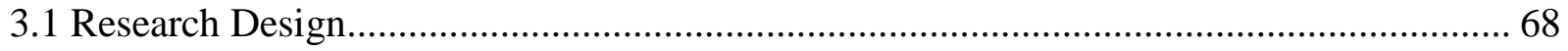

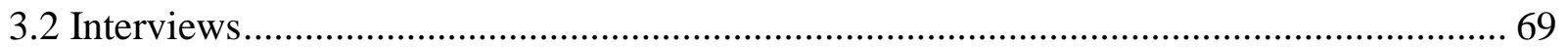

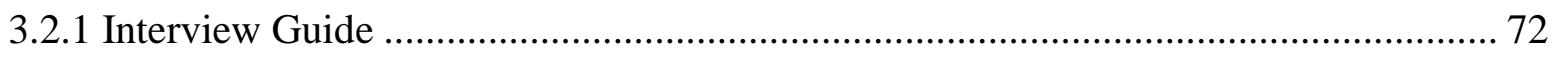

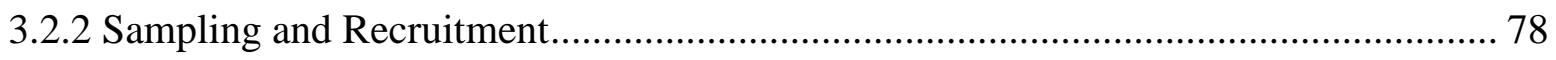

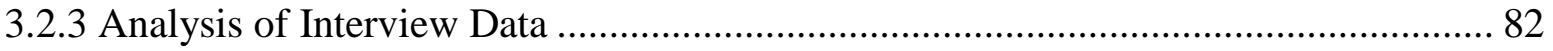

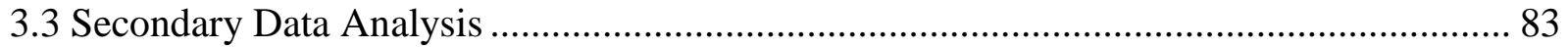

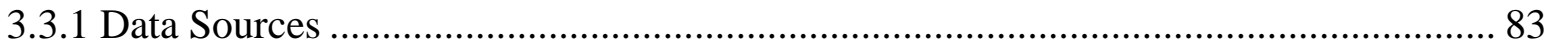

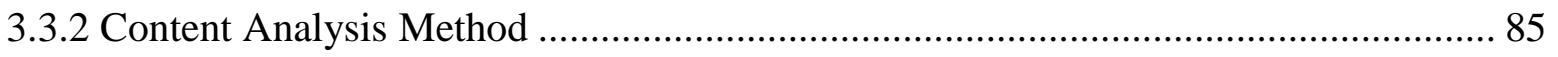

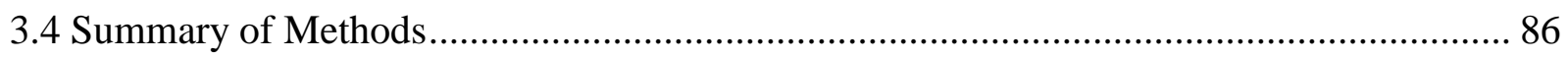

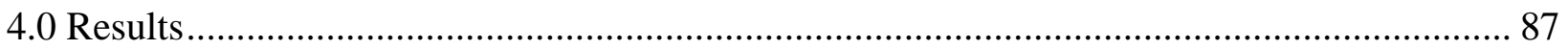

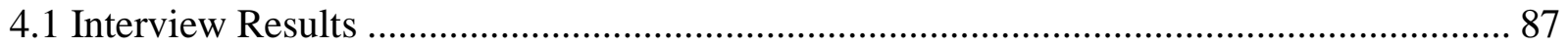

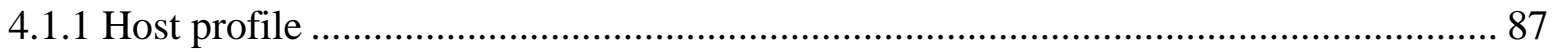

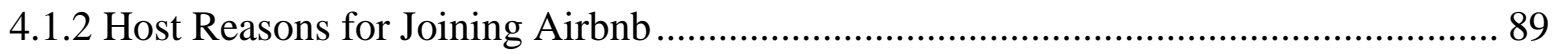

4.1.3 Familiarity with Environmental Certification Programs ............................................. 92

4.1.4 Willingness and Motivations Toward Participation .................................................... 93

4.1.5 Barriers to Participation ....................................................................................... 96

4.1.6 Preferred Type of Assessment ................................................................................. 98

4.1.7 Willingness to Participate in an External Program .................................................... 100

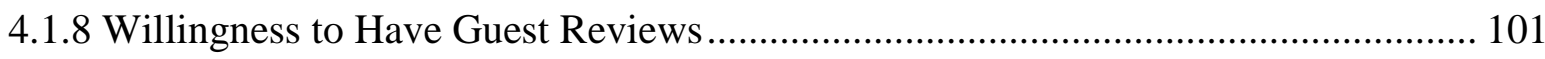

4.1.9 Comments Regarding Environmental Features …………...................................... 102

4.1.10 Guest Engagement Regarding Environmental Features and Behaviour.................. 102

4.1.11 Preference for Levels Versus Pass/fail Certification .............................................. 104

4.1.12 Perceived Value of Program to Guests ............................................................... 105

4.1.13 Environmental Categories............................................................................................ 107

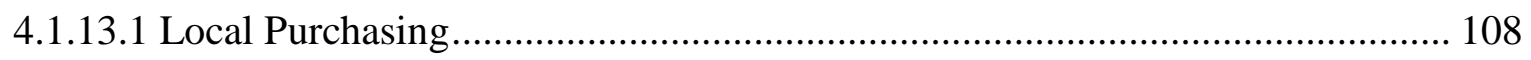




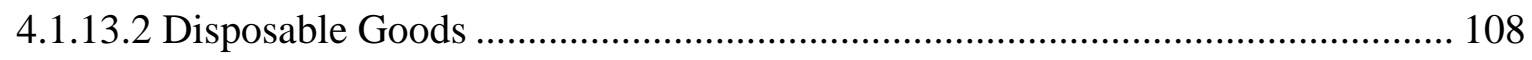

4.1.13.3 Energy Conservation................................................................................. 110

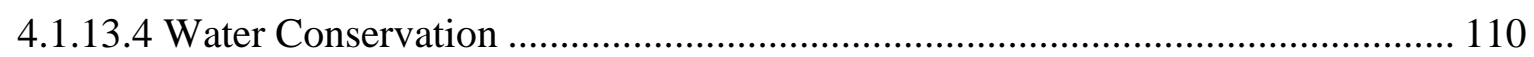

4.1.13.5 Transport Greenhouse Gas Emissions ………………..................................... 112

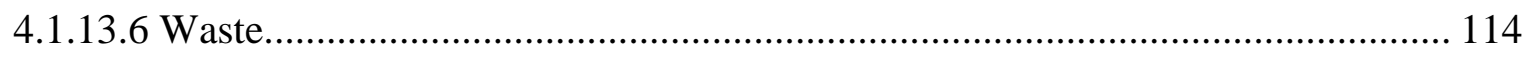

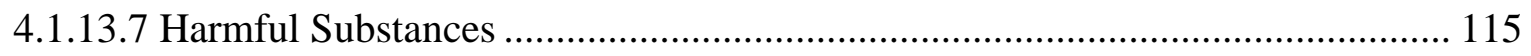

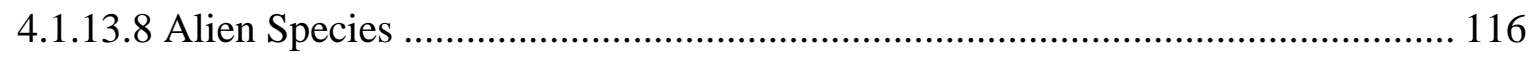

4.1.13.9 Other Themes from Environmental Criteria ................................................... 117

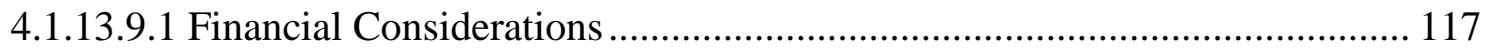

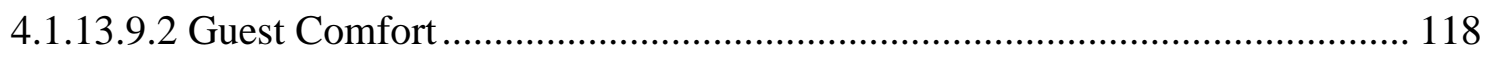

4.1.13.9.3 Guests Environmental Impact ............................................................... 119

4.1.14 Performance Versus Continuous Improvement .................................................... 120

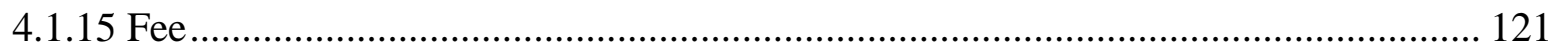

4.1.16 Awareness of 2014 Airbnb Environmental Report................................................. 124

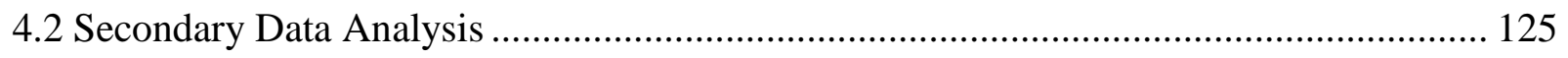

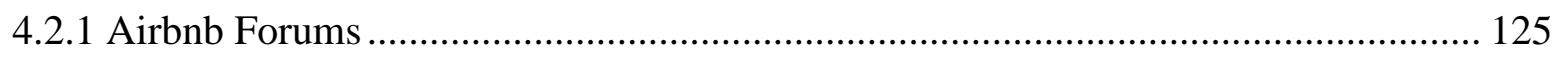

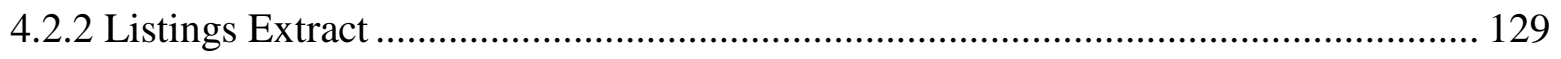

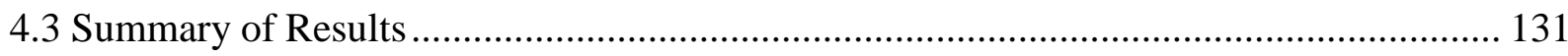

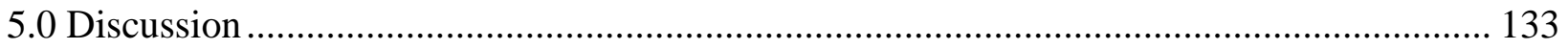

5.1 Research Question 1: Would Airbnb homeowner hosts be willing to participate in an environmental certification program? .............................................................................. 133

5.2 Research Question 2: What would motivate Airbnb homeowner hosts to participate in an environmental certification program?........................................................................... 136

5.3 Research Question 3: What program design elements would enhance the likelihood of their

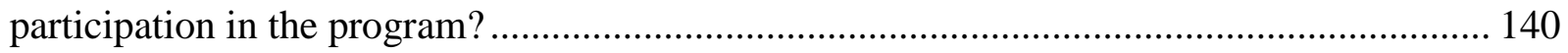

5.3.1 Integration with Existing Airbnb User Experience...................................................... 140

5.3.2 Demonstrated Commercial Benefit or Consumer Demand ....................................... 144

5.3.3 Managing the Guest Experience ......................................................................... 145

5.3.4 Levels Versus Pass/ fail .................................................................................... 148

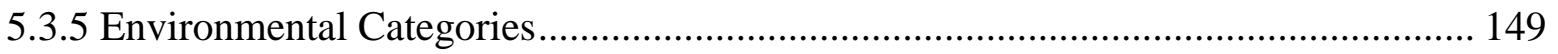

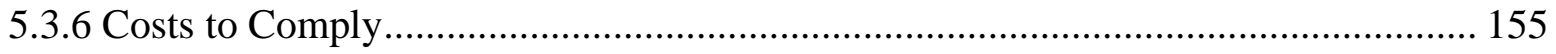

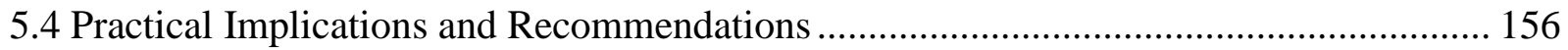

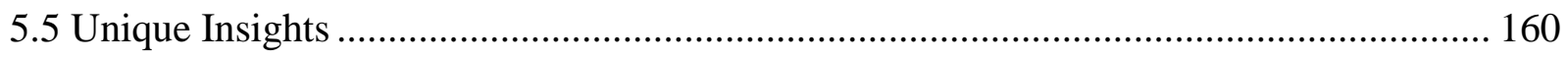




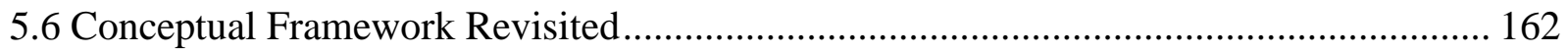

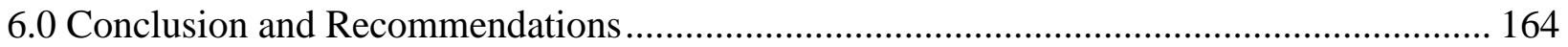

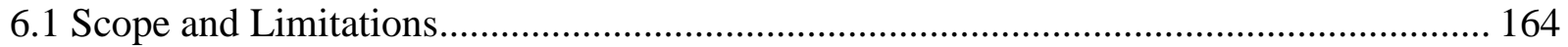

6.2 Recommendations for Future Research ............................................................. 166

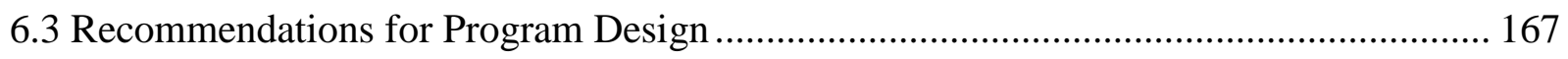

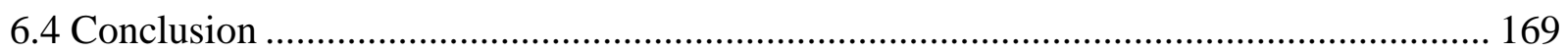

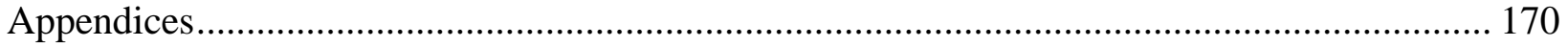

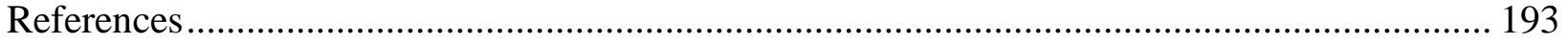




\section{List of Tables}

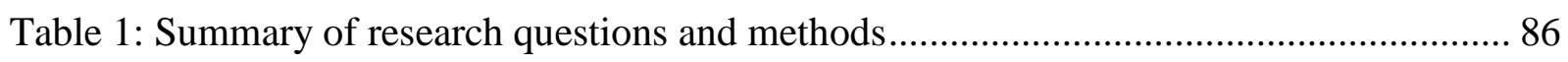

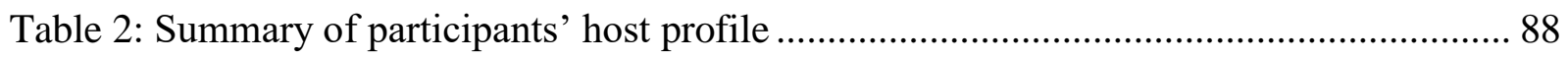

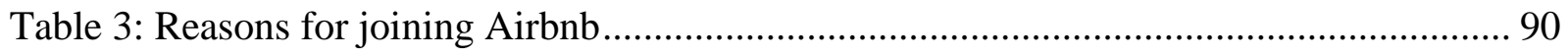

Table 4: Willingness to participate in an environmental certification program .................... 93

Table 5: Motivations mentioned by host status .......................................................... 96

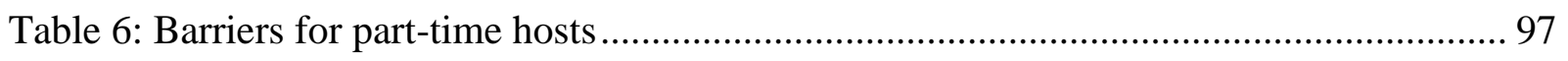

Table 7: Summary of perceived value of program to guests .......................................... 105

Table 8: Summary of host activities across environmental categories ................................ 107

Table 9: Summary of willingness to pay a fee............................................................... 122

Table 10: Summary of forum posts and comments .................................................... 126

Table 11: Summary of summative content analysis from Airbnb extract .......................... 130

Table 12: Summary of fit for environmental categories ............................................... 150 


\section{List of Figures}

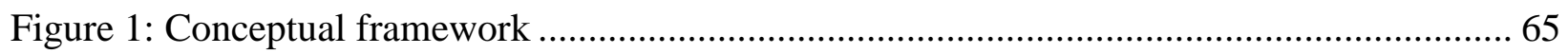

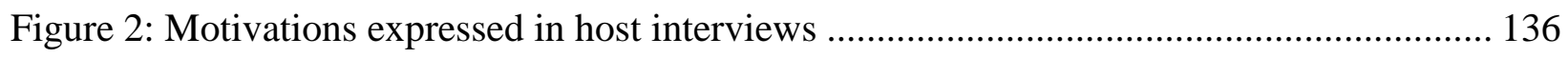

Figure 3: Conceptual framework revisited for Airbnb hosts .............................................. 163 


\section{List of Appendices}

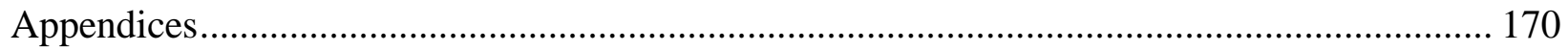

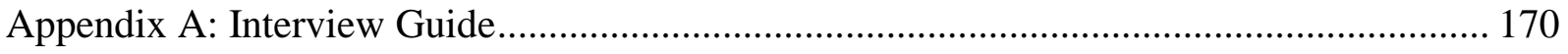

Appendix B: Certification Program Handout .................................................................... 174

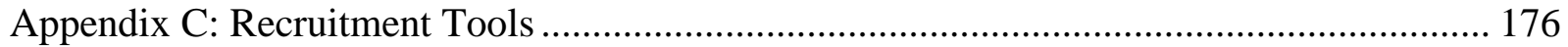

Figure C1: Request for Participation ................................................................... 176

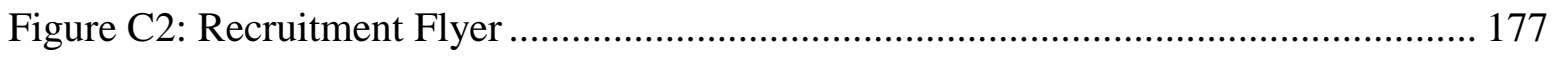

Appendix D: Secondary Data Analysis Results......................................................... 178

Table D1: Airbnb Forum Extract .............................................................................. 178

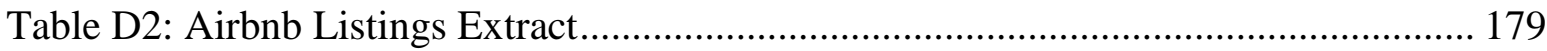

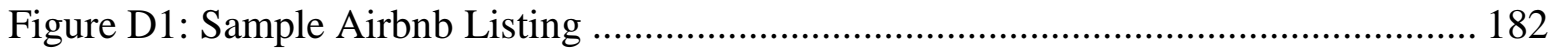

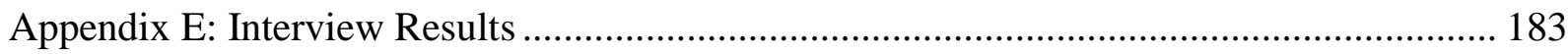

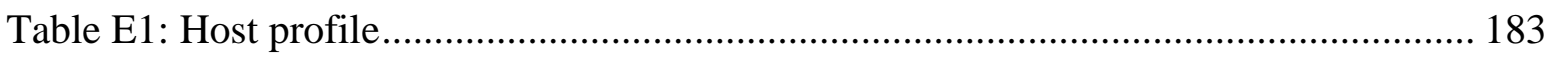

Table E2: Reasons for joining Airbnb by frequency ............................................... 183

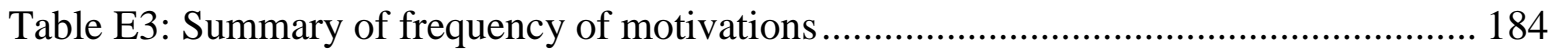

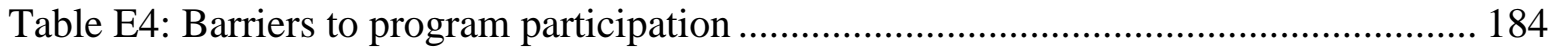

Table E5: Willingness to allow guest reviews of environmental initiatives..................... 184

Table E6: Willing to engage guests regarding environmental features ........................... 184

Table E7: Participant preference for type of certification ......................................... 184

Appendix F: Example of Qualitative Data Coding ........................................................ 185

Appendix G: GSTC Hotel Criteria, Section D - Maximize benefits to the environment and minimize negative impacts 


\subsection{Introduction}

This study explores the opportunity to develop an environmental certification program targeting Airbnb hosts. Since its birth in 2008, Airbnb has grown at an incredible pace and is now one of the highest valued accommodations companies globally, rivalling traditional market leaders (Shankman, 2015; King, 2016; Newcomer \& Huet, 2016). It is one of the most successful organizations to emerge from the consumer movement labelled collaborative consumption, a movement prioritizing low-cost, temporary use of items over ownership (Gansky, 2010; Bardhi, Eckhardt, \& Arnould, 2012).

Some academics and researchers claim collaborative consumption benefits the environment by promoting a more efficient use of resources (Botsman \& Rogers, 2010a), and Airbnb has pursued initiatives that suggest it intends to brand itself as an environmentally responsible choice for travelers (Airbnb, 2014; "Airbnb Partners with Nest," 2014). This is an unsurprising marketing approach given the fact that much research has shown a growing concern for environmental issues among travelers, especially amongst younger demographics (Esparon, Gyuris, \& Stoeckl, 2014; Kubickova, Nusair, \& Hu, 2015); however, a discrepancy seems to exist between environmental attitudes and purchase behaviour (Watkins, 1994; Lubbert, 2001; Font \& Wood, 2007).

Environmental certification is the process by which a service provider is awarded a logo for adhering to certain environmental standards (Black \& Crabtree, 2007). Hospitality providers have pursued environmental certification in order to demonstrate their environmental commitment (Geerts, 2014). In the context of Airbnb the hospitality provider is the host as they offer their residence to guests and are responsible for managing the property and listing. Given the apparent demand for environmentally responsible choices, the environmental claims by 
Airbnb and the frequent use of environmental certification within the hospitality industry, this research will explore whether Airbnb hosts would be interested in participating in such a program.

This exploratory study asks three research questions: 1) Would Airbnb homeowner hosts be willing to participate in an environmental certification program? 2) What would motivate Airbnb homeowner hosts to participate in an environmental certification program? 3) What program design elements would enhance the likelihood of their participation in the program? Interviews with hosts will be used to gather data related to these research questions. Secondary data analysis from Airbnb listings as well as Airbnb host forums will also be used to help triangulate the data.

Given the novelty of Airbnb, very little academic research has been done on the company, its hosts or its guests. Existing research has tended to focus on marketing, economic impacts or guest motivations (Guttentag, 2013, 2016; Yannopoulou, Moufahim, \& Bian, 2013; Zervas, Proserpio, \& Byers, 2014), though researchers have called for studies exploring the environmental aspects of the sharing economy (Heo, 2016), of which Airbnb is a leading organization. No research to date has been done on the environmental concerns of hosts or their motivations to pursue environmental certification. Adoption of such programs has been shown to be driven by a wide variety of motivations, but with smaller organizations the focus seems to be driven by economic considerations and personal environmental values (Tzschentke, Kirk, \& Lynch, 2008b; van Haastert \& de Grosbois, 2010; Sampaio, Thomas, \& Font, 2012).

This research will help to demonstrate whether Airbnb homeowner hosts in the Greater Toronto Area (GTA) would be interested in participating in an environmental certification program. The research could also be used to help guide the design and development of such a 
program; though given the limited geographic scope and sample the findings lack generalizability. That said, this study will contribute to the growing body of research on Airbnb as well investigate certification with reference to a previously unexamined cohort, private individuals providing hospitality services by renting part or all of their residence.

\section{Definitions:}

In the context of this thesis the term environmental certification refers to a "voluntary procedure that sets, assesses, monitors and gives written assurance that a business, product, process, service or management system conforms to a specific requirement" (Black \& Crabtree, 2007a, p. 20). This intentionally broad definition is used as this research is investigating host opinions regarding the program design elements of a certification program and therefore the definition could not include reference to specific program design elements or criteria.

Regarding the term environmental impacts, in the context of this research this is taken to represent the broad impact across a number of environmental criteria as outlined by the Global Sustainable Tourism Council's environmental criteria for hotels, specifically Section D Maximize benefits to the environment and minimize negative impacts (Global Sustainable Tourism Council, 2016) (see Appendix G). This list was reviewed to determine those categories relevant to Airbnb as explained in section 3.2.1, and includes items such as water conservation, energy conservation, waste, and harmful substances (see Appendix A for all categories). This overlaps closely with the categories included in Airbnb's definition of environmental impacts as outlined in their report "A Greener Way to Travel: The Environmental Impacts of Home Sharing" (Airbnb, 2014). 


\subsection{Literature Review}

This literature review will explain the origination and growth of Airbnb into a leading hospitality organization. It will then outline the environmental initiatives undertaken by Airbnb and how the company fits into the broader collaborative consumption movement. The remainder will explain the concept of environmental certification and its context within the hospitality tourism industry, including its adoption by hospitality providers and awareness among consumers. Special attention will be paid to the role of environmental certification in smaller organizations given their similarities to the Airbnb hosting model.

Research regarding homeowner's adoption of environmental initiatives was not included in this literature review. The author acknowledges that viewing Airbnb homeowner hosts through this lens would appear to be equally valid; however, given the lack of research on Airbnb hosts it is unclear how the dynamic between homeowner and accommodations provider manifests itself in Airbnb hosts. Therefore, it is unclear whether one should be prioritized over the other, or whether they should be viewed in combination.

\subsection{Airbnb}

\subsubsection{Overview}

Founded in 2008, Airbnb is one of the newest entrants into the hospitality industry. It is not a traditional accommodations provider though as it is an online platform that operates on the principle of home-sharing, also known as peer-to-peer accommodation rental services. The company works by allowing individuals, which the company refers to as hosts, to rent part or all of their property to guests for a fee (Airbnb, n.d.-a). Airbnb provides an online platform that allows these hosts to list their properties, which guests can then search for and book using the site. Unlike a hotel, the company does not own any of the properties that are listed on the platform. A host has control over how often they want to make their property available, whether 
it be for a couple of nights a year or for the entire year (Airbnb, n.d.-j). Airbnb generates revenue by taking a $3 \%$ share from each booking in addition to a service fee ranging from $6-12 \%$ (Airbnb, n.d.-j). The remainder of the booking fee is retained by the host.

Airbnb has experienced rapid growth since its inception in 2008. The company has grown from 40 million guest arrivals (counted as number of Airbnb trips per guest) in 2015 to 80 million in 2016 (Gallagher, 2017), and from approximately 1.4 million listings in 2015, to over 2 million in 2016 (Airbnb, n.d.-a; Lehr, 2015). This growth has outpaced traditional hotel chains Marriott and Hilton, as well as rival online accommodation platform Expedia (Shankman, 2015; Winkler \& MacMillan, 2015). It is also estimated that Airbnb is booking the same or more guests annually than its main competitors such as Marriott and Hilton, and that Airbnb's growth will continue to significantly outpace these traditional hotel brands (Heo, 2016; King, 2016). The company is now valued at $\$ 30$ billion (Newcomer \& Huet, 2016). This is higher than the valuation of traditional brands such as Hilton and Hyatt, and second only to Marriott (Wieditz, 2017); however, these valuations of private technology start-ups are often inflated (Frier \& Newcomer, 2015).

This tremendous growth has been met with mixed reviews in the hospitality industry. Airbnb maintains that it is a complement to the hotel industry as it encourages travel and thus increases the size of the hospitality market (Airbnb, n.d.-g; Guttentag, 2013; Griswold, 2015). However, the company appears to becoming a larger threat in major tourism cities such as New York, San Francisco and Los Angeles (Griswold, 2015; Lane \& Woodworth, 2016). Many industry experts and researchers alike have now expressed their opinion that Airbnb is a threat to the traditional hotel industry (Guttentag, 2013; Griswold, 2015). This is especially true of low 
and mid-range hotels given Airbnb's low price point (Zervas et al., 2014). In fact, recent research by Guttentag (2016) on Airbnb guest motivations found that over 93\% of guests in the sample would have chosen some other type of paid accommodation, with the most frequently chosen alternative being a mid-range hotel at $43.1 \%$, the second most being budget hotels at $17 \%$, and $4 \%$ for up-scale hotels. Airbnb claims that it provides extra capacity that hotels cannot meet and is therefore helping to grow the amount of available revenue as opposed to taking revenue from hotels; however, "a mere $2.3 \%$ of the overall sample indicated that the availability of Airbnb prompted them to take a trip they would not have otherwise taken" (Guttentag, 2016, p. 202).

Focusing on the industry impacts, a report from the Cowen and Company research group suggested that Airbnb's share of hotel and short-term rentals in the U.S. market will increase to $13 \%$ in the year 2025, up from $2.3 \%$ in 2016 , and it will cut hotel industry growth by $1 \%$ over the next decade (King, 2016). Despite this growth, Airbnb continues to look to new revenue streams; for example, in 2015 the company introduced a new corporate partnership program to target business customers, and hosts can now earn a business travel ready badge (Newcomer, 2015; Kulwin, 2016). The company also revealed a new feature called "Trips" at their November 2016 host conference, the Airbnb Open (Airbnb, 2016d; Ting, 2016). "Trips" allows guests to use the platform to book experiences and get recommendations for places to visit in addition to finding accommodation (Airbnb, 2016d). This looks to be an effort by the company to enter the pre-packaged travel market and grasp a greater share of travel dollars by offering tours and experiences specially crafted and offered by local hosts (Ting, 2016). It therefore appears that Airbnb is not satisfied with its current level of penetration and is poised to build off its early success by attempting to gain a greater share of travel dollars through new services. 


\subsubsection{Legal Issues}

Notwithstanding their rapid growth, Airbnb has also faced criticism from legislators as well as the public in cities where it operates. The company has been accused of avoiding taxation, distorting rental markets, and facilitating rentals that led to extensive property damage and vandalism (Leland, 2012; McCartney, 2012; Guttentag, 2013; Fiest, 2015).

In many cities, such as San Francisco, New York and Paris, short-term rentals require special permits and are usually only allowed in certain areas (Said, 2012; Leland, 2012;

Guttentag, 2013). In these cases, many Airbnb rentals are considered illegal if the property owner does not have one of these special permits. These illegal Airbnb operations have raised concerns among municipal governments as Airbnb hosts are avoiding laws created specifically for the short-term rentals they are offering. For example, these permits would allow cities to know where Airbnb properties are and thus have them subject to inspection, similar to other hospitality properties (Guttentag, 2013).

Without any regulation Airbnb is also able to have properties anywhere in a city. This could be problematic for communities or buildings that are not used to an influx of tourists suddenly being subject to a rapid inflow and overturn of tourists. There have already been several documented cases of Airbnb properties being vandalized and damaged by renters with complaints running from noise issues in cities like New York and San Francisco (Said, 2012; Leland, 2012), to reports of a house in Calgary being vandalized by Airbnb guests, resulting in damage of approximately $\$ 150,000 \mathrm{CAD}$ (Fiest, 2015).

Airbnb has also received criticism with regards to taxation. As many of the properties are informal rentals, municipalities are unable to collect taxes that would typically be charged to hospitality companies. In Chicago for example, visitors pay $16.4 \%$ tax on a hotel room, which is 
similar to rates charged in New York, Boston, Kansas City and Seattle (McCartney, 2012). In Toronto hotels have the option of charging a voluntary fee of up to $3 \%$ that's used to fund the Greater Toronto Hotel Association's Destination Marketing Program, which provides financial resources to the city's tourism body (Greater Toronto Hotel Association, n.d.; Murthy, 2016). These taxes are typically used to pay for tourism infrastructure such as convention centres and airports, as well as to fund municipal operations (McCartney, 2012). Usually, these taxes are also used to help promote the destination as a tourism attraction thereby benefitting all facets of the local tourism industry. By avoiding this tax Airbnb is benefitting from tourism promotion activities at no cost to their operations.

To tackle these issues, some regions are now beginning to enact legislation to control the growth of the company and bring it under a regulatory framework. Cities and regions all over the world, such as San Francisco, New York, Chicago and London have all introduced various forms of legislation targeting the short-term rental market, but ostensibly aimed at Airbnb (Walters, 2017; Fraser, 2017). For example, in October of 2015 the provincial government of Quebec enacted legislation that would require Airbnb hosts to abide by the same rules as other rental accommodations, including obtaining the same government permits as hotels and collecting provincial hospitality tax (Dougherty, 2015). Despite its apparent rigidness, there have been doubts regarding the effectiveness of this new law as fewer than 500 of the over 10,000 provincial listings have secured permits (Marowtis, 2016). Other cities like London and Amsterdam have enacted limits on the amount of days a host can make their property available, while Vancouver has stipulated that only a host's primary residence can be offered as a shortterm rental (Fraser, 2017). Some analysts believe this regulation is slowing Airbnb's growth in a 
few major markets like New York, though they clarify that growth does remain strong and Airbnb remains a threat to hotels (Kharpal, 2017).

\subsubsection{Airbnb in the Greater Toronto Area}

Many of the same criticisms Airbnb has faced internationally have been echoed in the Greater Toronto Area (GTA), however; Airbnb has begun to demonstrate some willingness to work with municipalities to address these issues. In 2016 the company released data on its operations in Toronto as part of its community compact initiative (Horgan, 2016), which was following on the heels of a similar release of data on the New York market (Isaac, 2015). This handing over of data has been viewed as an effort to show some goodwill and provide information that may assist in drafting legislation targeting short-term rentals (Isaac, 2015). Additionally, the company hopes to demonstrate that most of its hosts offer only one or two properties on the site, and are using Airbnb as supplemental income (Isaac, 2015; Kalinowski, 2016). The release of the Toronto data was particularly focused on demonstrating that the company is not distorting rental markets or contributing to a housing shortage (Horgan, 2016).

According to the Toronto figures the city has 8,600 hosts, with nearly $90 \%$ of hosts having just one entire home listing, nearly $75 \%$ of these entire home listings are shared for 90 days or less, and over $80 \%$ of hosts earn less than $\$ 12,780$ annually (Airbnb, 2016a, 2016c). While some have claimed that these data lack transparency and does not dispel accusations that a small number of hosts who list multiple properties account for a disproportionate amount of revenue (Clampet \& Petri, 2016; Horgan, 2016; Kalinowski, 2016), this data suggests that in the Toronto market the majority of Toronto hosts are part-time renters of their primary residence using the site to provide supplemental income. 
The company released an updated economic impact report for Toronto in February of 2017 outlining Airbnb's impact in the city over the previous year (urbanmetrics inc., 2017). The report suggested that Airbnb guests visiting Toronto spent approximately $\$ 417$ million, $\$ 40$ million of which is a direct result of Airbnb's presence in the city (urbanmetrics inc., 2017). The report states that this financial infusion to the economy from Airbnb is mostly due to Airbnb's affordability, which allows individuals to come who otherwise could not have afforded to, and also allows those who do come to stay longer (urbanmetrics inc., 2017). According to the report, Toronto is now Airbnb's fourth largest market in North America with more than 15,000 listings, and a 105\% growth in guest arrivals from 2015 to 2016 (urbanmetrics inc., 2017; Kalinowski, 2017). The presence of the service in the city is set to continue to grow along with tourism to the city. In fact, with passenger volume at Pearson International Airport expected to grow from 41 million in 2015 to roughly 65 million by 2035 (Frontier Economics Ltd., 2016; urbanmetrics inc., 2017), Airbnb is poised to become an increasing player in the accommodations landscape. Given the fact that this service is experiencing significant growth, and is also encouraging individuals to travel more and stay longer at their destination, Airbnb guests will be increasingly contributing to tourism related environmental impacts.

The release of this Toronto specific data is one of the first major steps Airbnb has taken to address growing concerns in the Toronto region regarding its influence on the housing market and disruptive rental properties (CBC News, 2016). Ontario does not have laws forbidding shortterm rentals; however, many condominium boards do not allow it and municipalities can create by-laws aimed at restricting short-term rentals (Weisleder, 2014; Leask, 2016). Public consultations regarding how to address short-term rentals in the City of Toronto were held in March and April of 2017 (City of Toronto, 2017), and although councilors say a ban is unlikely, 
growing pressure from disgruntled residents and Airbnb opposed stakeholder groups like Fairbnb may result in some type of regulation targeting short-term rentals (Fairbnb, n.d.; CBC News, 2016). In fact, Fairbnb.ca released its own report in early 2017 which attempted to debunk many of Airbnb's most auspicious claims (Wieditz, 2017). The report contained several accusations from tax avoidance to undermining communities, but focused on the disruption to the rental market being caused by Airbnb (Wieditz, 2017). The report suggested that due to the majority of listings being for entire homes, by definition these hosts are not "sharing" their space, and because a small number hosts operating multiple listings control a disproportionate amount of the revenues from Airbnb, Airbnb is shrinking the rental market by substituting possible rental properties with short-term rentals (Wieditz, 2017).

It is worth mentioning that Airbnb itself is beginning to facilitate and financially support grassroots movements among hosts in areas like San Francisco to fight legislation targeting Airbnb (Kelly, 2015). It appears it has employed a similar strategy in Toronto as public consultations have been well attended by pro-Airbnb individuals, many of whom wore matching Airbnb t-shirts. Given the rapid growth of Airbnb in Toronto, measured at $288 \%$ over the past two years (Kelly, 2015; Kalinowski, 2016), it is not surprising that Airbnb is actively involved in securing favourable legislation.

\subsubsection{Airbnb Environmental Branding Initiatives}

Airbnb has developed various initiatives to bolster its public image by promoting the positive effects of its business. Many of these have been focused on demonstrating the positive economic impacts Airbnb has on its community. For example, the company releases Home Sharing Activity Reports in many of its major markets internationally that highlight how Airbnb is helping the local economy through tourism activity and income for local hosts (Airbnb, n.d.- 
g). These reports fall under their broader program called the Community Compact, an initiative designed to illustrate the positive impacts Airbnb has on cities (Airbnb, n.d.-g).

The Community Compact identifies three major commitments Airbnb is making to cities where there are large Airbnb communities. These commitments are, treat every city personally and help ensure our community pays its fair share of hotel and tourist taxes; build an open and transparent community; and promote responsible home sharing to make cities stronger (Airbnb, n.d.-c).

While the aforementioned initiatives focus on highlighting the economic upside of Airbnb, the company has also made efforts to establish itself as environmentally conscious. In 2014 the company announced a partnership with Nest, a manufacturer of smart thermostats (“Airbnb Partners with Nest," 2014). The partnership provided selected hosts in the U.S. with a Nest thermostat paid for by Airbnb ("Airbnb Partners with Nest," 2014). While information was not available for how hosts were selected or their motivations for enrolling in such a program, based on the following quote from Lex Bayer, Head of Global Payments and Business Development at Airbnb, this appears to have been an effort to promote a more environmentally friendly lifestyle as opposed to saving hosts money. With regards to the program, he stated:

Airbnb wants to help hosts on their quest to be green. We want to enrich the lives of our hosts, their properties, and the communities they live in. This partnership with Nest gives our hosts access to state of the art technology that is both beautiful in design and at the same time is good for the planet. (Airbnb, n.d.-b, par. 4)

However, this program seems to have been unsuccessful as a review of Airbnb listings done by the researcher in December 2016 found only eight of their over two million properties 
listed as participating in the program (Airbnb, n.d.-e). No information was available regarding how the program was implemented, whether it is still functioning, and why the adoption rate was so low. According to a report from Airbnb though, it appears though that the company has launched a new partnership with another smart thermostat company named Vivint, as well as a partnership with SolarCity to allow hosts access to solar panels at reduced cost (Airbnb, 2017a).

The company has also partnered with the United Nations Environment Programme (UNEP) to promote sustainable travel, particularly during the 2016 Olympic Games, which included the publishing of a list of "sustainability tips" for travelers (Airbnb, 2016b). In April 2017 the company also announced its participation in the United Nations World Tourism Organisation’s (UNWTO) International Year of Sustainable Tourism for Development campaign, a year-long initiative aimed at increasing awareness and possibilities for sustainable travel (Airbnb, 2017b). It is unclear if Airbnb has launched any new initiatives or events related to this campaign as of July 2017. A company report released in March 2017 also highlighted some of the localized efforts aimed at reducing environmental impacts such as providing water management consultant services in Cape Town, South Africa during water shortages (Airbnb, 2017a).

Finally, an analysis of Airbnb’s branding activities by Yannopoulou, Moufahim and Bian (2013) found a discourse of sustainability present on website and social media content. This study revealed that through the use of user-generated content Airbnb has crafted its brand to achieve a desirable brand identity (Yannopoulou et al., 2013). 


\subsubsection{Airbnb Environmental Impact Report}

In addition to the Nest partnership, 2014 also saw the release of a report on the environmental benefits of home-sharing, commissioned by Airbnb (Airbnb, 2014). According to Airbnb's press release the study found that:

Airbnb promotes a more efficient use of existing resources and is an environmentally sustainable way to travel. Traveling on Airbnb results in significant reduction in energy and water use, greenhouse gas emissions, and waste, and encourages more sustainable practices among both hosts and guests. (Airbnb, 2014, par. 3)

The report was conducted by Cleantech Group, a business service organization focused on promoting sustainable innovation (Cleantech Group, n.d.). The report claimed that North American hosts demonstrate environmental awareness by providing recycling options, owning energy efficient appliances, and avoiding provision of single use toiletry products (Airbnb, 2014). This report though has been criticized due to its lack of transparency, sponsorship by Airbnb, and the fact that it came at a time when the company was being heavily criticized for disrupting rental markets in major cities (Montgomery, 2014; Snyder, 2014; Volkmann, 2015; Hamilton, 2015). The report also may have suffered from some measurement issues, particularly an inflated measure of hotel resource use as it included resource use by non-occupied rooms as well as amenities, including restaurants, golf courses, and conference rooms (Cleantech Group, 2014). Regardless, this appears to have been another attempt by Airbnb to establish an environmentally friendly reputation.

Airbnb has claimed it is environmentally friendly and has pursued initiatives consistent with that assertion, although some of these claims remain dubious. These efforts have been seen by some as a public relations response to negative attention the company has received around 
claims of tax avoidance and rental market distortion (McCartney, 2012; Montgomery, 2014;

Kalinowski, 2016), and there does not appear to be consensus that Airbnb is truly a more environmentally responsible travel choice over traditional hospitality options (Volkmann, 2015), and academic research has not been done to verify the claims made in the report from Cleantech Group. The company has promoted a partnership with Nest under the pretense that it is to promote "green" behaviour among hosts, which after two years appears to have almost no adoption, though it appears this program has been revitalized in partnership with Vivint. It has engaged with various United Nations groups in order to promote sustainable travel, though the outcome of its most recent engagement with the UNWTO remains unclear. It is worth noting that Airbnb has no official environmental policy regarding their properties; the company only requests that hosts abide by local regulations (Airbnb, n.d.-h), although based on the selfcommissioned research Airbnb seems to believe their hosts have a strong environmental ethic.

The development of an environmental certification program could give hosts the opportunity to demonstrate their environmental commitment to their guests, thus helping to legitimize Airbnb's claims of having an environmentally conscious host population. Hospitality researcher Dr. Rachel Dodds suggests hosts may be a target for environmental programs stating with regards to environmental sustainability, "Airbnb could do more to educate the consumer and make an impact... Perhaps this is a missed opportunity for Airbnb" (Volkmann, 2015, par. 42). Additionally, as stated by Hamilton (2015) "as a single point of contact for millions of hosts and travelers, Airbnb can easily reach out to that community - whether it's to educate, nudge or incent more sustainable behaviour" (para. 35). While there have been regionally targeted efforts to educate guests and hosts (e.g., 2016 Olympic Games and Cape Town), a certification program could be a wide-reaching and standardized way to promote sustainable behavior. To date there 
has not been an academic study examining hosts' interest in committing to environmental initiatives.

\subsubsection{Airbnb and Collaborative Consumption}

Airbnb is just one example of a company capitalizing on a widespread consumption trend which is the adoption of collaborative consumption, otherwise known as the "sharing economy". Collaborative consumption is an economic and cultural phenomenon that is changing the way people consume by capitalizing on the idling capacity of assets such as cars, properties, and tools. This model allows individuals to access goods and services at a much lower cost than ownership (Botsman \& Rogers, 2010a). In this model individuals gain access to goods and services by paying a nominal fee for the experience of temporarily accessing them, thereby valuing the functionality of an item over the convenience and control afforded by ownership (Gansky, 2010; Bardhi et al., 2012; Tussyadiah, 2015). Sharing economy refers both to companies that offer temporary use over ownership (e.g., Netflix, Zipcar) and individuals who rent out resources they own (e.g., Airbnb, Uber) (Guttentag, 2016).

This trend emerged in the early 2000s, but has experienced significant growth in recent years (Binninger, Ourahmoune, \& Robert, 2015). This growth has been attributed to several factors such as the low-cost model, desire for more social interactions, increased pressure on resources, and changing attitudes towards consumption (Gansky, 2010; Tussyadiah, 2015; Hamari, Sjoklint, \& Ukkonen, 2016). Its adoption has also been aided by the sense of trust built between users fostered by the peer review systems built into most platforms (Botsman \& Rogers, 2010b; Gansky, 2010). The ubiquity of the Internet has also helped fuel this new industry, as most successful organizations in the sharing economy are technology companies that offer web- 
based platforms allowing users to interact and share resources, such as Airbnb and the ridesharing application Uber (Binninger et al., 2015; Tussyadiah, 2015).

Generally speaking, collaborative consumption is believed to help reduce negative impacts as it can limit overconsumption by using existing resources more efficiently, thus requiring fewer new products to be produced (Botsman \& Rogers, 2010a; Binninger et al., 2015). According to Prothero et al. (2011), "by shifting the paradigm away from individual ownership to collectivity and sharing, less demand for consumer goods may give way to a new economy that could help take on problems such as pollution and excessive energy usage" (p. 36). Additionally, Gansky (2010) argues that increased awareness of environmental issues among consumers is a motivating factor to find ways to use resources more efficiently. This issue of increased awareness of environmental issues will be discussed in greater detail in further sections.

This notion of sustainability seems to have been leveraged as a marketing tactic for some organizations. Research examining the sustainability dimension of collaborative consumption websites and consumer blog posts related to those websites in France found that these websites frequently promote the concept of sustainability or a reduced ecological footprint in their marketing messages (Binninger et al., 2015); though it should be noted that Airbnb was not one of the sites included in that study. As for the consumers in that study, ecological motives for choosing collaborative consumption were mentioned, however it was relatively infrequent compared to more socially driven motives such as the desire to develop social skills and the pursuit of social equality (Binninger et al., 2015). These findings appear to indicate that these 
companies are using environmental messages in their marketing, but that they may not be resonating strongly with customers.

Another recent study by Hamari et al. (2016) found that factors such as sustainability, economic benefits, and enjoyment influence participation in collaborative consumption. The researchers found that the strongest factors influencing behavioural intentions were enjoyment and economic benefits, and that while perceived sustainability positively influences attitudes towards sustainable consumption, it does not strongly influence behavioural intentions (Hamari et al., 2016). This discrepancy between attitude and behaviour with regards to environmental concerns has been widely documented by other researchers and will be discussed in detail in the section 2.8 .

With regards to peer-to-peer accommodation rental services specifically, which includes Airbnb, research by Tussyadiah (2015) found that sustainability, in terms of environmental and social responsibility, was a motivator for travelers choosing peer to peer accommodation rentals although it was not as strong as the economic factor. The author used online surveys to measure both the drivers and deterrents of collaborative consumption and found that in order to attract additional consumers, peer-to-peer accommodation businesses need to "highlight the sustainability and economic benefits from collaborative consumption (e.g., by offering transparent, side-by-side comparison with competing accommodation businesses)" (Tussyadiah, 2015, p. 11). An environmental certification program, with transparent criteria and a customer facing logo, can allow customers to make that comparison.

The sharing economy has been the focus of limited academic research due to its novelty, and the research that is available tends to suggest that low cost is the primary motivator. 
However, preliminary research by Tussyadiah (2015), Hamari (2016) and Binninger et al. (2015) shows that environmental values play a role in customers' perception of collaborative consumption, and companies are reinforcing this perception through their marketing. Recently there has been a call for more research on this topic. A research note from Heo (2016) states several research prospects worth pursuing regarding the sharing economy and tourism, including the relationship between environmentally responsible tourism and participants in the sharing economy. This research study can help elucidate this relationship with a particular focus on Airbnb hosts as a subset of sharing economy participants.

\subsubsection{Motivations and Barriers for Choosing Airbnb}

A recent study by Guttentag (2016) examined the motivations of travelers for choosing Airbnb. Guttentag (2016) used cluster analysis in his study of motivational factors for Airbnb use and developed five distinct groups of consumers, each representing approximately one-fifth of the sample. While sampling was non-random Guttentag (2016) asserts that "given the representativeness detected within the overall sample, it is reasonable to conclude that the segment sizes are roughly similar and there is no single segment that dominates the Airbnb guest population" (p. 179).

The five segments identified were money savers, home seekers, collaborative consumers, pragmatic novelty seekers, and interactive novelty seekers (Guttentag, 2016). Overall, the results revealed that low-cost was the dominant factor, followed by convenient location and access to household amenities (Guttentag, 2016). This appears to echo the Airbnb economic impact report for Toronto which found that "approximately $90 \%$ of Airbnb guests in Toronto relied on the platform as a means of saving money compared to hotels" (urbanmetrics inc., 2017, p. 3). 
The environmentally friendly motivation was ranked as one of the least powerful factors overall; in fact, there was an overall slight disagreement with Airbnb being chosen for its environmental benefits. However, this was ranked as one of the stronger factors for a subset of respondents identified as "collaborative consumers" (Guttentag, 2016), a group defined by their desire for authenticity, social interaction, and support for the philosophy of Airbnb. Collaborative consumers were also more likely to be backpackers and to use shared accommodations than the other traveler segments (Guttentag, 2016). Interestingly, the collaborative consumer group was ranked as the most loyal to Airbnb, and also the most likely to have been an Airbnb host themselves (Guttentag, 2016), possibly suggesting that these values are more strongly demonstrated in the host population.

Airbnb has released its own data regarding environmental preferences of its guests and indicated that " $72 \%$ of Airbnb guests say the environmental benefits of home sharing were of at least some importance in their choice of Airbnb" (Airbnb, 2017a, p. 2). Viewed in isolation this claim appears to indicate a strong environmental preference among Airbnb guests; however, the source data of this claim was not available nor was clarification regarding how this factor related to other considerations such as price, location, convenience could not be found. Therefore, the findings by Guttentag (2016) provide a more thorough understanding of guest motivations.

In terms of barriers to choosing Airbnb Tussyadiah (2015) cited trust as one of the major barriers. This distrust was demonstrated both towards the accommodations host as well as the actual service platform, which in this case is Airbnb. This finding was echoed in a Morgan Stanley report (Nowak et al., 2015) on Airbnb which found that after lack of awareness, concerns over privacy and safety were the most commonly cited reasons for why someone had not yet 
tried Airbnb. Airbnb has tried to address this concern through its review system, and the inclusion of a picture along with descriptive personal information in guest profiles (Guttentag, 2016). This trust issue is important though, as needs such as safety, quality and price must be satisfied before a consumer will consider environmental factors (Bien, 2006b; Font \& Wood, 2007; Dodds \& Joppe, 2009), suggesting that until Airbnb overcomes this trust barrier environmental factors may remain a secondary consideration for guests.

\subsection{Environmentalism in the Accommodations Industry}

The accommodations industry is responsible for a variety of environmental impacts including land alteration, energy use, carbon emissions and waste production (Gössling, 2002). Hotels and tourism operations began to demonstrate concern for the environment starting in the 1960s (Vernon, Essex, Pinder, \& Curry, 2003; Goldstein \& Primlani, 2012), but it was the early 1990s with the release of the Brundtland Report in 1987 and the Rio Earth Summit in 1992, that marked the beginning of a renewed focus on environmental issues in the tourism industry (Honey, 2002; Vernon et al., 2003; Dodds \& Joppe, 2009; Williams \& Ponsford, 2009; Jarvis, Weeden, \& Simcock, 2010). With regards to hotels specifically, most major chains began introducing modest changes to improve environmental performance at this time, such as recycling programs, optional towel laundry service, and installation of more efficient plumbing and lighting fixtures (Ayala, 1995; Honey \& Stewart, 2002).

Around this same time industry associations began developing their own environmental guidelines to respond to the growing demand for more environmentally responsible travel (Honey, 2002). Efforts took the form of codes of conduct, statements of principle, best practices, awards, and eco-labels as well as the establishment of new business forums like The International Ecotourism Society (Honey, 2002). Within the hotel industry a group of major 
hotel chain executives founded the International Hotels Environment Initiative (IHEI) in 1992 to "increase general environmental awareness and to establish valid guidelines within the global hotel industry" (Honey, 2002, p. 43). Since then the accommodations industry has been one of the leading sectors within tourism in terms of sustainability reporting, along with transportation, with initiatives focused on reducing water, energy and waste becoming commonplace among many of the world's leading hotel brands (Jayawardena, Pollard, Chort, Choi, \& Kibicho, 2013). In fact, Hilton, Marriott Starwood, Accor Hotels and Rezidor all have instituted programs ostensibly aimed at protecting the environment (Weaver, 2009; El Dief \& Font, 2010; Hamilton, 2015).

These broad efforts though, as well as the motives supporting them, have come under some criticism. It has been suggested that these actions were likely done in order to avoid, or influence the development of government environmental regulation (Hjalager, 1996; Honey, 2002). These efforts have also been labelled as greenwashing, a term used to describe corporate initiatives that are intended to demonstrate commitment to the environment, but which in reality provide little or no protection to the environment (Honey, 2002; Black \& Crabtree, 2007; Jones, Hillier, \& Comfort, 2014). In these cases, environmental initiatives are essentially used as a marketing tactic, targeting consumers with environmental concerns without actually addressing those concerns; one of the most common examples being the towel and linen re-use programs seen in many hotels (El Dief \& Font, 2010), as these programs are usually cost savings masked as environmental concern. Due to their typically voluntary nature it has also been argued that sustainability reporting by companies has been primarily used for improving brand image rather than measuring the social or environmental impacts of the company (Tyrrell, Paris, \& Biaett, 2013). Perhaps due to this perceived deception, research has shown though that consumers are 
increasingly sensitive to greenwashing efforts and are becoming more discerning when evaluating environmental claims (Horiuchi, Schuchard, Shea, \& Townsend, 2009; Pomering \& Johnson, 2009; Baker, Davis, \& Weaver, 2013; Geerts, 2014).

When companies do pursue environmental programs, cost-savings appears to be a primary motivator. Research conducted by Jones, Hillier and Comfort (2014) examining sustainability reporting of the world's leading hotel chains found that many of these companies seem to choose sustainability initiatives that deliver cost benefits. With regards to how these companies define their sustainability agenda, Jones et al. (2014) state:

these definitions can be interpreted as being developed around efficiency and a commitment to securing competitive advantage within the marketplace, and they reflect business demands rather than fundamental concerns for sustainability or for the maintenance and enhancement of natural ecosystems. While a number of the top ten hotel chains' environmental commitments are designed to reduce natural resource consumption, for example, they also produce cost savings. (p. 12)

It is not surprising that these large, multinational companies choose environmental initiatives that also deliver cost benefits, but as will be explained in section 2.10 and 2.12 the motivations for pursuing certification appear to be more varied, especially among smaller organizations.

Weaver (2009) argues that the initiatives adopted by these large and established tourism companies are mostly token gestures and are relatively non-threatening with respect to their current business model. He suggests that their goal in implementing these actions is to deflect 
negative attention, build greater brand equity and further establish themselves as the industry leaders and that this "paradigm nudge", as he calls it, by industry reflects the equally unambitious and tepid response by consumers to these issues (Weaver, 2009). Weaver states that "the respective attitudes of industry and the general public are therefore remarkably similar, from strong accordance with the rhetoric of sustainability to an equally strong unwillingness to engage in personal sacrifice to attain the ends espoused by that rhetoric" (Weaver, 2009, p. 36). The issue of consumer demand for these programs will be further explored in section 2.7.

The tourism industry holistically is a significant source of environmental impacts due to the resources required, and emissions produced from air travel, accommodations and leisure activities (Gössling, 2002). While transportation is responsible for the majority of energy use and $\mathrm{CO}_{2}$ emissions, accommodations are responsible for up to one-fifth of tourism related $\mathrm{CO}_{2}$ emissions (Gössling, 2002; Gössling \& Buckley, 2016). Broadly speaking, environmental impacts of small and medium-sized businesses are not well understood due to a lack of research; however, it is speculated that due to the number of these businesses (approximately $90 \%$ of businesses and $70 \%$ of economic activity in Europe), their collective environmental impact is substantial (Hillary, 2000). It has been estimated that these businesses may account for up to $70 \%$ of environmental pollution, though due to the lack of research this number is largely unsubstantiated (Hillary, 2000). Nevertheless, they represent a potentially major source of environmental impacts, especially as many lack awareness of their environmental impacts or the resources to address them (Hillary, 2000; Schaper \& Carlsen, 2004).

As with the sector at large, minimal research has been done regarding the environmental impacts of smaller accommodations even though they represent a substantial portion of the 
accommodations sector (van Haastert \& de Grosbois, 2010; Dodds \& Holmes, 2011). In fact, it has been suggested that up to $90 \%$ of tourism related businesses are small businesses (Toth, 2002; Graci \& Dodds, 2015), and Statistics Canada data indicates that $98 \%$ of employment in the accommodations and food services sector is from SME's, with the smallest businesses (1-19 employees) accounting for $46 \%$ of employment (Innovation Science and Economic Development Canada, 2016). Actual energy intensity of smaller accommodations such as B\&Bs compared to hotels seems to vary based on factors such as climate, building condition, heating, plumbing, and occupancy, with some studies showing relatively high energy intensity (Becken, Frampton, \& Simmons, 2001), and some showing lower comparative energy intensity (Kuo \& Chen, 2009). Despite the ambiguous data, as Airbnb's share of this sector continues to grow, so too will its share of environmental impacts.

\subsection{Environmental Certification in the Tourism Industry}

\subsubsection{Overview of Certification Programs}

In order to legitimize claims of environmental concern and dispel accusations of greenwashing, many firms choose to pursue environmental certification (Wiengarten, Pagell, \& Fynes, 2013; Geerts, 2014). Certification is a "voluntary procedure that sets, assesses, monitors and gives written assurance that a business, product, process, service or management system conforms to a specific requirement” (Black \& Crabtree, 2007a, p. 20). In an environmental context certification typically includes assurances or indicators related to environmental issues like energy use, water use, greenhouse gas emissions, and use of chemical or harmful substances (Honey \& Stewart, 2002; Bricker \& Schultz, 2011; Jayawardena et al., 2013). It should be noted that the terms eco-label, eco-certification and environmental certification are all terms used somewhat interchangeably as they all represent a designation indicating conformance to some set of environmental criteria. It has been argued that they represent different things as certification 
indicates conformance to some baseline criteria, where as an eco-label is usually awarded only to businesses demonstrating significantly better performance than their peers (Bien, 2006a; Graci \& Dodds, 2015). Within this literature review the term eco-label will primarily be used when referring to research or external sources that specifically used that term. Alternatively, the term environmental certification program will be used when referring to the research being done for this thesis. These terms have been used interchangeably in previous studies on the topic (Synergy Ltd, 2000; Black \& Crabtree, 2007; Golden et al., 2010; Karlsson \& Dolnicar, 2016).

The term environmental management system (EMS) will also be used; however, much less frequently than the aforementioned terms. This term refers to a system that allows organizations to better manage their environmental impacts (Wu, Chu, \& Liu, 2007; Chan, 2008). EMS's require assessment to ensure compliance with the standards of the program, so in this way they are very similar to a certification program (Hsiao, Chuang, Kuo, \& Yu, 2014; Sanchez-Medina, Diaz-Pichardo, \& Cruz-Bautista, 2016); however, EMS's are typically more comprehensive and rigorous including guidelines for management and operations. According to the International Organization for Standardization (ISO) an EMS is "part of the management system used to manage environmental aspects, fulfil compliance obligations, and address risks and opportunities" (International Organization for Standardization, 2015b, p. 2). More specifically it touches on a range of organizational components including "structure, planning activities, responsibilities, practices, procedures, processes and resources for developing, implementing, achieving and reviewing, and maintaining the environmental policy" (Chan, 2008, p. 188). Generally speaking, EMS's include certification, but not all certification programs are EMS's. 
The ISO14001 standard is one of most popular global EMS standards (Toth, 2002;

Perkins \& Neumayer, 2010; Graci \& Dodds, 2015). ISO 14001 is an international environmental management system standard that is part of the larger ISO 14000 suite of standards focused on environmental management (International Organization for Standardization, 2015a). ISO 14001 "helps organizations improve their environmental performance through more efficient use of resources and reduction of waste, gaining a competitive advantage and the trust of stakeholders" (International Organization for Standardization, 2015, p. 2).

It is a voluntary standard that can be applied to all types and sizes of organization as it does not include specific performance criteria; as such it is a process based standard (Honey \& Stewart, 2002). It is the only standard in the suite of ISO 14000 standards focused on environmental management, that a company can be certified against (Chan, 2008; Gavronski, Ferrer, \& Paiva, 2008). There are mixed opinions regarding the effectiveness of ISO 14001, but generally, research tends to support the fact that ISO 140001 leads to improvements in environmental performance (Prajogo, Castka, Yiu, Yeung, \& Lai, 2016).

\subsubsection{History and Growth of Certification Programs}

Along with broader environmental efforts, environmental certification programs also began to emerge shortly after the 1992 Earth Summit (Honey, 2002; Bien, 2006a). One of the major outcomes of this summit was Agenda 21, which called for environmental and social responsibility across all industries; this was followed by the creation of various forms of certification for agriculture and commodities such as bananas, timber, and coffee (Bien, 2006a). In the ten years following the Earth Summit more than 60 environmental tourism certification programs were developed, with that number growing to 80 by 2007 (Font, 2002; Bien, 2006a). 
Currently there are over 400 eco-labels worldwide, with approximately 150 focusing on tourism (Sustainability in tourism: A guide through the label jungle, 2016; Castka \& Corbett, 2016; Gössling \& Buckley, 2016; Park \& Millar, 2016). Among environmental tourism certification programs, the majority focus on accommodations, specifically small scale operations (Synergy Ltd, 2000; Font, 2003; Dodds \& Joppe, 2009). Font (2003) ascertained that approximately two-thirds of tourism focused environmental certification programs are managed by either NGOs, private tourism associations or consultancies, with the other one-third managed by government agencies. Comparing the market penetration of these labels remains challenging though as reliable data on membership is not available from all schemes (Burgin \& Hardiman, 2010; Font, 2012).

\subsection{Environmental Certification in the Hospitality Industry}

Environmental certification programs for hospitality providers are usually focused on the activities of a particular organization and can range from relatively weak enforcement such as awards to strong enforcement through third-party accreditation and audits (Black \& Crabtree, 2007). In fact, it has been argued that some of these weaker awards are an act of greenwashing themselves (Dodds \& Joppe, 2005; Millar \& Baloglu, 2011). Additionally, given the lack of global monitoring of these programs or an agreed set of minimum standards it is difficult to determine whether these programs, broadly speaking, deliver improvements (Dodds \& Joppe, 2005).

Another criticism of certification programs is that it is usually quite challenging for certifying bodies to discern what actions were by a company as a direct result of pursuing certification, and which initiatives were already in place (Morgenstern \& Pizer, 2007). Some research has shown that firms that adopt voluntary environmental certification are already 
compliant with the associated requirements and thus require minimal investments in order to participate in the program, or were already investing in environmental initiatives prior to the program (Tzschentke, Kirk, \& Lynch, 2004; Ayuso, 2007; Morgenstern \& Pizer, 2007; Vidovic \& Khanna, 2007).

However, a strong program design that is transparent, includes measurable criteria, and requires third-party auditing can help separate legitimate programs from the weaker ones (Synergy Ltd, 2000; Font, 2002). For example, Castka and Corbett (2016) used surveys to investigate expert opinions on the governance of 41 eco-labels and found that these experts ranked the Forestry Stewardship Council (FSC) as better governed than other forestry certifications like the Sustainable Forestry Initiative (SFI) and Sustainable Forest Management Certification (CSA). This better ranking was based on examining the presence of six assurance practices: governmental control, third-party audits, verifies accredited, chain of custody, field site visits, and standard setting (Castka \& Corbett, 2016). The researchers found that eco-labels that utilized independently accredited verifiers and were managed by a government agency are generally perceived by experts, to be better governed (Castka \& Corbett, 2016).

\subsection{Adoption of Environmental Certification}

Several major international hotel chains have pursued some type of environmental certification program. This includes Hilton Worldwide achieving ISO 14001 certification for its more than 3,750 properties (Hilton Worldwide, n.d.), as well as Marriott and Starwood having both mandated that all newly constructed buildings will be LEED certified (Hamilton, 2015). In fact, Starwood achieved LEED certification for its global headquarters in early 2015, part of a broader sustainability goal that includes reducing energy use by $30 \%$, water use by $20 \%$, and 
carbon emissions by $30 \%$ at all hotels globally by 2020 (“Starwood Hotels \& Resorts' Global Headquarters Earns Highest Environmental Certification,” 2015).

With specific regards to certification, the Rezidor Hotel Group - which operates over 500 hotels in Europe, Middle East and Africa, and is Europe's ninth largest hotel group by number of rooms (Rezidor Hotel Group, 2016; “Top 10 hotel groups in Europe,” 2016) - aims to have all of its hotels environmentally certified as part of its Responsible Business program (Rezidor Hotel Group, n.d.). As of the end of 2015 , a total of 272 or $77 \%$ of their hotels had received certification (Rezidor Hotel Group, n.d.). With regards to this goal the company states:

external confirmation of our hotels' environment performance is essential to our business. Eco-labels provide an independent third-party audit of each hotel's practices and actions to protect the environment. Our target is to have $100 \%$ of our hotels eco labelled. (Rezidor Hotel Group, n.d., par. 1)

One of the more prominent programs targeting hotels specifically is the Green Key Ecorating program based. This Canadian program, founded in 1997, evaluates and certifies properties globally based on their sustainable practices, including energy conservation, water conservation, solid waste management and hazardous waste management (Green Key Global, n.d.-b). The program to date has over 1,700 participating hotels (Green Key Global, n.d.-b). In 2009, Fairmont Hotels and Resorts, which operates over 70 luxury hotels globally, announced that it intends on achieving Green Key certification for its 20 American properties (Fairmont, 2009). Somewhat confusingly, there is another certification program named Green Key based in Denmark, which has over 2,500 certified properties in more than 53 countries (Green Key, n.d.). 
Another international program is Green Globe, founded in 1994, which offers environmental certification across all sectors of the tourism industry (Parsons \& Grant, 2007). This program had 211 individually certified hotels under the Green Globe Standard in 2007 (Weaver, 2009); a review of its members on the Green Globe website in October 2016 revealed that this number had increased to 532. This program will be described in further detail in section 2.14 .

Overall, it is difficult to accurately predict the market penetration of eco-labels, as the penetration for eco-labelled products varies greatly by product category and by region (Rex \& Baumann, 2007). For example, while market share for eco-labeled paper in Nordic countries is above $70 \%$, organically labeled food in those same countries represents less than $10 \%$ of market share (Rex \& Baumann, 2007). Furthermore, a study of eco-label organizations by the Nicholas Institute for Environmental Policy Solutions at Duke University revealed that only $25 \%$ of these organizations were aware of any studies that examined the market share of their label (Golden et al., 2010).

Within the accommodations industry, data from 2005 seems to indicate the penetration is below 1\% (Dodds \& Joppe, 2005); however, based on the growth of these programs among some of the largest hotel brands internationally, and the significant gap with regards to measurement, the accuracy of this value can be called into question.

\subsection{Core Components of Environmental Certification Programs}

Many different types of certification programs exist with varying design elements, though common components include standards, assessment, certification, accreditation and recognition (Font, 2002; Toth, 2002; Bien, 2006a). 


\subsubsection{Standards}

The standard is typically a list of requirements that must be met in order to qualify for certification (Toth, 2002). A property may already be meeting these criteria or may require financial investments to ensure criteria are met. The standards in these programs can generally be divided into either process based or performance based, although a growing number of programs constitute a mix of both (Font, 2002; Honey \& Stewart, 2002; Toth, 2002; Bien, 2006a).

Process based programs include many EMS's, such as ISO 14001 and the EcoManagement and Audit System (EMAS) (Honey \& Stewart, 2002; Graci \& Dodds, 2015). These programs do not require adherence to any metrics or benchmarks, typically only requiring that the organization show continuous improvement relative to past performance (Graci \& Dodds, 2015). Process based programs are generally regarded as being more versatile than performance based as they can be applied cross-industry and focus on general improvements as opposed to strict metrics (Honey \& Stewart, 2002). This versatility also helps organizations that operate in different geographies as performance benchmarks for resource use can vary greatly by geography and climate (Synergy Ltd, 2000; Font, 2002); for example, a hotel in Norway has very different energy needs than a hotel in Mexico. They also ensure that a company has internal controls in places to sustain improved performance, as well the appropriate resources to support continued measurement of indicators by incorporating environmental management as part of an organization's culture (Bien, 2006a).

Critics argue that the lack of specificity makes these programs too broad to be effective as environmental impacts are not accurately measured (Honey \& Stewart, 2002). Additionally, because companies have the flexibility to craft their own environmental policy against which their compliance will be measured, organizations may develop very weak policies (Honey $\&$ 
Stewart, 2002). Essentially, process based programs measure how a business does something as opposed to what it does; it requires continuous improvement but not specific level of performance (Honey \& Stewart, 2002; Bien, 2006a; Graci \& Dodds, 2015). Therefore, this type of standard does not ensure that an organization is actually limiting its environmentally destructive behaviour, only that it has a system in place to monitor and improve performance (Toth, 2002). Two organizations could both be subject to the same process standard, but vary greatly in their actual performance. This leads to statements by authors such as Krut and Gleckman that "a company making weapons for biological warfare can be certified to ISO 14001" (Honey \& Stewart, 2002, p.54). Given their breadth they can also be very costly, with cost estimates of up to $\$ 40,000$ for medium-sized companies (Honey \& Stewart, 2002). Due to these drawbacks there is a growing consensus that process based programs alone are not enough to ensure environmentally responsible practices as companies can achieve recognition just by setting up a program, rather than meeting specific performance benchmarks (Synergy Ltd, 2000; Honey \& Stewart, 2002).

Performance based programs measure an organizations performance against a set of externally determined benchmarks, objectives or criteria (Honey \& Stewart, 2002; Graci \& Dodds, 2015). The key differentiator to process based programs is that all organizations applying for certification are subject to the same benchmarks and goals (Honey \& Stewart, 2002). Blue Flag certification program for beaches is an example of this type of program as it requires certain microbiological levels to be met (Honey \& Stewart, 2002).

These programs are typically less costly than process based programs to implement as they do not require establishing organization wide management systems (Honey \& Stewart, 2002; Graci \& Dodds, 2015). This makes them better suited for small and medium sized 
enterprises, which account for $80-90 \%$ of tourism organizations globally (Toth, 2002; Graci \& Dodds, 2015). They can also provide easier comparisons between organizations, especially among organizations within the same climactic or geographical circumstances (Honey \& Stewart, 2002; Bien, 2006a). Additionally, because these programs measure actual achievement and not intent they represent a more promising path to achieving sustainability (Honey \& Stewart, 2002).

That said, this type of program does have its drawbacks. Challenges exist primarily around the measurement of the criteria in the program. For example, if the data is self-reported as opposed to measured by a third-party the program's credibility could be called into question (Bien, 2006a). Also, many measures are ambiguous, or undefined which can lead to debates regarding whether they were achieved or not (Toth, 2002). They are generally considered less thorough than process based systems as they may only measure a few indicators, whereas a process-based standard requires an entire management system designed to continually monitor performance across the business along with the resources available to do so (Bien, 2006a).

It appears that there is a growing trend to incorporate both process and performance criteria in programs so as to leverage the benefits of each style (Synergy Ltd, 2000; Font, 2002; Honey \& Stewart, 2002). The Nordic Ecolabels for Hotels for example represent a hybrid of both programs that include elements such as performance criteria for water use, and a process focus on staff training (Honey \& Stewart, 2002).

Given the growing recognition that neither process nor performance alone can promise the environmental improvements desired by consumers and society, it appears that this hybrid approach will continue to be refined and gain in popularity. As stated in a Synergy (2000) report commissioned by World Wildlife Fund, this hybrid approach "encourages business to establish 
comprehensive environmental management systems that deliver systematic and continuous improvements, include performance targets and also encourage business to invest in technologies that deliver the greatest economic and environmental benefits within a specific region" (p. 29).

In terms of the standards setting process, standards can be developed by recognized standards development organizations or by ad hoc groups, such as industry groups (Toth, 2002). The former are usually considered stronger than the latter as they typically leverage a broader stakeholder group and develop consensus-based standards, which is an indication of a more credible program (Toth, 2002; Graci \& Dodds, 2015). Castka and Corbett (2016) determined that having a transparent and consensus-based standards setting process results in more favourable media coverage of an eco-label regardless of the other design elements. Consensus-based standards setting refers to consulting broad groups of stakeholders openly, in the process of creating the standards (Balzarova \& Castka, 2012). The researchers concluded that "if a label is generally excellent but not open- and consensus-based, the media appear more likely to mistrust it and to report less favorably than such a label deserves based on its actual merits" (Castka \& Corbett, 2016, p. 321).

\subsubsection{Assessment}

Assessment can take the form of either first-, second- or third-party (Font, 2002; Toth, 2002). Third-party verification is generally perceived as more credible and trustworthy given the independent verification of the standards (Font, 2002; D’Souza, Taghian, Lamb, \& Peretiatko, 2007; Castka \& Corbett, 2016), and this sense of trust and credibility in an eco-label is regarded

as a key success factor for any program (Castka \& Corbett, 2016). However, this element is also usually the costliest given its time consuming and rigorous nature (Fennell \& Malloy, 2007; Rattan, 2015). As such, third-party assessment is not universal, with many programs opting to 
pursue first- or second-party assessment (Font, 2002; Castka \& Corbett, 2016). First-party or self-assessment is when an individual or organization declares their conformance to the standards (Toth, 2002). Second-party assessment is when an organization that is offering a product assesses the suppliers of that product so that they can ensure to their customers that the product meets the standards (Toth, 2002). Given their lack of independence, first- and second-party assessments are considered weaker than third-party (Synergy Ltd, 2000; Font, 2002; Bien, 2006a; Black \& Crabtree, 2007).

Rattan (2015) suggests using a combination of styles to reduce costs associated with assessment, with the ultimate goal being "that the certification is financially attainable for all parties involved but is still reputable, legitimate and transparent" (p. 118). As an example, the Australian National Ecotourism Accreditation Programme (NEAP) employs a mixture of secondand third-party assessment strategies in order to minimize the costs of training verifiers as well as due to the significant distance between applicants (Font, 2002).

\subsubsection{Certification}

Certification is the provision of documented assurance that a product meets the standards. This certification can take a number of forms from pass/ fail system to a graded system (Toth, 2002; Bien, 2006a). Graded schemes are often considered preferable by companies to pass/ fail schemes as they acknowledge various levels of achievement, and motivate firms to improve and thus achieve a higher grade (Bien, 2006a). Field studies by Toth (2002) revealed that hoteliers prefer graded systems to pass/ fail as they did not want minor compliance issues to deny them any recognition of their environmental commitment. Costa Rica's Certification for Sustainable Tourism (CST) is an example of a graded scheme as it has five different award levels based on the weighted score of a questionnaire (Honey \& Stewart, 2002); as is the Green Tourism 
Business Scheme in the United Kingdom which uses gold, silver, and bronze levels of achievement (Sampaio et al., 2012).

The certification process can be also be classified as either first-, second- or third-party based on how the assessment is done and thus how the logo is awarded (Toth, 2002). For example, with first-party or self-assessment a company can declare its product or service complies with certain requirements and display the appropriate logo; however, a third-party certification requires that an independent body conduct and review the assessment to determine whether a certificate should be awarded (Toth, 2002).

\subsubsection{Accreditation}

Accreditation qualifies an organization to perform assessment and certification (Toth, 2002; Bien, 2006a; Black \& Crabtree, 2007). Essentially, accreditation is "certifying the certifier" (Bien, 2006a, p. 16) as it requires an independent third-party, unrelated to the certifier or program applicants, to evaluate the certifier and verify they are capable of properly performing assessment and certification activities (Toth, 2002; Black \& Crabtree, 2007). Accreditation is most common in decentralized certification programs where various certifiers all evaluate conformance to the same standard, such as ISO which uses a network of accredited certifiers to administer its ISO 14001 certification (Toth, 2002). Similarly, the Global Sustainable Tourism Council (GSTC) accredits other certification programs to ensure they meet minimum global standards and to validate their use of independent third-parties (Global Sustainable Tourism Council, n.d.-d). The history of the GSTC will be further discussed in section 2.14 .

\subsubsection{Recognition}

Recognition is the acknowledgment of an organizations certification, usually through the awarding of some type of logo that signals to consumers that the property has met the required 
environmental standards (Synergy Ltd, 2000; Dodds \& Joppe, 2009; Graci \& Dodds, 2015). This logo may then be used to inform the decision-making of consumers or individuals dealing with the certified organization (Toth, 2002; Graci \& Dodds, 2015). In this sense Font (2012) argues, "eco-labels are meant to be useful marketing brands by translating complex issues into a simple, endorsed and meaningful message" (p. 302).

Beyond the presence of a logo though, recognition also refers to the acceptance of the standard by stakeholders based on their reputation and credibility (Toth, 2002). This credibility is usually shaped by the aforementioned design elements (e.g., open and transparent standards development and third-party assessment), but can be aided through endorsement from a government agency or NGO (Toth, 2002). Additionally, the program could subscribe to the guidelines of an international accreditation body like the International Social and Environmental Accrediting and Labelling Alliance (ISEAL), which publishes Codes of Good Practice which aim to guide the creation of credible standards globally (ISEAL Alliance, n.d.; Toth, 2002; Graci \& Dodds, 2015).

In order to be accepted by the targeted industry (i.e. potential applicants) the program must be perceived to deliver benefits to the business (Toth, 2002). These benefits will be further explained in section 2.11, but a key element for all programs looking to gain acceptance is a marketing program that educates consumers and companies on the benefits of the program (Toth, 2002).

\subsubsection{Fee}

An application or membership fee is usually charged to organizations applying for certification to help fund the administration of the program (Synergy Ltd, 2000; Font, 2002, 2012; D’Souza et al., 2007). In exchange the applicants usually get access to training materials 
that can help them become certified (Green Key Global, n.d.-b; Font, 2012). Although a fee is typically charged to applicants by the certification body, these programs are usually subsidized by governments or NGO's to help fund the operating costs of the program (Font, 2012). It has been argued that these subsidies are necessary in order to keep fees low, thus improving the likelihood of certification to deliver financial benefits either through improved efficiency or brand image (Font, 2012).

Membership fees vary from program to program and can range depending on the size of the business and assessment style (Synergy Ltd, 2000), especially since the assessment can represent a significant portion of the program's costs (Fennell \& Malloy, 2007; Rattan, 2015). For example, the Canadian Green Key program charges its members $\$ 450$ annually and uses a self-assessment tool (Green Key Global, n.d.-a), whereas Green Globe charges an annual fee between $\$ 750$ and $\$ 5,000$ based on hotel size, plus costs of consulting and third-party auditing (Green Globe, n.d.-d). Beyond the application or membership fee, organizations many need to pay consultants to help them achieve certification as well as invest in new equipment or programs in order to meet the program requirements (Synergy Ltd, 2000; Toth, 2002; Wu et al., 2007; Chan, 2011).

\subsection{Consumer Demand for Environmental Certification}

Consumer demand for environmentally superior products has been the subject of much academic and industry research. It appears that a growing number of tourists are coming to expect environmentally friendly operations from hospitality providers (Manaktola \& Jauhari, 2007; Williams \& Ponsford, 2009; Millar \& Baloglu, 2011; Jayawardena et al., 2013). Given the option of choosing an eco-friendly hotel or another one, all other things being equal, the 
consumer is more likely to choose the eco-friendly option, so long as those environmental practices can be observed (Manaktola \& Jauhari, 2007).

Research by Andereck (2009) found that tourists place fairly high levels of importance on environmentally friendly practices at tourism sites and businesses, ranging from energy conservation to landscaping using native plants. This study also found support for environmental practices specifically among individuals whose motivations for travel are primarily focused on interaction with nature, as well as among younger travelers (Andereck, 2009). This preference for environmentally responsible travel options among younger travelers has been observed in other studies (Jayawardena et al., 2013; Esparon et al., 2014; Kubickova et al., 2015). For example, research conducted by Kubickova et al. (2015) examining the buying intentions of Generation Y or Millennials (defined by the researchers as individuals born after 1975) found that "hotels participating in green practices will gain a competitive edge while attracting and retaining Generation Y as a future guests” (p. 24). This could be especially important for Airbnb as younger travelers appear to be the most frequent users of peer-to-peer accommodation rental services (PWC, 2015; Kokalitcheva, 2015; Guttentag, 2016).

This expectation does not appear to be limited to young or nature-oriented travelers though. According to the 2012 Canadian Travel Intentions Survey, $42 \%$ of business travelers stated that evidence of energy efficiency or recycling influences their choice of accommodations, an increase from just 5\% in 2011 (Hamilton, 2015). The Hotel Association of Canada's 2014 Travel Intentions Survey revealed a similar trend, finding that $44 \%$ of Canadian business travelers felt eco-certification of hotels was important, an increase from 18\% in 2013 (Hamilton, 2015). 
Numerous European surveys have highlighted the fact that consumers have a stated preference for "green" certified products and services, and want more information regarding environmental impacts when choosing destinations (Lubbert, 2001; Fairweather, Maslin, \& Simmons, 2005; Budeanu, 2007; Font \& Wood, 2007). For example, a report funded by the European Commission that looked at studies from Italy, Germany and the Netherlands found broad support for use of an eco-label (Consultancy and Research for Environmental Management (CREM), 2000). Some of the highlights include strong support among Italians for an environmental certification for accommodations; that the majority of domestic and foreign German tourists agreed that an eco-label would be useful; and that among the Dutch, $86 \%$ thought it would be important to provide information on the environmental performance of accommodations, with a scoring system or eco-label being the most frequently identified method of doing so (Consultancy and Research for Environmental Management (CREM), 2000).

Staying within the European context, a Danish study revealed that among guests who had stayed in a Green Key certified hotel (referring to the Danish Green Key program), 69\% expressed a willingness to pay extra to stay in a certified hotel in the future (Budeanu, 2007; Burgin \& Hardiman, 2010). Additionally, a study of German tourists by Lubbert (2001) found that the information provided by an eco-label was its most important attribute as it allowed comparison between products.

Another study among international visitors to New Zealand split tourists into either having biocentric values or being ambivalent, with the former viewing nature as requiring protection from use for economic or social gains, and the latter not demonstrating strong environmental values (Fairweather et al., 2005). The researchers found that both groups viewed eco-labels as important, and that the biocentric group believed eco-labels should be used in New 
Zealand, would select an accommodation with an eco-label, and were more likely to pay a premium (Fairweather et al., 2005).

The fact that individuals with pro-environmental attitudes or preferences are more likely to purchase environmentally responsible products has been observed in other studies (Eagles \& Cascagnette, 1995; Sirakaya-Turk, Baloglu, \& Mercado, 2014; Gao, Mattila, \& Lee, 2016). Specifically, this was one of the findings of a meta-analysis of behavioural intention studies by Gao, Mattila and Lee (2016). The researchers analyzed 26 studies published between 2000 and 2014 and found that with respect to green initiatives in hospitality firms "the more positive attitudes consumers have, the higher personal value and more benefits they perceive from green initiatives (i.e. internalized perceptions), the more likely they are to engage in green consumptions in a hotel/restaurant" (Gao et al., 2016, p. 113). The authors also found that green initiatives can positively influence the perceived quality, satisfaction and image of a hospitality firm, and in turn boost the revisit intention and willingness to pay for an environmental hotel (Gao et al., 2016). They go on to suggest that pursuing an environmental certification can signal environmental commitment, as well as stating that due to the breadth of the authors' analysis, these relationships appear to be well established (Gao et al., 2016). The authors note however that service quality outweighs the importance of green initiatives, and that if quality is compromised the willingness to pay a premium will be absent (Gao et al., 2016), a finding echoed in other studies (D’Souza et al., 2007; Burgin \& Hardiman, 2010). Budeanu (2007) posits that associating quality with environment can attract increased customer attention. This claim seems consistent with other research indicating that respondents believe that the quality of a hotel with an eco-label was better than that of a hotel without one (Esparon et al., 2014; Park \& Millar, 2016). 
An important caveat mentioned in multiple studies is that attitude does not necessarily translate into willingness to pay, and therefore attitude measures may overstate demand (Fairweather et al., 2005; Manaktola \& Jauhari, 2007; Beaumont, 2011). This gap between attitude and behaviour will be further explored in section 2.8 .

Some authors believe that a growing demand for environmentally friendly destinations is reflected in instances where customers do not return to destinations that fail to demonstrate environmental commitment (Miller, 2003). For example, Middleton and Hawkins (1998) state “the evidence indicates that tourists are not specifically demanding so-called 'green' or 'ecolabels' on the products they select, but they will not return to destinations which fail to offer environmental quality as part of the tourism experience" (p. 28). However, their description of environmental quality relates more to the physical environment experienced by the tourist, for example, water pollution, air pollution and otherwise spoiled landscapes (Middleton \& Hawkins, 1998), as opposed to the resource consumption of specific accommodations. This broad notion of environmental quality would typically be out of the control of a single accommodations provider, so it is unclear how this reluctance to re-visit would be affected by a certification program.

\subsection{Consumer Behaviour Regarding Environmental Products}

Despite all the research on consumer demand, there is a definite gap between stated intention and actual purchase behaviour when it comes to "green" products, and this gap is well documented in academic literature (Roberts, 1996; Davies, Fahy, \& Taylor, 2005; Manaktola \& Jauhari, 2007; Milfont, 2009; Olson, 2013). For tourist accommodations specifically, factors such as price, location, quality, and facilities are typically given more weight (Font, 2001; Sanders, 2005; Font \& Wood, 2007). Previous studies on green purchasing behavior appear to indicate that environmental integrity of a product is not a primary decision factor (Hobson \& 
Essex, 2001; Sharpley, 2001; Honey \& Stewart, 2002). Even among consumers that claim they are concerned about environmental issues, factors such as price, convenience, brand recognition and word of mouth are given priority (Font \& Wood, 2007). For example, a German study of both domestic and international German tourists found the majority of respondents were in favour of an eco-label being used for tourism products; however, they were less supportive when asked whether they would take such a label into account when making holiday decisions (Lubbert, 2001). Additionally, according to Watkins (1994), a survey of American tourists found that while $71 \%$ would prefer to stay in hotels that demonstrate an environmental commitment, the majority were not willing to pay extra to support this commitment.

This discrepancy between self-reported intentions and actual beaviour was also found with regards to eco-labels. In a study of whale watching tourists, Karlsson and Dolnicar (2016) compared stated intentions with actual behaviour by surveying customers from both an ecocertified and a non-eco-certified operator. The researchers found that while $60 \%$ of respondents stated they were influenced by the environmental impact of the tour operator, the vast majority of customers did not know whether their operator was certified or not (Karlsson \& Dolnicar, 2016). However, a subset of the customers were aware that the operator they had chosen was certified (Karlsson \& Dolnicar, 2016). This led Karlsson and Dolnicar (2016) to conclude that while a small group of environmentally concerned tourists do pay attention to eco-certification, most tourists in this study were not affected by the presence of an eco-certification.

One of the reasons proposed to explain this gap between attitude and behaviour is the social desirability bias (Milfont, 2009; Karlsson \& Dolnicar, 2016). Put simply, social desirability bias is the "tendency to give answers that make the respondent look good" (Paulhus, 
1991, p. 17), and it is typically observed in personality assessments (Edwards, 1957). In the context of environmental research, the presence of this bias would suggest that individuals state they are more environmentally friendly than they actually are because it is socially desirable. Despite these claims, research by Milfont (2009) found that self-reported environmental attitudes and behaviour are not strongly affected by social desirability bias. This is consistent with other studies indicating that social desirability has a weak, if not negligible, impact on self-reported environmental attitudes and behaviours (Kaiser, Ranney, Hartig, \& Bowler, 1999; Hartig, Kaiser, \& Bowler, 2001; Mayer \& Frantz, 2004). Therefore, the research being conducted in this study is unlikely to be influenced by social desirability bias. There are other factors in addition to social desirability bias that have been identified as potentially responsible for this gap such as unforeseen circumstances arising and changing intentions over time, measurement issues and common method biases (Juster, 1966; Podsakoff, MacKenzie, Lee, \& Podsakoff, 2003; Sun \& Morwitz, 2010).

In cases where individuals do base their decisions on environmental factors Miller (2010) argues that a primary reason is the concept of selfish altruism, which is described as the tendency to "purchase a product that benefits the consumer as well as the wider world, rather than just the wider world" (p. 35). Researchers claim this phenomenon is observed when tourists state their intention to visit a "green" hotel, but not a willingness to pay extra (Lee, Hsu, Han, \& Kim, 2010). Selfish altruism may be observed among those Airbnb guests who perhaps choose Airbnb based on environmental values, but also because of its affordability; such as the collaborative consumer group identified by Guttentag (2016), as they agreed with the environmentally friendly factor as a motivator, but not as strongly as they did with low-cost. 
Even in situations where consumers do choose an environmentally certified property, the positive benefits of that choice could be subject to the rebound effect, explained by Hertwich (2005) as a behavioural response to an environmental measure that offsets the effect of that measure. In the context of hospitality, this would be someone using a device like a water efficient shower or energy efficient air conditioner longer or more intensely, thus consuming more resources, with the knowledge that environmental measures are in place to limit resource use (Budeanu, 2007). This can be further exasperated by the fact that tourists have been shown to consume relatively excessively while vacationing (Carr, 2002) and may ignore environmental impacts that they consider while at home (Wearing, Cynn, Ponting, \& McDonald, 2002; Weaver, 2009; Hibbert, Dickinson, Gössling, \& Curtin, 2013; Cohen, Higham, \& Reis, 2014).

Furthermore, tourists have been shown to give priority to concerns such as time, costs, comfort, and convenience, over the environment (Frew \& Winter, 2010); or just a sense that environmental protection is not their responsibility as a tourist (Lubbert, 2001). For example, Carr (2002) found that British tourists behaved more hedonistically while travelling internationally. Similarly, Wearing (2002) observed a general apathy towards environmental criteria among Australian backpacker's, even though most of them tended to engage in environmental practices at home, like recycling and donating to environmental organizations. Budeanu (2007) argues that to offset this effect "successful demands for changes of tourist behaviour with respect to resource consumption (of, for instance, water or energy) and waste generation require clear explanations of the reasons and ways of avoiding the consumption of unnecessary resources" (p. 503). 


\subsection{Awareness of Environmental Certification Programs}

Broadly speaking, lack of awareness has been found to be a major issue for environmental certification programs (Archer, Kozak, \& Balsillie, 2005; Fairweather et al., 2005; Font \& Wood, 2007; Dodds \& Joppe, 2009). For example, research by Fairweather, Maslin and Simmons (2005) studying awareness of eco-labels among international tourists to New Zealand, discovered that only $20 \%$ were able to recall any businesses with an eco-label and that only $13 \%$ had ever heard of any tourism eco-label. Similarly, an earlier study of German tourists were also found to demonstrate low awareness of tourism related eco-labels (Consultancy and Research for Environmental Management (CREM), 2000). This low awareness is not helped by the fact that many eco-label organizations claim they lack the funding necessary to promote their programs (Big Room \& World Resources Institute, 2010).

A more recent study by Park and Millar (2016) examining US traveler's familiarity with and perceived credibility of lodging eco-labels revealed similar results. Their findings showed that the Energy Star logo and TripAdvisor's GreenLeaders logo were the most credible and most familiar respectively (Park \& Millar, 2016). The researchers suggested that Energy Star's ranking was due to its government-sponsorship, presence on household appliances, and age (20 years); while the GreenLeaders ranking was due to the positive brand equity and recognition of TripAdvisor (Park \& Millar, 2016). The Green Key logo was the least familiar logo to consumers (Park \& Millar, 2016). This suggests that longevity and marketing have an influence on awareness and that certification programs need to invest in customer education to improve awareness. This is likely a worthwhile activity given that other research has shown that tourists express positive attitudes towards eco-labels and want to learn more about them (Puhakka \& Siikamaki, 2012). 
Additionally due to the great variety of programs there appears to be a concerning level of confusion among tourists regarding the various programs' requirements (Lubbert, 2001; Honey, 2002; Fairweather et al., 2005; Dodds \& Joppe, 2009). This confusion can be a barrier to use, and can relegate the eco-label to an awareness building tool as opposed to being considered in the purchase decision (Budeanu, 2007).

Once awareness is built though, there appears to be a positive response from consumers (Chafe, 2007). A survey of Australian travelers found that, after reviewing a description of a national eco-label, the majority of respondents stated that they would be either "a lot more likely" or "a little more likely" to choose certified businesses (Chafe, 2007). Additionally, research among Dutch, German and Italian tourists found that environmental certification is the preferred method for communicating environmental performance (Consultancy and Research for Environmental Management (CREM), 2000; Chafe, 2007).

It remains unclear then how influential the presence of environmental certification is for making travel accommodations decisions. However, according to some researchers this is due to the fact that environmental certifications are still relatively new in the travel industry and have not had sufficient time to establish themselves (Bien, 2006a; Font \& Wood, 2007). In fact research by The International Ecotourism Society suggests that consumer demand for certification will likely develop long after a certification program is well established, typically 820 years, and that needs such as safety, quality and price must be satisfied before a consumer will consider environmental factors (Bien, 2006b; Font \& Wood, 2007; Dodds \& Joppe, 2009). Even with this long adoption time though, one may presume that since some of these programs 
began in the 1990s they would be familiar to consumers by now. However, the funding and marketing constraints mentioned earlier in this section may have served to lengthen this period.

Weaver (2009) suggests that one way to build public awareness would be through "the emergence of credible and widely subscribed universal certification-based eco-label" (Weaver, 2009, p. 38). As will be discussed in section 2.14, this was the original goal of the Global Sustainable Tourism Council (GSTC); however, the initiative was refocused away from becoming a recognized, global accreditation body and towards being an advisory role.

While the aforementioned research findings suggest that consumers seem to be more aware of environmental issues when traveling, the influence of environmental certification remains largely unclear due to the problems regarding lack of awareness, lack of data on the penetration of the programs, and the discrepancy between consumer attitudes and behaviour. Nevertheless, as was described earlier, the industry is pursuing these certifications. The following section will explain the motives driving the adoption of environmental certification.

\subsection{Motivations for Pursuing Environmental Certification}

Despite the ambiguity regarding how consumers make their hospitality decisions, it appears the expectation that consumers have voiced for environmentally friendly products has been one of the motivating factors for organizations pursuing environmental certification, though it is certainly not the sole motivation. Research into motivations for pursuing certification has revealed a broad range of factors such as cost savings, government regulations, stakeholder pressure, marketing benefits, improved environmental performance, and personal ethics (Fryxell, Lo, \& Chung, 2004; Boiral, 2007; Qi et al., 2011; Wiengarten et al., 2013); these factors resemble those stated for pursuing voluntary environmental initiatives in other industries more 
generally (Grimstad, 2011). In some cases, companies may already be operating according to the standards, so certification is merely the public recognition of existing practices (Boiral, 2007).

Bansal and Roth (2000) examined motivations for environmental initiatives among multinational firms and grouped motivations into three major categories: competitiveness, legitimation, and ecological responsibility. Competitiveness motivations tended to be conspicuous and encompassed any motivation that was intended to improve profitability, including the pursuit of eco-labelling or green marketing and cost reduction measures (e.g., using less energy, selling recycled waste) (Bansal \& Roth, 2000). Legitimation referred to actions triggered by a desire to be "compliant" and mitigate risks of non-compliance, whether that be with stakeholder expectations, government, or industry associations (Bansal \& Roth, 2000), including complying with legislation, establishing environmental oversight within the organization, and conducting environmental audits (Bansal \& Roth, 2000). The third motivation was ecological responsibility, and was typified by the desire to "do the right thing"; actions were justified based on ethical reasons not business performance (Bansal \& Roth, 2000). These initiatives were usually championed by a leader within the organization and were usually expressed through creative and ambitious programs, as opposed to copycat initiatives aimed at keeping up with competitors (Bansal \& Roth, 2000). The authors noted that additional factors can influence the type of motivation such as issue salience and individual concern, which is the degree to which individuals care about the environment and the amount of power they have to act on those concerns (Bansal \& Roth, 2000). It is important to note that, similar to other studies (Gavronski et al., 2008; Garay \& Font, 2012b), Bansal and Roth (2000) point out that motivations can be mixed. 
Other researchers have grouped the motivations into internal drivers such as improving environmental or operational performance and external drivers, such as meeting customer demands or matching competitors' actions (Fryxell et al., 2004; Prajogo et al., 2016). With regards to internal versus external motivations, companies that pursue internal motivations are generally found to have more positive perceptions of the effectiveness or value of the environmental certification (Fryxell et al., 2004; Prajogo et al., 2016).

At an individual level, research done by Chan, Hon, Chan and Okumus (2014) examined the factors driving hotel employees' intentions to implement environmental practices in Hong Kong hotels. The authors found that that the degree of environmental knowledge, environmental awareness and environmental concern demonstrated by an employee is positively related to their ecological behaviour, which in turn positively influences their intention to implement environmental practices in a hotel (Chan, Hon, Chan, \& Okumus, 2014); similar to the effect pro-environmental attitudes have on consumer behaviour described in section 2.7.

At the executive level Rivera and De Leon (2005) found that among CEOs of Costa Rican hotels, the higher the education level the more likely they were to participate in a voluntary environmental certification program, and the better the environmental performance of their hotel. In depth interviews with these CEOs revealed that the majority of CEOs pursued voluntary certification for ethical reasons and expectations of improved financial performance, in the form of operational cost savings, and revenue from eco-conscious travelers (Rivera \& De Leon, 2005).

\subsection{Benefits of Environmental Certification}

Literature suggests a variety of perceived benefits that can be realized from environmental certification. These include: improved brand image, reduced threat of attacks on 
brand, increased credibility, cost savings from reduced resource use, increased employee satisfaction, and improved management structure (Conroy, 2002; Toth, 2002; Bien, 2006a; Dodds \& Joppe, 2009; Jarvis et al., 2010). Studies have also shown that environmental certification can lead to higher guest ratings for accommodation providers, as well as improved economic performance depending on size and location (Segarra-Ona, Peiro-Signes, Verma, \& Miret-Pastor, 2012; Peiro-Signes, Segarra-Ona, Verma, Mondejar-Jimenez, \& Vargas-Vargas, 2013). Some certification programs claim to increase occupancy, although this must be treated with some skepticism as the organizations applying for certification are already likely to be well managed and likely to experience high occupancy regardless (Font \& Buckley, 2001; Dodds \& Joppe, 2009).

Hillary (2004) references a pan-European Union study investigating eco-management and audit schemes that found that small- and medium-sized companies identified better image as the top benefit cited, and cost savings second, as opposed to large companies that identified cost savings as the primary benefit. In fact the smaller the company size the more likely that better image was identified as the primary benefit (Hillary, 2004). This benefit was ranked ahead of gaining more customers and greater customer satisfaction. These benefits though are with relation to companies that had already implemented an environmental management system, and there is contradictory research that suggests some business owners that have experience with these programs appear more skeptical regarding the marketing benefits, and whether certification meant anything to their customers (Ayuso, 2007; Jarvis et al., 2010).

Research by Rowe and Highman (2007) among ecotourism organizations in New Zealand found that operators did not perceive a marketing benefit from certification and that they questioned whether the benefits of certification were worth the costs (Rowe \& Higham, 2007). 
This may be because generally, New Zealand ecotourism operators do not believe there is significant demand among consumers for certification, though they do believe that demand is growing (Rowe \& Higham, 2007). This echoes findings from UK studies (Dewhurst \& Thomas, 2003; Tzschentke, Kirk, \& Lynch, 2008a) and a survey of European hoteliers (Bohdanowicz, 2005), both of which revealed a perception among hospitality providers that there is low consumer demand for environmental programs. Among hospitality providers this may represent an acknowledgement that while there appears to be growing demand for environmentally responsible accommodations, the demand may be overstated due to the gap between intention and behaviour described in section 2.8 .

The inclusion of a logo helps customers make an informed choice (Dodds \& Joppe, 2009; Graci \& Dodds, 2015); but this skepticism regarding the marketing benefits, combined with the stated unwillingness to pay extra for a certified hotel described earlier, could be problematic for hoteliers as studies have shown that "green" hotels are usually priced at a premium above traditional hotels (Kuminoff, Zhang, \& Rudi, 2010). Airbnb hosts may be subject to a similar complication if they would intend to raise their prices upon receiving certification.

\subsection{Motivations of Small Businesses for Pursuing Environmental Certification}

With regards to the accommodations industry, much of the research regarding motivations for certification to date has been focused on large multi-national hotel chains as they are at the leading edge of environmental management in this industry (Álvarez Gil, Burgos Jiménez, \& Céspedes Lorente, 2001; Chan, 2011), and have been shown to be more environmentally proactive than smaller firms (Claver-Cortés, Molina-Azorín, Pereira-Moliner, \& López-Gamero, 2007). There are however, some studies focused on small and medium enterprises that demonstrate that these organizations have different perspectives than larger 
companies regarding the motivations and barriers related to environmental certification (Hobson \& Essex, 2001; Hillary, 2004; Tzschentke et al., 2008b; Chan, 2011). This distinction is important as the management of an Airbnb property bears far greater resemblance to an individual owner-operator as opposed to a large multi-national hotel chain.

An investigation into small, independently-owned hospitality providers in Scotlandsuch as small hotels, guest houses and bed and breakfasts - found that those who had achieved environmental certification did so as a result of personal environmental values and lifestyle choices (Tzschentke et al., 2004, 2008b). Tzschentke et al. (2004) interviewed 30 owneroperators of small, independent accommodation properties to determine both their reasons for pursuing environmental measures, and specifically environmental certification through the Green Tourism Business Scheme. The researchers found the main reasons for adopting environmental measures were operational cost savings and an ethical obligation (Tzschentke et al., 2004), with the latter being shared by "an overwhelming majority of respondents" (p. 119). This ethical dimension was expressed through three main themes, namely "to do my bit", "it's the responsible thing to do", and "it's the right thing to do" (Tzschentke et al., 2004). The three main reasons discovered for pursuing environmental certification were "the prospect of commercial benefits, the knowledge that joining required little or no change to current practices, and the fact that the principles of the scheme were ones the owner-manager endorsed" (Tzschentke et al., 2004, p. 120). The prospect of commercial benefits was largely tied to improved public image and marketing potential of the green accreditation, including the ability to appeal to foreign customers who were perceived to be more environmentally conscious; and while it was cited as a key factor, the researchers suggest the most important decisional factor was the alignment of the certification with the owners' values (Tzschentke et al., 2004). In a later article based on the 
same data the authors state "central to the greening process had been the presence of an environmental consciousness, its development in turn influenced by factors that contributed to greening the individual and business practices" (Tzschentke et al., 2008, p. 130). The authors conclude that the ethical and social motivations for environmental action were considered in parallel with economic factors (Tzschentke et al., 2004).

The importance of personal environmental values among small hoteliers seems to be given added importance by Lowe (1988) who argues that when guests stay with small hoteliers they tend to adapt to the behavioural norms of the owners, even though they are a paying customer. He suggests this is explained by the sense of complacency and desire for relaxation among guests; the guests preferred to be told how to behave as opposed to having to decipher this for themselves (Lowe, 1988). This may be especially true in the Airbnb context given that hosts are typically offering part or all of their home, and that there is a "house rules" section for each posting where the host can list the expected behaviour of their guests. Therefore, guests may be more prone to adopt environmentally favourable behaviour if this is demonstrated or requested by the host.

Choosing to focus on the smallest of hospitality organizations, Vernon et al. (2003) studied English, tourism micro-businesses (businesses with fewer than ten employees) and found that both altruistic and financial motivations contributed to environmental performance improvements, but that financial considerations mediated the sense of altruism. The researchers concluded therefore that "a simple classification of businesses between financially motivated and altruistically motivated does not seem possible: the mix of motivations at work appears to be more complex" (Vernon et al., 2003, p.61); a conclusion similar to that made by Tzschentke et al. (2004), described earlier in this section. These findings may be especially salient when 
examining Airbnb hosts as these micro-businesses were run by owner-operators and have fewer than ten employees; therefore they are similar to hosts in terms of their involvement in the business, their role as the decision maker, and the lack of scalability of investments.

A small, qualitative study on Bed and Breakfasts belonging to the GTBS determined that adoption of environmental practices appears to depend on the degree of formality with which owner-operators view their businesses (Sampaio et al., 2012); those that view their B\&B as an extension of their lifestyle being more informal than those that view it as a distinct business and who are therefore more aware of the financial management of their business (Sampaio et al., 2012). The researchers found that the more informal businesses were more likely to adopt practices that confirmed personal objectives like "feeling good" about themselves; whereas the more formal businesses were more likely to adopt practices that satisfied personal and economic objectives (Sampaio et al., 2012).

A study of primarily small hotels in the Caribbean found that the most important motivation for adopting environmental management practices was based on the desire to conserve natural resources; this was followed by potential cost reductions, and the pursuit of a competitive advantage (Best \& Thapa, 2013). Open-ended responses to the motivation question all appeared to be non-economic factors, and included items such as:

to take care of the environment for the sake of children and future generations, educate staff and guests, live up to the company's social responsibility, improve the lives and livelihood of local communities, and simply because it was 'common sense' or the right thing to do (Best \& Thapa, 2013, p. 170). 
The authors Best and Thapa (2013) note that this heavy consideration for natural resource depletion is likely due to tourism's dependency on natural attractions in the area, and the attention this environmental degradation has garnered in Caribbean islands since the early 1990’s.

Dewhurst and Thomas (2003) found that small accommodations businesses in a UK national park demonstrated a range of attitudes and behaviours towards environmental practices with some basing decisions more on economic factors and some prioritizing personal values. While nearly all businesses agreed that environmental practices can help save money, the justification for pursuing improvements across issues of energy and water use, purchasing policies, waste and recycling, transport, aligned with whether the owner-operator prioritized economic concerns or personal values. Similar to what has been observed among travelers, the study found that for business owners "lifestyle goals and personal motivations are important in determining attitudes and behaviour towards sustainability" (Dewhurst \& Thomas, 2003, p. 390).

Focusing on the Ontario small accommodations market, van Haastert and de Griosbois (2010) studied the implementation of various environmental initiatives in bed and breakfasts in the Niagara region. They found unanimous environmental concern and willingness to improve the environmental performance of their business, exhibited by the fact that all of the respondents had implemented some type of initiative to reduce negative environmental impacts of their B\&B (van Haastert \& de Grosbois, 2010). The study determined motivations for these initiatives to be a mix of personal values, cost-savings and lifestyle habits (i.e. continuation of habits learned in childhood like reusing plastic bags). In terms of what these properties were actually doing, the most popular initiatives in order were energy conservation, waste management, water conservation; additional categories mentioned included environmental education activities (e.g., 
attending seminars), minimizing the use of chemicals and transport related emissions, as well as use of native plants (van Haastert \& de Grosbois, 2010).

There is clearly a mix of motivations at work, and while these studies are relevant with regards to Airbnb hosts, Airbnb hosts cannot be easily lumped in with other small scale hotel operators given that many of them only offer their property part time, use the funds as supplemental income, and are not likely to be experienced hospitality providers prior to hosting on Airbnb. These circumstances put them in a unique position and research into their motivations regarding environmental certification may lead to unique insights being discovered.

\subsection{Barriers to Environmental Certification}

Barriers to adopting environmental certification in small firms include lack of training and awareness, lack of legislative support, lack of qualified verifiers/ consultants, perceived costs, inability to identify the benefits, lack of relevant information, and a disconnect between the standards design and the businesses (Gerstenfeld \& Roberts, 2000; Schaper \& Carlsen, 2004; Chan, 2011; Garay \& Font, 2012b; Best \& Thapa, 2013). Font (2012) has also suggested that standards are often created on the basis of what strong environmental performers are already doing, and therefore lack an appreciation for how challenging it may be for less experienced firms to achieve the standard.

A study of tourism microbusinesses in Cornwall, England by Vernon et al. (2003) identified a number of both direct and indirect barriers to pursuing environmental certification. Direct barriers were those that the business owner felt would impact the day to day operations and included time, effort and cost, while indirect barriers were those outside the control of the business and included the limited length of the tourism season and increased competition. They also did not want to do anything that could disrupt customer satisfaction, and also tended to 
distance themselves from environmental responsibility, claiming that these issues are the domain of planners and bureaucrats (Vernon et al., 2003). For example, many of the respondents identified infrastructure issues that need to be addressed regionally, such as the development of public transit and reviewing waste and recycling policies (Vernon et al., 2003). The authors also discovered a lack of awareness among these business owners regarding their impacts on the environment (Vernon et al., 2003), an issue observed in other studies (Dewhurst \& Thomas, 2003; Chan, 2011; Coles, Dinan, \& Warren, 2016).

The cost barrier for small businesses to adopt environmental initiatives has been identified in other studies crossing multiple industries (Gerstenfeld \& Roberts, 2000; Rutherfoord, Blackburn, \& Spence, 2000; Hillary, 2004; Bhaskaran, Polonsky, Cary, \& Fernandez, 2006; Revell \& Blackburn, 2007). In light of this perceived barrier, a review of ecocertification among small tourism businesses concluded “despite considerable efforts by policymakers to present ecoefficiency as a cost-saving measure, many small businesses appear resistant to implementing voluntary changes to reduce environmental impacts" (Burgin \& Hardiman, 2010, p. 9).

Barriers were also examined by van Haastert and de Grosbois (2010). They found three barriers; budgetary constraints, lack of knowledge, and customer attitudes and expectation. With regards to budgetary constraints, in some cases this was based on perceived cost, and in some cases the participant actually researched the cost of the investment (van Haastert \& de Grosbois, 2010). Van Haastert and de Grosbois (2010) determined that "although some of the participants saw the long-term benefits of some of the initiatives (such as low-flush toilets or energy star rated appliances), they had financial difficulty with making the up-front investment" (p. 189), which the authors believe can be attributed to these B\&Bs acting as supplemental income for a 
majority of owners. This may be especially salient with regards to Airbnb owners as it is also primarily a source of supplemental income. This finding was supported by similar research into Canadian B\&Bs done by Dodds and Holmes (2011), which determined financial restrictions to be the strongest barrier to adoption of sustainable initiatives. Regarding lack of awareness, there was a mix of lack of understanding of the negative impacts of their amenities (e.g., belief that fireplaces were not harmful to environment), as well as a sense that these smaller operations bear little or no responsibility compared to larger firms (van Haastert \& de Grosbois, 2010). Finally, the owners also noted that while they believe their guests to have positive attitudes towards their environmental efforts, their customers can be wasteful when it comes to use of resources (e.g., energy and water), as they have no incentive to use less and do not want to sacrifice comfort or quality (van Haastert \& de Grosbois, 2010). As a result, many owners have engaged with their guests either in-person or by leaving a note, requesting them to be more mindful of their consumption (van Haastert \& de Grosbois, 2010). The authors believe this role of educator is necessary if owners want guests to engage in environmentally responsible behaviour.

In order to overcome these barriers, researchers propose educating small businesses on the economic and environmental benefits of becoming environmentally certified, and building networks of small business to share experiences and advice (Schaper \& Carlsen, 2004; Burgin \& Hardiman, 2010; Dodds \& Holmes, 2011). Additionally, Gerstenfeld and Roberts (2000) suggest environmental standards should be inexpensive, sensitive to the limitations of small to mediumsized enterprises (SME's), co-operative, locally based, user-friendly and flexible. Researchers also suggest that once certification is achieved these businesses should advertise their certification and the corresponding environmental outcomes to add credibility to their new, “green” image (Burgin \& Hardiman, 2010; Dodds \& Holmes, 2011). Finally, Dodds and 
Holmes's (2011) research showed that among B\&Bs in the maritime provinces of New Brunswick, Nova Scotia and Prince Edward Island, certification was viewed as an incentive for adopting sustainable practices. The researchers suggest an environmental certification for B\&Bs could unite this sector's sustainability efforts (Dodds \& Holmes, 2011).

\subsection{Development of Environmental Certification Programs}

Exploring firms' motivation for pursuing environmental certification only tells half the story. Equally important is determining what led to the development of these environmental certification programs in the first place. Consumer demand for environmental products was discussed earlier as a growing trend, and mentioned as a potential motivator for pursuing certification. However, these certification programs have historically been created without any evidence of consumer demand (Font \& Wood, 2007), instead being initiated by pressure from intermediaries, NGO's or other activist groups (Conroy, 2002). As tourism certification researcher Amos Bien (2006b) states, "successful certification programs have almost never been created because of pre-existing consumer demand for certification... case after case has demonstrated that consumer demand develops after a certification program with a credible standard is well-established" (par. 5).

One of the more popular programs that exemplify this situation is The Forest Stewardship Council (FSC). This program was established in 1993 and it provides certification for timber products that meet its criteria for sustainability (Conroy, 2002). Although established in 1993, it came to prominence when it was adopted by industry giants MacMillan Bloedel and Home Depot in the late 1990s (Conroy, 2002). These companies adopted this standard not because of end consumer demand, but because of vigorous, public demonstrations targeting these companies by environmental groups such as Greenpeace, Natural Resources Defense Council 
and Rainforest Action Network (Buckley, 2002; Conroy, 2002). FSC is administered by Rainforest Alliance, and has become one of the most recognizable global standards among consumers (Buckley, 2002; Forest Stewardship Council, 2015); however, its origins rest not with consumer demand, but on pressure from other stakeholders.

Another case, specific to tourism, is that of Green Globe, a global tourism certification program available to all sizes of companies across all sectors of the tourism industry (Parsons \& Grant, 2007). Green Globe was developed in 1994 by the World Travel and Tourism Council, a group composed of tourism executives, in response to a challenge from Maurice Strong, chair of the 1992 Earth Summit, for the tourism industry to develop a framework incorporating sustainable development principles (Parsons \& Grant, 2007). Guided by the target areas laid out in Agenda 21, the objective of the program was to help inform tourism organizations on how they could contribute to sustainability objectives within those target areas (Parsons \& Grant, 2007). Similar to the FSC, this certification program was not initiated based on consumer demand, but since its inception has actively promoted itself to customers while simultaneously encouraging certified organizations to highlight their certification in order to build awareness (Green Globe, n.d.-c; Parsons \& Grant, 2007). In order to facilitate this promotion the organization is active on multiple social media platforms including Youtube, Facebook and Twitter, and has also developed a customer facing app that allows travelers to search for and book certified hotels using their smartphone (Green Globe, n.d.-a).

The Global Sustainable Tourism Council (GSTC) is another tourism body rooted in international sustainability goals. The organization began as the Partnership for Global Sustainable Tourism Criteria in 2007 as a coalition of more than thirty international organizations whose focus was to "foster increased understanding of sustainable tourism 
practices and the adoption of universal sustainable tourism principles" (Global Sustainable Tourism Council, n.d.-c). The initiative was spearheaded by the Rainforest Alliance, the United Nations Foundation, the United Nations Environment Programme (UNEP), and the United Nations World Tourism Organization (UNWTO) (Global Sustainable Tourism Council, n.d.-c; Jarvis et al., 2010). The roots of this program actually date back to the Sustainable Tourism Stewardship Council (STSC), which was an effort to establish an international accreditation body for sustainable tourism initiated in 2001 (Buckley, 2002; Honey, 2002; Jarvis et al., 2010). The STSC was first proposed by Rainforest Alliance at the Ecotourism and Sustainable Tourism certification Workshop in 2000, held in Mohonk, New York (Font, 2002; Honey, 2002). This workshop included delegates from several certification bodies internationally, and the purpose was to develop a framework that could be applied to all certification programs internationally (Black \& Crabtree, 2007; Honey, 2008). Similar to the Forestry Stewardship Council, this endeavor was also spearheaded by the NGO community.

The STSC merged with the Partnership for Global Sustainable Tourism Criteria in 2009 to become the Global Sustainable Tourism Council (Rainforest Alliance, 2009). This merger was facilitated by the UN Foundation and funded by the UNEP (Global Sustainable Tourism Council, n.d.-c; Rainforest Alliance, 2009). As opposed to being an international accreditation body, the GSTC is now a consultative organization that publishes voluntary environmental and social evaluation criteria, known as the GSTC Criteria (Buckley, 2012). The GSTC reviewed 60 certification programs to develop its initial set of hotel and tour operator criteria, and continues to undergo reviews every two years to refine the criteria, according to the ISEAL Code of Best Practice (Global Sustainable Tourism Council, n.d.-c; Graci \& Dodds, 2015). 
The GSTC criteria are organized around four main themes: effective sustainability planning through the incorporation of sustainable management systems; maximizing social and economic benefits to the local community; reduction of negative impacts to cultural heritage; and, reduction of negative impacts to environmental heritage (i.e., conservation of biodiversity and reducing pollution) (Bricker \& Schultz, 2011; Graci \& Dodds, 2015). Just as Green Globe was borne out of the Earth Summit as described earlier, the themes and criteria of the GSTC align closely with the UN Millennium Development Goals (Graci \& Dodds, 2015). In addition to publishing its list of baseline criteria, the GSTC has a membership body composed of travel companies, hotels, tourism boards, tour and UN agencies (Global Sustainable Tourism Council, n.d.-b). Membership in GSTC does not require any formal commitments or meeting of criteria. Instead members pay a fee to belong to the organization and get access to resources that can help an organization improve the sustainability of its operations (Global Sustainable Tourism Council, n.d.-b).

A review of the GSTC's members reveals that Airbnb is a member of the GSTC and that Molly Turner, Airbnb's Director of Public Policy \& Civic Partnerships, was elected to their board of directors in 2015 (Global Sustainable Tourism Council, 2015). While it remains unclear what Airbnb's primary objectives were in joining the GSTC and pursuing a board seat, it appears that it is at least interested in appearing environmentally conscious, and now has access to resources used by certification bodies around the world to design and develop these programs.

While consumer demand for environmental certification among Airbnb guests remains unclear, pressure from environmental groups and a desire to avoid damage to their valuable and global brand could motivate Airbnb to adopt environmental certification into its business model, 
similar to the timber industry and the hundreds of hotels certified by Green Globe (Green Globe, n.d.-b).

\subsection{Conceptual Framework}

Based on the literature reviewed a conceptual framework was built to guide the research (see Figure 1).

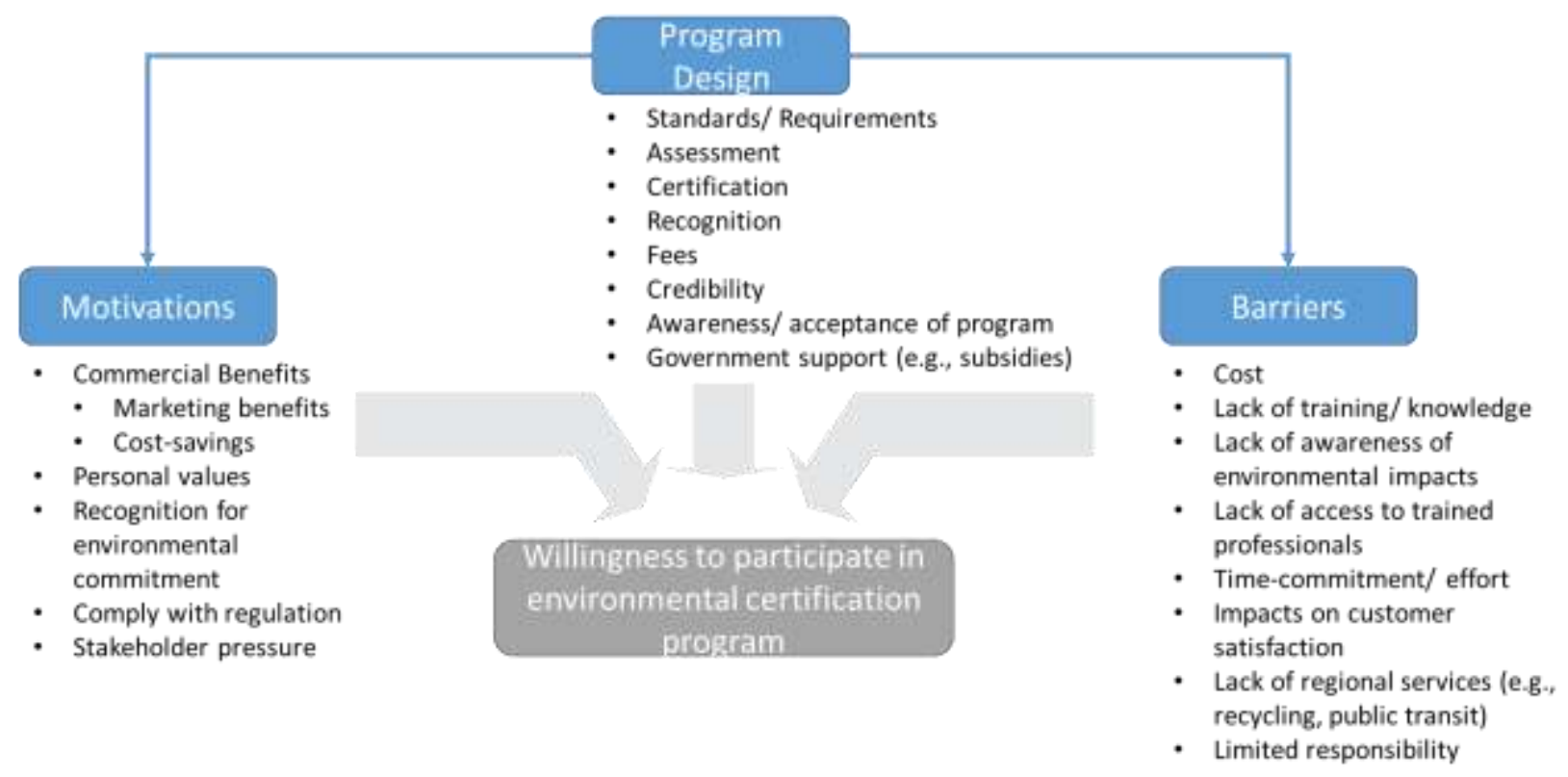

Figure 1: Conceptual framework

As discussed, numerous motivations have been identified related to the adoption of environmental certification programs. While a range of motivations exist, commercial benefits, personal values and recognition of environmental commitment are among the most frequently cited in the context of small accommodations providers (Dewhurst \& Thomas, 2003; Vernon et al., 2003; Tzschentke et al., 2004, 2008b; van Haastert \& de Grosbois, 2010). Barriers refers to those issues that may limit an organization's ability to participate, with the most commonly cited being cost (Chan, 2011; Dodds \& Holmes, 2011; Garay \& Font, 2012a; Best \& Thapa, 2013). Program design includes the standards, assessment style, certification style, recognition, and 
fees. It also refers to the perception of the program and whether it is viewed as being credible, and its level of awareness or acceptance among consumers and the industry. Government support was also included as this can influence adoption by providing subsidies or sponsorship (Font, 2012).

Elements of the program design can influence both the motivations and barriers towards participation in an environmental certification program. The arrow linking program design to barriers indicates the association between these two concepts in that the barriers can often be dependent on the program design. For example, cost of participation and compliance can be influenced by the application fee, the standards themselves, and the assessment style (Synergy Ltd, 2000; Toth, 2002; Wu et al., 2007; Chan, 2011); or as Font (2013) suggested standards may be challenging to achieve is they are designed based on relatively strong environmental performers as opposed to less experienced organizations. Similarly, program design can influence motivations in the sense that organizations may pursue certification if they are already compliant with the requirements, thereby achieving recognition of their existing environmental performance (Boiral, 2007).

Given that the research is evaluating willingness to participate in an environmental certification program, perceived benefits of the program has not been included in the conceptual framework. This is because evaluation of benefits from certification is typically conducted after adoption, so that the practical experience of the business can be measured (Hillary, 2004; Ayuso, 2007). Therefore, the concept of benefits does not have the same influence over the decision to participate as motivations, barriers and program design.

Past researchers have grouped these motivations into different frameworks such as Bansal and Roth's (2000) grouping into themes of competitiveness, legitimation and ecological 
responsibility, or the more simple internal versus external (Fryxell et al., 2004; HerasSaizarbitoria, Boiral, \& Arana, 2016; Prajogo et al., 2016). Similar groupings of internal versus external has also been done for barriers (Hillary, 2004; Chan, 2008), and benefits (Hillary, 2004). However, due to the open-ended and exploratory nature of this research (see section 3.0), this type of categorization was premature.

As explained by Day and Arnold (1998), the decision to pursue environmental initiatives is usually a complicated mix of risks and rewards. This complexity is reflected through the presence of motivations, barriers and program design factors, which collectively influence the decision to participate in an environmental certification program. This conceptual framework guided the development of the three research questions: 1) Would Airbnb homeowner hosts be willing to participate in an environmental certification program? 2) What would motivate Airbnb homeowner hosts to participate in an environmental certification program? 3) What program design elements would enhance the likelihood of their participation in the program? The question of barriers was investigated in the interview guide and through the investigation of the third research question, as the discussion exploring why certain design elements were favourable revealed perceived barriers. 


\subsection{Methods}

This exploratory study asks three research questions: 1) Would Airbnb homeowner hosts be willing to participate in an environmental certification program? 2) What would motivate Airbnb homeowner hosts to participate in an environmental certification program? 3) What program design elements would enhance the likelihood of their participation in the program? This chapter will explain the general research design of this study, as well as the methods used to investigate these research questions. This study used primary data from interviews as well as secondary data from Airbnb forums and Airbnb listings, and the following sections will explain the sampling, collection, and analysis of this data. All collection and analysis was done by the author.

\subsection{Research Design}

Due to the recent emergence of Airbnb and the associated lack of published, academic research on the topic, this study was exploratory in its nature. Exploratory research generally uses qualitative methods as they allow for study of issues in more depth and detail (Patton, 2002; Neuman \& Robson, 2014), and generally do not incorporate a specific theory (Neuman \& Robson, 2014). Previous studies on the topic have incorporated various theoretical approaches to either explain what motivated an organization to adopt environmental practices (Delmas \& Toffel, 2004; Tzschentke et al., 2008b; Best \& Thapa, 2013), or to develop new explanations using the grounded theory approach (Bansal \& Roth, 2000; van Haastert \& de Grosbois, 2010). The theoretical point of departure for this research is that it does not seek to explain a certain behaviour or develop a theory around certain behaviour. Instead this research seeks to uncover the opinions and motivations among hosts towards participating in program that has not yet been developed, thereby potentially influencing the design and development of such a program. Similar to other exploratory research, it was a qualitative descriptive study (Getz \& Carlsen, 
2000; Alonso \& Ogle, 2010; Sampaio et al., 2012), which did not incorporate a theoretical basis, followed the lines of naturalistic inquiry in that variables are not manipulated and outcomes are not restricted, used open-ended interviews, and responses were coded according to their content (Sandelowski, 2000; Patton, 2002). The expected end result for a qualitative descriptive study like this is "a straight descriptive summary of the informational contents of data organized in a way that best fits the data" (Sandelowski, 2000, p. 338).

Though interviews were the primary data collection method secondary data sources were examined using a content analysis focused on environmental related keywords. This secondary data analysis included an extract of Airbnb listings from the Greater Toronto Area, and on the Airbnb Community forum. The content analysis served as data triangulation, to help provide additional data and strengthen the results (see section 3.3).

\subsection{Interviews}

The qualitative method this study used for primary data collection was interviews. Interviews can be either structured, semi-structured or unstructured, with each style varying in the flexibility allowed to the researcher during the interview (Sommer \& Sommer, 1991). The semi-structured interview style was used as it allowed for the interviewer to react to the individual respondent and provide additional detail when necessary, as well as explore interesting lines of thought while maintaining consistency in the questions asked between the interviews (Sommer \& Sommer, 1991). This flexibility was important for this study as environmental certification is not a very well-known concept (Font \& Wood, 2007; Dodds \& Joppe, 2009; Graci \& Dodds, 2015), and as such could require clarification of certain terms by the interviewer. While surveys have been the predominant data collection instrument used to study environmental issues in the hospitality industry (Gao et al., 2016), semi-structured 
interviews have been employed by other researchers investigating adoption of environmental standards in both tourism (Tzschentke et al., 2004, 2008b; Alonso \& Ogle, 2010; Jarvis et al., 2010) and non-tourism businesses (Bhaskaran et al., 2006; Revell \& Blackburn, 2007;

Gabzdylova, Raffensperger, \& Castka, 2009).

Qualitative interviews are subject to certain limitations. While they allow for study of issues in more depth and detail, this depth of understanding comes at the expense of generalizability (Patton, 2002). Issues with validity and reliability due to small sample size and lack of quantifiable data have also been raised as criticisms of this method (Neuman \& Robson, 2012). Lincoln and Guba (1985) suggest that instead of reliability and validity, qualitative data be evaluated based on the credibility, transferability, dependability and confirmability of the data.

Credibility is similar to validity in that it is focused on the "truth value" of the data (Neuman \& Robson, 2012, p. 285). In qualitative research this can be achieved through memberchecking, which is the process of reviewing the researcher's interpretations and conclusions with members of the group (Lincoln \& Guba, 1985). Member-checking was done by sending transcribed interviews to subjects for their review prior to analysis. No respondents requested to change or withdraw their responses. Also, a brief summary of the results of this study will be sent to those respondents that requested a copy, and their feedback will be considered in any subsequent publications related to this thesis.

Transferability refers to the "extent to which the findings of the study can be applied to other contexts" (Neuman \& Robson, 2012, p. 288). This can be achieved by employing what Lincoln and Guba (1985) refer to as thick description, meaning that the researcher keeps a very detailed account of their study so that future researchers can determine to what degree the 
findings are applicable to other contexts. To that end all transcriptions were done verbatim and transcribed interviews will be kept on file for five years so that future researchers can examine the raw data alongside the published thesis to determine applicability beyond the study sample. The use of secondary data in the form of Airbnb listings and Airbnb forum posts (see section 3.3) also aims to provide supporting insight into the research questions outside of the interview sample.

Dependability concerns the consistency of the results. Given the subjective nature of qualitative analysis dependability can be improved through an external audit; someone who examines the data collected to determine if they would come to similar conclusions as the researcher (Neuman \& Robson, 2012). Originally, the researcher planned on conducting an external audit in addition to the thesis committee review of the work; however, due to time and financial resource restrictions this was not executed.

Finally, confirmability refers to the neutrality of the research, or the absence of researcher biases and motivations (Neuman \& Robson, 2012). Similar to dependability and transferability, this can be improved through an external audit and keeping a detailed record of all research notes and data, including interview transcriptions (Neuman \& Robson, 2012). To that end, and as mentioned earlier, interview transcriptions will be stored for a period of five years so that other researchers can access them if so desired.

The researcher conducted both face-to-face and phone interviews based on the preference of the respondent. Face-to-face interviews were conducted in a public location chosen by the subject. This was done in the interest of the subject's convenience, but also due to ethics board safety guidelines prohibiting interviews from being inside the subject's home unless a second researcher is present. Interview duration ranged from 20-60 minutes and each interview was 
audio recorded with the consent of the respondent. Once complete, the recordings were transcribed verbatim as soon as possible after the interview while the interview is still in recent memory "so that the researcher has a better chance of deciphering audio material that may be difficult to understand" (Neuman \& Robson, 2012, p. 256). Contact information for the respondents was confidential and only the primary researcher had access to it, and this information was kept on an encrypted USB as well as in a password protected file. Additionally, personal identifiable information was disassociated from the transcripts by each respondent being assigned a number. This disassociation ensured that all interview data remained anonymous.

\subsubsection{Interview Guide}

To ensure that each respondent was asked the same set of questions an interview guide was used. An interview guide lists the questions to be reviewed so that the interviewer can follow "the same lines of enquiry with each person interviewed" (Patton, 2002, p. 343), while also allowing the interviewer to probe and explore topics that warrant such attention (Patton, 2002). This guide helps to make the data collection more consistent and systematic (Patton, 2002; Neuman \& Robson, 2012).

The interview guide was pretested with two Airbnb hosts in order to review the clarity and understandability of the questions. These pretests resulted in minor changes to the interview guide such as the addition of examples regarding the environmental categories. As stated in section 3.2, while reliability and validity are more difficult to achieve in qualitative research, piloting the data collection tool with members of the target population can help to improve the clarity of questions. This is important as unclear questions can lead to unclear responses, in 
addition to potentially causing discomfort or confusion for the respondent, which could damage any sense of rapport with the interviewer and disrupt the interview process (Patton, 2002).

The interview guide was split into two major sections (see Appendix A), with the first focusing on the hosting profile of the respondent and the second focusing on questions related to environmental certification. The first section of the interview guide included high-level questions about the host profile and their property. This included how long they have been a host, how frequently they rent their property, what drew them to hosting, and whether they are a "superhost". The purpose of these questions was to determine if their responses to the remaining interview questions may differ based on their hosting experience and frequency. The superhost question in particular was designed to differentiate those more experienced and professional hosts, as a host must meet certain requirements to become a superhost such as; having at least $80 \% 5$-star reviews, responding quickly and to at least $90 \%$ of messages, rarely canceling reservations, and hosting at least ten trips per year (Airbnb, n.d.-f). This section of the interview guide also inquired as to the type of property based on the options available on the Airbnb platform (i.e. private room, shared room, or entire home). This was done to help give general context for the later questions regarding program design and potential changes to the property (e.g., if the host only offers a private room how do they feel about making changes that may impact the entire property).

The next section discussed willingness to participate in a potential program. As recommended by Park and Millar (2016) to be done in future studies on environmental certification, this section began with a question asking respondents if they are familiar with the concept of environmental certification and to describe what that term means to them. This was done to determine the baseline knowledge of the respondent, and to determine whether those 
with more knowledge or experience regarding these programs have unique insights from those with less knowledgeable or experience.

This was followed by an overview of the main components of an environmental certification program, which was presented to each respondent regardless of baseline knowledge (see Appendix A). The aim of this overview was to familiarize respondents with the concept of environmental certification programs. The provision of a definition for environmental certification has been used in previous studies on the topic (Fairweather et al., 2005; Puhakka \& Siikamaki, 2012; Park \& Millar, 2016), possibly due to the lack of public awareness on the topic described in section 2.9. Providing a definition can also improve validity as it ensures each respondent has a similar point of reference when answering subsequent questions regarding the specific components.

Respondents were provided with an explanation of core components such as their voluntary nature, standards, assessment, certification, and recognition. Definitions for standards, assessment/ certification (including explanation of first-, second-, and third-party), and recognition were referenced from Toth (2002). Assessment and certification were grouped into one explanation given their similar classifications as explained in section 2.6.2 and 2.6.3. The use of Toth's (2002) explanation of the concepts underlying certification was used based on the thoroughness of the explanations, and the fact that his explanations have been referenced extensively (Font, 2002, 2012, Dodds \& Joppe, 2005, 2009; Bien, 2006a; Chan, 2008; Graci \& Dodds, 2015). This overview was read to each respondent by the interviewer, after which the respondent had the opportunity to ask for any clarification regarding any of the components discussed. Accreditation was not reviewed with the participants as accreditation bodies accredit those organizations that conduct assessments and issue certifications; therefore, these bodies do 
not interact with the applicant, which in the case of this research would be the host. Thus, to the applicant accreditation bodies do not represent a unique program design element.

After the overview of environmental certification was read the respondent was asked whether they would be interested in participating in this type of program. This question was aimed at answering the Research Question 1. The respondent was then asked probing questions to uncover their motivations behind their willingness or unwillingness to participate, which was designed to address Research Question 2. As part of this line of questioning the respondent was asked to identify any barriers that would impact their ability to participate in the program. This probe was designed to determine how the host's motivations or desire to participate could be influenced by other considerations. Both of these questions were open-ended and respondents were not prompted with examples of either motivations or barriers in order to minimize any risk of bias.

The next four questions asked about specific program design elements in order to address Research Question 3. This portion included questions regarding the style of assessment (including the potential of guest reviews) and certification based on the descriptions provided earlier in the interview, as well as asked about the host's willingness to educate guests on environmental issues. This portion also inquired as to whether the host believed guests would value this type of program. The intention of this question was to determine if hosts believed their guests would care about this program, and to contrast this belief against their willingness to participate.

The next part of the interview guide asked respondents to comment on their compliance with high level categories from the GSTC's environmental criteria for hotels, specifically Section D - Maximize benefits to the environment and minimize negative impacts (Global 
Sustainable Tourism Council, 2016). Version 3 of this document was published in December 2016, although for this research version 2 was referenced as version 3 was not available when the interview guide was being developed (see Appendix $\mathrm{G}$ for both versions). Respondents were asked to what degree they comply with these criteria, and if not compliant, their perceived difficulty towards becoming compliant. This section was also designed to address Research Question 3. These criteria were chosen as Airbnb is a member of this organization, suggesting Airbnb has access to these criteria, and also because the criteria are intended to represent a broadly accepted baseline that can help inform other certification programs (Global Sustainable Tourism Council, n.d.-a; Bricker \& Schultz, 2011). The criteria also align closely with suggested environmental improvement areas for small tourism firms identified in the other research (Dewhurst \& Thomas, 2003; Schaper \& Carlsen, 2004). Although it has been suggested that the GSTC are relatively weak criteria (Buckley, 2012), given their intentionally broad applicability and association with Airbnb, they provide relevant environmental categories for this research.

This section was followed by a question asking whether hosts would be more comfortable committing to continuous improvement or meeting environmental performance indicators. Most existing certification programs fall into either of these two styles with regards to their requirements (Honey \& Stewart, 2002; Graci \& Dodds, 2015). Therefore, this question also contributes to Research Question 3, as does the next question regarding the influence of a fee on hosts' willingness to participate. Many certification programs charge a fee in order to participate in the program to help cover administration and assessment costs (see section 2.6.6), therefore it was important to inquire as to how this may affect host's opinions. The respondents were probed regarding the general range they would be willing to pay to determine what approximate cost may discourage participation. Additionally, they were asked who they thought should pay for the 
administration of the program to provide insight into how the financial design of the program may influence their participation.

The final question asked whether they were aware of the Airbnb environmental impacts of home sharing report published in 2014. The purpose of this question was to determine if any hosts were familiar with the report and how they came upon it; if it was something the host searched for and found then this may indicate an interest in the environmental impacts of Airbnb. Also, the researcher was interested in whether the findings had any influence on their willingness to participate in a certification program (e.g., if Airbnb is already environmentally superior to hotels then there may not be a desire to become certified).

Respondents participating in face-to-face interviews were provided with a handout that included the overview of the core components that was read to them, as well as the GSTC criteria (see Appendix B). This handout also included examples for each of the GSTC criteria in case the respondent was unsure of what the criteria meant. This handout also provided examples of existing certification logos. The intention of the handout was to act as a reference in case the respondent needed reminding of the various components as the questions regarding those components were asked. The handout was provided just prior to reviewing the program components so as to avoid the example logos influencing the respondents knowledge of existing certification programs.

The question of whether to provide an estimate of cost of certification was another consideration; however, it was omitted from the interview guide given the wide range of costs that may be required to participate based on the program criteria, auditing scheme, and existing home design and fixtures. One study estimating the cost of implementing an EMS system estimates the cost per employee for a privately owned business at $\$ 531$, although this article 
studied large facilities with an average employee count of 320 (Darnall \& Edwards Jr., 2006). Another study of Spanish hotels estimated the costs of applying to an eco-label as between $€ 1500$ and $€ 3500$, but these hotels ranged in size from less than 50 to more than 300 rooms (Ayuso, 2007). Based on the size of the operations it would not be reasonable to expect these costs to reflect the costs required for an individual Airbnb host.

Finally, prefatory statements were used during the interview to transition between groups of questions. Prefatory statements indicate to the interviewee that a certain topic is about to be discussed thus giving them time to focus on that topic and allowing them a moment to gather their thoughts around that topic (Patton, 2002).

\subsubsection{Sampling and Recruitment}

The target population for this research was Airbnb homeowner hosts in the Greater Toronto Area (GTA). Similar to research by Tzschentke et al. (2008), the aim of the study was to speak with the decision-maker as investigation into the motivations behind pursuing certification must be conducted with the individual that would have final say over how the Airbnb property is managed, and be responsible for implementing any changes necessary for certification. This decision-maker could take the form of the owner, or a property management company that handles all Airbnb related decisions for the owner. Homeowners were also selected over condominium owners as it is currently not illegal for homeowners to offer short-term rentals in Ontario; however, many condominium boards do not allow short-term rentals (Weisleder, 2014; CBC News, 2016). Interviewing condominium hosts therefore presented a greater personal risk to participants than that for homeowner hosts. Additionally, in Ontario, condominium by-laws and rules may restrict certain types of renovations which may limit a host's ability to comply with certain criteria (Consumer Protection Ontario, 2016). The author acknowledges that this is a 
limitation of the research as condominiums represent a substantial share of the Airbnb market in the GTA.

Prior to recruitment a request for participation message (see Appendix C, Figure C1) was developed and approved by Ryerson's Research Ethics Board. Recruitment began in November 2016 and was done through online host forums, social networks, and in-person meetup groups. The researcher posted requests for participation on his personal Facebook page as well as in the "Airbnb Toronto and GTA" Facebook group. Recruitment messages were also posted in the discussion boards for the meetup groups "Toronto AIRBNB Hosts" and "Toronto/ North York Short Term Rental Investors". Meetup is an online platform that allows individuals who share a common interest to connect online, create groups, and schedule meetings for these groups so that the members can connect in-person (Meetup, n.d.). The researcher attended a meeting of the Toronto AIRBNB Hosts meetup group to try to recruit participants, which resulted in the recruitment of one participant. Additionally, the researcher attended an Airbnb community meeting for the Beaches-East York neighbourhood. This meeting was hosted by the Airbnb Canada Public Policy team and was designed as an opportunity for hosts in that neighbourhood to ask questions to Airbnb staff regarding potential policy affecting the platform. There were approximately 15 attendees, however none were willing to participate in the research. After interview completion the recruitment message was also sent as an electronic document to all participants along with their transcripts so that they could forward the recruitment message to anyone in their social network they knew that may have been interested in participating.

In order to increase the participation rate, the request for participation was adjusted in early February 2016 to include an incentive of a $\$ 10$ Starbucks gift card. The revised recruitment message including the new incentive was then re-posted in the "Airbnb Toronto and GTA" 
Facebook group. A flyer was also developed in early February of 2016 and posted around the Ryerson campus (see Appendix C, Figure C2), although there were no responses to these flyers.

The sampling technique used was convenience sampling as respondents were those who were willing to participate from online requests posted in social networks and on meetup groups. Snowball sampling was also used by sending participants the recruitment message for them to pass along to other potential participants. Snowball sampling uses information or contacts from one case to identify other cases (Neuman \& Robson, 2012). This type of sampling is particularly effective for sampling within a network of individuals either directly or indirectly related (Neuman \& Robson, 2012). As of September 2016 there were 8,600 Airbnb hosts in the GTA (Airbnb, 2016c), so it is unreasonable to believe they are all connected; however, the presence of host meetup groups in the city such as "Toronto AIRBNB Hosts" (Rekrut, n.d.) suggested there were connections between hosts that might be leveraged for this study.

Sampling continued until thematic saturation, or redundancy was reached. Redundancy, as described by Lincoln and Guba (1985), is the point at which no new information is being discovered from respondents. This strategy leaves the sample size open to maximize collection of information (Lincoln \& Guba, 1985; Neuman \& Robson, 2012). Crabtree and Miller (1992) suggest that while using redundancy as the indicator for completeness, 12-20 interviews are usually required to achieve a substantial variation of opinions (Crabtree \& Miller, 1992).

The final sample included 14 hosts all of whom own and manage at least one Airbnb property. Most lived in the GTA but one participants property was located in the Niagara region, however this was not grounds for exclusion given that short-term rentals in Niagara, similar to Toronto, are not illegal. While this is a relatively small sample size, as stated by Sampaio et al. (2012) "the rules that guide sampling in quantitative research do not apply for detailed 
qualitative enquiry ... the key issues are to ensure that participants meet the stipulated criteria" (p. 184). This small sample resembles that of similar studies investigating the in-depth opinions of small tourism firms (Alonso \& Ogle, 2010; van Haastert \& de Grosbois, 2010; Sampaio et al., 2012).

This sampling method is non-random which will limit the generalizability of the results; however, this is common in qualitative research (Neuman \& Robson, 2012). Additionally, given this research is exploratory and focusing on a previously unexamined population, the findings are meant to help to provide preliminary insights that can distinguish between areas that require additional research and areas that may not be worth pursuing.

There was a risk that this sampling method would be subject to self-selection bias. This bias occurs when a disproportionate number of individuals agree to participate in research due to their interest in the topic, thus not reflecting the population being studied (Fairweather et al., 2005). An attempt to minimize this bias was taken by stating in all recruitment material that no previous experience or familiarity with environmental certification was required for participation.

There was also the potential risk of the influence of social desirability bias, but as discussed in section 2.8, research has shown that this does not have a significant effect in environmental studies. Additionally, any risk of this bias should have been mitigated by the fact that the interview questions did not directly enquire as to the environmental attitudes of the respondents, and rather focused on their interest in environmental certification, while also allowing the interviewees to explain their responses. Interviews have been used in other studies to try and combat this intention-behaviour gap by allowing the researcher to explore in detail the 
reasoning behind stated intentions (Davies et al., 2005; Young, Hwang, McDonald, \& Oates, 2010).

\subsubsection{Analysis of Interview Data}

Following the data collection phase interview transcripts were prepared for coding in Microsoft Excel, and then coded by the researcher. Coding is the process by which the researcher reviews responses to identify key themes and concepts (Neuman \& Robson, 2012).

Interview data were first subject to open coding, which serves as an initial review of the data where the researcher notes any themes, concepts, or terms that are visible in the data (Patton, 2002; Neuman \& Robson, 2012). At this early stage there is no structure to the coding as any potential item of importance was coded. These preliminary codes were then reviewed and grouped per common themes or concepts, leading to subsequent reviews of the interview data to ensure the groupings were reasonable. Though it may seem unstructured, it is not unusual as the coding process is iterative and cyclical jumping back and forth between defining and sorting of codes (Glesne, 1999). In order to identify significant information contained in the responses the coded data was then reviewed again, with particular attention to the frequency, position and pregnancy of statements (Sjöström \& Dahlgren, 2002). This approach was suggested by Sjostrom and Dahlgren (2002) and identifies frequency as how often a phrase is articulated, position as the placement of a phrase, with more significant elements usually found in the earlier portions of an answer, and pregnancy as the weight of a phrase especially in comparison to other phrases (e.g., a respondent stating that one element is more important than another). For an example of how codes were applied by the researcher see Appendix F. 


\subsection{Secondary Data Analysis}

For this study a content analysis of two secondary data sources was done to help triangulate the data. Data triangulation refers to using multiple data sources to evaluate consistency between sources and in doing so strengthen study results (Patton, 2002). The two data sources were an extract of listing data for all Airbnb listings in the City of Toronto retrieved December 2015 and postings on the Airbnb Community forum. The focus of the content analysis was to ascertain whether environmental features or environmental aspects of a property have been a topic of discussion among hosts, or used to promote one's property on their Airbnb listing.

\subsubsection{Data Sources}

The first source examined was an extract of listing data from all Airbnb listings in the Greater Toronto Area (City of Toronto as well as districts of Halton, Peel, York and Durham) from December 2015. The data were scraped from the Airbnb site using a custom software and retrieved 7,500 listings. The scrape collected publicly available information appearing on the listing across a variety of variables including text based data such as host bio and summary, as well as property amenity details such as gym, internet, kitchen, and television. The data did not include host last name, address, contact info, or any other personal identifiable information; although their publicly visible, Airbnb username was included.

For the purposes of this research only the summary section was used. The summary section is a free text section of the listing that allows the host to highlight the key features of the property. When viewing a listing on the Airbnb platform the summary appears in the "About this listing" section below the key property details and banner photo of the property (see Appendix D, Figure D1). This section was chosen as it allows hosts to describe their property in their own words and it is positioned at the top of the page so that it is the first text description a prospective 
guest would see about the property. The summary has a limit of 500 characters; therefore, the host presumably highlights features that they believe would help attract guests or differentiate their property. The analysis of this section can help to provide complimentary data on whether hosts are promoting environmental features of their property, and where those features appear in the summary relative to features such as location, amenities and other property details. While this does not directly address the research questions it serves to illuminate whether hosts are promoting environmental features of their property when advertising to guests, which serves to indicate a belief that guests' care about these features. Although the interview sample focused exclusively on non-condominium properties, there was no property type filter applied to this scraped data as it was anonymous and did not require any contact with the hosts, unlike inperson interviews.

The other data source is the Airbnb Community forum. This is an online forum where hosts and travelers can ask questions, start conversations or share advice (Airbnb, n.d.-c). This site is open to anyone and one does not need have an Airbnb profile to post in the forum. The forum separates content into eight groups whose titles describe their general theme; welcome \& announcements, new hosts, hosts, community help, where in the world, travelers, Airbnb open and host newsletter. There is also a separate section called host voice that is intended as a forum where existing hosts can share with Airbnb suggestions for new features or ideas for improvement (Airbnb, n.d.-d). For this research, only posts and comments in the host voice, new hosts, hosts, host newsletter and community help section were reviewed as these groups are all opportunities for hosts to make suggestions to Airbnb, or discuss issues with each other. They therefore represent an opportunity to see what issues are important to hosts. An analysis of the content of these posts may directly address the research questions of this study by hosts 
expressing an interest in environmental certification, or it may provide complimentary data by hosts broadly demonstrating interest in environmental issues.

\subsubsection{Content Analysis Method}

The summative content analysis will be used to analyze the secondary data sources. Summative content analysis produces a frequency count of a predetermined list of keywords, as well as the opportunity to develop codes during the data analysis process (Neuman \& Robson, 2012). This list of keywords will be used to search through both data sources and identify listings and forum posts that may be relevant to the research questions. Those sources will then be reviewed and coded based on the themes and content contained in those items. The keywords used were based on the nomenclature used in the research to refer to environmental initiatives in the hospitality industry, and included the words "Green", "Sustainable/ Sustainability”, "Eco”, and "Environment/ Environmental". These keywords resemble those used in other environmentally focused, summative content analysis studies (Wiese, Kellner, Lietke, Toporowski, \& Zielke, 2012). Sources that contained any of these words were reviewed and sorted into either relevant or non-relevant categories based on their content. For example, if a property summary says it is near a Green P parking lot it was deemed not relevant. In the case of the forums, those relevant entries were then coded for themes and concepts as they relate to the research questions, primarily research questions one and three as these entries did not allow inferences to be made regarding the motivations for participating in an environmental certification program. For the listings extract the relevant listings were examined to see how environmental features of their property are being promoted relative to features such as location, amenities and other property details. The researcher also considered including keywords based on the GSTC criteria used in the interview guide, such as local purchasing and disposable goods (see Appendix A); however, in the interviews these were discussed with the participant in the 
context of being used to determine eligibility for a certification program, and the researcher would not be able to apply the same contextual framework to the listings and forum posts. Therefore, these keywords, if they appeared, would not provide the same relevancy to the research questions as they do in the interviews.

\subsection{Summary of Methods}

Table 1 below shows a summary of the research questions and the associated methods used to address those research questions.

Table 1:

Summary of research questions and methods

\begin{tabular}{|l|l|l|}
\hline Research Question & Methods \\
\hline $\begin{array}{l}\text { 1) Would Airbnb homeowner hosts be willing to } \\
\text { participate in an environmental certification } \\
\text { program? }\end{array}$ & Interviews & $\begin{array}{l}\text { Secondary data } \\
\text { analysis - forums }\end{array}$ \\
\hline $\begin{array}{l}\text { 2) What would motivate Airbnb homeowner } \\
\text { hosts to participate in an environmental } \\
\text { certification program? }\end{array}$ & Interviews \\
\hline $\begin{array}{l}\text { 3) What program design elements would } \\
\text { enhance the likelihood of their participation in } \\
\text { the program? }\end{array}$ & Interviews & $\begin{array}{l}\text { Secondary data } \\
\text { analysis - forums }\end{array}$ \\
\hline
\end{tabular}

Interviews being the primary research method will be used to address each research

question, with the secondary data sources serving as a form of data triangulation. As stated in

section 3.3.2 analysis of the forums did not allow inferences to be made regarding the

motivations regarding participation in an environmental certification program. With regards to

the listings extract, it was primarily used to complement findings from the interviews regarding relative value of environmental features. 


\subsection{Results}

This chapter will provide a summary of the results related to both the interviews and secondary data analysis. Interview data are presented with a focus on major themes that emerged from the discussions, and is organized based on the sections and questions as they appear in the interview guide. Secondary data analysis results are presented based on the source, with a similar focus on themes.

\subsection{Interview Results}

\subsubsection{Host profile}

A brief description of each participant's host profile, including superhost status, hosting frequency, property details and experience can be found in Table 2 (a more itemized breakdown of this table can be found in Appendix E, Table E1). This table also includes the participants' stated reasons regarding what drew them to becoming an Airbnb host. Pseudonym's have been assigned to each participant and will be used throughout the results section when referring to the participants individually. Any participant who indicated they were currently a superhost were marked as such. In total, eight of the 14 interviewees had superhost status. Hosts whose property was available to rent for equal to or greater than nine months of the year were identifed as fulltime hosts with the remainder marked as part time. This time period is based on the fact that the Airbnb sponsored reports focused on the Ontario and Toronto market both use this threshold to indicate hosts that could otherwise be using their property for a long-term rental, thus suggesting that this time period indicates full-time availability (Airbnb, 2016a, 2016c). Full-time hosts made up nine of the 14 participants, three of which were property managers. Two of these property managers' portfolio of properties included homes for rent on Airbnb, and one was an Airbnb host themselves for their home, but whose company only managed condominiums (this participant was Jane, and for Jane the interview was focused on her experience as a host, not as a property 
manager). All superhosts also identified as full-time hosts, and all part-time hosts were non-

superhosts. Property details were based on the categories used by the Airbnb platform (i.e. entire

home, private room, shared room), with nine study participants renting their entire home, four

renting a private room, and one who rented a private room year-round but also rented their entire

home when they were away. Experience indicated when participants began hosting on Airbnb

and ranged from four months to over six years.

Table 2:

Summary of participants' host profile

\begin{tabular}{|r|l|l|}
\hline Interview & Pseudonym & Profile \\
\hline 1 & Rob & $\begin{array}{l}\text { Rob is a part-time host who rents his entire home, usually when he and his } \\
\text { wife are out of town. He's been a host for approximately four months and } \\
\text { joined Airbnb because of the opportunity to make some extra money and } \\
\text { because he knew of friends who had done it. }\end{array}$ \\
\hline 3 & Mary & $\begin{array}{l}\text { Mary has rented her property on Airbnb once before, but plans on doing it } \\
\text { more as she begins travelling for work. She rents her entire room and began } \\
\text { hosting six months ago. She was drawn to hosting based on her experience } \\
\text { with the service as a guest, Airbnb's host insurance policy (\$1MM for liability } \\
\text { and property damage), and the extra income it provides. }\end{array}$ \\
\hline 4 & $\begin{array}{l}\text { Rannah is a superhost that rents between two and three private rooms in her } \\
\text { property, which are available for rent year-round. Hannah has been a host for } \\
\text { over three years and was drawn to hosting by the ability to make some money } \\
\text { to help pay for her mortgage, and the enjoyment she gets from having guests } \\
\text { and getting to know people from around the world. }\end{array}$ \\
\hline 5 & $\begin{array}{l}\text { Rachel is a part-time host that uses Airbnb to find renters for a private room in } \\
\text { her house. She has been using Airbnb for over two years, but only uses the } \\
\text { service sporadically (approximately five times over the two years). She was } \\
\text { drawn to Airbnb by her desire to host people and show off her city, as well as } \\
\text { develop relationships with her guests. }\end{array}$ \\
\hline 6 & Mike & $\begin{array}{l}\text { Mike is a property manager that uses Airbnb to find short-term rentals to } \\
\text { bridge the gap between longer term rentals. His portfolio includes a home that } \\
\text { he rents on Airbnb. He has been using Airbnb for six months and began using } \\
\text { it as an opportunity to increase his business's revenue. }\end{array}$ \\
\hline $\begin{array}{l}\text { Sarah is a part-time host that rents her entire property, primarily for longer } \\
\text { periods when she and her family are away. She's been a host for over three } \\
\text { years and began hosting after it was recommended to her by a friend as a great } \\
\text { way to make some extra money. }\end{array}$ \\
\hline $\begin{array}{l}\text { Will is a superhost and property manager whose mix of units include houses } \\
\text { available for rent on Airbnb. He has been using the service for two years and } \\
\text { was drawn to it by the revenue potential. }\end{array}$ \\
\hline
\end{tabular}




\begin{tabular}{|r|l|l|}
\hline Interview & Pseudonym & Profile \\
\hline 8 & Peter & $\begin{array}{l}\text { Peter is a superhost who rents a coach house on his property full-time. He has } \\
\text { been a host for a year and was drawn to hosting by the opportunity to make } \\
\text { some extra money off an otherwise empty space, as well as the sense of } \\
\text { security he got from having people staying on his property. }\end{array}$ \\
\hline 10 & Alex & $\begin{array}{l}\text { Greg is a part-time host that rents his entire property when he and his wife go } \\
\text { away during the summer. He's been doing it for over two summers now and } \\
\text { was drawn to Airbnb after he heard of friends doing it. He also liked the fact } \\
\text { that he could make some extra money, that there would be somebody in his } \\
\text { home while he was gone, and enjoyed the opportunity to introduce people to } \\
\text { his neighbourhood. }\end{array}$ \\
\hline 11 & Katie & $\begin{array}{l}\text { Alex is a superhost that rents his entire property full-time and has been doing } \\
\text { so for three years. His wife introduced him to Airbnb and he began using it } \\
\text { because of the financial benefits. }\end{array}$ \\
\hline 12 & Heather & $\begin{array}{l}\text { Katie is a superhost that rents out her basement full-time, as well as the entire } \\
\text { property occasionally. She has been a host for about a year and was drawn to } \\
\text { hosting by the desire to share her home and her husband's desire to meet new } \\
\text { people; although she states they wouldn't host without the financial benefit. }\end{array}$ \\
\hline 13 & $\begin{array}{l}\text { Heather is s superhost that rents a private room in her home full-time. She's } \\
\text { been hosting for over three years and began hosting based on her desire to run } \\
\text { a B\&B and share her home. }\end{array}$ \\
\hline Caitlin & $\begin{array}{l}\text { Caitlin is a superhost that rents her entire Niagara vacation property full-time. } \\
\text { She has been hosting on Airbnb for roughly six months and was drawn to the } \\
\text { service by her familiarity with Airbnb as a guest and the opportunity to make } \\
\text { extra income that could help her afford the vacation property. She also enjoys } \\
\text { acting as a host to her guests. }\end{array}$ \\
\hline $\begin{array}{l}\text { Jane is a superhost that rents a room in her home full-time. Jane is also a } \\
\text { property manager and has been hosting on Airbnb for over six years. She was } \\
\text { drawn to Airbnb by the combination of extra income, meeting new people, } \\
\text { and a desire to host and entertain guests. }\end{array}$ \\
\hline
\end{tabular}

\subsubsection{Host Reasons for Joining Airbnb}

The reasons for joining Airbnb fell into four overarching themes: financial, comfort, home-sharing, and hosting. As can be seen in Table 3, participants may have indicated one or more than one of these themes in their interview as their reason for joining Airbnb. The reasons as they appear for each participant in Table 3 are ordered principally based on their position as they occurred in the participant's response. The frequency count of these themes is illustrated in Appendix E, Table E2. 
Table 3:

Reasons for joining Airbnb

\begin{tabular}{|c|c|c|c|c|c|}
\hline Pseudonym & Superhost & Frequency & $\begin{array}{l}\text { Property } \\
\text { details }\end{array}$ & $\begin{array}{l}\text { Experience as an } \\
\text { Airbnb host } \\
\text { (approximately) }\end{array}$ & $\begin{array}{l}\text { Reasons for } \\
\text { joining } \\
\text { Airbnb }\end{array}$ \\
\hline Rob & No & Part-time & $\begin{array}{l}\text { Entire } \\
\text { home }\end{array}$ & 4 months & $\begin{array}{l}\text { Financial; } \\
\text { Comfort }\end{array}$ \\
\hline Mary & No & Part-time & $\begin{array}{l}\text { Entire } \\
\text { home }\end{array}$ & 6 months & $\begin{array}{l}\text { Comfort; } \\
\text { Financial }\end{array}$ \\
\hline Hannah & Yes & Full-time & $\begin{array}{l}\text { Private } \\
\text { room }\end{array}$ & Over 3 years & $\begin{array}{l}\text { Financial; } \\
\text { Home-sharing }\end{array}$ \\
\hline Rachel & No & Part-time & $\begin{array}{l}\text { Private } \\
\text { room }\end{array}$ & Over 2 years & $\begin{array}{l}\text { Hosting; } \\
\text { Home-sharing; } \\
\text { Comfort }\end{array}$ \\
\hline Mike & No & $\begin{array}{l}\text { Full-time - } \\
\text { property } \\
\text { manager }\end{array}$ & $\begin{array}{l}\text { Entire } \\
\text { home }\end{array}$ & 6 months & Financial \\
\hline Sarah & No & Part-time & $\begin{array}{l}\text { Entire } \\
\text { home }\end{array}$ & Over 3 years & $\begin{array}{l}\text { Financial; } \\
\text { Comfort }\end{array}$ \\
\hline Will & Yes & $\begin{array}{l}\text { Full-time - } \\
\text { property } \\
\text { manager }\end{array}$ & $\begin{array}{l}\text { Entire } \\
\text { home }\end{array}$ & 2 years & Financial \\
\hline Peter & Yes & Full-time & $\begin{array}{l}\text { Entire } \\
\text { home }\end{array}$ & 1 year & $\begin{array}{l}\text { Financial; } \\
\text { Comfort }\end{array}$ \\
\hline Greg & No & Part-time & $\begin{array}{l}\text { Entire } \\
\text { home }\end{array}$ & 2 - 3 years & $\begin{array}{l}\text { Comfort; } \\
\text { Financial; } \\
\text { Hosting }\end{array}$ \\
\hline Alex & Yes & Full-time & $\begin{array}{l}\text { Entire } \\
\text { home }\end{array}$ & 3 years & Financial \\
\hline Katie & Yes & Full-time & $\begin{array}{l}\text { Both } \\
\text { entire } \\
\text { home and } \\
\text { private } \\
\text { room }\end{array}$ & 1 year & $\begin{array}{l}\text { Home-sharing; } \\
\text { Financial }\end{array}$ \\
\hline Heather & Yes & Full-time & $\begin{array}{l}\text { Private } \\
\text { room }\end{array}$ & Over 3 years & $\begin{array}{l}\text { Hosting; } \\
\text { Home-sharing }\end{array}$ \\
\hline Caitlin & Yes & Full-time & $\begin{array}{l}\text { Entire } \\
\text { home }\end{array}$ & 6 months & $\begin{array}{l}\text { Comfort; } \\
\text { Financial; } \\
\text { Hosting }\end{array}$ \\
\hline Jane & Yes & $\begin{array}{l}\text { Full-time - } \\
\text { host and } \\
\text { property } \\
\text { manager }\end{array}$ & $\begin{array}{l}\text { Private } \\
\text { room }\end{array}$ & Over 6 years & $\begin{array}{l}\text { Financial; } \\
\text { Home-sharing; } \\
\text { Hosting }\end{array}$ \\
\hline
\end{tabular}

Financial reasons, defined as the ability to make extra income using Airbnb, was the most

common theme. It was mentioned 12 times in total with eight of those 12 occurrences being the primary reason given. Additionally, for Mike, Will and Alex it was the only reason mentioned. 
Many participants who claimed this reason gave answers similar to that of Rob, who when asked their reason for joining stated, "Ummm, just the income, like we figured our house is our only asset so we might as well try to monetize that."

The next most common category was comfort. Comfort included both one's familiarity with the service, through either their experience as a guest or a friend's recommendation of the service; as well as a sense of safety/ security as a result of features such as the host insurance policy, and the comfort knowing someone (i.e. their guests) was "watching over their home". As Greg put it, “um, well, I guess the first thing is I heard of friend's doing it, and it sounded like quite a neat idea... it was also nice to think we could have somebody in the house, just water the plants and those types of things."

The final two themes, home-sharing and hosting, had five mentions each. Home-sharing is defined as the ability to share one's space and in doing so meet new people. This reason was only expressed as the primary reason by one participant, but four times as the secondary reason. This theme was characterized by a desire to share space or live with guests, as well as interact with them. As Katie explained:

we were always interested in the collaborative economy but more in the real sense of the collaborative economy like we have this extra space so why not share it with people... Um, and, for my husband it's more about- I like meeting people I'm really social but if they're in my house I don't necessarily love to socialize unless there's a real connection, but he just loves like, meeting all these people from different places, like we geteveryone's been great we've had a really good experience with people, so there's that social aspect of it. 
As might be expected, the five participants that mentioned this reason were also the only five participants that rented a private room in their residence. Therefore, they were the only hosts in the sample actually practicing the act of sharing their home with their guests; as opposed to those who rent their entire property and would therefore not be sharing space with their guests. No other reason was so strongly associated with a particular host feature.

Finally, hosting was expressed as a desire to show off one's city/ community, entertain guests or just the general enjoyment one gets from hosting people. Grouped in this theme was also the idea that being an Airbnb host fulfilled a dream of running a more traditional bed and breakfast. Hosting and home-sharing were similar in that they both included the desire to interact with guests; however, they are distinct in that the latter emphasized the concept of sharing or "living with" guests, whereas the former emphasized (or expressly used the term) hosting. The following excerpt from Rachel represents the hosting theme:

I'd always thought it'd be kind of fun to run a bed and breakfast or something like that.

So it was kind of a way to get my foot in the door and see what that would be like... and I do like to help people and show them around so for me it was kind of, it was fun.

\subsubsection{Familiarity with Environmental Certification Programs}

Overall, interviewees were somewhat familiar with the concept of environmental certification, though Greg had a more thorough understanding of these programs in that he was able to explain the use of a logo in exchange for meeting specific environmental criteria, and was also able to identify two existing programs (Green Key and Green Globe). While a few of the interviewees were not familiar, most were aware of the existence of these programs and were able to vaguely explain the program either by highlighting the presence of requirements or 
identifying certain measures such as towel and linen re-use programs or energy conservation measures. Each participant was provided with the overview as discussed in section 3.2.1 irrespective of their level of familiarity.

\subsubsection{Willingness and Motivations Toward Participation}

Interviewees expressed definite interest in participating in an environmental certification program for Airbnb properties, as seen in Table 4, although a few stated it would depend on the requirements of the program and financial benefit; these caveats will be explored further in section 4.1.5.

Table 4:

Willingness to participate in an environmental certification program

\begin{tabular}{|l|l|l|}
\hline $\begin{array}{l}\text { Willing to Participate } \\
\text { in Program? }\end{array}$ & Participants & Total \\
\hline Yes & $\begin{array}{l}\text { Rob, Hannah, Rachel, Mike, Will, Peter, } \\
\text { Greg, Katie, Heather, Caitlin, Jane }\end{array}$ & 11 \\
\hline Depends & $\begin{array}{l}\text { Mary (requirements and commercial } \\
\text { benefits) } \\
\text { Sarah (requirements) } \\
\text { Alex (commercial benefits) }\end{array}$ & 3 \\
\hline
\end{tabular}

A variety of motivations to participate were identified (see Appendix E, Table E3). The

most strongly emphasized motivations fell under the themes of personal values and commercial benefits. 'Personal values' included an alignment with one's personal environmental ethic, the ability to "feel good" about your property, and that certification would contribute to the greater good. 'Commercial benefits' included the ability to differentiate one's property, attract more or specific guests (e.g., green guests or millennials), and achieve cost-savings. These motivations were often mentioned in tandem, as can be seen in this quote from Jane:

Uh yeah, I think I would, because I like, care about the environment, and I also think it's a good way to promote my space, you know for those other, sort of, environmentally conscious travelers. 
Less common motivations included the 'ability to attract like-minded guests', 'recognition for environmental commitment' and the desire to measure or understand 'household environmental impacts'. The ability to attract like-minded guests was determined to be distinct from the ability to attract specific guests, which was included under commercial benefits. This was done because the participants that mentioned ability to attract like-minded guests clearly stated their interest in attracting guests that shared the same personal values as them, as opposed to their property being more attractive for a specific subset of guests. For example, the following quote from Caitlin illustrates her desire to attract like-minded guests:

Um, I would be interested in such a program, and one of the reasons is if there was some kind of way that guests can search out properties, I feel like you attract guests that have similar values as you do, which is not always easy otherwise, you know? So you can kind of adjust your profile a little bit to kind of write we care about the environment, which I do, um, but this [environmental certification program] self-selects a little bit more which I think is important for Airbnb hosts to find the right guest fit.

Whereas Jane wanted to attract "green" guests: “...I also think it's a good way to promote my space, you know for those other, sort of, environmentally conscious travelers."

Recognition for environmental commitment was mentioned as a motivator among hosts that believed they had already implemented multiple measures to minimize their environmental impacts, as demonstrated by the following quote from Rachel:

Well I think you know, already now there's a lot of things I do around my home to be more energy efficient. Like I've always recycled, you know I use energy efficient bulbs I try to do, you know I hang dry things instead of putting them in the dryer. There's a lot of 
things I do already because that's what I believe in...it would almost just sort of reinforce, you know what it does is it paints a better picture of the host, because it's genuine, you're already doing those things anyway.

Along the same lines, Katie explained, "first of all I think we'd probably be doing a lot of the things that it required so it would be nice to be recognized for that." This quote indicates the influence program design can have on motivations illustrated in the conceptual framework.

The final motivator mentioned was the desire for a measurement of household environmental impacts, either through an energy audit or some other type of assessment. As Caitlin noted:

I would like having a third-party assessment actually, and I've actually thought about doing it independently, um, just getting someone to come and kind of do their own little evaluation to see if they can make any recommendations, but I wasn't sure you know how expensive is it going to be.

Of the three participants that stated their participation in this program would depend on some condition, commercial benefits was the most popular motivation. As demonstrated by Alex regarding whether he would participate:

I would, but with condition... I wouldn't because just to save the environment, we're too disconnected to that, there's too many steps between me and the demise of the planet that give me any connection to that. You'd have to draw me to the revenue potential, because in our immediate needs we do this [host on Airbnb] for revenue.

Motivations were also separated by superhost status to determine whether hosts with this status demonstrated a variation in motivations (see Table 5). 
Table 5:

Motivations mentioned by host status

\begin{tabular}{|l|l|l|}
\hline Motivation & Superhost (n) & Non-superhost (n) \\
\hline Personal values & 6 & 5 \\
\hline Commercial benefits & 7 & 3 \\
\hline $\begin{array}{l}\text { Ability to attract like-minded } \\
\text { guests }\end{array}$ & 3 & 2 \\
\hline $\begin{array}{l}\text { Household environmental } \\
\text { impacts }\end{array}$ & 1 & 1 \\
\hline $\begin{array}{l}\text { Recognition of environmental } \\
\text { commitment }\end{array}$ & 1 & \\
\hline
\end{tabular}

As seen in Table 5, both superhosts and non-superhosts included personal values

and commercial benefits as the main motivations, with superhosts slightly skewed

towards the latter and non-superhosts slightly skewed towards the former. Superhosts

accounted for all mentions of the motivation 'ability to attract like-minded guests'.

In summary, there was near consensus regarding the willingness to participate in an environmental certification program for Airbnb, with no participants expressing an unwillingness to do so. In explaining their motivations, interviewees mentioned a range of motivations with the most popular being personal values and commercial benefits.

\subsubsection{Barriers to Participation}

The most commonly mentioned barrier to participating in this type of program was the potential associated costs (see Appendix E, Table E4). Other barriers included the time commitment required, perceived credibility of the program (i.e. not interested if not credible), rigour of the standards, and if there were any trade-offs with comfort.

Rigour of the standards refers to the standard being difficult to achieve, and in both instances was mentioned along with the cost barrier. As Sarah stated, "my house is very old so I'd say we'd have a hard time passing, but I would be very interested in doing it unless it was like really hard or expensive to do." When discussing the cost barrier, solar panels were 
mentioned three times as an example of a requirement that would be too costly, for example Greg explained:

well I guess it depends what the level- what the criteria were. I mean if I had to have solar panel heating, that would be a massive um, investment, so that would be a restriction for me. So it think it would be the level of investment that it would take.

The cost barrier was also mentioned by each of the part-time hosts that responded to this question (Rachel did not identify any barriers), as illustrated in Table 6.

Table 6:

Barriers for part-time hosts

\begin{tabular}{|l|l|l|l|}
\hline Pseudonym & Superhost & Frequency & Barriers \\
\hline Rob & No & Part-time & $\begin{array}{l}\text { Cost; Rigour of the } \\
\text { standards }\end{array}$ \\
\hline Mary & No & Part-time & $\begin{array}{l}\text { Cost; Time } \\
\text { commitment; } \\
\text { Trade-offs with } \\
\text { comfort }\end{array}$ \\
\hline Rachel & No & Part-time & $\begin{array}{l}\text { No barriers } \\
\text { identified }\end{array}$ \\
\hline Sarah & No & Part-time & $\begin{array}{l}\text { Cost; Rigour of the } \\
\text { standards }\end{array}$ \\
\hline Greg & No & Part-time & Cost \\
\hline
\end{tabular}

The cost barrier may be of special concern to part-time hosts, all of whom also happen to

be non-superhosts, due to the fact their marginal income from hosting is likely lower than that of a full-time host. Therefore, while cost was a concern to multiple full-time hosts as well, it may be especially salient to part-time hosts as any cost associated with participation would represent a larger share of their income from Airbnb compared to full-time hosts. Part-time hosts also accounted for the only mentions of rigour of the standards as a barrier. Again, due to their less frequent hosting they may be more sensitive to the difficulty in achieving the standards, as they 
may perceive challenging standards as not worth the effort. Full-time hosts did not associate as strongly as part-time hosts with one particular barrier.

Five of the participants either did not perceive any barriers to participating or expressed a barrier that was not dependent on program design; for example Mike explained, "I have money partners that put money in so I don't know if it's a barrier or not, it's my talents and abilities in order to sell them on the need to do this [environmental certification].”

\subsubsection{Preferred Type of Assessment}

When asked what type of assessment they thought was most appropriate for an environmental certification program, as opposed to providing a straightforward answer, the participants tended to discuss the pros and cons of the various styles (self-, second- and thirdparty assessment). Within these discussions three major themes emerged: credibility, cost, and simplicity. Regarding credibility, numerous participants suggested that some type of external verification is required as not all hosts would be honest in their self-assessment. As Peter stated:

I feel like for someone like me I'm a pretty honest person and I would, I would be fine handling it myself, but I think in general it would probably be a good idea to have a second- or third-party do it. It's pretty easy to just like click a box and say oh yeah there's solar panels... if it was Airbnb or someone hired out [third-party] that wouldn't make a difference to me, but I do think it should be someone that's not the host.

Interviewees explained that this external verification could be achieved either by leveraging the existing guest review process, or by employing second- or third-party assessment, as exemplified by Hannah: 
I think the self-assessment would be the most cost-efficient, but I would say maybe on a periodic basis to have maybe the second- or third-party sort of go on a random basis to verify... however, if it's on the Airbnb website and it's very clear like you know that there's this certificate or certification and when you click on the certification it says your host meets all these criteria, if you book that place as a guest and you go there and you're expecting that this host meets all this criteria and you see that they're not you could do a whistleblower and say hey you know the host is not an eco-friendly house and then, so they could investigate right.

The cost theme was represented through both concerns over the cost of third-party assessment, as well as support for the cost-efficiency of self-assessment. This was demonstrated in the previous quote from Hannah, as well as by Jane:

Um, you know, again it's a cost thing, like if an environmental organization was willing to do third-party audits at no cost I think some people might find that appealing because it does lend legitimacy to the program, but again it's like, what are the realities of that, who's gonna pay for that to happen.

Greg expressed the potential trade-off between credibility and cost by stating:

um, I would not be a fan of self-assessment. Um, I think that would lead to lies essentially, um, so in terms of whether it would be second-party or third-party, I mean I guess it, I mean third-party would be more expensive but more reliable, um and so I guess it depends where that cost is met, who's gonna meet that cost. And so I'm, I'm, um I mean ideally it would be third-party because I think that would be the most reliable and the most trustworthy. 
The theme of simplicity revolved around general support for self-assessment given it would be the easiest for the hosts to comply with and for Airbnb to implement as it could be incorporated with the guest review process. Also, as Katie pointed out, Airbnb already uses a self-assessment to award their business travel ready designation:

so I think Airbnb seems to be moving towards doing less and less so I cannot imagine they would put anything into this assessment. I mean like I said with the superhost it's all based on the metrics from the website so it seems to be an automatically generated, you know $\mathrm{x}$ response rate, how many stars you have, how many booking you have, it's pretty automatic. Whereas the business-ready, it's a checklist of things but then they're very obvious things so when the guest comes if you're lying and you don't have an iron or you don't have a workspace they'll know.

This designation comes in the form of a Business Travel Ready badge that is awarded to hosts that comply with certain criteria related to business travel such as excellent reviews for accuracy and cleanliness, as well as amenities such as wireless internet, a laptopfriendly workspace, and an iron (Airbnb, n.d.-i). In exchange for meeting these criteria the host is awarded a badge on their listing that looks like a briefcase, to indicate their property is business travel ready.

Overall, there was general agreement that second- or third-party assessment would lend credibility to the program, but that this would cost more and be a deviation from Airbnb's existing strategy of using guest ratings and feedback to validate host claims.

\subsubsection{Willingness to Participate in an External Program}

The majority of participants were willing to participate in an external program not associated with Airbnb. Four participants added the caveat though that they wanted whatever 
logo they were awarded through an external program to be visible on their listing. For this consideration to be satisfied an external program would seem to require some type of integration with the Airbnb platform. As Greg put it, "I mean I'd still be interested, I mean the problem I would see is how as an Airbnb host would I be able to market that on my Airbnb listing if Airbnb didn't recognize it and allow me to upload a logo or whatever it was."

\subsubsection{Willingness to Have Guest Reviews}

Almost all interviewees also expressed their willingness to be evaluated by guests on their environmental initiatives, similar to the existing guest review process. Currently hosts are evaluated out of five stars on their properties accuracy, cleanliness, communication, check-in, value, and location. Participants felt that if they were claiming they had implemented environmental measures then it was fair to be evaluated on this (see Appendix E, Table E5).

One of the interviewees who was willing to be subject to guest reviews highlighted that it is important that the criteria being evaluated is transparent and based on features visible to the guest. As explained by Rob:

Yeah I think that's good as long as it's um, as long as it's transparent, I mean things like low-flow toilets you can see and measure. Some of the other things, like how well a house is insulated, I would think things like that would be harder for a guest to see off hand, but if the guidelines are there and explained to them then I think they would get some value out of that.

Two participants expressed concern over the subjectivity of evaluating environmental features, with both citing past instances where they received poor reviews for cleanliness. These participants believed that disparate personal standards were responsible for these poor reviews, 
and were concerned that the same situation could arise with regards to environmental standards. As stated by Sarah:

The problem is it's so subjective right, and so the cleanliness, I have hired professionals to come in and clean and then still got a bad rating on cleanliness, so it's kind of like, I don't know that person and if they tell me my house was not clean I don't know what their standards are and I don't know how comfortable I'd be if I- because I feel I know the subject matter, and if I say that my house meets a certain criteria and then somebody who I don't know and may have no expertise in the field comes in and says it isn't, I don't know I think I would find that annoying.

\subsubsection{Comments Regarding Environmental Features}

Most participants had never received any comments regarding the environmental performance of their property. Jane received a compliment regarding her vegetable garden and Heather was told that the recycling system in Toronto is complicated. Caitlin had also received a comment from someone expressing appreciation for their environmental efforts, although clarified that this was not a common occurrence, stating "yeah most people kind of ignore it, however I received one comment saying they appreciated my efforts for being environmentally friendly which I was happy about.” Although even these participants acknowledged that aside from these few comments they generally did not receive any comments regarding the environmental features of their property.

\subsubsection{Guest Engagement Regarding Environmental Features and Behaviour}

All interviewees except one stated they were either already informing guests of environmental features, or were willing to inform guest of these features (see Appendix E, Table E6). The most common environmental practice already being promoted was recycling/ composting, followed by minimizing energy use (e.g., turning off lights, reducing laundry use). 
The general theme from interviewees that were already engaging guests as well as those willing to engage guests regarding environmental features was a desire to passively inform guests of how to use environmental features of the house or reduce their environmental impact. These passive forms of engagement included using an automated message, pdf booklet, or house guide which is a collection of house rules and instructions hosts leave out for their guests. These participants explained that they preferred this passive type of instruction as they did not want to come across as pushy or preachy to their guests. As stated by Heather, "I wouldn't have a problem leaving a written document, like a prepared sort of sheet in my house manual, but I wouldn't want to, you know I'm not into giving people lectures on how to live.”

One participant was not willing to engage guests regarding how to reduce their environmental impact. Alex noted that he saw it as the host's responsibility to reduce the environmental impact of the property and not the guests, and used the hotel industry as an example. This participant was emphatically against putting this responsibility on the guest, as exemplified by his response:

no, no I'm glad you said that because I think that's fucking bullshit. I hate when I go into a hotel and the onus is put on me... You guys here [hotels] you're just trying to save money... it's your [the hotels] job to make your shit more efficient, use less water with your appliances and all that sort of stuff. It's not my- you can't put that responsibility on me I'm your guest.

Rachel and Peter also both noted that while they do inform their guests of recycling practices in their home (and also in Rachel's case energy usage by adjusting the thermostat when the guest is not home), guests do not have an incentive to comply with 
recycling rules or reduce their resource consumption, and because of this they consume more resources.

\subsubsection{Preference for Levels Versus Pass/fail Certification}

Participants mainly preferred that certification be awarded based on levels as opposed to a pass/fail system (see Appendix E, Table E7). The strongest justification for levels appeared through the theme of fairness, in that many of the participants felt that levels were more fair in that they were able to recognize a range of environmental commitment, and because some hosts may be restricted in what they can do based on their property or budget. This was summarized by Mike, who stated:

I think you have to have a rating system, I don't think it should be pass/ fail, I think you're gonna encounter so many different types of individuals, um and how much can each afford is gonna be a big determining factor, so for somebody to be able to opt in at a very low level and then improve over time and get to a higher certification level. I think that is the best way to go for a program like this.

The ability to improve, as well as the sense of encouragement that levels provided was mentioned by other interviewees as well. Pass/ fail was also criticized by two interviewees as they believed the "fail" aspect was too negative and would discourage participation. As stated by Will “if you get silver, then you can get tips on what you could do to get gold, you're not failing...failing is a negative connotation."

Pass/ fail was supported by Alex because he believed it was a better indicator of commitment than a tiered system, stating "no I think for me it's not about simplicity it's about commitment, and look you're either doing it or you're not." 
Sarah did not have a strong opinion over which method she preferred, though she believed that pass/fail would be easier; however, it was unclear in what sense (i.e. easier for hosts, easier to manage, easier to develop and implement). Mary and Katie both indicated that their primary consideration with either system would be the achievability of the standards. Similar to the barrier of rigour expressed in section 4.1 .5 , these participants wanted to ensure that the program requirements were reasonable and attainable by the hosts. Katie also brought up the issue of fairness in this regard stating, "I would think either here are the 10 things if you do 5 of them you pass or fail, or do a graded system... I don't think it's fair to ask people to do all of them or you get no recognition right."; this indicates that Katie is also concerned with fairness, but believes that this can be incorporated through either system.

\subsubsection{Perceived Value of Program to Guests}

The three general themes that emerged from the responses regarding whether this program would be valued by guests were optimism, guarded optimism, and pessimism, with each theme represented fairly evenly across the participants (see Table 7).

Table 7:

Summary of perceived value of program to guests

\begin{tabular}{|l|l|l|}
\hline $\begin{array}{l}\text { Perceived value of program } \\
\text { to guests }\end{array}$ & Participants & Total \\
\hline Optimism & Mike, Peter, Katie, Heather & 4 \\
\hline Guarded optimism & Rob, Sarah, Will, Greg, Caitlin, Jane & 6 \\
\hline Pessimism & Mary, Hannah, Rachel, Alex & 4 \\
\hline
\end{tabular}

Optimism was characterized by a strongly stated belief that some consumers, or a certain sub-set of consumers (e.g., millennials) would value this program, as demonstrated by Heather "oh some of them would sure, not all of them but some of them."

Guarded optimism included responses that believed some consumers would value this program but expressed hesitation or ambivalence as part of their response by either second- 
guessing themselves, or demonstrating a sense of unsureness in their response. For example, Jane stated “I think so, but I don't know how much- I think they'd be like oh that's cool, but I don't know if it would be a huge drive to book environmentally safe place." Although similar, this group was distinct from the optimistic group in that they demonstrated less confidence in the belief that consumers would value this program. It should be noted that among both the optimistic and guardedly optimistic responses there was an acknowledgement that price is still likely to be a primary consideration, ahead of environmental performance. Millennials were mentioned in both the optimism and guarded optimism responses as both the target market for Airbnb, as well as a cohort that would be particularly interested in this program.

Pessimism was expressed as a general belief that environmental criteria would not be a major decision factor for guests, and would be considered secondary to factors such as price, location, and value. Some participants in this group did believe that "all other things equal", environmental certification could be used as a differentiator to choose between two properties, but again, only after the aforementioned factors were satisfied. As Hannah put it:

yeah, um, I don't think it would be as valuable as location and price... if you had two properties next to each other and they had the same pictures and one had a little eco sticker on it somebody might say oh I want to stay there, but that's only if they look the same, and they cost the same."

Interestingly, Mary and Alex, both of whom expressed pessimistic views towards the perceived value of this program, were also two of the individuals who stated that their willingness would depend on demonstrating consumer demand or revenue potential. Therefore, it appears these respondents would need to be convinced of the value of this program to guests before they would pursue certification. 


\subsubsection{Environmental Categories}

As mentioned in section 3.2.1, the environmental categories discussed with participants were based on those available from the GSTC's environmental criteria for hotels, Section D Maximize benefits to the environment and minimize negative impacts (see Appendix G). Table 8 summarizes the responses for each of the environmental categories. 'Already doing' included participants who stated that they were already doing these activities to some extent on their property. 'Easy' referred to those hosts who were not following this practice, but believed it would be easy to incorporate it into their property. 'Challenging' referred to those who were not following this practice, but believed it would be difficult to incorporate it into their property because of certain barriers. 'Unsure' referred to participants who were not sure whether or not they were currently adhering to a certain category or were unsure about their willingness to change. 'Not willing' referred to participants who were unwilling to incorporate a certain category into their property. 'N/A' meant the category was not applicable to their property. As can be seen, for all the questions, except local purchasing and alien species, the majority of participants stated they were already adhering to these principles to some extent.

Table 8:

Summary of host activities across environmental categories

\begin{tabular}{|c|c|c|c|c|c|c|}
\hline Category & $\begin{array}{l}\text { Already } \\
\text { doing }\end{array}$ & Easy & Challenging & Unsure & Not willing & N/A \\
\hline Local purchasing & 4 & 0 & 0 & 0 & 0 & 10 \\
\hline Disposable goods & 10 & 3 & 1 & 0 & 0 & 0 \\
\hline $\begin{array}{l}\text { Energy } \\
\text { conservation }\end{array}$ & 9 & 0 & 4 & 1 & 0 & 0 \\
\hline $\begin{array}{l}\text { Water } \\
\text { conservation }\end{array}$ & 6 & 3 & 2 & 1 & 2 & 0 \\
\hline $\begin{array}{l}\text { Transport } \\
\text { Greenhouse gas } \\
\text { emissions (GHG) }\end{array}$ & 8 & 1 & 2 & 1 & 2 & 0 \\
\hline Waste & 9 & 5 & 0 & 0 & 0 & 0 \\
\hline $\begin{array}{l}\text { Harmful } \\
\text { substances }\end{array}$ & 9 & 1 & 3 & 1 & 0 & 0 \\
\hline Alien species & 4 & 2 & 0 & 5 & 0 & 2 \\
\hline
\end{tabular}




\subsubsection{Local Purchasing}

The majority of interviewees stated that local purchasing was not applicable to their property as they did not provide food or beverages to their guests. Some of these participants stated that they provide coffee or tea; however, as those are not domestically produced in Canada the option to purchase those locally is not available, so if that was the only food or beverage product the host supplied to their guests they were counted as not applicable. A few participants claimed they were already doing this to some extent, usually with reference to food and beverage related gifts that they leave their guests. For example, Peter stated:

yeah I always, every guest that checks in I leave them, depending on who it is, I leave them something, and it's usually like baked goods or a local beer or something like that but it's always something I've got locally.

and Caitlin stated:

I always leave them wine, um sometimes like local cheeses, honey, I always leave some type of consumables. Also I have soaps that are made locally and hand washes that are made locally and I also leave locally grown flowers, so I make a big effort.

Rachel also stated that she will inform guests of the local farmer's market, which would allow the guest to buy locally for themselves.

\subsubsection{Disposable Goods}

With regards to disposable goods, 13 of the 14 participants had either already taken steps to reduce disposable goods, or were willing to do so. Ten of the participants had already implemented changes such as using bulk toiletries, encouraging the use of tap water versus bottled water, and avoiding coffee pods. As Heater put it: 
we also actually suggest to people, we tell them that Toronto water is totally safe to drink, so they don't need to- I mean some people will, they use plastic bottles anyway, whether it's just a force of habit or they don't trust the water, but we do have in our house manual that Toronto's water is perfectly safe to drink and it tastes good.

The use of coffee pods was included in the interview handout (see Appendix B) as an example of a disposable good that could be replaced with a less wasteful option. Many interviewees responded to this by stating their dislike of these products for environmental reasons. Peter had already switched from these pods to a less wasteful coffee option based on personal values, as he described:

I did have one of those coffee maker things... and I got rid of it because I couldn't, uh it was awful, the pod things, and I don't know I got rid of it, and now I give them just a French press and I have a couple espresso makers and stuff... when I realized they weren't recyclable (the coffee pods) I got rid of it and went back to the press.

One participant, Alex, was unsure regarding his willingness to reduce disposable goods and referred to coffee pods in his response. This interviewee got these pods for free, and because of this seemed reluctant to switch to a less wasteful coffee option. Alex was also skeptical regarding whether switching to a different type of coffee maker would reduce his environmental impact, stating:

Keurig wouldn't be easy for me because one of my friends' wife reps for them and she gives me everything for free so it wouldn't be easy for me...but let's just say it wasn't, would it be easy? What's the option, give them a coffee machine with filters and Maxwell house tins, is that better? Is it really making a bigger impact? 


\subsubsection{Energy Conservation}

Regarding energy conservation most participants claimed they had already taken steps to address their energy use, citing the purchase of renewable energy through a green energy provider (Bullfrog Power), in-home technology investments (e.g., smart thermostats, smart lighting systems, solar panels, LED lights) and behaviour changes (e.g., using appliances at offpeak hours, using fans instead of air-conditioning). Other participants stated that they believed they could become more energy efficient, but that the cost barrier prevented them from doing so. As Alex stated:

our home is over 100 years old, the thing needs to be torn down, but I mean throwing out some numbers, to go in there and retrofit our house to be completely sealed shut and energy efficient would be, you know we've thrown some money at it, but it would be a significant capital expenditure.

Caitlin noted her lack of knowledge on the topic as a barrier stating, "I mean I've of course toyed with the idea of getting solar panels and stuff, but that's like, I don't know how, I don't know how I would implement that... I would need someone to come and help me".

Hannah was unsure whether she would be willing to invest in energy efficiency, and also claimed cost of the investments as the primary consideration, stating:

yeah, I mean my background is in cost management, expense management, and um I generally go for things that are cheaper, but if I know it's going to make a significant impact if the price differential is not significant I would be willing to pay extra.

\subsubsection{Water Conservation}

The water conservation category received a variety of responses, with the most popular answer again being 'already doing', but with two participants also claiming they were not willing 
to make changes regarding water conservation. Participants who claimed they were already taking measures to reduce water consumption mentioned investments in low-flow fixtures, such as toilets, faucets and shower heads. As Mike put it:

oh absolutely, absolutely, low-flow toilets, low-flow shower heads, you know raindrop heads... we're pushing more and more towards independent metering on a unit by unit bases so we can determine water consumption in an Airbnb unit and when it goes up and when it goes down, and who's a good tenant who's a bad tenant and all that kind of stuff.

For participants willing to make changes to their property to become more waterefficient, cost was the primary consideration that was raised when qualifying what would determine their ability to invest in these types of measures. Peter also mentioned guest comfort as a barrier as he was reluctant to invest in something that may not meet guest expectations:

You know what I honestly feel like the problem is that I feel like when you're hosting, there's a certain standard that people expect... I don't know like even the low-flow toilet with the dual flush and things like that. I don't know I feel like, first of all they break way more often, there's more mechanics to them, so that's a consideration, but I just think in general people expect a certain quality to things and just the way that they work, if there's not amazing water pressure you'll get bad reviews.

As illustrated in Table 8, two of the participants were not willing to invest in water conservation measures, for separate reasons. Will believed that because of the abundance of water in Canada and because of how inexpensive it is, there is no incentive for them to reduce their water consumption, stating "because we live in Canada there's no real incentive to conserve water because we have the most amount of water in the world." Alex on the other hand believed 
that it is the government's responsibility to manage water supply and that residents, and therefore Airbnb guests, should not be responsible for water conservation. As he put it:

sorry, so you touch on points that in this political ecosystem frustrate the hell out of me, because it's like okay government, you sold our water at cheap ass fucking rates, you deflated our resources and now you want me to slow my flow because you can't negotiate good contracts with the United States... like why should my guests have a shitty shower when it's our water because our government sold our water at a really stupidly low rate and now we're at risk of not having enough.

It should be noted that this is the same participant who was unwilling to engage with guests to promote environmental behaviour as explained in section 4.1.10, thus demonstrating a consistent aversion to putting the responsibility of limiting resource consumption on his guests.

\subsubsection{Transport Greenhouse Gas Emissions}

Similar to water conservation, this category received a range of responses, with the majority belonging to the 'already doing' category. Most participants in this category explained that they were providing guests with information on how to use public transit, ride-sharing (e.g., Uber), or bike-sharing options near their property. As Rob stated:

yeah so we definitely do that because of where we are, uh like right now we personally don't have a car and we don't need one. In our little booklet we tell everyone that unless you have to, to not try to drive downtown to all the various attractions and things like that, so I mean like transit is really easy where we are we suggest taking an Uber or even the bike share program, there's a spot right at our street, I think people generally use it. 
It should be noted though that some of the participants that were already doing this explained that they were providing this information because it is a feature of their property or because the information is important to visitors, and that they are not (or would not be) providing this information in the context of environmental impacts. As Sarah explained "we do definitely, we never put it [public transit] in that context, we've never said like it's better for the environment, but we always, that's in our guide, how easy it is to get on the transit."

Among those who stated they would be willing to encourage alternative uses to vehicles, Mary stated they would prefer some type of automated message to guests. Caitlin and Jane both stated they were willing to provide public transit related information to guests but stated that based on their location, it is easier to use an automobile for transportation. It should be noted that Caitlin's property is in the Niagara region and Jane's is in Mississauga, both of which do not have as extensive a public transit network as in Toronto. As Jane stated:

it's a little bit difficult because of our location, Mississauga being very car-centric. But we do live across from a big bus loop, so we tell people if you know where you're going, check out the bus first and see if it's easier to take that, because it's literally across the street, so there's really no excuse. But then again, a lot of people that come here already have their car with them.

Others stated that while they may provide information on public transit, they were not willing to encourage public transit use over automobile use as they want their guests to have the choice to use whatever transportation method they prefer, without feeling guilty. As Alex stated:

they're the ones who are spending their money, I don't have the right- again I don't want them to feel guilty for taking their car... It's not my right, they should be enjoying this 
experience, let them enjoy it within their moral and ethical guidelines, it's not my right to impose them.

Staying true to his earlier responses, Alex continued to prioritize guest comfort and choice over environmental considerations. Expressing a sentiment similar to Alex, Heather stated, "like I said we don't lecture people on using the public transit system, but we say it's clean, it's pretty efficient."

\subsubsection{Waste}

All interviewees stated they were already following practices to reduce waste or believed it would be easy to institute such measures. For this question, those participants that were already doing this included those that both had recycling and/or composting available in their property and who also instructed guests on how to use them. This included nine participants who all stated that they instructed their guests on how to use their recycling and composting (if available) either in-person, or through instructions provided in written form, such as in the house manual, a welcome note, information card, or posters on the bins. As Greg stated:

right, so we don't do anything about reducing waste, we don't encourage them to reduce waste but we do encourage them to use the three bins properly, we have posters we stick on the bins and we have more details we put on the fridge, and we ask them to follow that.

Other participants felt that it would be easy to begin instructing guests on proper recycling and composting guidelines. As Sarah put it, "I would think it would be easy actually, I think I, I'm kicking myself that I haven't done it yet, like just to say to them what goes where". 


\subsubsection{Harmful Substances}

Regarding the use of harmful substances, since none of the participants had a pool, this question focused primarily around the use of chemical cleaning agents versus more innocuous, eco-friendly products. Many of these hosts were already using eco-friendly cleaners to some extent in place of chemical substances. They elaborated by stating they are either purchasing these products themselves or selecting cleaning services that use environmentally friendly products. As Will stated, "yeah we have a cleaning service but our cleaning service only uses organic and bio-degradable material.” Two of the participants qualified their responses by saying that cost is a factor when considering the purchase of eco-friendly cleaning products, as demonstrated by Rob, "like cleaning products, most of ours are definitely environmentally friendly. But still, to the point of cost, like if something is way more expensive we generally wouldn't but still that's our preference."

Four interviewees stated that they would be willing to begin using these substances in place of chemical cleaners, but had certain considerations or restrictions around using these products. For example, Mike stated he wanted to use their products but were not aware of a cleaning company in their area that offered eco-friendly cleaning services, while Greg stated that he just required more guidance as to what cleaning products were eco-friendly versus non ecofriendly. Alex stated that they use chemical cleaners because of the scent and the associated perception of cleanliness:

I think it's more about concern that an eco-friendly product doesn't associate cleanliness as well as something like Pine Sol does... I don't give them the un-eco products because of cost, I do it because I'm not sure if people are convinced the eco-friendly products feel clean as well as like a chlorine or a bleach. 
Heather also noted that scent is a factor for why she chose chemical cleaners, but she seemed to prioritize speed and convenience of cleaning products, stating:

I go the easy route and it's not environmentally friendly, or not particularly I guess, I use a lot of those disinfecting handiwipes just because it's quick and easy, and it means I'm not transferring germs everywhere.

\subsubsection{Alien Species}

The question of substituting alien species with native plants resulted in multiple unsure answers as several participants claimed not to know whether or not their greenspace or garden included native species. These hosts each had some type of greenspace or garden but explained that they did not consciously choose to plant native species and stated alternate reasons behind plant choice such as personal preference (e.g., vegetable garden), or a desire for a lowmaintenance garden. Some of these individuals believed that their desire for low-maintenance likely overlapped with native species as the reason these plants are low-maintenance plants is because they do well in Ontario's climate. For example, Jane stated:

well, I'm pretty sure they're mostly native species because they're the easiest ones to grow. Um, I'm not a gardening expert but I'm pretty sure, pretty sure like, they grow here, I can't go and plant a palm tree in my backyard, so I have things that I see everywhere else like peonies and hydrangeas and stuff, and I assume they're native because they're perennials and they can deal with our climate.

Three participants stated they have already incorporated native plants into their gardens or greenspace. Some of these individuals also stated that the desire for a low-maintenance garden was what drew them to native species, but what separated these individuals from those that were 
unsure is that they stated that they are aware that the plants on their property are native, even though this may not have been a conscious decision. As Peter stated:

I have basically a hosta garden, and um, that's mostly, it's quite shaded at the back so I'm pretty limited to what I can grow so uh, ferns and hosta do quite well and they are native plants. I actually, to be honest with you I didn't consciously make that decision.

Mike and Katie both expressed interest in selecting native plants for their greenspace and didn't mention any perceived barriers to doing this. Mary, Sarah and Will do not have greenspace as part of their property so this question was not applicable for them.

\subsubsection{Other Themes from Environmental Criteria}

\subsection{Financial Considerations}

The financial consideration was a theme that emerged across several of the environmental categories discussed with the participants. Cost was mentioned both as a concern, a consideration and with regard to potential cost savings across disposable goods, energy conservation, water conservation, harmful substances, and alien species. This theme primarily emerged in the context of participants discussing the trade-offs in adopting more environmental measures. Will demonstrated this theme from a cost savings perspective when discussing energy conservation:

we have a bunch of things that are automated, so when guests check out we turn off all the electricity and all the heating, and everything, and all the cooling in our units. Then when guests come in we enable the electricity and everything else so that's a massive cost savings actually.

Heather demonstrated this from a cost consideration perspective when discussing water conservation: 
um, well the only thing we could really do is change the shower head I think, I mean the toilet's already low flow sort of thing, so I don't know what else it would be. It's a pretty minimal expense, like, I don’t know \$20 or something.

Finally, with regards to cost being a concern Peter and Jane demonstrated this when discussing technology and energy conservation, stating respectively, "my whole house would be on solar panels if I had the money to do it" and "I'd love to get like Nest [smart thermostat] or something but they're just so expensive."

\subsection{Guest Comfort}

Another common theme that emerged in this section was the notion of guest comfort, and hosts' sensitivity to making changes that would negatively affect guest comfort. This theme was present in the categories disposable goods, energy conservation, water conservation, transport greenhouse gas, waste, and harmful substances. For example, as stated by Katie in reference to energy conservation, "we do our laundry on cold and things like that, um, but for our guests we don't really, you know, we want them to feel like they're on holiday and they're not having to think about that kind of stuff." Peter shared a similar point of view regarding water conservation, stating "a lot of time comfort doesn't equal eco-friendly. Not all the time, but you know."

Similarly, some participants did not think it was appropriate to lecture their guests, stressing they should be allowed the freedom to make their own choices. As stated by Alex regarding transport greenhouse gas emissions, "so to go in there and tell your guests how to enjoy their experience, it's like, I don't have the right, they're the ones who are spending their money... it's not my responsibility to make them feel guilty for taking a car." This sentiment was also expressed in section 4.1.10 where interviewees expressed a preference for passive engagement with guests regarding their homes environmental features. 
This attention to guest comfort is perhaps due to a concern over guest reviews, although that was only explicitly stated by Peter who explained, "I just think in general people expect a certain quality to things and just the way that they work, if there's not amazing water pressure you'll get bad reviews."

\subsection{Guests Environmental Impact}

The final theme that emerged throughout this section of the interview was the notion that guests are not concerned about their environmental impact and that the hosts cannot control guest behaviour. This was mentioned by multiple participants with particular reference to energy conservation, water conservation and waste, though this theme was most prevalent when discussing waste. As Rob put it:

I think the guests, to be fair the guests don't really seem to care they throw everything wherever it is easiest for them to put it... we find that when the guests come we're always picking things out of the garbage and putting it back in the recycling because we only have such a small garbage can.

This action of sorting recycling after guests leave was also mentioned by Peter, Alex, Caitlin and Jane. Regarding energy conservation and water conservation, the two concerns expressed were the inability to control guest behaviour and the over-consumption of energy and water. Sarah summarized this concern by stating:

yeah the only challenge I could see is if your guest, I mean your guest could be as water and energy inefficient as they want to be right... I mean you could setup all these systems but if they leave all the lights on and the put their garbage, put the compost in the garbage then there's not much, uh but yeah. 


\subsubsection{Performance Versus Continuous Improvement}

The majority of participants were unable to provide a clear answer regarding whether performance measurement or continuous improvement is most appropriate for an environmental certification program for Airbnb. Instead interviewees explained what they thought would be important to consider when determining this aspect of the program. Out of these discussions, three themes emerged explaining the reasoning of the participants: control, simplicity and achievability. Similar to guests' environmental impact, discussed in the previous section, control refers to the idea that hosts cannot control guest behaviour and that aspect must be considered when determining what type of evaluation method is most appropriate. As stated by Rob:

yeah I think it would make more sense just to have a set of standards that you need to have in place and then whether or not you need to actually like use it to a certain performance would be tough because what we found is that everyone is totally different with the way they use the house too, we have some people who have booked it because they have family in town so they're there the whole time so the lights are on the oven is on, like they're using it a lot. Others they're barely there because they're out and about so they have almost no impact on the house. I think it would be hard to do that when everyone's going to use the property differently.

Simplicity refers to hosts preference for whatever is easier for them. Some of these hosts did not state a preference for either continuous improvement or performance, and instead stated they did not care as long as it was easy for them to comply. This justification was often accompanied with a criticism of one of the methods, for example as stated by Heather, "I'm not into measuring things so the easy one would be my route... so whatever would be easier, I mean 
that would sort of be my route for that sort of thing." The difficulty hosts expressed in being able to separate host and guest resource consumption also fell under this theme, as stated by Greg:

I don't know how you're gonna, like in my house, like if I rent it out for two weeks in August how're you gonna know how much water is used by them or me or- um so I think that could potentially get quite granular. I mean if you have places that are purely rented out on Airbnb then you might be able to do something a bit different, but for sporadic, you know, a weekend here, I think that might become quite difficult.

Similar to the discussion around levels versus a pass/fail certification, and as discussed in section 4.1.11, achievability refers to preferring whatever method encourages participation or is perceived as more favourable to the host's eligibility. As Sarah put it:

I guess either way it would depend if they, if the metrics are appropriate to my house, like there's just certain things that I wouldn't be able to do based on like the age of the house and where it is...so I suppose, I think um, that's a really good question, I think I would prefer the uh, not the continuous improvement the other one, but again I wouldn't have a strong opinion, I think either one is fine for me as long yeah, like the measures are appropriate.

\subsubsection{Fee}

Regarding the payment of a fee to help fund the program, most participants were receptive to paying a fee to participate in the program, but stipulated that they would only do so under certain conditions (see Table 9). 
Table 9:

Summary of willingness to pay a fee

\begin{tabular}{|c|c|c|c|c|}
\hline Participant & $\begin{array}{l}\text { Willingness } \\
\text { to pay }\end{array}$ & $\begin{array}{l}\text { Justification (depends } \\
\text { on) }\end{array}$ & Notes & $\begin{array}{l}\text { Range of } \\
\text { fee }\end{array}$ \\
\hline Rob & Depends & Value of program & $\begin{array}{l}\text { Must demonstrate cost savings or } \\
\text { commercial benefits }\end{array}$ & $\begin{array}{l}\text { Based on } \\
\text { value }\end{array}$ \\
\hline Mary & Depends & $\begin{array}{l}\text { Fee amount as a } \% \text { of } \\
\text { Airbnb revenue }\end{array}$ & Must demonstrate cost savings & $\begin{array}{l}\text { Based on } \% \\
\text { of revenue }\end{array}$ \\
\hline Hannah & Depends & Cost/ benefit & $\begin{array}{l}\text { Reluctant to pay fee for } \\
\text { something already in place } \\
\text { (environmental measures) }\end{array}$ & $\$ 250$ \\
\hline Rachel & $\begin{array}{l}\text { Fee is } \\
\text { unnecessary }\end{array}$ & $\begin{array}{l}\text { Use self-assessment } \\
\text { and guest reviews to } \\
\text { avoid fee }\end{array}$ & $\begin{array}{l}\text { Reluctant to pay fee for } \\
\text { something already in place } \\
\text { (environmental measures) }\end{array}$ & $\begin{array}{l}\text { Fee is } \\
\text { unnecessary }\end{array}$ \\
\hline Mike & Depends & Fee amount & $\begin{array}{l}\text { Self-assessment with guest review } \\
\text { would allow for low cost program }\end{array}$ & $\$ 100$ \\
\hline Sarah & Depends & $\begin{array}{l}\text { Fee amount as a } \% \text { of } \\
\text { Airbnb revenue }\end{array}$ & & $\begin{array}{l}20 \% \text { of } \\
\text { revenue }\end{array}$ \\
\hline Will & Depends & Fee amount & & $\begin{array}{l}\text { \$50 a year } \\
\text { (multiple } \\
\text { properties) }\end{array}$ \\
\hline Peter & Depends & Fee amount & & $\$ 100$ \\
\hline Greg & Depends & $\begin{array}{l}\text { Fee amount as a } \% \text { of } \\
\text { Airbnb revenue }\end{array}$ & & $\$ 150$ \\
\hline Alex & Depends & $\begin{array}{l}\text { Perceived benefit } \\
\text { (guest demand) }\end{array}$ & $\begin{array}{l}\text { If hosts care about environment } \\
\text { they should do it themselves }\end{array}$ & $\begin{array}{l}\text { Based on } \\
\text { value }\end{array}$ \\
\hline Katie & Depends & $\begin{array}{l}\text { Assessment style (fee } \\
\text { for third-party, no fee } \\
\text { for self-assessment) }\end{array}$ & & $\$ 50$ \\
\hline Heather & No & $\begin{array}{l}\text { Self-assessment with } \\
\text { guest reviews should be } \\
\text { used as its free }\end{array}$ & & $\begin{array}{l}\text { Not willing } \\
\text { to pay fee }\end{array}$ \\
\hline Caitlin & Depends & $\begin{array}{l}\text { Integrity of program } \\
\text { and value to host }\end{array}$ & $\begin{array}{l}\text { Program should provide guidance } \\
\text { to hosts on how to improve } \\
\text { environmental performance }\end{array}$ & $\$ 1,000$ \\
\hline Jane & Depends & Fee amount & $\begin{array}{l}\text { Reluctant to pay fee for } \\
\text { something already in place } \\
\text { (environmental measures) }\end{array}$ & $\$ 15$ \\
\hline
\end{tabular}

The most frequently mentioned condition was the actual amount of the fee, either as a set

value or as a percentage of income from the Airbnb property. Several participants noted that they would pay the fee as long as it was reasonable. For example, Sarah stated: 
I guess it would sort of depend on how much money we're making off Airbnb. If it was like, you know, $50 \%$ of what we make in a given year then it might not seem that- but if it was like $20 \%$ or $10 \%$ then that would probably seem reasonable.

Other individuals mentioned that a fee would only be acceptable if the program was credible, used third-party assessment, demonstrated value through increased demand, or by providing education regarding how to improve. As Alex, put it:

I don't mind the fee as long as I knew there was a benefit. It's like okay if I knew as a host, like for instance the superhost badge, I don't know the benefit but I do feel the benefit. I do know that there's a checkmark on the website that a lot of people will click, and even though I can't associate a cost with that benefit I do feel the benefit. You would have to convince me that enough people are clicking the little green checkbox that would make it worth my while.

Multiple participants suggested that if the program was self-assessment they would see no reason to have a fee.

Some participants suggested that they either would not pay the fee above a certain level, or pay at all, because they can pursue environmental initiatives according to their own personal values. As Hannah stated:

you know it depends on what the fee is, and if you look at the cost benefit factor, is it worthwhile to do, so then you're incurring a fee on top of incurring costs in order to qualify, at some point you're going to reach a threshold where you say well, it's not doing me any good, and it's only a thing that you're doing because you're conscious of the environment, but if I'm conscious of the environment and I want to feel good that I'm 
contributing to reducing garbage and waste then I don't need to be certified to do that it's just one of those things you do for yourself.

Regarding the range of the fee, responses varied widely with several interviewees stating they were unable to state an actual value regarding the limit of the fee they were willing to pay as it was dependent on what the program was delivering in terms of value or benefit.

Several participants believed that Airbnb should subsidize the program as it would benefit their brand to be associated with an environmental image, as suggested by Mary:

Yeah I think Airbnb should subsidize it in one way because I feel like as a more, uh, larger and larger competitor and a larger larger player in this space, they'll you know, every company needs a CSR [corporate social responsibility] policy which kind of outlines them as a good company so I feel like they get positive benefit from me having green places on it [the Airbnb platform] so I would hope that they subsidize it.

Though a near equal amount believed the hosts should pay for the administration as they are choosing to pursue certification and it is therefore their responsibility to implement the changes.

Overall the conversations around the fee were largely inconclusive. Aside from determining that there was a general willingness to pay a fee, the amount and conditions on that fee varied widely among the sample, and the perceived value of that fee would depend largely on the design elements of the program (e.g., type of assessment, perceived benefits, credibility).

\subsubsection{Awareness of 2014 Airbnb Environmental Report}

One of the 14 participants was aware of the 2014 Environmental Impacts of HomeSharing report released by Airbnb, although they were unfamiliar with the details. Greg stated: 
I've heard some, I've heard stats, or not stats, but I've heard stories from a report. I don't know if it was that specific one but I know they came out with some claims that Airbnb guests are greener than hotel guests.

\subsection{Secondary Data Analysis}

This section will describe the findings from the content analysis performed on two secondary data sources that attempt to shed further light on the issue under study; Airbnb forums and Airbnb GTA listings. Results are based on a keyword search of both sources using the words "Green", "Sustainable/ Sustainability", "Eco", and "Environment/ Environmental”. The results from the Airbnb forum are intended to demonstrate whether hosts outside of the interview sample are interested in environmental initiatives, including environmental certification. The Airbnb listings extract and the examination of the summary column is intended to illustrate to what degree hosts incorporate environmental messaging in their property summary relative to other features; thus illustrating whether hosts believe this is of value to guests. Both sources and their associated content analysis serve as a form of data triangulation for the interview results.

\subsubsection{Airbnb Forums}

A keyword search of the five Airbnb forums (the host voice, new hosts, hosts, host newsletter and community help) returned a total of 15 entries, 13 of which were posts and two were comments. However, one of those comments was determined to be a duplicate of a post and was therefore removed, leaving 14 items to be analyzed, as seen in Table 10. The search returned conversations from the host voice, new hosts, hosts, and community help forums, but no results from the host newsletter forum. The items were analyzed and grouped according to three themes: environmental hosting, guest behaviour and chemical/ fragrance sensitivity. It should be noted that the cumulative number of posts in the forums included in the search is over 36,000 , so the 
themes revealed through this keyword search and content analysis represent a small amount of the commentary in this forum.

Table 10:

Summary of forum posts and comments

\begin{tabular}{|c|c|c|c|c|c|}
\hline $\begin{array}{l}\text { Author } \\
\text { name }\end{array}$ & $\begin{array}{l}\text { Search } \\
\text { term }\end{array}$ & Forum & $\begin{array}{l}\text { Posting/ } \\
\text { comment }\end{array}$ & Post title & Code \\
\hline $\begin{array}{l}\text { Mick \& } \\
\text { Pamela }\end{array}$ & Green & Host voice & Posting & Add a "Green" Rating! & $\begin{array}{l}\text { Environmental } \\
\text { hosting }\end{array}$ \\
\hline Ian & Green & Host voice & Posting & $\begin{array}{l}\text { Encourage hosts and guests } \\
\text { to be more green }\end{array}$ & $\begin{array}{l}\text { Environmental } \\
\text { hosting }\end{array}$ \\
\hline Juliet & Green & Host voice & Posting & multiple & $\begin{array}{l}\text { Environmental } \\
\text { hosting }\end{array}$ \\
\hline Kika & Green & Host voice & Posting & $\begin{array}{l}\text { Making the Airbnb Brand } \\
\text { Greener! }\end{array}$ & $\begin{array}{l}\text { Guest } \\
\text { behaviour }\end{array}$ \\
\hline $\begin{array}{l}\text { Mick \& } \\
\text { Pamela }\end{array}$ & Eco & Host voice & Posting & $\begin{array}{l}\text { Filter for Eco- } \\
\text { friendly/chemically } \\
\text { sensitive people }\end{array}$ & $\begin{array}{l}\text { Chemical/ } \\
\text { fragrance } \\
\text { filter }\end{array}$ \\
\hline Donna & Eco & New hosts & Posting & $\begin{array}{l}\text { How can I list, and find } \\
\text { other, chemical-free, } \\
\text { environmentally-safe } \\
\text { apartments? }\end{array}$ & $\begin{array}{l}\text { Chemical/ } \\
\text { fragrance } \\
\text { filter }\end{array}$ \\
\hline Henry & Eco & Hosts & Posting & Sustainability Awards & $\begin{array}{l}\text { Environmental } \\
\text { hosting }\end{array}$ \\
\hline Asi & Environment & $\begin{array}{l}\text { Community } \\
\text { help }\end{array}$ & Posting & $\begin{array}{l}\text { An Airbnb Environment } \\
\text { Club! }\end{array}$ & $\begin{array}{l}\text { Environmental } \\
\text { hosting }\end{array}$ \\
\hline Angela & Environment & $\begin{array}{l}\text { Community } \\
\text { help }\end{array}$ & Comment & $\begin{array}{l}\text { An Airbnb Environment } \\
\text { Club! }\end{array}$ & $\begin{array}{l}\text { Environmental } \\
\text { hosting }\end{array}$ \\
\hline $\begin{array}{l}\text { Tiffany and } \\
\text { Paul }\end{array}$ & Environment & Hosts & Posting & $\begin{array}{l}\text { We are a lush and "green" } \\
\text { environment ... are there } \\
\text { any designations that help } \\
\text { promote that? }\end{array}$ & $\begin{array}{l}\text { Environmental } \\
\text { hosting }\end{array}$ \\
\hline Casdell & Environment & Hosts & Posting & $\begin{array}{l}\text { Energy efficiency - remind } \\
\text { guests to switch off lights }\end{array}$ & $\begin{array}{l}\text { Guest } \\
\text { behaviour }\end{array}$ \\
\hline Mala & Environment & Hosts & Posting & Wasteful guest & $\begin{array}{l}\text { Guest } \\
\text { behaviour }\end{array}$ \\
\hline $\begin{array}{l}\text { Karsten \& } \\
\text { Venus }\end{array}$ & Environment & New hosts & Posting & conserving energy & $\begin{array}{l}\text { Guest } \\
\text { behaviour }\end{array}$ \\
\hline $\begin{array}{l}\text { Melissa \& } \\
\text { Kurt }\end{array}$ & Environment & Host voice & Posting & Allergen free homes & $\begin{array}{l}\text { Chemical/ } \\
\text { fragrance } \\
\text { filter }\end{array}$ \\
\hline
\end{tabular}


Environmental hosting accounted for seven of the 14 entries, with six of these postings calling for some type of environmental feature being built into the listing and one calling for Airbnb to promote more environmentally responsible behaviour. The six entries calling for the incorporation of an environmental feature are particularly relevant for this research as they all called for some type of recognition for hosts' environmental performance through either a certification, designation, rating or award. For example, Juliet recommended that Airbnb "allow hosts to earn a green certification, by providing recycling, composting, low energy consumption and transit access." Similarly, Henry suggested "It would seem a good idea for Airbnb to promote Eco Tourism and Sustainability in general by offering Sustainability Awards - a visible rosette of recognition to those properties that pass a cretain (sic) criteria of sustainability." Additionally, Angela suggested "I also think that Airbnb could start doing some kind of green star program. Hotels do it! Maybe the hosts that did 10 or more out of a possible 20 environmentally responsible behaviours could get a green star etc." Three of these same individuals also suggested examples of categories that could be considered when creating an environmental designation. Mick \& Pamela, Juliet and Henry each mentioned waste (i.e. recycling and compost) and energy as areas to be evaluated; other items mentioned included water conservation (Henry), avoiding use of chemical cleaning agents (Mick \& Pamela), and providing organic food (Mick \& Pamela) (see Appendix D, Table D1 for links to full post content). As mentioned there was one individual, Asi, who wanted Airbnb to promote more environmental behaviour among hosts and guests through the forming of an environment club:

I suggest that we will have an environment club in Airbnb, to help each other, suggest and exchange ideas, push Airbnb to help us to do more about it. on how we all can reduce 
our ecological footprint, conserve, Refuse, Reduce, Reuse, and only than Recycle, which always on the long run also helps us to save money, and be better businesswoman/man.

Guest behaviour was mentioned four times in the forum, and in all four cases concerns over energy usage was mentioned, while concerns over proper use of waste/ recycling containers was mentioned once. In two of these cases there was a direct reference to the environment in the posting, while the other two cases did not have a specific reference to environmental concern. With regards to those referencing the environment, Kika stated in her post titled "Making the Airbnb Brand Greener!”:

In the interests of continuous improvement, please find a way to address the following: 1 . Leaving the lights on, heating on and windows and even doors open even though the house rules say not to when they leave the house. 2. Not separating rubbish into the right containers.

While the content of this post does not include an environmental reference, the title does. Casadell on the other hand appeared to be reaching out to other hosts for advice:

The lights were left ON for almost 12 hours, which is a complete waste of energy... I know that many guests are thoughtful of the environment and switch off lights and appliances (e.g. Heater/ AC) when not in use... I know there are technology solutions such as NEST [smart thermostat] that allow to control lights and heating/cooling remotely. But is there a non-technology or cheaper way to do this?

Finally, chemical/ fragrance sensitivity was mentioned in three posts, and in all cases the author(s) called for ways to designate and filter for homes that are chemical free. These 
suggestions were all tied to a personal chemical sensitivity issue of the individual(s) who were posting. For example, Melissa and Kurt stated:

I have severe allergies and sensitivities so keep my home clean scent and chemical free. Unfortunately this is an extremely difficult thing to find on Airbnb... There needs to be a badge for this....like a super host type designation that celebrates having a clean air allergen free home.

Although these comments have a specific focus on chemical sensitivity as opposed to general environmental measures, avoiding the use of chemical substances is one of the GSTC criteria that was discussed with the interview participants and therefore these comments were included as they fall under the broad concept of environmental certification. Additionally, two of the three postings (Melissa \& Kurt, Mick \& Pamela) associated this avoidance of chemical agents to environmental concern. As demonstrated by Mick and Pamela, "we offer a chemical free/synthetic fragrance free space. In part due to our own chemical sensitivities and in part because of our desire to protect and preserve the environment."

As mentioned, the keyword search of the Airbnb forum returned a very small number of posts relative to the cumulative number across all five forums. Nevertheless, this content analysis of the Airbnb forum does reveal that the concept of environmental certification has been suggested to Airbnb through the host voice forum by multiple hosts outside of the interview sample. Additionally, it indicates that one of its typical components, the use of chemical products, along with the issue of guest resource consumption, have been raised as host concerns.

\subsubsection{Listings Extract}

The keyword search of the Airbnb listings returned 113 of the 7,500 listings for analysis. After initial review, 84 of these listings were deemed not relevant as the keyword appeared in a 
context not related to the environmental features of the property. For example, properties that referred to public greenspace, or mentioned the term "environment" when referring to the overall atmosphere of the home were not included. This review left 29 listings to be analyzed, as can be seen in Table 11 (see Appendix D, Table D2 for full excerpt of listings). There were fewer unique hosts than listings as some hosts have multiple listings that used similar language.

Table 11:

Summary of summative content analysis from Airbnb extract

\begin{tabular}{|l|r|r|}
\hline Keyword search results & $\begin{array}{l}\text { Unique } \\
\text { listings }\end{array}$ & $\begin{array}{l}\text { Unique } \\
\text { hosts }\end{array}$ \\
\hline Green & 18 & 17 \\
\hline Eco & 8 & 6 \\
\hline Environment/ Environmental & 3 & 1 \\
\hline Sustainable/ Sustainability & 0 & 0 \\
\hline Total & 29 & 24 \\
\hline
\end{tabular}

The property summary for each of these listings was reviewed, with particular focus paid on how the environmental features of the property were described relative to other features. As mentioned in section 3.3.1, this was done to determine if factors such as location, price, amenities and other property details are positioned ahead of environmental features, to serve as an indication of their relative, perceived value to guests. The keyword was classified as either being high, medium or low priority based on its position relative to other features, as can be seen in Appendix D, Table D2.

An analysis of these 29 listings revealed that the environmental features of the home were usually preceded by more traditionally valued features such as location, neighbourhood, amenities, property size or general property description (e.g., condominium, age of property, number of bedrooms, number of bathrooms). In 11 of the cases the environmental feature was listed before other property features, and in most cases either referred to the presence of 
"greenery" or the property being a variation of environmentally-friendly (e.g., green-friendly, eco-friendly). For example:

An environmentally friendly house with big gardens, lots of light, and with clean and welcoming rooms. There is a piano in the house waiting for you! Two lovely cats will cheer you up! Great neighbourhood! Come and enjoy beautiful Toronto!

This appears to indicate, that while a small group of hosts seem to believe that environmental features of their property are valuable to guests, thus warranting their mention in the brief summary, more traditional characteristics like location, neighbourhood and amenties are of a higher priority to guests. As stated earlier, the 29 listings represent a very small portion of the total 7,500 listings, so it could be suggested that not only do very few hosts have environmental features, but only a minority of those hosts believe these to be more valuable than traditional features. However, it should be noted that because this was a direct extract from the site there is the possibility that there are hosts who have environmental features on their property and have chosen not to include them in their summary, so these 29 listings are not necessarily reflective of the entire GTA host population; they only represent those hosts that have environmental features and have chosen to include them in their summary. It is also not able to be definitively stated that the position of the various features relative to other features indicates their perceived value to guests, but given the limited number of characters allowed in the summary it is reasonable to believe only features that the host believes are important would be highlighted.

\subsection{Summary of Results}

The interview participants represented a variety of host characteristics in terms of professionalism, experience, frequency and property type. These respondents indicated a 
willingness to participate in an environmental certification program for Airbnb and mentioned five motivations for doing so, with the primary motivations being commercial benefits and personal values. Themes such as fairness, credibility, cost, simplicity and control emerged with regards to program design. As such, participants appeared to demonstrate a preference for selfassessment, a graded scheme, external verification and a program design that would be consistent with the existing Airbnb user experience.

The secondary data analysis revealed that it appears more traditional characteristics like location, neighbourhood and amenities are of a higher priority to guests than environmental characteristics of the property. Additionally, analysis of the Airbnb forums revealed that the concept of environmental certification has been suggested to Airbnb by multiple hosts outside of the interview sample. 


\subsection{Discussion}

This section will explain what the results reveal about the research questions, drawing upon data collected from the interviews and secondary data analysis. These results will be compared and contrasted against previous research to illustrate which results are consistent with past studies, and which results represent new contributions to the literature. The discussion is organized according to research questions, themes that emerged from the interviews and finishes with some practical implications and unique insights.

\subsection{Research Question 1: Would Airbnb homeowner hosts be willing to participate in an environmental certification program?}

There was definite interest expressed by interviewees regarding their willingness to participate in an environmental certification program. No participants expressed that they would not be interested, though Mary, Sarah and Alex did express that it would depend on factors such as the perceived commercial benefits and the rigourousness of the requirements. This willingness to participate among these hosts was bolstered by multiple expressions of interest in participating in an environmental certification program from the Airbnb host forums. While the number of posts calling for this type of program represented a very small share of the total posts, these posts indicate that there is interest in this program from parties outside of the sample. The majority of these posts calling for some type of environmental recognition were in the host voice section, which is a platform intended to allow hosts to make recommendations or suggestions directly to Airbnb. Therefore, it appears these hosts are requesting Airbnb to develop and implement this type of program, rather than raising it as a point of discussion between hosts.

As mentioned though among the interview respondents, some suggested that participation would depend on the perceived commercial benefits and the rigourousness of the requirements. This aspect of commercial benefits was also mentioned as one of the most common motivations 
for pursuing environmental certification (discussed in further detail in section 5.2), and the rigourousness was also raised as a potential barrier to pursuing certification. The other barriers to participation raised by the interviewees included cost, time-commitment, credibility, and tradeoffs with comfort, and are consistent with previous research on the topic (Vernon et al., 2003; van Haastert \& de Grosbois, 2010; Garay \& Font, 2012a; Best \& Thapa, 2013). These barriers also serve to illustrate the relationship between program design and barriers described by the conceptual framework (section 2.15), for example the rigourousness of the requirements and the associated costs are largely dependent on the program design.

In addition to the specific question asking about barriers to participation in a potential program, these hosts frequently mentioned barriers to their participation when discussing the specific environmental categories. For example, Caitlin mentioned her lack of knowledge when discussing the prospect of installing solar panels, which was another barrier found in the literature (van Haastert \& de Grosbois, 2010). Additionally, just as Vernon et al. (2003) found some tourism microbusinesses distancing themselves from environmental impacts, Alex demonstrated a similar perspective in his response regarding water conservation stating it is the government's responsibility to manage water.

The most frequently mentioned barrier or consideration throughout the interviews was the cost or financial barrier. This is in line with previous studies both focused on the accommodations sector (Chan, 2011; Dodds \& Holmes, 2011; Garay \& Font, 2012a; Best \& Thapa, 2013), and other industries (Hillary, 2004; Bhaskaran et al., 2006; Revell \& Blackburn, 2007) that have found multiple barriers exist regarding adopting environmental initiatives, but that the strongest barrier is usually cost. In this study, as with van Haastert and de Grosbois' (2010) research, some participants seemed to have actually researched the cost of the investment 
such as Peter with regards to solar panels and Jane with regards to a Nest thermostat; but most of the cost concerns were regarding the perceived cost. Van Haastert and de Grosbois (2010) speculated that this cost barrier was especially strong for B\&B owners in their study as their B\&Bs acted as supplemental income for a majority of owners. This appears to be the case with this sample as well, as part-time hosts were particularly sensitive to the cost barrier. This also has particular relevancy for Airbnb hosts in Toronto as based on the most recent data it appears that the majority of Toronto hosts are part-time renters of their primary residence using the site to provide supplemental income (Airbnb, 2016a, 2016c). Additionally, among the sample supplementary income was the most common reason for joining Airbnb; therefore, it is understandable that any cost diminishing this supplementary income would be a concern.

Researchers suggest that to overcome these barriers small businesses should be educated on the economic and environmental benefits of becoming environmentally certified, and networks of small businesses be used to share experiences and advice (Schaper \& Carlsen, 2004; Burgin \& Hardiman, 2010). In the context of Airbnb it appears that the possibility to implement both of these suggestions exists through the Airbnb community platform, where the host newsletter could be used to educate hosts on the benefits, and the various host focused forums (e.g., host voice, hosts, community help) could be used to share experiences and advice.

Generally, it appears that hosts both within and outside of the sample would be willing to participate in an environmental certification program. While some explained that it would depend on certain elements of the program design, there was a general enthusiasm towards pursuing this type of program. The motivations behind this willingness along with elements of the program design that may encourage participation will be discussed in the following sections. 


\subsection{Research Question 2: What would motivate Airbnb homeowner hosts to participate in an environmental certification program?}

While there was near unanimous interest in pursuing certification, the motivations to do so varied and included personal values, commercial benefits, ability to attract like-minded guests, household environmental impacts, and recognition of environmental commitment (see Figure 2). Personal values and commercial benefits were the most salient motivations which is consistent with earlier research on the topic that focused on small accommodation firms (Vernon et al., 2003; Tzschentke et al., 2004, 2008b; van Haastert \& de Grosbois, 2010; Best \& Thapa, 2013). The dominance of these two themes, and their frequently simultaneous appearance, also indicates that the concept of selfish altruism may be at work among this sample, in that these participants are motivated to pursue environmental certification for personal values, so long as it also delivers commercial benefits.

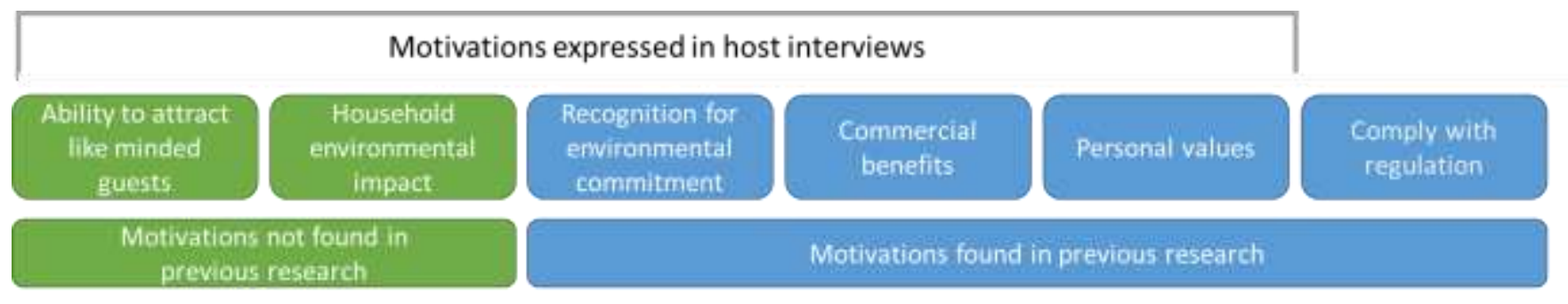

Figure 2: Motivations expressed in host interviews

Recognition for environmental commitment has also been mentioned in previous research (Boiral, 2007), though not as frequently as personal values and commercial benefits. This suggests that despite the unique nature of Airbnb hosts (i.e. part-time, supplemental income, home-sharing) compared to small accommodations owner-operators, these two groups seem to align on their major motivations when pursuing environmental initiatives.

However, differences did emerge, particularly the ability to attract like-minded guests and to understand household environmental impacts. These were two motivations that were not 
observed in past research, and can likely be traced to the unique situation that Airbnb hosts find themselves in compared to small-accommodations, in that the property being rented is often the home of the host. As a result hosts may be interested in finding ways to attract guests who have shared values, particularly those hosts who share their home with guests or who rent their space frequently. It seems this is the case in this sample as all three hosts who mentioned the motivation 'ability to attract like-minded guests' were full-time hosts and superhosts, indicating they accept more bookings and guests than part-time hosts. Two of these hosts also included home-sharing as one of their reasons for joining Airbnb which indicates that these hosts are not only offering their property for most of the year, but that they went into hosting with a desire to share their space and interact with their guests. It is perhaps unsurprising then that they seek guests with similar values given they are interacting with a higher volume of guests. While this is a new motivation in terms of environmental certification, it appears that Airbnb hosts are already demonstrating a desire to attract guests with similar values. Research by Ikkala and Lampinen (2015) has shown that hosts select guests who have similar interests by reading guest profiles and their previous reviews, especially when they have multiple guests to choose from. Additionally, some hosts intentionally keep the price of their listing below market price in order to attract a greater volume of guest requests and thus give themselves more control over guest selection (Ikkala \& Lampinen, 2014, 2015). Therefore, this ability to attract like-minded guests does seem to align with existing host behaviour. Regarding property type this motivation was split evenly across private room, entire home and both suggesting that in this sample this motivation was not influenced by host property type.

With regards to understanding household environmental impacts, this was not associated with any particular aspect of the host profile. Based on responses from interviewees who raised 
this motivation it appears the focus is on getting a better understanding of their homes energy use. It was unclear whether the end goal was to use this information to reduce energy use and thus save costs, or whether it was based on some other factor such as a desire to reduce waste, or a general interest in their properties environmental performance. If the root of this motivation was a desire to reduce costs then this motivation would be more appropriately identified as a commercial benefit. It should be noted that while participants expressed some motivations as stronger than others, in many cases the motivations were mixed which mirrors previous research on both larger accommodation firms (Bansal \& Roth, 2000; Gavronski et al., 2008) and smaller firms (Vernon et al., 2003; Tzschentke et al., 2004; Garay \& Font, 2012a).

One motivation that was expressed in previous research on environmental management that was absent from the interview responses was that of compliance with government regulation (Bansal \& Roth, 2000; Fryxell et al., 2004; Boiral, 2007). There are likely multiple reasons for this; firstly, this motivation is not usually found in research in the hospitality industry, and is more common among research focused on more production and export-related industries like manufacturing and consumer electronics, as these industries have to be concerned with consumer preferences and environmental standards of foreign markets where their product is sold (Fryxell et al., 2004; Wu et al., 2007). Secondly, this may be due to the fact that the legislative framework surrounding Airbnb is just beginning to take shape; in Toronto specifically, short-term rental legislation entered the public consultation phase in March and April 2017 with legislation expected be proposed sometime in 2017 (Dunn, 2017). Hosts therefore have so far been operating outside of any legislative framework, meaning they did not have to consider by-laws, acquire a business license or engage in any other bureaucratic activities prior to hosting. It is perhaps unsurprising then that they do not consider compliance as a motivator. The respondents, 
especially the part-time hosts may also view themselves more as homeowners than as owneroperators of a business, and therefore not think of their Airbnb as being subject to regulations targeting businesses.

In a similar context, it has been argued that hotels pursue these programs in order to proactively avoid government-led environmental regulation (Hjalager, 1996; Honey, 2002). It will be interesting to see if Airbnb deploys some type of environmental initiative or seeks to encourage their hosts to be more environmentally friendly as a way to proactively get ahead of any environmentally focused legislation. As described in section 2.1.3 Airbnb has begun supporting hosts organizing in opposition to short-term rental legislation (Kelly, 2015), so perhaps the foundation is there to spur hosts to act as a collective group on environmental issues as well. This will likely vary greatly though from region to region and will be based on how governments classify Airbnb rentals, and also depend on whether environmental regulation already applies to accommodations providers in that jurisdiction. In Ontario, it seems unlikely that environmental regulation targeting hotels would be applied to Airbnb units as the application of these regulations appears based on number of units. For example, under Ontario's Environmental Protection Act, hotels are required to conduct annual waste audits, but this only applies to buildings with over 75 units (Government of Ontario, 1994; Ontario Restaurant Hotel and Motel Association, 2011). Therefore, Airbnb may not perceive this as a plausible legislative risk in the Greater Toronto Area, or the rest of the province.

In examining the hosts based on superhost status, it appears that superhosts are slightly skewed towards commercial benefits as their primary motivation, while non-superhosts are slightly skewed towards personal values. While this does align with past research from Sampaio et al. (2012) which found that the more informal B\&B owners were more likely to adopt 
practices that confirmed personal objectives like "feeling good" about themselves; whereas the more formal B\&B owners were more likely to adopt practices that satisfied personal and economic objectives (Sampaio et al., 2012), the difference in this research is so minor that it should not be used to confirm their findings. The other interesting observation from this superhost analysis, as described earlier in this section, was that superhosts were responsible for all occurrences of the motivation 'ability to attract like-minded guests'.

Overall, the motivations stated from the interviewees aligned with previous research findings in that they were dominated by personal values and commercial benefits, and these motivations were typically mixed. However, the emergence of the ability to attract like-minded guests and a desire to measure or understand household environmental impacts indicate that Airbnb hosts do have unique motivations, likely attributable to their hosting situation, specifically sharing their living space and interacting directly with their guests.

\subsection{Research Question 3: What program design elements would enhance the likelihood of their participation in the program?}

Various design elements of an environmental certification program were discussed with participants to determine what design parameters would enhance their likelihood to participate in this type of program. This section of the discussion will include a review of how participants felt about those elements and about how that may influence their participation.

\subsubsection{Integration with Existing Airbnb User Experience}

The discussions of both the assessment and the willingness to participate in an external program revealed that hosts were looking for a program that would integrate well with the existing Airbnb platform design and user experience. As mentioned in section 4.1.6, there was general agreement that second- or third-party assessment would lend credibility to the program, but that this would cost more and be a deviation from Airbnb's existing strategy of using guest 
ratings and feedback to validate host claims. Across the themes that emerged in the discussion of assessment styles, there was repeated support expressed for leveraging the existing guest review process, given its ability to act as external verification and its cost advantages. Support for this assessment style was reinforced by the near unanimous willingness expressed by participants, to be evaluated by guests on their environmental features. Between the recognition of the cost and credibility benefits from using the existing guest review process, along with a willingness to extend this process to include environmental criteria, it appears extending the existing guest review process to environmental criteria would be the most promising assessment style from the perspective of hosts. Additionally, because the use of guest reviews would not be a deviation from the current user experience it would likely be easier for Airbnb to deploy and for guests to understand, contrary to a new assessment process. While second- and third-party assessment were generally viewed as more credible, there were significant cost concerns expressed around both the assessment style and the presence of a fee, which would presumably be required to fund a more independent assessment process.

The cost advantages of this process were further reiterated during the discussion on the presence of a program fee, where participants expressed their belief that if the current model of using guest reviews and self-assessments were to be used, then there should be no fee. The interviewees understood that there would have to be tangible benefits or an external assessment if there was to be a fee. This use of guest reviews would also align with Rattan's (2015) suggestion of using a combination of monitoring styles to reduce costs, in order to achieve a program that is "financially attainable for all parties involved but is still reputable, legitimate and transparent" (p. 118). 
In order to minimize concerns of hosts regarding this guest review process the standards should minimize the risk of subjectivity. This could perhaps be achieved by explaining to guests what the basis of the certification is (i.e. how do hosts qualify for certification and its various levels if applicable), or by only including criteria visible to guests. This latter suggestion is supported by Manaktola and Jauhari's (2007) argument that observability of environmental practices is required for guests to proactively choose environmentally responsible accommodations. Guest reviews would also serve to satisfy the credibility concerns of participants who expressed a distrust of other hosts and a need for some type of external verification. This distrust of other hosts noted by the participants is interesting as it's been suggested that the collaborative consumption movement as a whole is supported by a sense of trust between users (Botsman \& Rogers, 2010b; PWC, 2015). Airbnb has tried to build that trust between users though its review system and user profiles (Guttentag, 2016); however, these efforts have been focused on building trust between host and guests not hosts to hosts. This makes sense as host to guest interactions are the core of Airbnb's business; however, these results seem to suggest that host to host trust is not as strong. This mistrust mirrors previous research on small firm environmental behaviour finding a "lack of trust small firms have in each other to behave in a responsible manner without the threat of external regulation to restrain their behaviour" (Tilley, 2000, p.37).

As Katie suggested during her interview, one can already look at Airbnb's business travel ready badge for an example of how this program might work. As explained in section 4.1.6, the business travel ready badge is awarded to hosts that comply with certain criteria relevant to business travel such as excellent reviews for accuracy and cleanliness, as well as amenities such as wireless internet, a laptop-friendly workspace, and an iron (Airbnb, n.d.-i). This program uses 
a self-assessment, listings data (e.g., reviews and host response rate), and guest reviews to determine compliance, and awards a badge to indicate to consumers the property is business travel ready. An environmental certification program could use a similar process with a focus on environmental instead of business travel ready criteria.

The alternate to this self-assessment and guest review process would be to engage some type of external third-party to assess properties. Airbnb has shown it is capable and willing to engage in external third-parties to provide services to hosts; for example, they offer complimentary photography services to hosts to help improve the appearance and professionalism of their listing (Airbnb, n.d.-a). However, unlike with photography, it may prove difficult to find qualified people to assess properties for environmental compliance. Additionally, it would be inconsistent with the guest review process which is exclusively used as the check and balance mechanism on host claims. Given the deviation it would represent from the current operating model as well as the cost and complexity required to build or contract a network of assessors it seems implausible that second- or third-party assessment would be implemented.

Interestingly, participants were generally willing to participate in an external program, but also noted that some integration with the Airbnb platform would be required to allow for whatever form of recognition they received (e.g., badge, logo, icon) to be visible on their Airbnb listing. In the case of an external program though, the assessment would likely be managed by that program as opposed to being built into the Airbnb platform. As such it would represent a greater deviation from the existing user experience, and if third-party assessment was used, may also require a fee to help fund the program. Therefore, while hosts appear willing to participate in an external program, the realities of that program may impose barriers in the form of cost and functionality that would discourage participation. 


\subsubsection{Demonstrated Commercial Benefit or Consumer Demand}

Based on the commercial benefits motivation expressed by several respondents, it appears that being able to demonstrate that environmental certification can produce commercial benefits would encourage participation, particularly among those that stated this as their primary motivation. Some type of proof is likely required as there appears to be doubt among many of the participants regarding whether this program would be valued by guests. This doubt was evident in the responses regarding value to guests, which revealed themes of optimism, guarded optimism and pessimism. Even the optimists and guarded optimists believed that price was still the primary motivation for choosing Airbnb, supporting findings by Guttentag (2016) regarding Airbnb guest motivations. Pessimists and guarded optimists both believed that guests may value this program, but pessimists in particular clearly stated that this would only occur after traditional factors like price and location were satisfied, which supports previous findings (Manaktola \& Jauhari, 2007). The relative value of these traditional features was also supported by the secondary data analysis on the Airbnb listings extract, which demonstrated higher priority given to features like location, neighbourhood and amenities. This finding confirms previous research showing that other factors such as price, location, service quality and amenities are given more weight than environmental considerations (Font, 2001; Sanders, 2005; Font \& Wood, 2007; Gao et al., 2016). As summarized by Tzschentke et al. (2008a) with regards to perceived customer demand for environmental initiatives among B\&B operators "there is, however, often a discrepancy between word and deed, and what operators need is actual proof" (p. 169).

Previous research also seems to indicate that there is widespread skepticism in the tourism industry regarding travelers' demand for environmental certification (Dewhurst \& Thomas, 2003; Bohdanowicz, 2005; Rowe \& Higham, 2007), in addition to a lack of convincing evidence regarding consumers' willingness to pay extra for environmental features (Watkins, 
1994; D’Souza et al., 2007; Burgin \& Hardiman, 2010; Karlsson \& Dolnicar, 2016). This raises the question as to whether commercial benefits could be demonstrated to hosts, as outside of perhaps a very small segment of the population environmental criteria does not appear to be a major factor (Karlsson \& Dolnicar, 2016). If this commercial benefit cannot be demonstrated to hosts then it is likely that adoption will be limited to those for whom personal values is the primary motivation. This could still lead to promising levels of adoption given that personal values was one of the most strongly referenced motivations, but the lack of perceived commercial benefits would most likely limit adoption. However, if commercial benefits cannot be stated clearly from the beginning of this type of program, Airbnb could measure how early adopters of this program (presumably those who adopted based on personal values) perform since the introduction of the program; if commercial benefits are observed for those early adopters, whether through increased booking requests, views, or increased price, these demonstrated benefits could be used to promote the program to other hosts.

\subsubsection{Managing the Guest Experience}

In terms of engaging guests regarding their environmental impact, most respondents were doing this already or were willing to engage with guests. Among those that stated they would be willing to engage with guests, there was a definite preference for passive engagement through inclusion in the house guide or some other type of print message. This suggests that in terms of program design, any guest engagement requirement should permit these passive forms of communication to encourage participation. That is not to say that face-to-face communication could not be included as a requirement, only it should not be the minimum requirement; for example, it could represent a higher level of achievement (i.e. silver or gold in the case of a graded system). Though perhaps not as effective as direct face-to-face engagement, providing 
instructions and reasons regarding the ways to minimize resource use among guests has been recommended as an effective tool to promote pro-environmental behaviour (Budeanu, 2007).

From an assessment standpoint though, guest engagement raises some interesting considerations. Passive forms of communication would likely be easier to monitor through a second-party assessment as Airbnb could validate whether the house rules section on a listing includes instructions regarding pro-environmental behaviour. Face-to-face communication, or other forms of communication not built into the platform (e.g., house binder, information cards) would need to be assessed in-person though, either by a third-party or by guests themselves through the guest review process.

An interesting dichotomy also emerged from this question around guest engagement. While the majority of respondents said they already were, or were willing to inform guests on how to reduce their environmental impact, Alex was adamantly against this notion as he did not believe it was the guest's responsibility to reduce their environmental impacts. This opinion reflects the challenging situation environmental certification in the hospitality industry must confront; that is reducing environmental impacts without impacting guest comfort even though the guests themselves ultimately determine how much or how little resources are consumed. It has already been shown in past research that hospitality providers believe guests can be wasteful when it comes to consumption of resources (Carr, 2002; van Haastert \& de Grosbois, 2010), and the discussions in this research around water conservation, energy conservation and waste indicated that participants in this study echoed this belief. Interviewees also added that guests do not have an incentive to control their resource consumption nor do they seem to care about their environmental impact. The results from the Airbnb forum, specifically the theme of guest behaviour, indicate that Airbnb hosts outside the sample share a similar belief regarding their 
guests' resource consumption. This raises the question of whether guests in Airbnb's behave differently than in hotel's, specifically with regards to resource use. It could be suspected that because guests are in someone's home they may be more considerate of resource use, but the concerns raised by hosts seem to echo those raised by hotel staff.

Participants also raised the theme of guest comfort, and the associated apprehension towards implementing measures that would negatively affect guest comfort (e.g., water pressure), guest perceptions (e.g., smell associated with cleaning products), or make their guests feel guilty (e.g., suggesting alternate transit options). As highlighted by Peter, this apprehension is likely due to concerns that any such changes may negatively impact the host's reviews. This theme, along with the barrier of trade-offs with guest comfort, appears to demonstrate that even though there is an awareness of guest wastefulness, hosts prioritize guest comfort over addressing guest resource consumption. It also reveals a potential challenge regarding the program design, as measures must be designed that are not too onerous that they discourage participation, but that are also seen to be part of a credible program.

An interesting consideration for Airbnb though with regards to guest wastefulness is that unlike with traditional hotels, Airbnb hosts also review guests. This is a core component of Airbnb and as mentioned, is designed to build trust between users. The implementation of an environmental certification program, along with guest engagement could create an expectation among hosts that guests behave according to recommended environmental behaviour while in the home (e.g., recycling, energy conservation), and thus become part of the host review process for guests. This may be especially relevant for those hosts who are not motivated by commercial benefits (i.e. ability to attract like-minded guests and personal values) as they may be less concerned with the repercussions of criticizing their guests around their environmental 
behaviour, especially if there is an expectation that guests will abide by any environmentally focused house rules provided by the host.

\subsubsection{Levels Versus Pass/ fail}

Regarding the type of certification it appears that using some type of graded system or levels would allow for more participation than a strictly pass/ fail system, and would also encourage hosts to improve their environmental performance. Participants expressed concern regarding the fairness of a pass/fail system believing that because environmental performance can vary drastically from property to property it is not reasonable to judge all properties by the same criteria. Additionally, respondents believed that using levels would encourage hosts to improve over time and aspire to the higher levels. This preference for a graded system is shared by hoteliers (Toth, 2002), and many existing programs use levels in the form of graded systems (see section 2.6.3) for the same reasons raised by the hosts (Bien, 2006a).

In terms of designing an environmental certification program for Airbnb, using a graded system may be the most practical option given the wide range of properties listed on Airbnb. There are also many factors outside of the hosts control that could influence their ability to comply with environmental criteria. For example, in Toronto, where a majority of listings are condominiums, the host may not be able to make changes that are not compatible with the condominium's design (e.g., smart thermostats, installation of renewable energy services like solar panels), or that impact shared spaces like greenspace and the use of chemical cleaning agents in common areas. There are also factors that are not related to the property itself, but that still pertain to environmental impacts of the property, such as the availability of renewable energy options, public transit, or the presence of a municipal recycling and composting program. While all of these options are available in the GTA, they may not be in other areas where Airbnb 
operates, particularly rural areas. In these cases it could be considered "unfair", as the participants put it, to evaluate a host against criteria they cannot meet, or would be extremely challenged to meet. In fact, lack of recycling facilities has been raised as a practical constraint among small businesses that want to participate in sustainable waste management practices (Dewhurst \& Thomas, 2003).

Regarding how the program could be designed to encourage participation, interviewees did not seem to care about whether it was performance versus process (i.e. continuous improvement); instead preferring a program design that was simple and with requirements that are achievable. This theme of achievability was expressed both with regards to the type of certification (levels versus pass/fail) and performance versus process. This seems intuitive as the hosts want to ensure their property is eligible for certification, and that they can meet the requirements of any program that might be designed. When viewed in tandem with the concept of fairness discussed above, it seems that the most appropriate design for a program would use a graded system to acknowledge various levels of achievement. This variance between properties, combined with the lack of control over guest behaviour and the difficulty expressed in separating host versus guest resource consumption, suggests that measurement of actual consumption (e.g., litres of water per guest, kilowatt-hours of electricity per guest) would be difficult to achieve in an Airbnb context. There appears a need for sufficient flexibility to ensure the requirements are achievable, but this will need to be balanced against the credibility of the program to ensure that it is not attacked with claims of greenwashing.

\subsubsection{Environmental Categories}

The environmental categories discussed with hosts represent not only the broadly accepted categories for environmental certification from the Global Sustainable Tourism 
Council, but they also align with the types of initiatives already being implemented in Ontario B\&Bs (van Haastert \& de Grosbois, 2010). See Table 12 for an overview of which categories appear suitable for inclusion in an Airbnb environmental certification program.

Table 12:

Summary of fit for environmental categories

\begin{tabular}{|c|c|c|}
\hline Criteria & Description & $\begin{array}{l}\text { Will criteria } \\
\text { enhance likelihood } \\
\text { of participation }\end{array}$ \\
\hline $\begin{array}{l}\text { Local } \\
\text { purchasing }\end{array}$ & $\begin{array}{l}\text { Purchasing policies favor locally appropriate and } \\
\text { ecologically sustainable products, including food, } \\
\text { beverages and consumables. }\end{array}$ & No \\
\hline $\begin{array}{l}\text { Disposable } \\
\text { goods }\end{array}$ & $\begin{array}{l}\text { The purchase and use of disposable and consumable } \\
\text { goods is measured and the host actively seeks ways to } \\
\text { reduce their use. }\end{array}$ & Yes \\
\hline $\begin{array}{l}\text { Energy } \\
\text { conservation }\end{array}$ & $\begin{array}{l}\text { Energy consumption is monitored and measures are } \\
\text { adopted to minimize overall consumption, and } \\
\text { encourage the use of renewable energy. }\end{array}$ & Yes \\
\hline $\begin{array}{l}\text { Water } \\
\text { conservation }\end{array}$ & $\begin{array}{l}\text { Water consumption is monitored and measures are } \\
\text { adopted to minimize overall consumption. }\end{array}$ & Unclear \\
\hline $\begin{array}{l}\text { Transport } \\
\text { greenhouse } \\
\text { gas } \\
\text { emissions }\end{array}$ & $\begin{array}{l}\text { The individual encourages its customers to reduce } \\
\text { transportation-related greenhouse gas emissions. }\end{array}$ & Yes \\
\hline Waste & $\begin{array}{l}\text { Waste is monitored and mechanisms are in place to } \\
\text { reduce waste, and where reduction is not feasible, to re- } \\
\text { use or recycle it. }\end{array}$ & Yes \\
\hline $\begin{array}{l}\text { Harmful } \\
\text { substances }\end{array}$ & $\begin{array}{l}\text { The use of harmful substances, including pesticides, } \\
\text { paints, swimming pool disinfectants, and cleaning } \\
\text { materials, is minimized, and substituted when available, } \\
\text { by innocuous products or processes. All storage, use, } \\
\text { handling, and disposal of chemicals are properly } \\
\text { managed. }\end{array}$ & Yes \\
\hline $\begin{array}{l}\text { Alien } \\
\text { Species }\end{array}$ & $\begin{array}{l}\text { The host takes measures to avoid the introduction of } \\
\text { invasive alien species. Native species are used for } \\
\text { landscaping wherever feasible, particularly in natural } \\
\text { landscapes. }\end{array}$ & No \\
\hline
\end{tabular}

With regards to local purchasing, for most hosts this was not applicable outside of gifts.

Airbnb's are different from hotels in that they don't usually offer food, but they do have cooking facilities. For this criterion, perhaps then it would be more appropriate for an Airbnb focused 
program to direct guests how to engage in local purchasing (e.g., farmer's markets) rather than judging them on the provision of local goods, as this may not be applicable to many hosts.

Based on this sample, minimizing disposable goods appears to be a criteria that would be appropriate for hosts as many have already taken steps to reduce their use of disposable goods, whether it be by providing reusable shopping bags and water bottles or by substituting coffee pods for less wasteful options. In the Toronto context this may be aided by the fact that the tap water is safe to drink, therefore hosts are able to promote to their guests that they do not need to purchase bottled water. However, as some participants noted, some guests will purchase bottled water anyways. This demonstrates the issue raised earlier regarding the lack of control hosts have in guest resource consumption; in this context hosts can tell guests the water is safe to drink and provide water bottles, but the guests still may go out and buy plastic water bottles for reasons unbeknownst to the host. This impact can be mitigated by informing guests of recycling options in the home, but, as many participants have made clear, the guest may ignore these recycling options. This illustrates the limited impact hosts can have over guest resource consumption; however, this is an issue that seems inherent to environmental certification in accommodations so would not be unique to Airbnb. It does also not mean environmental certification is devoid of positive environmental impacts, but that there are limitations.

Regarding energy conservation, similar to disposable goods, most of the respondents had already taken steps to address energy conservation on their property. Unlike disposable goods though, reducing energy use is usually associated with cost-savings and this theme was mentioned by several of the respondents with regards to energy conservation. The challenges of defining the overall commercial benefits of environmental certification have already been noted, but due to the inherent cost-savings associated with energy conservation the commercial benefits 
of these specific initiatives could be explained to hosts to help encourage participation. Additionally, education or guidance regarding how to implement these measures, which was requested by one participant (Caitlin) could eliminate any knowledge barriers; in fact, access to knowledge has been noted in previous research as a way to assist smaller organizations in becoming certified (Sanders, 2005). Ultimately, the cost barrier may limit what hosts can do with regards to energy conservation; however, this cost barrier would depend on the actual requirement, and given the inherent cost-savings, and the current pursuit of these measures it seems sensible to include this criterion in an environmental certification program for Airbnb.

Similar to energy conservation, water conservation was being pursued by a majority of respondents, but the same cost concern emerged. As raised by one of the respondents, the potential for cost-savings is also much lower than with energy conservation due to the low cost of water for Toronto residents. There is also the perceived trade-offs with guest comfort that come with installing more efficient fixtures. It seems that for water conservation criteria to encourage participation, the criteria would have to ensure that guest comfort is not being compromised, and that the investments are not too costly. Past research among small- and medium-sized hospitality managers in the Australian tourism industry have also mentioned the cost barrier around water conservation efforts, despite being subject to water-shortages and rising water prices (Alonso \& Ogle, 2010). Given the availability and low-cost of water in the GTA there is even less pressure to conserve water; this fact combined with the concerns over guest comfort suggests that requiring water conservation measures may not encourage participation in an environmental certification program.

Regarding the mitigation of transport related greenhouse gas emissions, given the extensive public transit network in Toronto, along with the availability of taxi's, ride-sharing 
(Uber), and bike-share programs, it is perhaps unsurprising that most hosts are already providing guests with this information. In fact, the two guests that stated this would be difficult were those whose communities did not have as extensive a public transit network (Niagara region and Mississauga). Both participants were willing to provide this information to guests but noted that a more extensive public transit network needed to be developed first, echoing findings from similar research (Vernon et al., 2003) in which tourism businesses identified lack of public transit as a regional environmental issue.

Following the theme of guest comfort, some participants believed they should only provide transportation related information and then let the guest choose their mode of transportation, as opposed to explicitly encouraging them to avoid automobile travel, so as to not make guests feel guilty. This criterion appears like it could encourage participation in the program, as most hosts are providing this information to guests; however, it seems very location dependent, and based on concerns raised by some participants should focus more on provision of information as opposed to strict encouragement of environmentally superior travel modes. It should be noted though that whether this program exists or not, it's likely that the hosts that are already providing this information are not doing so from an environmental perspective, but because they see it as either an attractive feature of their property (as stated by Sarah), or because guests need to know about transportation options to get to the property. Therefore, if it were to be included as a criterion in the certification program it would most likely be a recognition of existing practices rather than motivation to change practices.

All hosts were currently engaged in waste reduction strategies, primarily through municipal recycling and composting programs. Similar to public transit, the availability of this feature is largely determined by local government, and outside of the hosts control, unless they 
decided to have on-site composting. Also, similar to public transit, this was one of the most common features already being promoted to guests; however, it is unclear what the motivation was for promoting this feature (e.g., easier for hosts to clean-up after guests, habitual, personal values). As with public transit, inclusion of this criterion may be more recognition of existing practices, though some respondents admitted they were not instructing guests on how to use these features, but believed it would be easy to begin doing so. Therefore, waste reduction appears to be an appropriate criterion to include in an Airbnb environmental certification program.

The use of harmful substances also appears to be a criterion that would encourage participation as many respondents are already doing this as well, and for those that are not, it seems education and perception are the major barriers. Hosts could be provided information as part of this program regarding what innocuous substances can be used as substitutes for chemical cleaning products. There is also the possibility, raised by one participant, that their cleaning company does not use these products. An environmental certification program though could encourage that host to either change cleaning companies or put pressure on their current company to adopt these practices. It would be interesting to see if certification would have any type of cascading effect on Airbnb focused cleaning services. The data from the Airbnb forums also suggests that the use of chemical cleaners is a concern for both personal sensitivity and environmental reasons. It therefore seems plausible that this could be a sub-item as part of an environmental certification program or a separate program, as it is a health concern for some guests, and would be valued in and of itself.

Given the confusion among hosts regarding whether or not their greenspace includes native species, it appears that this may not be an appropriate criterion to include in an 
environmental certification program for Airbnb. In addition to the fact that hosts don't even know if they're complying with this or not, the assessment of this feature may be challenging as it would require somebody with advanced knowledge of horticulture to determine whether each species of plant is native or non-native. This is something that could likely only be executed by a trained third-party, but as has been raised by the interviewees there are cost concerns with that. In lieu of a third-party, it would seem unreasonable to believe that a typical host or guest would have the knowledge to evaluate the origin of each species in a greenspace, nor would guests likely be willing to do this as part of their general evaluation of their stay. Due to the complexity and burdensome nature of this criteria it does not seem like a good fit for an Airbnb environmental certification program.

\subsubsection{Costs to Comply}

For nearly every topic of discussion where there may be a financial implication, this issue was raised by the participants. This included cost as a barrier, unwillingness to pay a fee, preference for self-assessment, and several of the environmental categories, particularly energy and water conservation. The cost of participating in this program is clearly a major concern among hosts, and past research has suggested that environmental standards for SME's should be inexpensive in order to spur participation (Gerstenfeld \& Roberts, 2000). Unsurprisingly then, participation would likely be encouraged by not requiring a fee to participate, and by including criteria that do not require a significant financial outlay; or if they do require a financial investment, an explanation of the associated cost-savings. Generally speaking, programs that keep costs low by using self-assessment and weak criteria suffer from credibility issues. As already discussed though, given the unique position of Airbnb it is conceivable that they can design a program similar to their business travel ready badge that satisfies the calls for external verification to achieve credibility, but doesn't require trained third-party verifiers, which would 
represent a significant cost. In this case, similar to the business travel ready program, hosts would likely not be charged a fee to participate thus removing another cost barrier.

\subsection{Practical Implications and Recommendations}

As mentioned in section 5.3.6, it is conceivable that Airbnb could deploy this type of program leveraging a process similar to their business travel ready designation. However, Airbnb developed the business travel ready badge to penetrate a new customer market. If the company does not see the revenue potential of developing this type of program then they may not be willing to invest in an environmental certification badge. While there was a belief among participants that this program may be valued by younger travelers (i.e. millennials), consistent with previous research (Jayawardena et al., 2013; Esparon et al., 2014; Kubickova et al., 2015), and past research has shown a concern for environmental factors when travelling (Lubbert, 2001; Fairweather et al., 2005; Budeanu, 2007; Font \& Wood, 2007; Hamilton, 2015), definitive consumer demand for environmental certification is lacking. As mentioned in section 2.14 though, the creation of these programs has historically not been driven by consumer demand; instead they trace their roots to industry coalitions or public pressure from activist groups and NGO's (Conroy, 2002; Font \& Wood, 2007). Airbnb has already faced legal challenges and public criticism in many of the municipalities in which it operates, including Toronto, primarily focused on issues of property damage and economic impacts. Although it has not encountered broad criticism regarding its environmental impacts, once economic issues are resolved through legislation, the focus could shift to more social and environmental impacts. As shown in the forums, there have been proactive calls for this program to be created, albeit from a small number of hosts, but if calls for this type of program grow Airbnb may be forced to address them. As suggested by the some of the participants, this program could be good publicity for 
Airbnb and could contribute towards the environmentally responsible image it appears to have tried to foster with previous initiatives.

If Airbnb were to develop this type of label, past research by Castka and Corbett (2016) suggest the development of the requirements should be open- and consensus-based, in order to avoid negative media attention. This could be potentially done by requesting ideas or feedback through the host forums, as well as by engaging experts in the field of environmental certification. As mentioned, Airbnb has been susceptible to negative media attention in the past, and previous environmental initiatives have been accused of being an attempt to deflect from negative media attention. If Airbnb were to be furtive in the development of this program it could attract negative media attention and counteract any possibility of improved brand image.

In terms of design, the ability for hosts to meet the criteria would depend on the strictness of the requirements, and the associated cost of meeting the requirements. There is room for flexibility in these programs through the use of a graded system, and given the calls for fairness and achievability among the host sample, this type of system appears to be most promising. Additionally, given that some of the criteria may be location dependent and outside of hosts control (e.g., recycling, public transit, tap water, renewable energy), a process or continuous improvement based standard is more suitable as they are more appropriate in instances where performance can vary greatly from region to region (Synergy Ltd, 2000; Font, 2002). Based on these considerations the program could implement some type of checklist, similar to the business travel ready designation, that awarded hosts based on their level of compliance (e.g., bronze, silver, gold depending on the number of items a host has checked-off). This would appear to satisfy the calls for fairness and achievability, and reflect the variance between hosts and their properties. 
Once developed, the program would likely need to be promoted to both hosts and guests given the lack of awareness discovered among travelers regarding environmental certification programs (Archer et al., 2005; Fairweather et al., 2005; Font \& Wood, 2007; Dodds \& Joppe, 2009), as well as the apparent lack of awareness for these programs, or the Airbnb environmental impacts of home-sharing report among the interview participants. When targeting hosts the promotion for this type of program would do well to address the mixed motivations of hosts by focusing on both the positive environmental benefits as well as the potential commercial benefits. As suggested by Garay and Font (2012), environmental programs must speak to individuals driven by both financial and personal values, as to focus on only one runs the risk of being ignored by the other.

As a central point of contact for all hosts Airbnb could not only promote the program, but also provide hosts with educational information regarding how to meet the criteria. They have already developed a guide in association with the UNEP to help travelers reduce their environmental impacts while travelling, so it is conceivable that a similar guide could be developed and disseminated among hosts. Given Airbnb's stated partnership with the UNEP, UNWTO as well as their ties to the Global Sustainable Tourism Council they seemingly have access to resources and individuals with expertise in mitigating environmental impacts of travel, as well as environmental certification programs. The company has already demonstrated its ability to directly engage hosts on reducing environmental impacts through its water management program in Cape Town, though a certification program would likely require broader engagement across numerous environmental categories and geographies.. That said, Airbnb could also alter the program by geography or pilot it among certain regions or types of hosts. For example, it could test it out in one city first, or begin by only offering it to certain 
property types or superhosts. This piloting of the program could help the company determine its feasibility and make adjustments before a wider deployment. Airbnb has already demonstrated that it can collect taxes based on jurisdiction (Kokalitcheva, 2016), so presumably it could offer other services based on the location of the host. This could allow the program criteria to vary from region to region and perhaps include only criteria relevant to that region, an issue that some certification programs have had trouble negotiating, particularly among performance based programs (Synergy Ltd, 2000; Font, 2002).

The willingness to participate in this type of program expressed by the sample is encouraging and suggests that availability of this type of program could lead to reduced environmental impacts of Airbnb guests. This may be especially true given Lowe's (1988) suggestion that guests staying with small hoteliers preferred to be told how to behave as opposed to having to decipher this for themselves, and as the participants have made clear, the majority of them would be willing to instruct guests on how to reduce their environmental impacts through their house guide or some other form of print communication. Although guests do not have an incentive to reduce resource consumption, the combination of guest engagement regarding environmental behaviour (e.g., using public transit, instructions to recycle and compost) and the provision of environmental features (e.g., smart thermostat, low-flow water fixtures) could result in guests reducing their resource consumption more so than they would in a hotel; however, there is the risk that this could be offset by the rebound effect, as explained in section 2.8 . Additionally, the dual review system that allows hosts to review guests may also encourage guests to comply with host instructions. Again, this review system is another factor unique to Airbnb that is not present among typical hotels and thus may allow for greater compliance with environmental behaviour than would be seen in traditional accommodations. 


\subsection{Unique Insights}

In focusing on the potential for an environmental certification for Airbnb, this research addressed an area that to date has received very little research attention, that is environmental issues as they pertain to collaborative consumption, and Airbnb specifically. As such, this research has revealed some unique findings, likely due to the relative novelty and unique nature of Airbnb properties versus traditional accommodations providers. Firstly, based on the interviews and research of the forums, there is an indication that Airbnb hosts are willing to participate in an environmental certification program. This question has not been asked before and while the sample is not representative of the broader Airbnb host population, data collection from multiple sources does indicate that there is potential interest in this program both within and outside the sample.

Secondly, two motivations for pursuing certification were revealed that were not evident in past research on the topic; that is the ability to attract like-minded guests and the desire to measure household environmental impacts. As explained, these motivations are likely based on the fact that the properties on Airbnb are also hosts' homes. While personal values and commercial benefits were the most strongly expressed motivations, mirroring previous research, these two novel motivations illustrate that hosts have unique considerations that make them distinct from typical small accommodation owner-operators. The ability to attract like-minded guests motivation may warrant special attention as a recent competitor to Airbnb in the shared accommodations space, Staybillety, focuses exclusively on matching hosts and guests with shared interests (Peltier, 2016); for example, university alumni, athletic associations, and various enthusiasts (e.g., Jimmy Buffet fans, Star Trek fans). While Staybillety is still in its infancy, and is not specifically focused on personal environmental values, this criterion could be used for 
matching hosts and guests on this new platform. If this desire for attracting like-minded guests is strong enough it could draw hosts away from Airbnb and towards Staybillety, or result in hosts posting their properties on both sites. Either way it could force Airbnb to incorporate this functionality into its user experience.

Many of the barriers identified by the participants had already been discovered in previous research, or were closely related to some of the more broad barriers discovered in past studies. For example, rigour of the standards is more specific, but similar to the barriers time commitment and effort, and therefore does not seem to represent an entirely new barrier. Perceived credibility of the program though appears to be a new barrier. This barrier appears to be largely dependent on the program design, as well as the expertise of the individual host. This issue of credibility was raised by participants with particular reference to the assessment styles, so it appears that participants acknowledge that credibility can vary based on assessment style, though it is unclear for how many this would translate into a barrier for participation. It may be the case that only those individuals who are particularly conscious of their environmental impact or have more expertise regarding environmental issues would consider credibility as a barrier to participation.

Another unique finding was the sense of mistrust among the hosts towards other hosts. While this feeling is not exclusive to this sample (Tilley, 2000), it warrants being highlighted given that trust between users has been identified as a key component of the collaborative consumption movement. As described, in the context of Airbnb this trust is supported and maintained through the mutual review system between guests and hosts, and it is this review system that hosts believe should be used as an external verification of other hosts. This is interesting as it suggests that while hosts do not necessarily trust each other to accurately self- 
assess, they do trust guests using the platform to accurately review hosts. This indicates that while trust between hosts may be low, trust between the host and guest is higher.

This leads to the final unique insight, which is the proposal from participants that the existing review system be leveraged for the assessment process. The finding itself is not necessarily surprising as it satisfies host concerns for a low-cost, low-complexity assessment process; however, it is a new type of assessment process for environmental certification programs that is made possible through the existing Airbnb user experience and platform design. There are obvious limitations to this as this type of system could be vulnerable to subjectivity among the guests, and be restricted to criteria that are visible to guests. Nevertheless it represents an innovative solution to the issue of assessment, typically the most costly and time-consuming component of these programs (Fennell \& Malloy, 2007; Rattan, 2015).

\subsection{Conceptual Framework Revisited}

Given the results of this research the conceptual framework was reviewed and adjusted to incorporate new findings. As can be seen in Figure 3, the motivations of ability to attract likeminded guests and measure household environmental impacts were added, along with the barriers rigour of the standards and perceived credibility of the program. As mentioned, rigour of the standards is not necessarily a new barrier; however, it was added to this conceptual framework as a means of specifying time commitment and effort. 


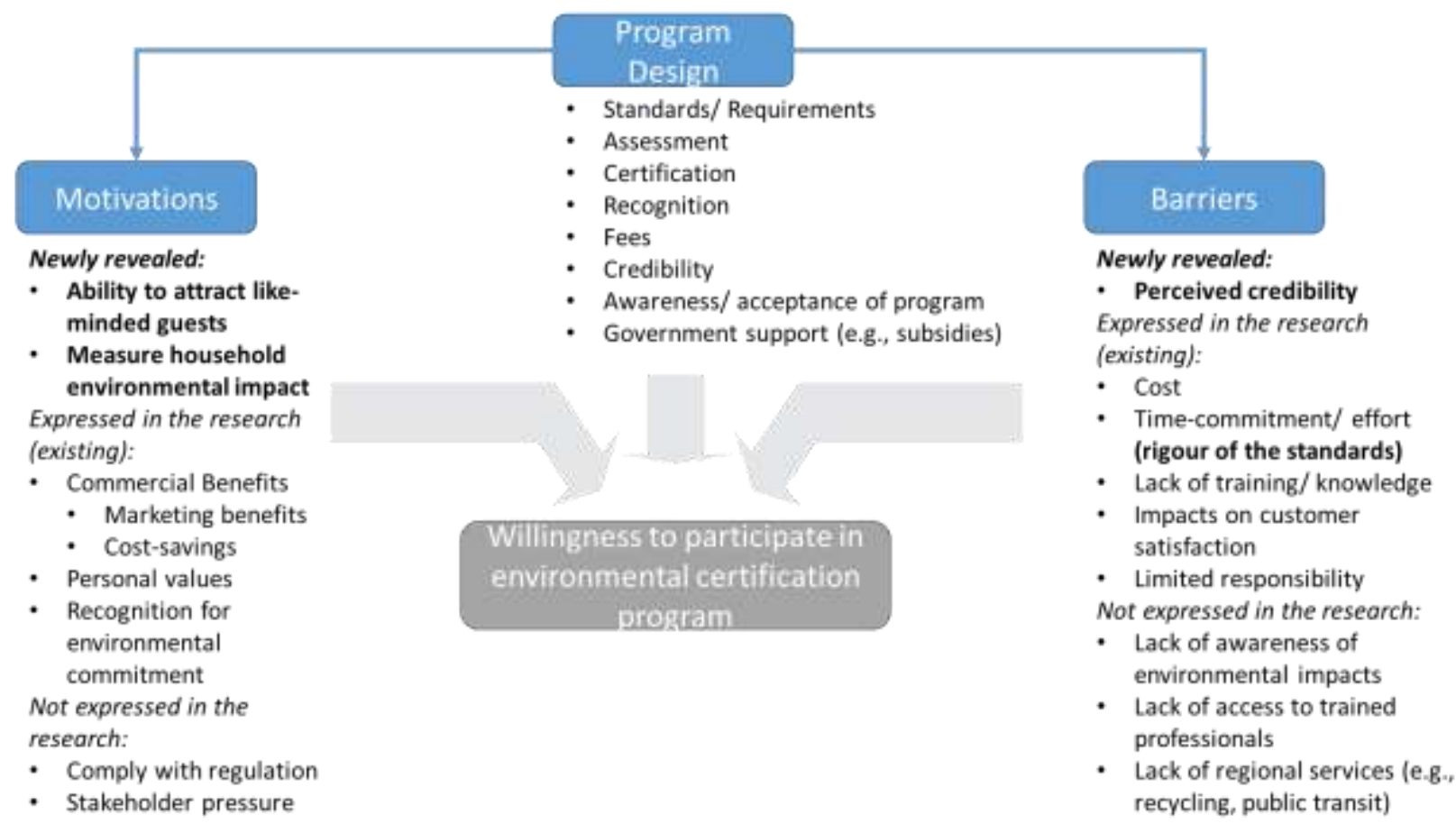

Figure 3: Conceptual framework revisited for Airbnb hosts

Regarding program design, no new elements were revealed in this research as program design questions were largely based on the existing categories in the original conceptual framework (see section 6.3 for a summary of recommended program design elements). However, the importance of this factor was revealed, specifically with reference to its influence on barriers. The barriers rigour of the standards and credibility both depend heavily on program design elements. The former depends on the actual program requirements, which would also strongly influence cost, and the latter depends on a mix of elements such as assessment style, government support, and recognition.

This conceptual framework now incorporates new findings specific to Airbnb and the home-sharing context, though it remains broadly applicable to environmental certification in the hospitality industry. Future research should validate and further refine this framework, especially in the context of home-sharing as there has been minimal research in this area to date. 


\subsection{Conclusion and Recommendations}

\subsection{Scope and Limitations}

As a qualitative research design, these results are not representative of the greater Airbnb host population in the GTA or beyond. This is consistent with in-depth qualitative research in general as there is a trade-off between depth of insight and generalizability. Several strategies and efforts were made to obtain as many interviews as possible, however, the total number of interviews was 14; and while saturation of responses appeared to be reached, additional interviews would have increased the trustworthiness of the results. Another potential limitation of the research is that the interviews were one-on-one with the decision-maker in the property; however, if that person shares the house with a spouse or partner, that person's input would also likely have an influence over the decision to pursue environmental certification. It is possible that self-selection bias played a role during the recruitment process in the form of hosts more familiar with environmental certification being more willing to participate, although since 13 of the 14 were respondents had only a vague understanding of the topic, it does not appear that familiarity with the concept influenced self-selection.

Additionally, due to the inclusion of certain specific examples with regards to the environmental categories discussed (e.g., use of coffee pods, provision of recycling facilities), host explanations of activities they are performing aimed at reducing environmental impacts may have overlooked activities that were not mentioned as examples, but that nonetheless do contribute to a reduced environmental impact. For example, eliminating the use of coffee pods and providing larger toiletry bottles were used as examples of reducing disposable goods, but providing reusable water bottles or shopping bags was not. While some hosts mentioned they did provide these to guests, hosts were not prompted to think about them in the same way they may have been prompted by the examples provided. Consequently, there may be more ways that hosts 
are reducing their environmental impacts that could be appropriate for this program that were not discovered in the host interviews. There is a risk that social desirability bias played a role in the participants' stated willingness to participate in an environmental certification program; however, as previous research has indicated, this phenomenon does not appear to play a role in environmentally focused studies.

As stated earlier, the scope of the study was delimited to freehold (detached or semidetached) homes, as many condominiums have by-laws that prohibit Airbnb style short-term rentals which could have presented potential ethical issues if these hosts were to be recruited. Condominiums though represent a substantial portion of the Airbnb listings in Toronto, and as such their omission from the sample represents a limitation of this research; however, proposed legislation for short-term rentals scheduled to be passed in 2017 could clarify the regulatory framework around Airbnb, thus removing this ethical concern and clearing the way for research to be done on this sample.

Additionally, condominiums likely have considerations related to environmental certification that may not apply to homeowners. As already mentioned, condominium owners would likely be restricted in the changes they can make to their property, particularly changes that may not compatible with the condominium's design (e.g., smart thermostats, installation of renewable energy services like solar panels), or that impact shared spaces (e.g., greenspace and common areas). On the other hand, there has been a growing number of LEED certified condominium buildings in Toronto (Lebour, 2010; TD Economics, 2015), and it is possible that hosts in these buildings may not feel the need to become certified or may pursue certification as recognition of existing practices. An Airbnb environmental certification program would likely face calls from these owners to recognize any existing environmental certification of their 
property. This could be incorporated into the program by allowing hosts to indicate whether their property is in a LEED certified building, and since hosts provide their address to Airbnb, this claim could be validated against the LEED certified building registry kept by the Canada Green Building Council, the group responsible for certifying LEED in Canada (Canada Green Building Council, n.d.; Lebour, 2010).

\subsection{Recommendations for Future Research}

In terms of future research surrounding this topic, there are several avenues that could be explored. Firstly, additional studies should be conducted with a larger and more representative sample including all property types, to determine if the willingness to participate and motivations revealed by this study apply to the greater Airbnb host population. Secondly, an examination of environmental attitudes among the host population could be conducted to determine if there is any association between pro-environmental attitudes and willingness to participate in this type of program, as historically these attitudes have shown to be predictors of environmental behaviour

(Eagles \& Cascagnette, 1995; Sirakaya-Turk et al., 2014; Gao et al., 2016), including adoption of environmental practices in the hospitality industry (Best \& Thapa, 2013; Chan et al., 2014). In a similar vein, an examination of the motivations responsible for the current level of engagement in environmental activities (e.g., recycling, promotion of public transit) could be conducted to determine whether they are consistent with the motivations expressed for enrolling in an environmental certification program.

Future research, especially larger quantitative studies, could also examine demographic characteristics (e.g., age, education, gender, income) of hosts to determine if differences regarding environmental commitment exist between various cohorts of the host population. These future studies may also choose to view hosts through the homeowner lens as opposed to a 
small hotelier. For example, if questions were positioned that focused on participant motivations as a homeowner instead of an Airbnb host, alternate motivations may be revealed (e.g., resale value of the home).

From the guest perspective, future research could focus on examining the willingness to pay for an environmentally certified property, or to what degree this feature may influence choice of Airbnb properties. Guttentag (2016) discovered in his research that environmental concern did not play a significant factor in guest motivations for choosing Airbnb; however, if this program were to exist and be presented to guests when selecting listings, it may exert more of an influence on their choices. Furthermore, guest resource consumption could be examined in Airbnb's and contrasted against resource consumption in other types of accommodations to see if differences exist, and what causes those differences (e.g., amenities, conscious behavioural choices, presences of the dual review system).

Additionally, there are multiple, host-focused research opportunities that would arise from the deployment of this type of program; this includes the benefits of the program, the barriers to participating, the perceived value of this program to their guests, and whether there is any influence of this program on the price of listings. Furthermore, the motivations of hosts who actually adopted this type of program, were it to be deployed, could be examined and contrasted against the motivations discovered in this research.

\subsection{Recommendations for Program Design}

Based on the information gleaned from participants with regards to the third research question, it appears the most plausible program design would leverage a process similar to the business travel badge, whereby hosts can select from a list of environmental criteria what criteria they are meeting as part of their property and hosting activities. Criteria that would appear to be 
most applicable and achievable to hosts based on this sample include disposable goods (e.g., provision of bulk toiletries, reusable shopping bags and advisement that the tap water is potable), energy conservation (e.g., smart thermostat), water conservation (e.g., dual flush/low-flow toilets), transport GHG emissions (e.g., provision of public transit and bike-sharing information), waste (e.g., provision of recycling and composting facilities as well as instructions on how garbage should be sorted), and harmful substances (e.g., use of non-chemical or scent-free cleaning agents). Local purchasing and alien species do not appear suitable for an Airbnb environmental certification program. All the examples provided are intentionally visible to the guests to reduce risks of subjectivity, and because the use of guest reviews as the validation mechanism necessitates that these criteria are visible. The list of which criteria the host is meeting should be available on the listing, perhaps as a sub-section of the amenities section on the listing, and any specific instructions should be included in the house rules section of the listing, thus providing for more passive engagement while also allowing Airbnb to validate that environmental related instructions are present on the listing.

Airbnb could engage leverage its partnerships with the UNEP, UNWTO and GSTC to develop the program criteria, and these can be reviewed with hosts using the host forums, so that hosts can provide feedback on the proposed design. The forums could also be used as a tool to promote the program; although Airbnb could likely engage in direct emails to hosts to engage them as well.

In order to address concerns of fairness, participants should be awarded different levels of achievement based on the number of criteria they comply with. This would acknowledge the variation between properties and hosts capabilities or budget, and would reduce barriers to participation out of the control of hosts (e.g., public transit network, municipal recycling 
programs). As the program is leveraging the existing user experience, there should be no direct costs to participate, and the presence of external verification by the guests should assuage concerns over credibility that usually accompany self-assessment. However, given that the guests are not trained to evaluate environmental performance and that the criteria would have to focus on visible elements, the program may face criticisms of greenwashing.

\subsection{Conclusion}

This qualitative study revealed that Airbnb homeowner hosts in the GTA are willing to participate in an environmental certification program for their properties. The participants expressed many of the same motivations found in previous research, as well as two new motivations, namely the ability to attract like-minded guests and the desire to measure household environmental impacts. This demonstrates that Airbnb hosts appear to have unique motivations driving them to be adopt environmentally friendly measures that separate them from traditional small accommodations providers like B\&Bs or small hotels. These unique motivations are likely a result of the Airbnb operating model, specifically the aspect of home-sharing. The concept of cost was a major theme that appeared throughout the interviews, and combined with other themes suggested that the program design should focus on leveraging the existing guest review system. While participants seemed enthusiastic towards adopting this type of program, the program design itself along with the associated requirements and costs to comply will ultimately be the determining factors for hosts considering environmental certification. While this research provides encouraging results regarding willingness to participate, and can be used as a first step towards crafting an environmental certification program for Airbnb, further exploration is likely required before developing and deploying this program to the Airbnb host community. 


\section{Appendices}

\section{Appendix A: Interview Guide}

Study Title: Exploring the Opportunity for an Environmental Certification Program for Airbnb Homeowner Hosts.

Researcher: Geoffrey Fudurich

Research Questions:

- Would Airbnb homeowner hosts be willing to participate in an environmental certification program?

- What would motivate Airbnb homeowner hosts to participate in an environmental certification program?

- What program design elements would enhance the likelihood of their participation in the program?

\section{Draft Interview Questions:}

\section{General Introduction:}

1. How long have you been an Airbnb host?

2. How frequently do you rent your property?

3. Can you confirm the property details as listed on Airbnb?

a. Detached, semi-detached, townhouse

b. Private room, shared room, entire home

4. What drew you to becoming an Airbnb host?

5. Are you a superhost?

\section{Willingness to Participate:}

Preamble: The following set of questions will introduce the concept of a voluntary environmental certification program for Airbnb and are designed to explore your opinions regarding such a program.

5. Are you familiar with the concept of environmental certification programs for hotels and tourism properties?

a. Probe: Can you describe what that term means to you?

b. Probe: Can you identify any existing environmental certification programs for hotels or tourism properties you are familiar with?

Preamble: Before beginning the next set of questions I want to take a moment to describe the typical elements of a certification program.

- Voluntary 
$\circ$ There is no penalty for not joining and organizations are free to join or leave membership as they see fit. Pursuing certification however may require financial investments to improve the environmental performance of the property.

- Standards

- The standard is typically a list of criteria that must be met in order to qualify for certification. These can include commitments across a variety of environmental criteria such as water conservation, energy conservation, and waste. A property may already be meeting these criteria or may require financial investments to ensure criteria is met.

- Assessment/ Certification

○ This is the process by which an organization is evaluated for their conformance to the standard. This is typically either done through a self-assessment, second-party or third-party assessment. Self-assessment is when an individual or organization declares their conformance to the standards; in this case of Airbnb self-assessment would be done by the host. Second-party assessment is when an organization that is offering a product assesses the suppliers of that product so that they can ensure to their customers that the product meets the standards; in the case of Airbnb the assessment would be done by Airbnb itself. Third-party assessment is done by someone not affiliated to organization or individual; in the case of Airbnb this would be done by some type of auditor not affiliated with Airbnb or the host. Once this is complete, certification is the provision of documented assurance that a product meets the standards. This certification can take a number of forms from pass/ fail system to a graded system.

- Recognition

○ Recognition is the acknowledgment of an organizations certification, usually through the awarding of some type of logo that signals to consumers that the property has met the required environmental standards.

Note: Before continuing do you have any questions about the elements of a certification program that we just reviewed?

6. If a voluntary environmental certification program existed for Airbnb hosts would you be interested in participating in such a program?

a. Probe: Can you explain why you feel that way?

b. Probe: What would motivate you to participate in such a program?

c. Probe: Besides what you mentioned in the previous question, are there any other benefits you believe you would receive as a host from participating in such a program?

d. Probe: Can you describe any perceived barriers to participating in such a program? 
7. As mentioned above a significant component of the certification process is who is responsible for assessment and certification; either first-party (self), second-party (Airbnb), or third-party (external organization). Can you please identify which of these systems you believe is most appropriate for a voluntary environmental certification program for Airbnb hosts?

a. Probe: Can you explain why you feel that way?

b. Follow-up: How would you feel about participating in a program that was not associated with Airbnb?

8. Would you be comfortable having guests reviewing your property's environmental initiatives? For example, validating claims made regarding your property's environmental initiatives, similar to the accuracy or cleanliness rating.

a. Probe: What type of comments have you received from guests regarding the environmental attributes of your property?

9. For many environmental certification programs guest education regarding how to reduce their environmental impact is an important component. Would you be comfortable engaging with your guests to educate them on how to reduce their environmental impact? For example, promoting recycling/ composting programs, adjusting room temperature, using public transit, washing clothes in cold water, limiting appliance use.

a. Probe: If you already do some of these things what is your current reason for giving guests this information?

b. Follow-up: Do you typically engage with your guests? If so, what prompts this engagement?

10. With regards to the type of evaluation and type of recognition, would you prefer a pass/ fail evaluation method or a grading mechanism; for example, gold, silver, and bronze levels of achievement?

a. Probe: Can you explain why you feel that way?

11. Do you think Airbnb guests would value such a program?

a. Probe: What makes you say that?

b. Probe: Is this based on your perspective as a host, guest or both?

Preamble: The following is a list of recommended environmental criteria for an environmental certification program. There are eight categories and I would like to ask you for each one, whether you believe it would be easy, difficult or not applicable to implement in your Airbnb property. 


\begin{tabular}{|c|c|c|c|}
\hline Criteria & Description & $\begin{array}{l}\text { Easy or } \\
\text { difficult }\end{array}$ & Comments \\
\hline $\begin{array}{l}\text { Local } \\
\text { purchasing }\end{array}$ & $\begin{array}{l}\text { Purchasing policies favor locally appropriate and ecologically } \\
\text { sustainable products, including food, beverages and consumables. }\end{array}$ & & \\
\hline $\begin{array}{l}\text { Disposable } \\
\text { goods }\end{array}$ & $\begin{array}{l}\text { The purchase and use of disposable and consumable goods is } \\
\text { measured and the host actively seeks ways to reduce their use. }\end{array}$ & & \\
\hline $\begin{array}{l}\text { Energy } \\
\text { conservation }\end{array}$ & $\begin{array}{l}\text { Energy consumption is monitored and measures are adopted to } \\
\text { minimize overall consumption, and encourage the use of } \\
\text { renewable energy. }\end{array}$ & & \\
\hline $\begin{array}{l}\text { Water } \\
\text { conservation }\end{array}$ & $\begin{array}{l}\text { Water consumption is monitored and measures are adopted to } \\
\text { minimize overall consumption. }\end{array}$ & & \\
\hline $\begin{array}{l}\text { Transport } \\
\text { greenhouse } \\
\text { gas emissions }\end{array}$ & $\begin{array}{l}\text { The individual encourages its customers to reduce transportation- } \\
\text { related greenhouse gas emissions. }\end{array}$ & & \\
\hline Waste & $\begin{array}{l}\text { Waste is monitored and mechanisms are in place to reduce waste, } \\
\text { and where reduction is not feasible, to re-use or recycle it. }\end{array}$ & & \\
\hline $\begin{array}{l}\text { Harmful } \\
\text { substances }\end{array}$ & $\begin{array}{l}\text { The use of harmful substances, including pesticides, paints, } \\
\text { swimming pool disinfectants, and cleaning materials, is } \\
\text { minimized, and substituted when available, by innocuous } \\
\text { products or processes. All storage, use, handling, and disposal of } \\
\text { chemicals are properly managed. }\end{array}$ & & \\
\hline Alien Species & $\begin{array}{l}\text { The host takes measures to avoid the introduction of invasive } \\
\text { alien species. Native species are used for landscaping wherever } \\
\text { feasible, particularly in natural landscapes. }\end{array}$ & & \\
\hline
\end{tabular}

12. Are there any other features not described above that you believe are important to include in a voluntary environmental certification program for Airbnb?

13. Would you be more comfortable committing to continuous improvement in the categories discussed above or being assessed based on performance indicators?

14. How would a fee associated with participating in this program influence your decision to pursue certification?

a. Probe: Is there a general range of how much you would be willing to pay annually?

b. Probe: Who do you believe should pay for the administration of the program?

15. Are you aware of the Airbnb environmental impacts of home sharing report published in 2014? yes/no

Closing remarks:

Those are all the questions, thank you again for participating. Do you have any other comments or questions you would like to ask me before ending the interview? 


\section{Appendix B: Certification Program Handout}

\section{Typical elements of an environmental certification program:}

- Voluntary

○ There is no penalty for not joining and organizations are free to join or leave membership as they see fit. Pursuing certification however may require financial investments to improve the environmental performance of the property.

- Standards

- The standard is typically a list of criteria that must be met in order to qualify for certification. These can include commitments across a variety of environmental criteria such as water conservation, energy conservation, and waste. A property may already be meeting these criteria or may require financial investments to ensure criteria is met.

- Assessment/ Certification

○ This is the process by which an organization is evaluated for their conformance to the standard. This is typically either done through a self-assessment, second-party or third-party assessment. Self-assessment is when an individual or organization declares their conformance to the standards; in this case of Airbnb self-assessment would be done by the host. Second-party assessment is when an organization that is offering a product assesses the suppliers of that product so that they can ensure to their customers that the product meets the standards; in the case of Airbnb the assessment would be done by Airbnb itself. Third-party assessment is done by someone not affiliated to organization or individual; in the case of Airbnb this would be done by some type of auditor not affiliated with Airbnb or the host. Once this is complete, certification is the provision of documented assurance that a product meets the standards. This certification can take a number of forms from pass/ fail system to a graded system.

- Recognition

- Recognition is the acknowledgment of an organizations certification, usually through the awarding of some type of logo that signals to consumers that the property has met the required environmental standards.

Examples:
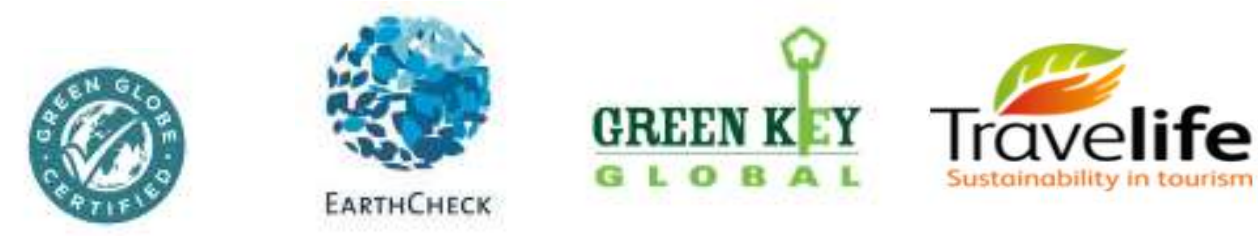


\section{Typical categories of an environmental certification program:}

\begin{tabular}{|c|c|c|}
\hline Criteria & Description & Examples \\
\hline $\begin{array}{l}\text { Local } \\
\text { purchasing }\end{array}$ & $\begin{array}{l}\text { Purchasing policies favor locally appropriate } \\
\text { and ecologically sustainable products, } \\
\text { including food, beverages and consumables. }\end{array}$ & - Purchasing food from local farmers \\
\hline $\begin{array}{l}\text { Disposable } \\
\text { goods }\end{array}$ & $\begin{array}{l}\text { The purchase and use of disposable and } \\
\text { consumable goods is measured and the host } \\
\text { actively seeks ways to reduce their use. }\end{array}$ & $\begin{array}{l}\text { - Using larger toiletry packages as opposed to } \\
\text { single-use items (e.g., shampoo) } \\
\text { - Providing coffee maker or French press } \\
\text { instead of coffee pods }\end{array}$ \\
\hline $\begin{array}{l}\text { Energy } \\
\text { conservation }\end{array}$ & $\begin{array}{l}\text { Energy consumption is monitored and } \\
\text { measures are adopted to minimize overall } \\
\text { consumption, and encourage the use of } \\
\text { renewable energy. }\end{array}$ & $\begin{array}{l}\text { - Requesting that customers use appliances at } \\
\text { off-peak hours } \\
\text { - Using renewable energy (e.g., Bullfrog } \\
\text { power) }\end{array}$ \\
\hline $\begin{array}{l}\text { Water } \\
\text { conservation }\end{array}$ & $\begin{array}{l}\text { Water consumption is monitored and measures } \\
\text { are adopted to minimize overall consumption. }\end{array}$ & $\begin{array}{l}\text { - Installing water efficient bathroom fixtures } \\
\text { (e.g., faucet, showerheads) }\end{array}$ \\
\hline $\begin{array}{l}\text { Transport } \\
\text { greenhouse } \\
\text { gas emissions }\end{array}$ & $\begin{array}{l}\text { The individual encourages its customers to } \\
\text { reduce transportation-related greenhouse gas } \\
\text { emissions. }\end{array}$ & $\begin{array}{l}\text { Recommending use of public transit over } \\
\text { driving } \\
\text { Providing information regarding public } \\
\text { transit }\end{array}$ \\
\hline Waste & $\begin{array}{l}\text { Waste is monitored and mechanisms are in } \\
\text { place to reduce waste, and where reduction is } \\
\text { not feasible, to re-use or recycle it. }\end{array}$ & $\begin{array}{l}\text { - Promoting use of recycling bin and green bin } \\
\text { (composting) }\end{array}$ \\
\hline $\begin{array}{l}\text { Harmful } \\
\text { substances }\end{array}$ & $\begin{array}{l}\text { The use of harmful substances, including } \\
\text { pesticides, paints, swimming pool disinfectants, } \\
\text { and cleaning materials, is minimized, and } \\
\text { substituted when available, by innocuous } \\
\text { products or processes. All storage, use, } \\
\text { handling, and disposal of chemicals are } \\
\text { properly managed. }\end{array}$ & $\begin{array}{l}\text { - Purchasing and promoting use of } \\
\text { environmentally friendly cleaning products } \\
\text { and laundry detergent }\end{array}$ \\
\hline Alien Species & $\begin{array}{l}\text { The host takes measures to avoid the } \\
\text { introduction of invasive alien species. Native } \\
\text { species are used for landscaping wherever } \\
\text { feasible, particularly in natural landscapes. }\end{array}$ & $\begin{array}{l}\text { - Substituting foreign species with native } \\
\text { species in gardens }\end{array}$ \\
\hline
\end{tabular}




\section{Appendix C: Recruitment Tools}

\section{Figure C1: Request for Participation}

Hello,

Ryerson

University

My name is Geoffrey Fudurich and I am a graduate student at Ryerson University in the Environmental Applied Science and Management program. I am contacting you to see if you might be interested in participating in a research study for my thesis about exploring the opportunity for an environmental certification program for Airbnb homeowner hosts. Environmental certification is a voluntary process through which a business receives recognition for demonstrating environmental commitment in their business activities. Please note that no prior knowledge of the topic of environmental certification is required to participate in this research.

This research is being done as part of my Master's thesis and my supervisor's name is Dr. Kelly MacKay, Associate Dean Research and Graduate Programs in the Ted Rogers School of Management. The research is being done independently as part of my thesis and is in no way affiliated with Airbnb or any other third party organization.

To participate you need to be an Airbnb host whose property is a stand-alone home (e.g., not a condominium or apartment), and who owns their Airbnb property. You must also be the individual responsible for managing your Airbnb property (i.e. you are the decision maker regarding how the home is presented to Airbnb guests and you are the main point of contact for the guests).

If you agree to volunteer, you will be asked to participate in a one on one interview with the researcher. The interview will last approximately 30 minutes and can take place at a time and location of your choosing, so long as it is in a public location (e.g., coffee shop, public park, etc.).

Your participation will involve participating in one session and answering questions related to your interest in and perceptions towards an environmental certification program for your Airbnb property(ies). In appreciation of your time, you will receive a \$10 Starbucks gift card.

Your participation is completely voluntary and if you choose not to participate it will not impact your relationship with the researcher, or Ryerson University. Upon completion of the research project a summary of findings will be provided via email to you if you wish to receive them.

The research has been approved by the Ryerson University Research Ethics Board.

If you are interested in more information about the study or would like to volunteer, please contact gfudurich@ryerson.ca. 
Figure C2: Recruitment Flyer

\section{Ryerson}

University

\section{AIRBNB HOSTS NEEDED FOR RESEARCH IN ENVIRONMENTAL CERTIFICATION}

Looking for:

- $\quad$ Airbnb hosts in the Greater Toronto Area

- $\quad$ Airbnb hosts that rent part or all of a house or townhouse (i.e. not condominiums)

If you answered yes to the above noted questions you are invited to volunteer in this study exploring the opportunity for an environmental certification program for Airbnb homeowner hosts. Environmental certification is a voluntary process through which a business receives recognition for demonstrating environmental commitment in their business activities. Please note that no prior knowledge of the topic of environmental certification is required to participate in this research.

You will be asked to participate in an approximately 30 minute interview either in person or over the phone.

In appreciation of your time, you will receive a $\$ 10$ Starbucks gift card.

The research is being done independently as part of a master's thesis and is in no way affiliated with Airbnb or any other third party organization.

If you are interested in participating in this study or would like more information, please contact:

Geoffrey Fudurich

Email: gfudurich@ryerson.ca

Or scan the QR code to draft an email indicating

your interest in participating

(option to add message

before sending)

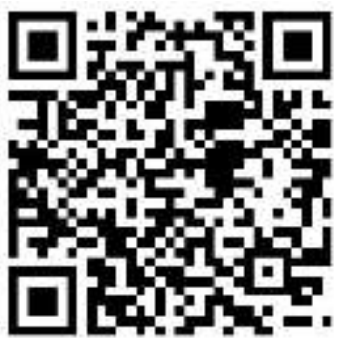

This research study has been reviewed and approved by the Ryerson University Research Ethics Board. 


\section{Appendix D: Secondary Data Analysis Results}

Table D1: Airbnb Forum Extract

\begin{tabular}{|c|c|c|c|c|c|c|}
\hline $\begin{array}{l}\text { Author } \\
\text { Name }\end{array}$ & $\begin{array}{l}\text { Search } \\
\text { term }\end{array}$ & Forum & $\begin{array}{l}\text { Posting/ } \\
\text { comment }\end{array}$ & Post title & Code & Link \\
\hline $\begin{array}{l}\text { Mick } \\
\& \\
\text { Pamela }\end{array}$ & Green & Host voice & Posting & $\begin{array}{l}\text { Add a "Green" } \\
\text { Rating! }\end{array}$ & $\begin{array}{l}\text { Environmental } \\
\text { hosting }\end{array}$ & $\begin{array}{l}\text { https://community.withairbnb.com/t5/ } \\
\text { Host-Voice/Add-a-quot-Green-quot- } \\
\text { Rating/idi-p/163038 }\end{array}$ \\
\hline Ian & Green & Host voice & Posting & $\begin{array}{l}\text { Encourage hosts } \\
\text { and guests to be } \\
\text { more green }\end{array}$ & $\begin{array}{l}\text { Environmental } \\
\text { hosting }\end{array}$ & $\begin{array}{l}\text { https://community.withairbnb.com/t5/ } \\
\text { Host-Voice/Encourage-hosts-and-guests } \\
\text {-to-be-more-green/idi-p/162306 }\end{array}$ \\
\hline Ian* & Green & Host voice & Comment & $\begin{array}{l}\text { Multiple Badges of } \\
\text { all types }\end{array}$ & $\begin{array}{l}\text { Environmental } \\
\text { hosting }\end{array}$ & $\begin{array}{l}\text { https://community.withairbnb.com/t5/ } \\
\text { Host-Voice/Multiple-Badges-of-all- } \\
\text { types/idi-p/162221 }\end{array}$ \\
\hline Juliet & Green & Host voice & Posting & multiple & $\begin{array}{l}\text { Environmental } \\
\text { hosting }\end{array}$ & $\begin{array}{l}\text { https://community.withairbnb.com/t5/ } \\
\text { Host-Voice/multiple/idi-p/161977 }\end{array}$ \\
\hline Kika & Green & Host voice & Posting & $\begin{array}{l}\text { Making the Airbnb } \\
\text { Brand Greener! }\end{array}$ & $\begin{array}{l}\text { Guest } \\
\text { behaviour }\end{array}$ & $\begin{array}{l}\text { https://community.withairbnb.com/t5/ } \\
\text { Host-Voice/Making-the-Airbnb-Brand- } \\
\text { Greener/idi-p/374567 }\end{array}$ \\
\hline $\begin{array}{l}\text { Mick } \\
\& \\
\text { Pamela }\end{array}$ & Eco & Host voice & Posting & $\begin{array}{l}\text { Filter for Eco- } \\
\text { friendly/chemically } \\
\text { sensitive people }\end{array}$ & $\begin{array}{l}\text { Chemical/ } \\
\text { fragrance } \\
\text { sensitivity } \\
\text { filter }\end{array}$ & $\begin{array}{l}\text { https://community.withairbnb.com/t5/Host- } \\
\text { Voice/Filter-for-Eco-friendly-chemically- } \\
\text { sensitive-people/idi-p/162941 }\end{array}$ \\
\hline Donna & Eco & New hosts & Posting & $\begin{array}{l}\text { How can I list, and } \\
\text { find other, } \\
\text { chemical-free, } \\
\text { environmentally- } \\
\text { safe apartments? }\end{array}$ & $\begin{array}{l}\text { Chemical/ } \\
\text { fragrance } \\
\text { sensitivity } \\
\text { filter }\end{array}$ & $\begin{array}{l}\text { https://community.withairbnb.com/t5/ } \\
\text { New-Hosts/How-can-I-list-and-find- } \\
\text { other-chemical-free-environmentally- } \\
\text { safe/m-p/62045/highlight/true\#M6656 }\end{array}$ \\
\hline Henry & Eco & Hosts & Posting & $\begin{array}{l}\text { Sustainability } \\
\text { Awards }\end{array}$ & $\begin{array}{l}\text { Environmental } \\
\text { hosting }\end{array}$ & $\begin{array}{l}\text { https://community.withairbnb.com/t5/ } \\
\text { Hosts/Sustainability-Awards/m- } \\
\text { p/62272/highlight/true\#M16733 }\end{array}$ \\
\hline Asi & Environment & $\begin{array}{l}\text { Community } \\
\text { help }\end{array}$ & Posting & $\begin{array}{l}\text { An Airbnb } \\
\text { Environment Club! }\end{array}$ & $\begin{array}{l}\text { Environmental } \\
\text { hosting }\end{array}$ & $\begin{array}{l}\text { https://community.withairbnb.com/t5/ } \\
\text { Community-Help/An-Airbnb- } \\
\text { Environment-Club/m-p/124746\#M6226 }\end{array}$ \\
\hline Angela & Environment & $\begin{array}{l}\text { Community } \\
\text { help }\end{array}$ & Comment & $\begin{array}{l}\text { An Airbnb } \\
\text { Environment Club! }\end{array}$ & $\begin{array}{l}\text { Environmental } \\
\text { hosting }\end{array}$ & $\begin{array}{l}\text { https://community.withairbnb.com/t5/ } \\
\text { Community-Help/An-Airbnb- } \\
\text { Environment-Club/m-p/124746\#M6226 }\end{array}$ \\
\hline $\begin{array}{l}\text { Tiffany } \\
\text { and } \\
\text { Paul }\end{array}$ & Environment & Hosts & Posting & $\begin{array}{l}\text { We are a lush and } \\
\text { "green" } \\
\text { environment ... are } \\
\text { there any } \\
\text { designations that } \\
\text { help promote that? }\end{array}$ & $\begin{array}{l}\text { Environmental } \\
\text { hosting }\end{array}$ & $\begin{array}{l}\text { https://community.withairbnb.com/t5/ } \\
\text { Hosts/We-are-a-lush-and-quot-green-quot- } \\
\text { environment-are-there-any/m- } \\
\text { p/90422/highlight/true\#M28145 }\end{array}$ \\
\hline Casdell & Environment & Hosts & Posting & $\begin{array}{l}\text { Energy efficiency - } \\
\text { remind guests to } \\
\text { switch off lights }\end{array}$ & $\begin{array}{l}\text { Guest } \\
\text { behaviour }\end{array}$ & $\begin{array}{l}\text { https://community.withairbnb.com/t5/ } \\
\text { Hosts/Energy-efficiency-remind-guests } \\
\text {-to-switch-off-lights/m- } \\
\text { p/355583/highlight/true\#M80744 }\end{array}$ \\
\hline Mala & Environment & Hosts & Posting & Wasteful guest & $\begin{array}{l}\text { Guest } \\
\text { behaviour }\end{array}$ & $\begin{array}{l}\text { https://community.withairbnb.com/t5/ } \\
\text { Hosts/Wasteful-guest/m- } \\
\text { p/44952/highlight/true\#M12214 }\end{array}$ \\
\hline $\begin{array}{l}\text { Karsten } \\
\& \\
\text { Venus }\end{array}$ & Environment & New hosts & Posting & conserving energy & $\begin{array}{l}\text { Guest } \\
\text { behaviour }\end{array}$ & $\begin{array}{l}\text { https://community.withairbnb.com/t5/ } \\
\text { New-Hosts/conserving-energy/m- } \\
\text { p/202895/highlight/true\#M19247 }\end{array}$ \\
\hline
\end{tabular}




\begin{tabular}{|l|l|l|l|l|l|l|}
\hline $\begin{array}{l}\text { Melissa } \\
\text { \& Kurt }\end{array}$ & Environment & Host voice & Posting & $\begin{array}{l}\text { Allergen free } \\
\text { homes }\end{array}$ & $\begin{array}{l}\text { Chemical/ } \\
\text { fragrance } \\
\text { sensitivity } \\
\text { filter }\end{array}$ & $\begin{array}{l}\text { https://community.withairbnb.com/t5/ } \\
\text { Host-Voice/Allergen-free-homes/idi- } \\
\text { p/162399 }\end{array}$ \\
\hline
\end{tabular}

*removed from analysis as comment was duplicate of author's posting

Table D2: Airbnb Listings Extract

\begin{tabular}{|c|c|c|c|c|}
\hline $\begin{array}{l}\text { Host } \\
\text { name }\end{array}$ & Summary & $\begin{array}{l}\text { Property } \\
\text { type }\end{array}$ & $\begin{array}{l}\text { Keyword } \\
\text { Category }\end{array}$ & $\begin{array}{l}\text { Keyword } \\
\text { priority }\end{array}$ \\
\hline Mena & $\begin{array}{l}\text { Large room in a calm, peaceful and safe neighbourhood. } \\
\text { Nice and green view. } \\
\text { Close to airport, Hyways, amenities, public transportation }\end{array}$ & $\begin{array}{l}\text { Private } \\
\text { room }\end{array}$ & $\begin{array}{l}\text { Green } \\
\text { (Greenspace) }\end{array}$ & Medium \\
\hline Sarah & $\begin{array}{l}\text { Large room, with queen bed \&amp; a walk out to a large backyard } \\
\text { surrender by a green space, park and trails. On main floor of a side split. } \\
\text { Loads of light \&amp; closet space for longer stays. In a very clean, warm } \\
\text { working class family home. Option for dinner }\end{array}$ & $\begin{array}{l}\text { Private } \\
\text { room }\end{array}$ & $\begin{array}{l}\text { Green } \\
\text { (Greenspace) }\end{array}$ & Medium \\
\hline Lisa & $\begin{array}{l}\text { Females pls. Males ok long term. Private large room. Access to semi } \\
\text { private bathroom. Kitchen and big green backyard with BBQ. large and } \\
\text { furnished, faces all day sun with large window. Bed, lamp, desk, chair, } \\
\text { closet, and armoire dresser. Great Wifi. }\end{array}$ & $\begin{array}{l}\text { Private } \\
\text { room }\end{array}$ & $\begin{array}{l}\text { Green } \\
\text { (Greenspace) }\end{array}$ & Medium \\
\hline Kiki & $\begin{array}{l}\text { Single bed in a lovely sun room, lots of greenery, in a cozy apartment. } \\
\text { Steps away from the Queen and King street car and easy access to the } \\
\text { Subway. } \\
10 \text { min walk to the lake and to High Park. Shared kitchen and bathroom, } \\
\text { with myself and my cat. }\end{array}$ & $\begin{array}{l}\text { Private } \\
\text { room }\end{array}$ & $\begin{array}{l}\text { Green } \\
\text { (Greenspace) }\end{array}$ & High \\
\hline Inger & $\begin{array}{l}\text { Zen Greenhouse Studio Sous-Terre, (basement) with } 30 \text { plants. High } \\
\text { ceilings, slate and quartz lights, walk-in two person shower with heat } \\
\text { lamp, chaise longues, full kitchen, queen bed, organic and linen sheets } \\
\text { from France. Sweet zen silent art studio. }\end{array}$ & $\begin{array}{l}\text { Entire } \\
\text { home/apt }\end{array}$ & $\begin{array}{l}\text { Green } \\
\text { (Greenspace) }\end{array}$ & High \\
\hline Rebecca & $\begin{array}{l}\text { Perfectly located on a small residential street, next to the bustling energy } \\
\text { of Parkdale and Ronces Village. All amenities nearby. Enjoy a well- } \\
\text { equipped kitchen and access to a front porch adorned with greenery, } \\
\text { amazing during Toronto thunderstorms. }\end{array}$ & $\begin{array}{l}\text { Entire } \\
\text { home/apt }\end{array}$ & $\begin{array}{l}\text { Green } \\
\text { (Greenspace) }\end{array}$ & Medium \\
\hline Jallan & $\begin{array}{l}\text { I love the natural light and the greenery that surrounds me. I feel like I'm } \\
\text { in the quiet suburbs but I'm in the urban city. }\end{array}$ & $\begin{array}{l}\text { Entire } \\
\text { home/apt }\end{array}$ & $\begin{array}{l}\text { Green } \\
\text { (Greenspace) }\end{array}$ & High \\
\hline Not listed & $\begin{array}{l}\text { Original Loblaws store in the heart of one of the coolest creative } \\
\text { neighbourhoods in Toronto. Great restaurants and cafes all around you. } \\
2000 \text { sqft. }+3000 \text { sqft green roof garden }+ \text { chef's kitchen }+ \text { dining room. } \\
\text { Loft queen bedroom + double bedroom + couches for up to } 3 \text { more quests. } \\
2 \text { full bathrooms with tubs. }\end{array}$ & $\begin{array}{l}\text { Entire } \\
\text { home/apt }\end{array}$ & $\begin{array}{l}\text { Green } \\
\text { (Greenspace) }\end{array}$ & Medium \\
\hline Dara & $\begin{array}{l}\text { Queen West Trinity Bellwoods Park } 2 \text { story loft }+ \text { bedroom/den } \\
\text { apartment. } \\
\text { Large deck, courtyard green space, laundry, A/C. Great restaurants, cafes, } \\
\text { shopping and parks, public transportation, and easy highway access. }\end{array}$ & $\begin{array}{l}\text { Entire } \\
\text { home/apt }\end{array}$ & $\begin{array}{l}\text { Green } \\
\text { (Greenspace) }\end{array}$ & Medium \\
\hline Enrico M & $\begin{array}{l}\text { Located on a quiet midtown residential street but close to both bus ( } 1 \text { min } \\
\text { walk) and subway ( } 7 \text { min bus ride) to connect you to down/uptown. Self- } \\
\text { contained with amenities including a jacuzzi, equipped kitchen, laundry, } \\
\text { access to your own green space. }\end{array}$ & $\begin{array}{l}\text { Entire } \\
\text { home/apt }\end{array}$ & $\begin{array}{l}\text { Green } \\
\text { (Greenspace) }\end{array}$ & Low \\
\hline Lisa & $\begin{array}{l}\text { Boutique art cottage nestled in downtown Toronto with view of CN } \\
\text { Tower. Steps to the Art Gallery of Ontario, OCAD, Queen Street West } \\
\text { and Kensington Market in Chinatown. Green friendly space! }\end{array}$ & $\begin{array}{l}\text { Entire } \\
\text { home/apt }\end{array}$ & Green & Low \\
\hline
\end{tabular}




\begin{tabular}{|c|c|c|c|c|}
\hline $\begin{array}{l}\text { Lucy \& } \\
\text { Ambroise }\end{array}$ & $\begin{array}{l}\text { A cozy apt in a green building. Cot for toddler available. } \\
\text { Dynamic neighbourhood: Charming shops \&amp; cafÃ } \odot \text {. Close to } \\
\text { restaurants, grocers, bars, library, movie theatres \&amp; pharmacy. } 3 \text { min } \\
\text { to Eglinton subway station. Please note we don't have a TV. }\end{array}$ & $\begin{array}{l}\text { Entire } \\
\text { home/apt }\end{array}$ & Green & High \\
\hline Matt & $\begin{array}{l}\text { Two bedroom space on main floor. Each has locked entrance. Full kitchen } \\
\text { with your own cutlery, dishes and cookware. First floor bathroom with } \\
\text { own towels, shampoo and soap. We offer wifi access, umbrellas and a } \\
\text { school locker w/ lock. Green friendly }\end{array}$ & $\begin{array}{l}\text { Private } \\
\text { room }\end{array}$ & Green & Low \\
\hline Matt & $\begin{array}{l}\text { Main floor of our green friendly home has a guest only entrance, } \\
\text { bathroom, kitchen \&amp; private room with lock. Guest only towels, } \\
\text { cutlery, dishes \&amp; linens. Fantastic transit to Toronto shopping } \\
\text { \&amp; tourist attractions in foodie destination Corso Italia }\end{array}$ & $\begin{array}{l}\text { Private } \\
\text { room }\end{array}$ & Green & High \\
\hline Kim & $\begin{array}{l}\text { One block from Trendy Queen West shops and restaurants our home } \\
\text { offers a quiet green oasis in the city. This is an unique artistic home; great } \\
\text { for hosting and relaxing. Back garden, romantic loft and modernist Living } \\
\text { / Kitchen space. }\end{array}$ & $\begin{array}{l}\text { Entire } \\
\text { home/apt }\end{array}$ & Green & Medium \\
\hline Etai & $\begin{array}{l}\text { 10th floor, } 750 \mathrm{sq} / \mathrm{ft} \text {, quiet, green, next to park on Yonge subway line } \\
\text { and minutes to downtown. } \\
\text { HD TV cable , high speed internet, } \\
\text { huge balcony with beautiful view all the way to lake ontario }\end{array}$ & $\begin{array}{l}\text { Entire } \\
\text { home/apt }\end{array}$ & Green & High \\
\hline Reza & $\begin{array}{l}\text { 750 SQF 9'Ceiling, Green Roof Canopy, Enhanced Window W/ Thermal } \\
\text { Protection And } 24 \text { Hour Concierge, Fitness, Yoga, Spa, Aerobic, Bbq, In } \\
\text { floor Pool, Hot Tub Business Centre, Board \&amp; Party Rooms, On-Site } \\
\text { Longo's Grocery. }\end{array}$ & $\begin{array}{l}\text { Entire } \\
\text { home/apt }\end{array}$ & Green & High \\
\hline Kristi & $\begin{array}{l}\text { This Riverdale 3rd floor beauty includes the use of the 1st floor and back } \\
\text { deck. High ceilings, screened windows. The owner is a musician and has a } \\
\text { green thumb. It is close to Queen street shops and restaurants as well as } \\
\text { Greektown on the Danforth. }\end{array}$ & $\begin{array}{l}\text { Private } \\
\text { room }\end{array}$ & Green & Medium \\
\hline Steve & $\begin{array}{l}\text { South facing room on the second floor. Three bathrooms. You are also } \\
\text { welcome to share our vegetarian kitchen, porch, yoga room, roof deck and } \\
\text { infrared cedar sauna. We are an eco-friendly 9-person community house } \\
\text { on a quiet street close to the subway. }\end{array}$ & $\begin{array}{l}\text { Private } \\
\text { room }\end{array}$ & Eco & Medium \\
\hline Murr & $\begin{array}{l}\text { This condo is a delight to live in! It's brand new- right at Yonge and } \\
\text { Sheppard, right in front of the subway and Whole Foods! The place is } \\
\text { lightly furnished and eco friendly with recycling, composting and no } \\
\text { household chemicals. Two bedrooms available and wifi! Washer and } \\
\text { Dryer on site! }\end{array}$ & $\begin{array}{l}\text { Entire } \\
\text { home/apt }\end{array}$ & Eco & Medium \\
\hline Murr & $\begin{array}{l}\text { This condo is a delight to live in! It's brand new- right at Yonge and } \\
\text { Sheppard, right in front of the subway and Whole Foods! The place is } \\
\text { lightly furnished and eco friendly with recycling, composting and no } \\
\text { household chemicals. Two bedrooms available and wifi! Washer and } \\
\text { Dryer on site! }\end{array}$ & $\begin{array}{l}\text { Private } \\
\text { room }\end{array}$ & Eco & Medium \\
\hline Andrea & $\begin{array}{l}\text { clean.comfy.cozy.quiet.boho/rustic style.eco-friendly.well-equipped } \\
\text { kitchen.tons of natural light.view of willow tree + lake. } 24 / 7 \text { public transit } \\
\text { out front-15min to High Park/20 to Ronces+Queen W/20 to subway.5min } \\
\text { walk to beautiful lakeshore trail. }\end{array}$ & $\begin{array}{l}\text { Entire } \\
\text { home/apt }\end{array}$ & Eco & Medium \\
\hline Christian & $\begin{array}{l}\text { Loft style junior one bedroom located on a quiet street just steps from } \\
\text { down town. Newly constructed low rise building with eco friendly } \\
\text { polished concrete floors and exposed duct work. Centrally located in the } \\
\text { down town area. } \\
\text { Please, read the details }\end{array}$ & $\begin{array}{l}\text { Entire } \\
\text { home/apt }\end{array}$ & Eco & Medium \\
\hline
\end{tabular}




\begin{tabular}{|c|c|c|c|c|}
\hline Emma & $\begin{array}{l}\text { Eco friendly space. Bus station is in front of house. direct bus to bloor } \\
\text { /high park station. House is fully furnished with water purifier. Karma } \\
\text { Exchange = Keep place clean with good vibe + Share your Dream of } \\
\text { profession }(1-2 \mathrm{~h})=\text { appreciation }\end{array}$ & $\begin{array}{l}\text { Private } \\
\text { room }\end{array}$ & Eco & High \\
\hline Sandra & $\begin{array}{l}\text { Fantastic location in a great area in a renovated Eco House! Breathe fresh } \\
\text { air while sleeping quietly in the most comfy bed that you can imagine. } \\
\text { Our place is small but beautiful. Enjoy the culinary delights of our area. } \\
\text { Accessible to downtown. }\end{array}$ & $\begin{array}{l}\text { Entire } \\
\text { home/apt }\end{array}$ & Eco & Medium \\
\hline Steve & $\begin{array}{l}\text { Heated cabin includes a sleep loft, toaster oven, kettle. Inside the house } \\
\text { are } 3 \text { shared bathrooms, a veggie kitchen, yoga room, roof deck and } \\
\text { infrared sauna. We are an eco-friendly 8-person community house on a } \\
\text { quiet street close to the subway. }\end{array}$ & $\begin{array}{l}\text { Private } \\
\text { room }\end{array}$ & Eco & Medium \\
\hline Mayte & $\begin{array}{l}\text { An environmentally friendly house with big gardens, lots of light, and } \\
\text { with clean and welcoming rooms. } \\
\text { There is a piano in the house waiting for you! } \\
\text { Two lovely cats will cheer you up! } \\
\text { Great neighbourhood! } \\
\text { Come and enjoy beautiful Toronto! }\end{array}$ & $\begin{array}{l}\text { Private } \\
\text { room }\end{array}$ & Environment & High \\
\hline Mayte & $\begin{array}{l}\text { An environmentally friendly house with big gardens, lots of light, and } \\
\text { with clean and welcoming rooms. } \\
\text { There is a piano in the house waiting for you! } \\
\text { Two lovely cats will cheer you up! } \\
\text { Great neighbourhood! } \\
\text { Come and enjoy beautiful Toronto! }\end{array}$ & $\begin{array}{l}\text { Private } \\
\text { room }\end{array}$ & Environment & High \\
\hline Mayte & $\begin{array}{l}\text { An environmentally friendly house with big gardens, lots of light, and } \\
\text { with clean and welcoming rooms. } \\
\text { There is a piano in the house waiting for you! } \\
\text { Two lovely cats will cheer you up! } \\
\text { Great neighbourhood! } \\
\text { Come and enjoy beautiful Toronto! }\end{array}$ & $\begin{array}{l}\text { Private } \\
\text { room }\end{array}$ & Environment & High \\
\hline
\end{tabular}




\section{Figure D1: Sample Airbnb Listing}

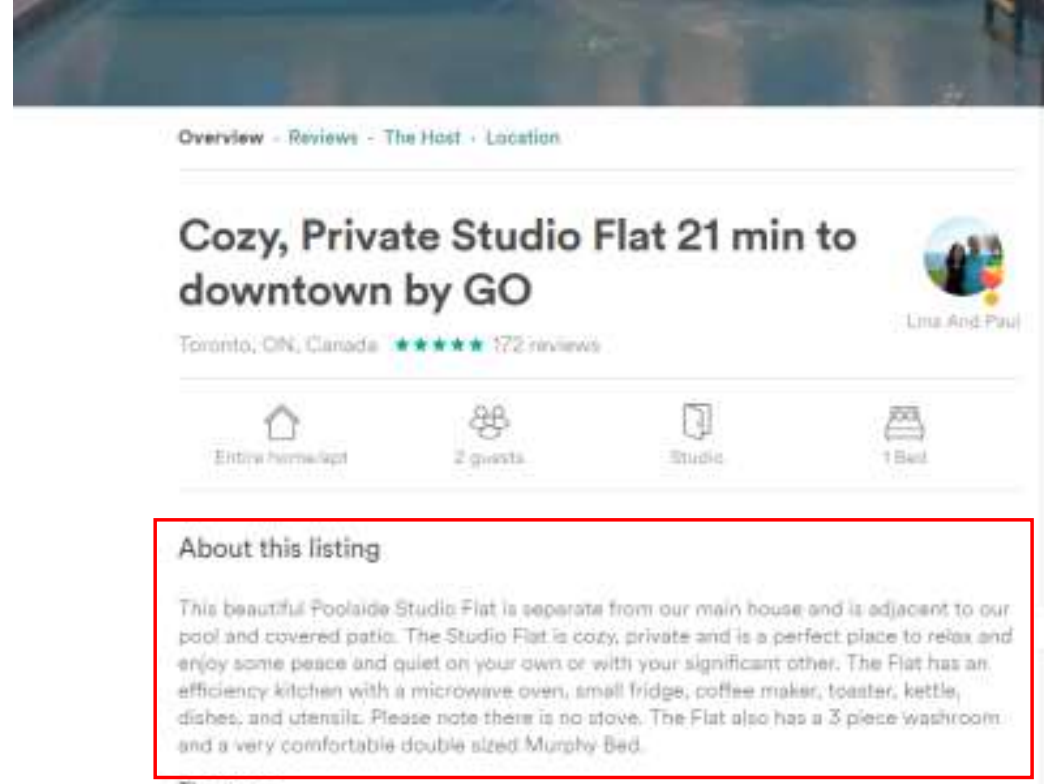

\\$75 CAD per night

Check in Chock Out

dd-mm-xyy dd-minyoy

Buesta

1ouet

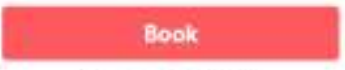

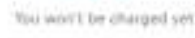

This boose is an people's minds.

in wees viewad 500 + lithes in

the pait woee

The space

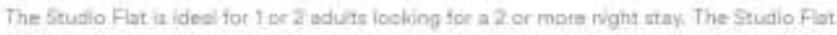
is limited to sduits ony and is not sibitoble for thildres: 


\section{Appendix E: Interview Results}

Table E1: Host profile

\begin{tabular}{|r|l|l|l|l|l|}
\hline $\begin{array}{l}\text { Participant } \\
\text { Number }\end{array}$ & Pseudonym & Superhost & Frequency & Property details & $\begin{array}{l}\text { Experience as } \\
\text { an Airbnb host } \\
\text { approximately) }\end{array}$ \\
\hline 1 & Rob & No & Part-time & Entire home & 4 months \\
\hline 2 & Mary & No & Part-time & Entire home & 6 months \\
\hline 3 & Hannah & Yes & Full-time & Private room & Over 3 years \\
\hline 4 & Rachel & No & Part-time & Private room & Over 2 years \\
\hline 5 & Mike & No & $\begin{array}{l}\text { Full-time - property } \\
\text { manager }\end{array}$ & Entire home & 6 months \\
\hline 6 & Sarah & No & Part-time & Entire home & Over 3 years \\
\hline 7 & Will & Yes & $\begin{array}{l}\text { Full-time - property } \\
\text { manager }\end{array}$ & Entire home & 2 years \\
\hline 8 & Peter & Yes & Full-time & Entire home & 1 year \\
\hline 9 & Greg & No & Part-time & Entire home & 2 - 3 years \\
\hline 10 & Alex & Yes & Full-time & Entire home & 3 years \\
\hline 11 & Katie & Yes & Full-time & $\begin{array}{l}\text { Both entire home } \\
\text { and private room }\end{array}$ & 1 year \\
\hline 12 & Heather & Yes & Full-time & Private room & Over 3 years \\
\hline 13 & Caitlin & Yes & Full-time & Entire home & 6 months \\
\hline 14 & Jane & Yes & $\begin{array}{l}\text { Full-time - host and } \\
\text { property manager }\end{array}$ & Private room & Over 6 years \\
\hline
\end{tabular}

Table E2: Reasons for joining Airbnb by frequency

\begin{tabular}{|l|r|l|}
\hline Category & Count & Example excerpt \\
\hline Financial & 12 & Alex: "well um, the revenue" \\
\hline Comfort & 7 & $\begin{array}{l}\text { Greg: "um, well, I guess the first thing is I heard of friend's doing } \\
\text { it, and it sounded like quite a neat idea." }\end{array}$ \\
\hline Home-sharing & 5 & $\begin{array}{l}\text { Heather: "So when I heard about Airbnb I thought wow this } \\
\text { would be kind of fun, we could try this out and see how it goes, } \\
\text { we have this really nice room that's not being used and it would } \\
\text { be nice to offer it to people. So we did that and never looked } \\
\text { back." }\end{array}$ \\
\hline Hosting & 5 & $\begin{array}{l}\text { Caitlin: "I do love hosting, so I like interacting with people I like } \\
\text { meeting them there, I like setting up the place, so I really like } \\
\text { that. I started using Airbnb about four years ago and the host idea } \\
\text { came very quickly" }\end{array}$ \\
\hline
\end{tabular}


Table E3: Summary of frequency of motivations

\begin{tabular}{|l|l|l|l|l|}
\hline Motivation & \multicolumn{2}{l|}{ Motivations for "yes" } & \multicolumn{2}{l|}{$\begin{array}{l}\text { Motivations for } \\
\text { "depends" }\end{array}$} \\
\hline & Primary & Secondary & Primary & Secondary \\
\hline Personal values & 8 & 2 & & 1 \\
\hline Commercial benefits & 8 & & 2 & \\
\hline $\begin{array}{l}\text { Ability to attract like-minded } \\
\text { guests }\end{array}$ & 3 & & & \\
\hline $\begin{array}{l}\text { Household environmental } \\
\text { impacts }\end{array}$ & 1 & 1 & & 1 \\
\hline $\begin{array}{l}\text { Recognition of environmental } \\
\text { commitment }\end{array}$ & 2 & & & \\
\hline
\end{tabular}

Table E4: Barriers to program participation

\begin{tabular}{|l|l|l|}
\hline Barriers & Participants & Total Mentions \\
\hline Cost & $1,2,6,8,9,10,14$ & 7 \\
\hline Time commitment & 2,11 & 2 \\
\hline Credibility & 10,13 & 2 \\
\hline Rigour of standards & 1,6 & 2 \\
\hline Trade-offs with comfort & 2 & 1 \\
\hline
\end{tabular}

Table E5: Willingness to allow guest reviews of environmental initiatives

\begin{tabular}{|l|l|l|}
\hline $\begin{array}{l}\text { Willing to have guest } \\
\text { reviews on environmental } \\
\text { features? }\end{array}$ & Participants & Total \\
\hline Yes & $\begin{array}{l}1,3,4,5,7,8,9,10,11, \\
12,13,14\end{array}$ & 12 \\
\hline Unsure (subjectivity) & 2,6 & 2 \\
\hline
\end{tabular}

Table E6: Willing to engage guests regarding environmental features

\begin{tabular}{|l|l|l|}
\hline Guest engagement & Participants & Total \\
\hline Already doing & $3,4,6,8,9,11,13,14$ & 8 \\
\hline Willing to do & $1,2,5,7,12$ & 5 \\
\hline Not willing to do & 10 & 1 \\
\hline
\end{tabular}

Table E7: Participant preference for type of certification

\begin{tabular}{|l|l|l|}
\hline $\begin{array}{l}\text { Type of Certification } \\
\text { Preference }\end{array}$ & Participants & Total \\
\hline Levels & $\begin{array}{l}1,3,4,5,7,8,9,12,13, \\
14\end{array}$ & 10 \\
\hline Pass/ fail & 10 & 1 \\
\hline Unsure/ other considerations & $2,6,11$ & 3 \\
\hline
\end{tabular}




\section{Appendix F: Example of Qualitative Data Coding}

\begin{tabular}{|c|c|c|c|}
\hline Participant & $\begin{array}{l}\text { Motivation } \\
\text { (barrier) } \\
\text { code }\end{array}$ & Excerpt & $\begin{array}{l}\text { Primary vs. } \\
\text { Secondary }\end{array}$ \\
\hline \multirow[t]{3}{*}{ Rob } & $\begin{array}{l}\text { Household } \\
\text { environmental } \\
\text { impacts }\end{array}$ & \multirow{2}{*}{$\begin{array}{l}\text { "I think obviously it's something that a, I would like } \\
\text { to do for my own house just to make sure it's energy } \\
\text { efficient, and environmentally friendly, but that also, } \\
\text { like if you can use that as a marketing tool to stand } \\
\text { out, I think that's good." }\end{array}$} & Primary \\
\hline & $\begin{array}{l}\text { Commercial } \\
\text { benefits }\end{array}$ & & Primary \\
\hline & $\begin{array}{l}\text { Personal } \\
\text { values }\end{array}$ & $\begin{array}{l}\text { "Ummm (pause), you get to feel good about it too } \\
\text { right? I think there's that." }\end{array}$ & Secondary \\
\hline \multirow[t]{2}{*}{ Mary } & $\begin{array}{l}\text { Commercial } \\
\text { benefits }\end{array}$ & \multirow{2}{*}{$\begin{array}{l}\text { "ummm it would depend on how much effort it would } \\
\text { require and how much do consumers or the potential } \\
\text { people staying in it would care about it. Umm, like I } \\
\text { think that because I only have one review if I } \\
\text { perceived it would help me get better reviews, like } \\
\text { people would try it more as they would with local } \\
\text { reviews, then maybe I would consider it um and if it } \\
\text { wasn't overly cumbersome I guess those would be the } \\
\text { kind of questions." }\end{array}$} & Primary \\
\hline & $\begin{array}{l}\text { Rigour of } \\
\text { standards } \\
\text { (barrier) }\end{array}$ & & \\
\hline \multirow[t]{3}{*}{ Hannah } & $\begin{array}{l}\text { Commercial } \\
\text { benefits }\end{array}$ & $\begin{array}{l}\text { "it's always nice to have little things next to your } \\
\text { listing you know, it kind of draws people's attention } \\
\text { to it, maybe people only want to stay at a facility that } \\
\text { is environmentally friendly, that meets the standards." }\end{array}$ & Primary \\
\hline & $\begin{array}{l}\text { Personal } \\
\text { values }\end{array}$ & \multirow[b]{2}{*}{$\begin{array}{l}\text { "well just cause I do kind of care about the } \\
\text { environment, but I do think I've done as much as I can } \\
\text { to the house to make it most efficient as it can be. I } \\
\text { did actually think about doing solar panels, but then it } \\
\text { just, it rubbed me the wrong way because it's almost } \\
\text { like a business, you gotta pay taxes and everything, if } \\
\text { you make money. Um, and then I thought there was } \\
\text { going to be issues with maintaining it and all the other } \\
\text { things, but um I think it would also maybe, bring } \\
\text { different kind of guests towards my way, like people } \\
\text { that are environmentally conscious as well, so people } \\
\text { that are of like mind get together and agree on things } \\
\text { more so that might be more in line with how I am as a } \\
\text { person." }\end{array}$} & Primary \\
\hline & $\begin{array}{l}\text { Ability to } \\
\text { attract like- } \\
\text { minded guests }\end{array}$ & & Primary \\
\hline Rachel & $\begin{array}{l}\text { Personal } \\
\text { values }\end{array}$ & $\begin{array}{l}\text { "Well I think you know, already now there's a lot of } \\
\text { things I do around my home to be more energy } \\
\text { efficient. Like I've always recycled, you know I use } \\
\text { energy efficient bulbs I try to do, you know I hang dry } \\
\text { things instead of putting them in the dryer. There's a } \\
\text { lot of things I do already because that's what I believe } \\
\text { in. I also, you know I believe with recycling like } \\
\text { people say throw things away, well you don't really } \\
\text { throw things away it's still out there it's all in the } \\
\text { earth somewhere. So I feel like you do it because it's } \\
\text { the right thing to do and not because you know, I } \\
\text { think I'm gonna get more. You know the reality is }\end{array}$ & Primary \\
\hline
\end{tabular}




\begin{tabular}{|c|c|c|c|}
\hline & & $\begin{array}{l}\text { with a lot of this green stuff is, because I've worked in } \\
\text { the sector, is that people either do it because it saves } \\
\text { time or it saves money. A lot of people don't do it } \\
\text { because they honestly feel that they're saving the } \\
\text { planet you know. So I think if you're generally doing } \\
\text { those kinds of things in the first place then why not } \\
\text { tell people you're doing those things so that if it's } \\
\text { important to those people they'll appreciate it as well" }\end{array}$ & \\
\hline & $\begin{array}{l}\text { Recognition } \\
\text { of } \\
\text { environmental } \\
\text { commitment }\end{array}$ & $\begin{array}{l}\text { "...it would almost just sort of reinforce, you know } \\
\text { what it does is it paints a better picture of the host, } \\
\text { because it's genuine, you're already doing those } \\
\text { things anyway." }\end{array}$ & Primary \\
\hline \multirow[t]{2}{*}{ Mike } & $\begin{array}{l}\text { Commercial } \\
\text { benefits }\end{array}$ & \multirow[b]{2}{*}{$\begin{array}{l}\text { "Um, absolutely we would be interested. I think, } \\
\text { couple of things, number one just to know a little } \\
\text { about me I'm a chemical engineer, so I know what uh } \\
\text { mankind does to the planet and I'm not happy about it. } \\
\text { I've been a bit of a tree hugger for the last few } \\
\text { decades for sure. Um, more importantly again though } \\
\text { it comes back to, I am in business to make money and } \\
\text { our target market are millennials, and thank god } \\
\text { there's a generation that really cares about the planet } \\
\text { and is trying to do something, and not as an individual } \\
\text { but as a group, as a, I think as a large group of people, } \\
\text { and we feel very strongly that millennials will be more } \\
\text { inclined to come to our properties over another } \\
\text { property if we are able to display the fact that we care } \\
\text { about the environment." }\end{array}$} & Primary \\
\hline & $\begin{array}{l}\text { Personal } \\
\text { values }\end{array}$ & & Secondary \\
\hline \multirow[t]{4}{*}{ Sarah } & $\begin{array}{l}\text { Rigour of } \\
\text { standards } \\
\text { (barrier) }\end{array}$ & \multirow{4}{*}{$\begin{array}{l}\text { "um, I would be interested if it weren't overly } \\
\text { cumbersome." } \\
\text { "um, because I think, because we're in it sort of to } \\
\text { make money, I think I would be interested because I } \\
\text { care about the environment and because I would like } \\
\text { to see if my house could be better or like what are the } \\
\text { areas, I've always wanted to do like an energy audit. } \\
\text { My house is very old so I'd say we'd have a hard time } \\
\text { passing, but I would be very interested in doing it } \\
\text { unless it was like really hard or expensive to do." }\end{array}$} & Primary \\
\hline & Cost (barrier) & & Primary \\
\hline & $\begin{array}{l}\text { Personal } \\
\text { values }\end{array}$ & & Secondary \\
\hline & $\begin{array}{l}\text { Household } \\
\text { environmental } \\
\text { impacts }\end{array}$ & & Secondary \\
\hline \multirow[t]{2}{*}{ Will } & $\begin{array}{l}\text { Personal } \\
\text { values }\end{array}$ & \multirow{2}{*}{$\begin{array}{l}\text { "yeah sure, because I care about the environment, I } \\
\text { feel like making a difference, and if there's cost } \\
\text { savings it's a plus." }\end{array}$} & Primary \\
\hline & $\begin{array}{l}\text { Commercial } \\
\text { benefits }\end{array}$ & & Primary \\
\hline \multirow[t]{2}{*}{ Peter } & $\begin{array}{l}\text { Personal } \\
\text { values }\end{array}$ & \multirow{2}{*}{$\begin{array}{l}\text { "yeah, I think for environmental reasons it would be } \\
\text { beneficial for everyone and I think it would also be, } \\
\text { just for my profile as an Airbnb host, I think um } \\
\text { something that a lot of guests would uh, look for. And } \\
\text { um, as conscious as I can be I find it difficult as a } \\
\text { host, like I'll go to clean up and they'll be tons of } \\
\text { recycling in the garbage, and they just never use } \\
\text { organic bins and things like that so I think it's um, to } \\
\text { do as much as I could on my part I think would kind }\end{array}$} & Primary \\
\hline & $\begin{array}{l}\text { Commercial } \\
\text { benefits }\end{array}$ & & Primary \\
\hline
\end{tabular}




\begin{tabular}{|c|c|c|c|}
\hline & & $\begin{array}{l}\text { of offset the kind of unknown kind of situations I get } \\
\text { into with the actual guests, you know what I mean?" }\end{array}$ & \\
\hline Greg & $\begin{array}{l}\text { Personal } \\
\text { values }\end{array}$ & $\begin{array}{l}\text { "uh, yes I would, and I think I would be interested } \\
\text { because um, I think the general direction of } \\
\text { accreditation is a positive one in raising the standards } \\
\text { up of all that particular sector." } \\
\text { "um, I would like to think that you know, eventually, I } \\
\text { mean this is a bit idealistic, but eventually having } \\
\text { some kind of accreditation that says you meet this } \\
\text { particular criteria becomes normal. And so } \\
\text { participating in that would just kind of be one step } \\
\text { towards pushing it in that direction." } \\
\text { "G: okay so it's more from kind of a personal, ethical } \\
\text { standpoint, or your personal values. } \\
\text { R: I think so yeah, yeah." }\end{array}$ & Primary \\
\hline Alex & $\begin{array}{l}\text { Commercial } \\
\text { benefits }\end{array}$ & $\begin{array}{l}\text { "it's a good question, um (pause), I would, but with } \\
\text { condition. I would because... you're making me think } \\
\text { while I say this. I wouldn't because just to save the } \\
\text { environment, we're too disconnected to that, there's } \\
\text { too many steps between me and the demise of the } \\
\text { planet that give me any connection to that. You'd } \\
\text { have to draw me to the revenue potential, because in } \\
\text { our immediate needs we do this for revenue, we do } \\
\text { this not to save the planet because it's saving the } \\
\text { planet, we do this to supplement our income. So you } \\
\text { would have to convince me that these programs can } \\
\text { do that." }\end{array}$ & Primary \\
\hline \multirow[t]{4}{*}{ Katie } & $\begin{array}{l}\text { Recognition } \\
\text { of } \\
\text { environmental } \\
\text { commitment }\end{array}$ & \multirow{4}{*}{$\begin{array}{l}\text { "uh, yeah I would. First of all I think we'd probably } \\
\text { be doing a lot of the things that it required so it would } \\
\text { be nice to be recognized for that. Um, it would } \\
\text { probably push us to do more and give us guidance on } \\
\text { how to do more to make our house quote unquote } \\
\text { greener. And um, number one it would, you know, um } \\
\text { help us stand out against the competition but also it } \\
\text { would probably attract- if they picked us for that } \\
\text { reason, it would attract more like-minded guests. } \\
\text { G: okay, so it would kind of give you a point of } \\
\text { differentiation versus other properties on Airbnb, and } \\
\text { also because it might just already align with the things } \\
\text { you're doing } \\
\text { R: or help us to become greener. Um, yeah I mean we } \\
\text { try our best but we're not very handy so if there was } \\
\text { like a checklist of things we could do to make our } \\
\text { home greener and we have this motivation do it } \\
\text { then... " }\end{array}$} & Primary \\
\hline & $\begin{array}{l}\text { Personal } \\
\text { values }\end{array}$ & & Primary \\
\hline & $\begin{array}{l}\text { Commercial } \\
\text { benefits }\end{array}$ & & Primary \\
\hline & $\begin{array}{l}\text { Ability to } \\
\text { attract like- } \\
\text { minded guests }\end{array}$ & & Primary \\
\hline \multirow[t]{2}{*}{ Heather } & $\begin{array}{l}\text { Personal } \\
\text { values }\end{array}$ & \multirow{2}{*}{$\begin{array}{l}\text { R: uh sure we'd be interested. Well I think it would } \\
\text { give you some credentials as a host and my husband is } \\
\text { very interested in environmental things, so I think he } \\
\text { would really like to do that. } \\
\text { G: okay, are there any- um, so I guess the main }\end{array}$} & Primary \\
\hline & $\begin{array}{l}\text { Commercial } \\
\text { benefits }\end{array}$ & & Primary \\
\hline
\end{tabular}




\begin{tabular}{|c|c|c|c|}
\hline & & $\begin{array}{l}\text { motivation would be kind of like your husbands } \\
\text { personal interest? } \\
\text { R: yeah personal interest, and it would probably, you } \\
\text { know, attract travelers that are also interested in the } \\
\text { environment. }\end{array}$ & \\
\hline \multirow[t]{2}{*}{ Caitlin } & $\begin{array}{l}\text { Ability to } \\
\text { attract like- } \\
\text { minded guests }\end{array}$ & \multirow[b]{2}{*}{$\begin{array}{l}\text { R: Um, I would be interested in such a program, and } \\
\text { one of the reasons is if there was some kind of way } \\
\text { that guests can search out properties, I feel like you } \\
\text { attract guests that have similar values as you do, } \\
\text { which is not always easy otherwise, you know? So } \\
\text { you can kind of adjust your profile a little bit to kind } \\
\text { of write we care about the environment, which I do, } \\
\text { um, but this self-selects a little bit more which I think } \\
\text { is important for Airbnb hosts to find the right guest fit. } \\
\text { G: okay. Beyond that are there any other reasons that } \\
\text { you would want to participate in this type of program? } \\
\text { R: I would like having a third party assessment } \\
\text { actually, and I've actually thought about doing it } \\
\text { independently, um, just getting someone to come and } \\
\text { kind of do their own little evaluation to see if they can } \\
\text { make any recommendations, but I wasn't sure you } \\
\text { know how expensive is it going to be, am I looking at } \\
\text { small things like the consumables I use in my house, } \\
\text { versus the overall waste management system that I } \\
\text { have in my house, like what am I doing here and how } \\
\text { much is it going to cost, but I have thought about it. } \\
\text { But I would like- I like evaluations and having other } \\
\text { peoples input so I think I wouldn't mind if that was } \\
\text { offered. }\end{array}$} & Primary \\
\hline & $\begin{array}{l}\text { Household } \\
\text { environmental } \\
\text { impacts }\end{array}$ & & Secondary \\
\hline \multirow[t]{2}{*}{ Jane } & $\begin{array}{l}\text { Personal } \\
\text { values }\end{array}$ & \multirow{2}{*}{$\begin{array}{l}\text { "Uh yeah, I think I would, because I like, care about } \\
\text { the environment, and I also think it's a good way to } \\
\text { promote my space, you know for those other, sort of, } \\
\text { environmentally conscious travelers." }\end{array}$} & Primary \\
\hline & $\begin{array}{l}\text { Commercial } \\
\text { benefits }\end{array}$ & & Primary \\
\hline
\end{tabular}




\section{Appendix G: GSTC Hotel Criteria, Section D - Maximize benefits to the environment and minimize negative impacts}

\begin{tabular}{|c|c|}
\hline $\begin{array}{l}\text { SECTION D: Maximize benefits to the } \\
\text { environment and minimize negative impacts }\end{array}$ & $\begin{array}{l}\text { SECTION D: Maximize benefits to the } \\
\text { environment and minimize negative impacts }\end{array}$ \\
\hline D1 Conserving resources & D1 Conserving resources \\
\hline $\begin{array}{l}\text { (Old)D1.1 Local purchasing } \\
\text { Purchasing policies favor locally appropriate } \\
\text { and ecologically sustainable products, including } \\
\text { building materials, capital goods, food, } \\
\text { beverages and consumables. }\end{array}$ & $\begin{array}{l}\text { D1.1 Environmentally preferable purchasing } \\
\text { Purchasing policies favour environmentally } \\
\text { sustainable suppliers and products, including } \\
\text { capital goods, food, beverages, building } \\
\text { materials and consumables. }\end{array}$ \\
\hline $\begin{array}{l}\text { (Old)D1.2 Disposable goods } \\
\text { The purchase and use of disposable and } \\
\text { consumable goods is measured and the } \\
\text { organization actively seeks ways to reduce their } \\
\text { use. }\end{array}$ & $\begin{array}{l}\text { D1.2 Efficient purchasing } \\
\text { The organization carefully manages the } \\
\text { purchasing of consumable and disposable } \\
\text { goods, including food, in order to minimize } \\
\text { waste. }\end{array}$ \\
\hline $\begin{array}{l}\text { (Old)D1.3 Energy conservation } \\
\text { Energy consumption is measured, sources are } \\
\text { indicated, and measures are adopted to } \\
\text { minimize overall consumption, and encourage } \\
\text { the use of renewable energy. }\end{array}$ & $\begin{array}{l}\text { D1.3 Energy conservation } \\
\text { Energy consumption is measured by type and } \\
\text { steps are taken to minimize overall } \\
\text { consumption. The organization makes efforts } \\
\text { to increase its use of renewable energy. }\end{array}$ \\
\hline $\begin{array}{l}\text { (Old)D1.4 Water conservation } \\
\text { Water consumption is measured, sources are } \\
\text { indicated, and measures are adopted to } \\
\text { minimize overall consumption. Water sourcing } \\
\text { is sustainable, and does not adversely affect } \\
\text { environmental flows. }\end{array}$ & $\begin{array}{l}\text { D1.4 Water conservation } \\
\text { Water risk is assessed, water consumption is } \\
\text { measured by type, and steps are taken to } \\
\text { minimize overall consumption. Water sourcing } \\
\text { is sustainable and does not adversely affect } \\
\text { environmental flows. In areas of high water } \\
\text { risk, context-based water stewardship goals are } \\
\text { identified and pursued. }\end{array}$ \\
\hline
\end{tabular}




\begin{tabular}{|c|c|}
\hline D2 Reducing pollution & D2 Reducing pollution \\
\hline $\begin{array}{l}\text { (Old)D2.1 Greenhouse gas emissions } \\
\text { Greenhouse gas emissions from all sources } \\
\text { controlled by the organization are measured, } \\
\text { procedures are implemented to minimize them, } \\
\text { and offsetting remaining emissions is } \\
\text { encouraged. }\end{array}$ & $\begin{array}{l}\text { D2.1 Greenhouse gas emissions } \\
\text { Significant greenhouse gas emissions from all } \\
\text { sources controlled by the organization are } \\
\text { identified, calculated where possible and } \\
\text { procedures implemented to avoid or to } \\
\text { minimize them. Offsetting of the organization's } \\
\text { remaining emissions is encouraged. }\end{array}$ \\
\hline $\begin{array}{l}\text { (Old)D2.2 Transport greenhouse gas emissions } \\
\text { The organization encourages its customers, } \\
\text { staff and suppliers to reduce transportation- } \\
\text { related greenhouse gas emissions. }\end{array}$ & $\begin{array}{l}\text { D2.2 Transport } \\
\text { The organization seeks to reduce } \\
\text { transportation requirements and actively } \\
\text { encourages the use of cleaner and more } \\
\text { resource efficient alternatives by customers, } \\
\text { employees, suppliers and in its own operations. }\end{array}$ \\
\hline $\begin{array}{l}\text { (Oid)D2.3 Wastewater } \\
\text { Wastewater, including gray water, is effectively } \\
\text { treated and is only reused or released safely, } \\
\text { with no adverse effects to the local population } \\
\text { and the environment. }\end{array}$ & $\begin{array}{l}\text { D2.3 Wastewater } \\
\text { Wastewater, including grey water, is effectively } \\
\text { treated and is only reused or released safely, } \\
\text { with no adverse effects to the local population } \\
\text { or the environment. }\end{array}$ \\
\hline $\begin{array}{l}\text { (Old)D2.4 Waste } \\
\text { Waste is measured, mechanisms are in place to } \\
\text { reduce waste, and where reduction is not } \\
\text { feasible, to re-use or recycle it. Any residual } \\
\text { waste disposal has no adverse effect on the } \\
\text { local population and the environment. }\end{array}$ & $\begin{array}{l}\text { D2.4 Solid waste } \\
\text { Waste, including food waste, is measured, } \\
\text { mechanisms are in place to reduce waste and, } \\
\text { where reduction is not feasible, to reuse or } \\
\text { recycle it. Any residual waste disposal has no } \\
\text { adverse effect on the local population or the } \\
\text { environment. }\end{array}$ \\
\hline $\begin{array}{l}\text { (Old)D2.5 Harmful substances } \\
\text { The use of harmful substances, including } \\
\text { pesticides, paints, swimming pool disinfectants, } \\
\text { and cleaning materials, is minimized, and } \\
\text { substituted when available, by innocuous } \\
\text { products or processes. All storage, use, } \\
\text { handling, and disposal of chemicals are } \\
\text { properly managed. }\end{array}$ & $\begin{array}{l}\text { D2.5 Harmful substances } \\
\text { The use of harmful substances, including } \\
\text { pesticides, paints, swimming pool disinfectants, } \\
\text { and cleaning materials, is minimized, and } \\
\text { substituted when available by innocuous } \\
\text { products or processes. All storage, use, } \\
\text { handling, and disposal of chemicals are } \\
\text { properly managed. }\end{array}$ \\
\hline
\end{tabular}




\begin{tabular}{|c|c|}
\hline $\begin{array}{l}\text { (Old)D2.6 Minimise pollution } \\
\text { The organization implements practices to } \\
\text { minimize pollution from noise, light, runoff, } \\
\text { erosion, ozone-depleting compounds, and air, } \\
\text { water and soil contaminants. }\end{array}$ & $\begin{array}{l}\text { D2.6 Minimize pollution } \\
\text { The organization implements practices to } \\
\text { minimize pollution from noise, light, nunoff, } \\
\text { erosion, ozone-depleting substances, and air, } \\
\text { water and soil contaminants. }\end{array}$ \\
\hline $\begin{array}{l}\text { D3 Conserving biodiversity, ecosystems and } \\
\text { landscapes }\end{array}$ & $\begin{array}{l}\text { D3 Conserving biodiversity, ecosystems and } \\
\text { landscapes }\end{array}$ \\
\hline $\begin{array}{l}\text { (Old)D3.4 Biodiversity conservation } \\
\text { The organization supports and contributes to } \\
\text { biodiversity conservation, including natural } \\
\text { protected areas and areas of high biodiversity } \\
\text { value. }\end{array}$ & $\begin{array}{l}\text { D3.1 Biodiversity conservation } \\
\text { The organization supports and contributes to } \\
\text { biodiversity conservation, including through } \\
\text { appropriate management of its own property. } \\
\text { Particular attention is paid to natural protected } \\
\text { areas and areas of high biodiversity value. Any } \\
\text { disturbance of natural ecosystems is minimized, } \\
\text { rehabilitated and there is a compensatory } \\
\text { contribution to conservation management. }\end{array}$ \\
\hline \multirow[t]{2}{*}{$\begin{array}{l}\text { (Old)D3.3 Alien species } \\
\text { The organization takes measures to avoid the } \\
\text { introduction of invasive alien species. Native } \\
\text { species are used for landscaping and } \\
\text { restoration wherever feasible, particularly in } \\
\text { natural landscapes. }\end{array}$} & $\begin{array}{l}\text { D3.2 Invasive species } \\
\text { The organization takes measures to avoid the } \\
\text { introduction of invasive species. Native species } \\
\text { are used for landscaping and restoration } \\
\text { wherever feasible, particularly in natural } \\
\text { landscapes. }\end{array}$ \\
\hline & $\begin{array}{l}\text { D3.3 Visits to natural sites } \\
\text { The organization follows appropriate guidelines } \\
\text { for the management and promotion of visits to } \\
\text { natural sites in order to minimize adverse } \\
\text { impacts and maximize visitor fulfiment. }\end{array}$ \\
\hline $\begin{array}{l}\text { (Old)D3.5 Wildlife interactions } \\
\text { Interactions with wildlife, taking into account } \\
\text { cumulative impacts, do not produce adverse } \\
\text { effects on the viability and behaviour of } \\
\text { populations in the wild. Any disturbance of } \\
\text { natural ecosystems is minimized, rehabilitated, } \\
\text { and there is a compensatory contributon to } \\
\text { conservation management. }\end{array}$ & $\begin{array}{l}\text { D3.4 Wildlife interactions } \\
\text { Interactions with free roaming wildlife, taking } \\
\text { into account cumulative impacts, are non- } \\
\text { invasive and responsibly managed to avoid } \\
\text { adverse effects on the animals concerned and } \\
\text { on the viability and behaviour of populations in } \\
\text { the wild. }\end{array}$ \\
\hline
\end{tabular}




\begin{tabular}{|l|l|}
\hline $\begin{array}{l}\text { (Old)D3.2 Captive wildlife } \\
\begin{array}{l}\text { No captive wildlife is held, except for properly } \\
\text { regulated activities, in compliance with local to } \\
\text { international law, Living specimens of } \\
\text { protected and wildlife species are only kept by } \\
\text { those authorized and suitably equipped to } \\
\text { house and care for them humanely. }\end{array}\end{array}$ & $\begin{array}{l}\text { No species of wild animal is acquired, bred or } \\
\text { held captive, except by authorized and suitably } \\
\text { equipped persons and for properly regulated } \\
\text { activities in compliance with local and } \\
\text { international law. Housing, care and handling } \\
\text { of all wild and domestic animals meets the } \\
\text { highest standards of animal welfare. }\end{array}$ \\
\hline $\begin{array}{l}\text { (Old)D3.1 Wildlife harvesting } \\
\text { Wildlife species are not harvested, consumed, } \\
\text { displayed, sold, or traded, except as part of a } \\
\text { regulated activity that ensures that their } \\
\text { utilization is sustainable, and in compliance } \\
\text { with local to international laws. }\end{array}$ & $\begin{array}{l}\text { Wildlife species are not harvested, consumed, } \\
\text { displayed, sold, or traded, except as part of a } \\
\text { regulated activity that ensures that their } \\
\text { utilization is sustainable, and in compliance } \\
\text { with local and international laws. }\end{array}$ \\
\hline
\end{tabular}

Note: At the time of this research version 3 (right column) had not yet been published so version 2 (left column) was used to determine the environmental categories. The highlighted portions below show the changes between the two versions.

Note: From Global Sustainable Tourism Council. (2016). GSTC Hotel Criteria. Retrieved from https://www.gstcouncil.org/images/Integrity_Program/Criteria/GSTCHotel_Industry_Criteria_with_hotel_indicators_21-Dec-2016_Final.pdf 


\section{References}

Airbnb. (n.d.-a). About Us. Retrieved June 7, 2016, from https://www.airbnb.ca/about/about-us

Airbnb. (n.d.-b). Airbnb Partners with Nest to Help Community Continue to Save Energy. Retrieved September 16, 2016, from https://www.airbnb.ca/press/news/airbnb-partnerswith-nest-to-help-community-continue-to-save-energy

Airbnb. (n.d.-c). Community. Retrieved April 1, 2017, from https://community.airbnb.com/t5/Community-Center/ct-p/community-center

Airbnb. (n.d.-d). Host Voice. Retrieved April 3, 2017, from https://community.withairbnb.com/t5/Host-Voice/idb-p/host-voice

Airbnb. (n.d.-e). Nest + Airbnb Wish List. Retrieved December 12, 2016, from https://www.airbnb.ca/wishlists/nests?locale=en

Airbnb. (n.d.-f). superhost. Retrieved March 28, 2017, from https://www.airbnb.ca/superhost?locale $=e n$

Airbnb. (n.d.-g). The Airbnb Community Compact. Retrieved July 22, 2016, from http://1zxiw0vqx0oryvpz3ikczauf-wpengine.netdna-ssl.com/wpcontent/uploads/2015/11/Airbnb-Community-Compact.pdf

Airbnb. (n.d.-h). What legal and regulatory issues should I consider before hosting on Airbnb? Retrieved March 21, 2016, from https://www.airbnb.ca/help/article/376/what-legal-andregulatory-issues-should-i-consider-before-hosting-on-airbnb?topic $=197$

Airbnb. (n.d.-i). What makes a listing Business Travel Ready? Retrieved May 8, 2017, from https://www.airbnb.ca/help/article/1185/what-makes-a-listing-business-travelready?topic $=372$

Airbnb. (n.d.-j). Why Host? Retrieved September 16, 2016, from https://www.airbnb.ca/host

Airbnb. (2014). A Greener Way to Travel: The Environmental Impacts of Home Sharing. Retrieved May 17, 2016, from http://blog.airbnb.com/environmental-impacts-of-homesharing/

Airbnb. (2016a). Airbnb, Housing, and the City of Toronto. Retrieved from https://www.airbnbaction.com/wp-content/uploads/2016/10/TorontoHousing2016.pdf

Airbnb. (2016b). Airbnb and UNEP team up to promote sustainability. Retrieved June 10, 2017, from https://www.airbnbcitizen.com/airbnb-and-unep-team-up-to-promote-sustainability/

Airbnb. (2016c). The Airbnb Community in Ontario. Retrieved from https://1zxiw0vqx0oryvpz3ikczauf-wpengine.netdna-ssl.com/wpcontent/uploads/2016/09/AIR.01_Ontario-Report-2016_V12_JL1.pdf

Airbnb. (2016d). Welcome to a world of trips | Airbnb Open Los Angeles. Youtube. Retrieved from https://www.youtube.com/watch?v=efNyRmTLbjQ 
Airbnb. (2017a). Airbnb: Helping travel grow greener. Retrieved from https://www.airbnbcitizen.com/wpcontent/uploads/2017/03/Airbnbandsustainabletravel2017.pdf

Airbnb. (2017b). Airbnb partners with the UNWTO to promote sustainable tourism. Retrieved July 10, 2017, from https://www.airbnbcitizen.com/airbnb-partners-with-the-unwto-topromote-sustainable-tourism/

Airbnb Partners with Nest to Help Community Continue to Save Energy. (2014, September 19). Energy Weekly News. Retrieved from http://search.proquest.com.ezproxy.lib.ryerson.ca/docview/1561092142?accountid=13631

Alonso, A. D., \& Ogle, A. (2010). Tourism and hospitality small and medium enterprises and environmental sustainability. Management Research Review, 33(8), 818-826. https://doi.org/10.1108/01409171011065626

Álvarez Gil, M. ., Burgos Jiménez, J., \& Céspedes Lorente, J. . (2001). An analysis of environmental management, organizational context and performance of Spanish hotels. Omega, 29(6), 457-471. https://doi.org/10.1016/S0305-0483(01)00033-0

Andereck, K. L. (2009). Tourists' perceptions of environmentally responsible innovations at tourism businesses. Journal of Sustainable Tourism, 17(4), 489-499. https://doi.org/10.1080/09669580802495790

Archer, H., Kozak, R., \& Balsillie, D. (2005). The impact of forest certification labelling and advertising: An exploratory assessment of consumer purchase intent in Canada. The Forestry Chronicle, 81(2), 229-244.

Ayala, H. (1995). Ecoresort: a "green" masterplan for the international resort industry. International Journal of Hospitality Management, 14(3-4), 351-374. https://doi.org/10.1016/0278-4319(95)00043-7

Ayuso, S. (2007). Comparing voluntary policy instruments for sustainable tourism: The experience of the spanish hotel sector. Journal of Sustainable Tourism, 15(2), 144-159. https://doi.org/10.2167/jost617.0

Baker, M. a., Davis, E. a., \& Weaver, P. a. (2013). Eco-friendly attitudes, barriers to participation, and differences in behavior at green hotels. Cornell Hospitality Quarterly, 55(1), 89-99. https://doi.org/10.1177/1938965513504483

Balzarova, M. A., \& Castka, P. (2012). Stakeholders' influence and contribution to social standards development: The case of multiple stakeholder approach to ISO 26000 development. Journal of Business Ethics, 111(2), 265-279. https://doi.org/10.1007/s10551012-1206-9

Bansal, P., \& Roth, K. (2000). Why companies go green: A model of ecological responsiveness. The Academy of Management Review, 43(4), 717-736.

Bardhi, F., Eckhardt, G. M., \& Arnould, E. J. (2012). Liquid relationship to possessions. Journal of Consumer Research, 39(3), 510-529. https://doi.org/10.1086/664037 
Beaumont, N. (2011). The third criterion of ecotourism: are ecotourists more concerned about sustainability than other tourists? Journal of Ecotourism, 10(April 2014), 135-148. https://doi.org/10.1080/14724049.2011.555554

Becken, S., Frampton, C., \& Simmons, D. (2001). Energy consumption patterns in the accommodation sector - The New Zealand case. Ecological Economics, 39(3), 371-386. https://doi.org/10.1016/S0921-8009(01)00229-4

Best, M. N., \& Thapa, B. (2013). Motives, facilitators and constraints of environmental management in the Caribbean accommodations sector. Journal of Cleaner Production, 52, 165-175. https://doi.org/10.1016/j.jclepro.2013.03.005

Bhaskaran, S., Polonsky, M., Cary, J., \& Fernandez, S. (2006). Environmentally sustainable food production and marketing: opportunity or hype? British Food Journal, 108(8), 677-690. https://doi.org/10.1108/00070700610682355

Bien, A. (2006a). A Simple User's Guide to Certification for Sustainable Tourism and Ecotourism (3rd ed.). International Ecotourism Society.

Bien, A. (2006b). Marketing Strategies for Sustainable and Ecotourism Certification. Retrieved from https://www.ecotourism.org/news/marketing-strategies-sustainable-and-ecotourismcertification

Big Room, \& World Resources Institute. (2010). Global Ecolabel Monitor: Towards Transparency. Retrieved from http://www.ecolabelindex.com/downloads/Global_Ecolabel_Monitor2010.pdf

Binninger, A.-S., Ourahmoune, N., \& Robert, I. (2015). Collaborative consumption and sustainability: A discursive analysis of consumer representations and collaborative website narratives. The Journal of Applied Business Research, 31(3), 969-986. Retrieved from http://search.proquest.com.ezproxy.lib.ryerson.ca/docview/1699068590?pqorigsite $=$ summon

Black, R., \& Crabtree, A. (2007). Achieving Quality in Ecotourism. In R. Black \& A. Crabtree (Eds.), Quality Assurance and Certification in Ecotourism. Cambridge, Massachusetts: CABI Publishing.

Bohdanowicz, P. (2005). European hoteliers' environmental attitudes: Greening the business. Cornell Hotel and Restaurant Administration Quarterly, 46(2), 188-204. https://doi.org/10.1177/0010880404273891

Boiral, O. (2007). Corporate greening through ISO 14001 : A rational myth ? Organization Science, 18(1), 127-146. Retrieved from http://www.jstor.org/stable/25146087

Botsman, R., \& Rogers, R. (2010a). Beyond Zipcar : Collaborative Consumption. Harvard Business Review, 88(10), 30.

Botsman, R., \& Rogers, R. (2010b). What's Mine is Yours. New York, NY: HarperCollins.

Bricker, K. S., \& Schultz, J. (2011). Sustainable tourism in the USA : A comparative look at the Global Sustainable Tourism Criteria. Tourism Recreation Research, 36(3), 215-229. 
Buckley, R. (2002). Tourism ecocertification in the international year of ecotourism. Journal of Ecotourism, 1(2-3), 197-203. https://doi.org/10.1080/14724040208668126

Buckley, R. (2012). Sustainability reporting and rertification in tourism. Tourism Recreation Research, 37(1), 85-90. https://doi.org/10.1080/02508281.2012.11081692

Budeanu, A. (2007). Sustainable tourist behaviour - a discussion of opportunities for change. International Journal of Consumer Studies, 31, 499-508. https://doi.org/10.1111/j.14706431.2007.00606.x

Burgin, S., \& Hardiman, N. (2010). Eco-accreditation: Win-win for the environment and small business? International Journal of Business Studies, 18(1), 23-38.

Canada Green Building Council. (n.d.). LEED: The International Mark of Excellence. Retrieved June 7, 2017, from http://www.cagbc.org/CAGBC/LEED/About_LEED/CAGBC/Programs/LEED/_LEED.asp $\mathrm{x}$ ?hkey=01b3d086-d0a4-42cf-9e61-7830d801c019

Carr, N. (2002). A comparative analysis of the behaviour of domestic and international young tourists. Tourism Management, 23(3), 321-325. https://doi.org/10.1016/S02615177(01)00089-9

Castka, P., \& Corbett, C. J. (2016). Governance of eco-labels: Expert opinion and media coverage. Journal of Business Ethics, 135(2), 309-326. https://doi.org/10.1007/s10551-0142474-3

CBC News. (2016, September 6). Airbnb ban? Not likely to happen, councillors say. Retrieved from http://www.cbc.ca/news/canada/toronto/airbnb-regulations-1.3749410

Chafe, Z. (2007). Ecotourism, Consumer Demand for Quality in Ecotourism. In R. Black \& A. Crabtree (Eds.), Quality Assurance and Certification in Ecotourism. Cambridge, Massachusetts: CABI Publishing.

Chan, E. S. W. (2008). Barriers to EMS in the hotel industry. International Journal of Hospitality Management, 27(2), 187-196. https://doi.org/10.1016/j.ijhm.2007.07.011

Chan, E. S. W. (2011). Implementing environmental management systems in small- and medium-sized hotels: Obstacles. Journal of Hospitality \& Tourism Research, 35(1), 3-23. https://doi.org/10.1177/1096348010370857

Chan, E. S. W., Hon, A. H. Y., Chan, W., \& Okumus, F. (2014). What drives employees' intentions to implement green practices in hotels? The role of knowledge, awareness, concern and ecological behaviour. International Journal of Hospitality Management, 40, 20-28. https://doi.org/10.1016/j.ijhm.2014.03.001

City of Toronto. (2017). Short-term rentals. Retrieved April 9, 2017, from http://www1.toronto.ca/wps/portal/contentonly?vgnextoid=deb7415ca6b69510VgnVCM10 000071d60f89RCRD

Clampet, J., \& Petri, A. (2016, January 20). Airbnb Data Highlights From Penn State's YearLong Host Study. Skift. Retrieved from https://skift.com/2016/01/20/airbnb-data-highlightsfrom-penn-states-year-long-host-study/ 
Claver-Cortés, E., Molina-Azorín, J. F., Pereira-Moliner, J., \& López-Gamero, M. D. (2007). Environmental strategies and their impact on hotel performance. Journal of Sustainable Tourism, 15(6), 663-679. https://doi.org/10.2167/jost640.0

Cleantech Group. (n.d.). About. Retrieved December 12, 2016, from http://www.cleantech.com/about/

Cleantech Group. (2014). Environmental Impacts of Home Sharing: Phase 1 Report. San Francisco, CA. Retrieved from https://www.airbnbaction.com/wpcontent/uploads/2016/10/Cleanteach_Airbnb-Environmental-Impact-Report.pdf

Cohen, S. A., Higham, J. E. S., \& Reis, A. C. (2014). Sociological barrers to developing sustainable discretionary air travel behaviour. In S. A. Cohen, J. E. S. Higham, P. Peeters, \& S. Gössling (Eds.), Understanding and Governing Sustainable Tourism Mobility: Psychological and Behavioural Approaches. London, U.K.: Routledge.

Coles, T., Dinan, C., \& Warren, N. (2016). Energy practices among small- and medium-sized tourism enterprises: A case of misdirected effort? Journal of Cleaner Production, 111, 399 408. https://doi.org/10.1016/j.jclepro.2014.09.028

Conroy, M. E. (2002). Certification Systems for Sustainable Tourism and Ecotourism: Can They Transform Social and Environmental Practices? In M. Honey (Ed.), Ecotourism \& Certification: Setting Standards in Practice. Washington, D.C.: Island Press.

Consultancy and Research for Environmental Management (CREM). (2000). Feasibility and Market Study for a European Eco-label for Tourist Accommodations (FEMATOUR). Amsterdam, Netherlands. Retrieved from http://ec.europa.eu/environment/archives/ecolabel/pdf/market_study/fematour.pdf

Consumer Protection Ontario. (2016). Condo owners rights and responsibilities. Retrieved April 7, 2017, from https://www.ontario.ca/page/condo-owner-rights-andresponsibilities\#section-4

Crabtree, B., \& Miller, W. (Eds.). (1992). Doing Qualitative Research. Newbury Park, California: Sage Publications.

D’Souza, C., Taghian, M., Lamb, P., \& Peretiatko, R. (2007). Green decisions: demographics and consumer understanding of environmental labels. International Journal of Consumer Studies, 31, 371-376. https://doi.org/10.1111/j.1470-6431.2006.00567.x

Darnall, N., \& Edwards Jr., D. (2006). Predicting the cost of environmental management system adoption: The role of capabilities, resources and ownership structure. Strategic Management Journal, 27(4), 301-320.

Davies, A., Fahy, F., \& Taylor, D. (2005). Mind the gap! Householder attitudes and actions towards waste in Ireland. Irish Geography, 38(2), 151-168. https://doi.org/10.1080/00750770509555856

Delmas, M., \& Toffel, M. (2004). Stakeholders and environmental management practices: An institutional framework. Business Strategy and the Environment, 13, 209-222. 
Dewhurst, H., \& Thomas, R. (2003). Encouraging sustainable business practices in a nonregulatory environment: A case study of small tourism firms in a UK national Park. Journal of Sustainable Tourism, 11(5), 383-403. https://doi.org/10.1080/09669580308667212

Dodds, R., \& Holmes, M. R. (2011). Sustainability in Canadian B\&Bs: Comparing the east versus west. International Journal of Tourism Research, 13(5), 482-495.

Dodds, R., \& Joppe, M. (2005). CSR in the tourism industry? The status of and potential for certification, codes of conduct and guidelines. IFC/World Bank, Washington. Retrieved from http://www.turismdurabil.ro/literatura/csr/additional_documents/I-

CSR+in+the+Tourism+Industry - study.pdf

Dodds, R., \& Joppe, M. (2009). Can certification programs help small and medium sized enterprises (SME) in lesser developed countries (LDC) to access markets? Territories and Tourism, 1-24.

Dougherty, K. (2015, October 22). Quebec's proposed Airbnb regulations a Canadian first. The Globe and Mail. Retrieved from http://www.theglobeandmail.com/report-onbusiness/quebecs-proposed-airbnb-regulations-a-canadian-first/article26936274/

Dunn, T. (2017, January 3). How to fix Toronto's short-term rental problems in 2017. CBC News. Retrieved from http://www.cbc.ca/news/canada/toronto/airbnb-regulation-20171.3909369

Eagles, P. F. J., \& Cascagnette, J. (1995). Canadian ecotourists. Tourism Recreation Research, 20(1), 22-28. Retrieved from http://resolver.scholarsportal.info/resolve/02508281/v20i0001/22_ce.xml

Edwards, A. (1957). The Social Desirability Variable in Personality Assessment and Research. New York, NY: Holt, Rinehart and Winston, Inc.

El Dief, M., \& Font, X. (2010). The determinants of hotels' marketing managers' green marketing behaviour. Journal of Sustainable Tourism, 18(2), 157-174. https://doi.org/10.1080/09669580903464232

Esparon, M., Gyuris, E., \& Stoeckl, N. (2014). Does ECO certification deliver benefits ? An empirical investigation of visitors' perceptions of the importance of ECO certification's attributes and of operators' performance. Journal of Sustainable Tourism, 22(1), 148-169.

Fairbnb. (n.d.). Fairbnb. Retrieved September 26, 2016, from http://fairbnb.ca/

Fairmont. (2009). Fairmont Hotels \& Resorts Joins Green Key Eco-rating Program in United States. Retrieved February 3, 2017, from http://www.fairmont.com/pressroom/articles/greenkeyecoratingprogram/

Fairweather, J. R., Maslin, C., \& Simmons, D. G. (2005). Environmental values and response to ecolabels among international visitors to New Zealand. Journal of Sustainable Tourism, 13(1), 82-98. https://doi.org/10.1080/17501220508668474

Fennell, D. A., \& Malloy, D. C. (2007). Codes of Ethics in Tourism: Practice, Theory, Synthesis. Cleveden, U.K.: Channel View Publications. 
Fiest, R. (2015, May 4). Damages could hit $\$ 150,000$ in Calgary home trashed by Airbnb renters. Global News. Retrieved from http://globalnews.ca/news/1978661/damages-could-hit150000-in-calgary-home-trashed-by-airbnb-renters/

Font, X. (2001). Regulating the Green Message: the Players in Ecolabelling. In X. Font \& R. Buckley (Eds.), Tourism Ecolabelling: Certification and Promotion of Sustainable Management. New York, NY: CABI Publishing.

Font, X. (2002). Environmental certification in tourism and hospitality: Progress, process and prospects. Tourism Management, 23(3), 197-205. https://doi.org/10.1016/S02615177(01)00084-X

Font, X. (2003, July). Labelling \& Certification: Benefits \& Challenges for Sustainable Tourism Management \& Marketing. ECOCLUB. Retrieved from http://ecoclub.com/news/050/expert.html\#1

Font, X. (2012). Sustainable Tourism Certification. In A. Holden \& D. A. Fennell (Eds.), The Routledge Handbook of Tourism and the Environment. New York, NY: Routledge.

Font, X., \& Buckley, R. C. (Eds.). (2001). Tourism Ecolabelling: Certification and Promotion of Sustainable Management. New York, New York: CABI Publishing.

Font, X., \& Wood, M. E. (2007). Sustainable Tourism Certification Marketing and its Contributions to SME Market Access. In R. Black \& A. Crabtree (Eds.), Quality Assurance and Certification in Ecotourism. Cambridge, Massachusetts: CABI Publishing.

Forest Stewardship Council. (2015). Market Info Pack: 2015. Retrieved from https://ic.fsc.org/preview.2015-fsc-market-info-pack.a-5067.pdf

Fraser, L. (2017, April 13). What Toronto can learn from other cities about regulating short-term rentals. $C B C$ News. Retrieved from http://www.cbc.ca/news/canada/toronto/airbnbregulations-toronto-london-amsterdam-1.4068835

Frew, E. A., \& Winter, C. (2010). Tourist response to climate change: Regional and metropolitan diversity. Tourism Review International, 13(4), 237-246.

Frier, S., \& Newcomer, E. (2015, March 17). The Fuzzy, Insane Math That's Creating So Many Billion-Dollar Tech Companies. Bloomberg Technology. Retrieved from https://www.bloomberg.com/news/articles/2015-03-17/the-fuzzy-insane-math-that-screating-so-many-billion-dollar-tech-companies

Frontier Economics Ltd. (2016). Toronto Pearson's Economic Impact: A report for the Greater Toronto Airports Authority. Retrieved from

https://www.torontopearson.com/uploadedFiles/Pearson/Content/About_Pearson/Economic _Impact/RPT-TorontoPearsonEconomicImpact2016.pdf

Fryxell, G. E., Lo, C. W. H., \& Chung, S. S. (2004). Influence of motivations for seeking ISO 14001 certification on perceptions of EMS effectiveness in China. Environmental Management, 33(2), 239-251. https://doi.org/10.1007/s00267-003-0106-2 
Gabzdylova, B., Raffensperger, J. F., \& Castka, P. (2009). Sustainability in the New Zealand wine industry: drivers, stakeholders and practices. Journal of Cleaner Production, 17(11), 992-998. https://doi.org/10.1016/j.jclepro.2009.02.015

Gallagher, L. (2017, February 15). Airbnb's Profits to Top \$3 Billion by 2020. Fortune. Retrieved from http://fortune.com/2017/02/15/airbnb-profits/

Gansky, L. (2010). The Mesh: Why the Future of Business is Sharing. New York, NY: Penguin Group.

Gao, Y. L., Mattila, A. S., \& Lee, S. (2016). A meta-analysis of behavioral intentions for environment-friendly initiatives in hospitality research. International Journal of Hospitality Management, 54, 107-115. https://doi.org/10.1016/j.ijhm.2016.01.010

Garay, L., \& Font, X. (2012a). Doing good to do well? Corporate social responsibility reasons, practices and impacts in small and medium accommodation enterprises. International Journal of Hospitality Management, 31(2), 329-337. https://doi.org/10.1016/j.ijhm.2011.04.013

Garay, L., \& Font, X. (2012b). Doing good to do well? Corporate social responsibility reasons, practices and impacts in small and medium accommodation Enterprises. International Journal of Hospitality Management, 31(2), 329-337.

Gavronski, I., Ferrer, G., \& Paiva, E. L. (2008). ISO 14001 certification in Brazil: motivations and benefits. Journal of Cleaner Production, 16(1), 87-94. https://doi.org/10.1016/j.jclepro.2006.11.002

Geerts, W. (2014). Environmental certification schemes: Hotel managers' views and perceptions. International Journal of Hospitality Management, 39, 87-96. https://doi.org/10.1016/j.ijhm.2014.02.007

Gerstenfeld, A., \& Roberts, H. (2000). Size matters: barriers and prospects for environmental management in small and medium-sized enterprises. In R. Hillary (Ed.), Small and MediumSized Enterprises and the Environment. Sheffield, UK: Greenleaf Publishing Ltd.

Getz, D., \& Carlsen, J. (2000). Characteristics and goals of family and owner-operated businesses in the rural tourism and hospitality sectors. Tourism Management, 21(6), 547560. https://doi.org/10.1016/S0261-5177(00)00004-2

Glesne, C. (1999). Becoming Qualitative Researchers: An Introduction (2nd ed.). New York, NY: Addison Wesley Longman.

Global Sustainable Tourism Council. (n.d.-a). Global Sustainable Tourism Criteria. Retrieved September 26, 2016, from https://www.gstcouncil.org/en/gstc-certification/gstccriteria/sustainable-tourism-gstc-criteria.html

Global Sustainable Tourism Council. (n.d.-b). Membership Categories \& Fees. Retrieved September 26, 2016, from https://www.gstcouncil.org/en/participate-in-gstc/become-amember/membership-categories-and-fees.html

Global Sustainable Tourism Council. (n.d.-c). Our History. Retrieved September 26, 2016, from https://www.gstcouncil.org/en/about/gstc-overview/our-history.html 
Global Sustainable Tourism Council. (n.d.-d). What We Do. Retrieved January 11, 2017, from https://www.gstcouncil.org/en/about/gstc-overview/welcome-to-sustainable-tourism.html

Global Sustainable Tourism Council. (2015). Board Election Results 2015. Retrieved September 26, 2016, from https://www.gstcouncil.org/en/about/news/1075-2015-board-electionresults.html

Golden, J. S., Vermeer, D., Clemen, B., Michalko, A., Nguyen, D., Noyes, C., ... Bunting, J. (2010). An Overview of Ecolabels and Sustainability Certifications in the Global Marketplace. Retrieved from https://center.sustainability.duke.edu/sites/default/files/documents/ecolabelsreport.pdf

Goldstein, K., \& Primlani, R. V. (2012). Current trends and opportunities in hotel sustainability. HVS Sustainability Services. Retrieved from http://www.hvs.com/article/5655/currenttrends-and-opportunities-in-hotel-sustainability/

Gössling, S. (2002). Global environmental consequences of tourism. Global Environmental Change, 12(4), 283-302. https://doi.org/10.1016/S0959-3780(02)00044-4

Gössling, S., \& Buckley, R. (2016). Carbon labels in tourism: Persuasive communication? Journal of Cleaner Production, 111, 358-369. https://doi.org/10.1016/j.jclepro.2014.08.067

Government of Ontario. Environmental Protection Act: Ontario Regulation 102/94 Waste Audits and Waste Reduction Work Plans (1994). Government of Ontario website. Retrieved from https://www.ontario.ca/laws/regulation/940102

Graci, S., \& Dodds, R. (2015). Certification and Labelling. In C. M. Hall, S. Gossling, \& D. Scott (Eds.), The Routledge Handbook of Tourism and Sustainability. New York, New York: Taylor \& Francis.

Greater Toronto Hotel Association. (n.d.). The Destination Marketing Program. Retrieved May 2, 2017, from http://www.gtha.com/Members/DestinationMarketingProgram.aspx

Green Globe. (n.d.-a). Competitive Advantages. Retrieved February 7, 2017, from http://greenglobe.com/competitive_advantages/

Green Globe. (n.d.-b). Green Globe Travel: Hotels and Resorts. Retrieved October 5, 2016, from http://greenglobe.travel/hotels-resorts/

Green Globe. (n.d.-c). Media Reach. Retrieved September 26, 2016, from http://greenglobe.com/media-reach/

Green Globe. (n.d.-d). Partners. Retrieved January 11, 2017, from http://greenglobe.com/partners/

Green Key. (n.d.). Our History. Retrieved February 2, 2017, from http://www.greenkey.global/history/

Green Key Global. (n.d.-a). FAQ’s. Retrieved January 11, 2017, from http:/greenkeyglobal.com/resources/faqs/

Green Key Global. (n.d.-b). Green Key Eco-Rating Program. Retrieved October 5, 2016, from http://greenkeyglobal.com/programs/eco-rating-program/ 
Grimstad, S. (2011). Developing a framework for examining business-driven sustainability initiatives with relevance to wine tourism clusters. International Journal of Wine Business Research, 23(1), 62-82. https://doi.org/10.1108/17511061111121416

Griswold, A. (2015, December 29). Airbnb is becoming a real threat to the hotel business in big US cities. Quartz. Retrieved from http://qz.com/582553/airbnb-is-becoming-a-real-threatto-the-hotel-business-in-big-us-cities/

Guttentag, D. (2013). Airbnb: disruptive innovation and the rise of an informal tourism accommodation sector. Current Issues in Tourism, 3500(September), 1-26. https://doi.org/10.1080/13683500.2013.827159

Guttentag, D. (2016). Why tourists choose Airbnb : A motivation-based segmentation study underpinned by innovation concepts. University of Waterloo. Retrieved from https://uwspace.uwaterloo.ca/bitstream/handle/10012/10684/Guttentag_Daniel.pdf?sequenc $\mathrm{e}=1 \&$ is Allowed $=\mathrm{y}$

Hamari, J., Sjoklint, M., \& Ukkonen, A. (2016). The sharing economy: Why people participate in collaborative consumption. Journal of the Association for Information Science and Technology, 67(9), 2047-2059. https://doi.org/10.1002/asi

Hamilton, T. (2015, September). Hotels, Airbnb battle for green cred. Corporate Knights. Retrieved from http://www.corporateknights.com/channels/built-environment/hotels-airbnbbattle-for-green-cred-14428152/

Hartig, T., Kaiser, F. G., \& Bowler, P. a. (2001). Psychological restoration in nature as a positive motivation for ecological behavior. Psychological Restoration in Nature as a Positive Motivation for Ecological Behavior, 33(4), 590-607. https://doi.org/10.1177/00139160121973142

Heo, C. Y. (2016). Sharing economy and prospects in tourism research. Annals of Tourism Research, 58(February), 166-170. https://doi.org/10.1016/j.annals.2016.02.002

Heras-Saizarbitoria, I., Boiral, O., \& Arana, G. (2016). Renewing environmental certification in times of crisis. Journal of Cleaner Production, 115, 214-223. https://doi.org/10.1016/j.jclepro.2015.09.043

Hertwich, E. G. (2005). Consumption and the rebound effect - An industrial ecology perspective. Journal of Industrial Ecology, 9(1-2), 85-98. https://doi.org/10.1162/1088198054084635

Hibbert, J. F., Dickinson, J. E., Gössling, S., \& Curtin, S. (2013). Identity and tourism mobility: an exploration of the attitude-behaviour gap identity and tourism mobility: An exploration of the attitude-behaviour gap. Journal of Sustainable Tourism, 21(7), 999-1016. https://doi.org/10.1080/09669582.2013.826232

Hillary, R. (2000). Introduction. In R. Hillary (Ed.), Small and Medium-Sized Enterprises and the Environment. Sheffield, UK: Greenleaf Publishing Ltd.

Hillary, R. (2004). Environmental management systems and the smaller enterprise. Journal of Cleaner Production, 12(6), 561-569. https://doi.org/10.1016/j.jclepro.2003.08.006 
Hilton Worldwide. (n.d.). Hilton Worldwide Earns ISO 9001 and ISO 14001 Certifications for Quality and Environmental Management. Retrieved October 5, 2016, from http://news.hiltonworldwide.com/index.cfm/news/hilton-worldwide-earns-iso-9001-andiso-14001-certifications-for-quality-and-environmental-management

Hjalager, A. M. (1996). Tourism and the environment: the innovation connection. Journal of Sustainable Tourism, 4(4), 201-218.

Hobson, K., \& Essex, S. (2001). Sustainable tourism: A view from accommodation businesses. The Service Industries Journal, 21(4), 133-146.

Honey, M. (Ed.). (2002). Ecotourism \& Certification: Setting Standards in Practice. Washington, D.C.: Island Press.

Honey, M. (2008). Who Owns Paradise? (2nd ed.). Washington, D.C.: Island Press.

Honey, M., \& Stewart, E. (2002). The Evolution of “Green” Standards for Tourism. In M. Honey (Ed.), Ecotourism \& Certification: Setting Standards in Practice. Island Press.

Horgan, C. (2016, September). Airbnb's Toronto data is a confusing mess. Maclean's. Retrieved from http://www.macleans.ca/news/canada/airbnbs-toronto-data-is-a-confusing-mess/

Horiuchi, R., Schuchard, R., Shea, L., \& Townsend, S. (2009). Understanding and preventing greenwash: A business guide. London. Retrieved from https://www.bsr.org/reports/Understanding_Preventing_Greenwash.pdf

Hsiao, T. Y., Chuang, C. M., Kuo, N. W., \& Yu, S. M. F. (2014). Establishing attributes of an environmental management system for green hotel evaluation. International Journal of Hospitality Management, 36, 197-208. https://doi.org/10.1016/j.ijhm.2013.09.005

Ikkala, T., \& Lampinen, A. (2014). Defining the price of hospitality: Networked hospitality exchange via Airbnb. In Proceedings of the companion publication of the 17th ACM conference on Computer supported cooperative work \& social computing (pp. 173-176). Baltimore, MD: ACM.

Ikkala, T., \& Lampinen, A. (2015). Monetizing network hospitality: Hospitality and sociability in the context of Airbnb. In Proceedings of the 18th ACM Conference on Computer Supported Cooperative Work \& Social Computing (pp. 1033-1044). Vancouver, B.C.: ACM.

Innovation Science and Economic Development Canada. (2016). Key Small Business Statistics June 2016. Ottawa, ON. Retrieved from https://www.ic.gc.ca/eic/site/061.nsf/vwapj/KSBSPSRPE_June-Juin_2016_eng-V2.pdf/\$file/KSBS-PSRPE_June-Juin_2016_eng-V2.pdf

International Organization for Standardization. (2015a). ISO 14000:2015. Geneva, Switzerland. Retrieved from http://www.iso.org/iso/iso14000

International Organization for Standardization. (2015b). Terms and definition in ISO 14001:2015 - where did they originate from? Retrieved January 11, 2017, from https://committee.iso.org/files/live/sites/tc207sc1/files/Terms and definitions in ISO 14001_2015 - where did they originate from.pdf 
Isaac, M. (2015, December 1). Airbnb Releases Trove of New York City Home-Sharing Data. The New York Times. Retrieved from http://www.nytimes.com/2015/12/02/technology/airbnb-releases-trove-of-new-york-cityhome-sharing-data.html

ISEAL Alliance. (n.d.). Our Codes of Good Practice. Retrieved January 12, 2017, from http://www.isealalliance.org/our-work/defining-credibility/codes-of-good-practice

Jarvis, N., Weeden, C., \& Simcock, N. (2010). The benefits and challenges of sustainable tourism certification: A case study of the Green Tourism Business Scheme in the west of England. Journal of Hospitality and Tourism Management, 17, 83-93. https://doi.org/10.1375/jhtm.17.1.83

Jayawardena, C. (Chandi), Pollard, A., Chort, V., Choi, C., \& Kibicho, W. (2013). Trends and sustainability in the Canadian tourism and hospitality industry. Worldwide Hospitality and Tourism Themes, 5(2), 132-150. https://doi.org/10.1108/17554211311314164

Jones, P., Hillier, D., \& Comfort, D. (2014). Sustainability in the global hotel industry. International Journal of Contemporary Hospitality Management, 26(1), 5-17. https://doi.org/10.1108/ijchm-10-2012-0180

Juster, F. T. (1966). Consumer buying intentions and purchase probability: An experiment in survey design. Journal of American Statistical Association, 61(315), 658-696.

Kaiser, F. G., Ranney, M., Hartig, T., \& Bowler, P. A. (1999). Ecological behavior, environmental attitude, and feelings of responsibility for the environment. European Psychologist, 4(2), 59-74. https://doi.org/10.1027//1016-9040.4.2.59

Kalinowski, T. (2016, September 22). Airbnb cutting into available rentals in city, study shows. The Toronto Star. Retrieved from https://www.thestar.com/business/2016/09/22/airbnbcutting-into-available-rentals-in-city-study-shows.html

Kalinowski, T. (2017, February 7). Airbnb says it gives Toronto a \$417M boost each year. The Toronto Star. Toronto, Ontario. Retrieved from https://www.thestar.com/business/2017/02/07/airbnb-says-it-gives-toronto-a-417m-boosteach-year.html

Karlsson, L., \& Dolnicar, S. (2016). Does eco certification sell tourism services? Evidence from a quasi-experimental observation study in Iceland. Journal of Sustainable Tourism, 24(5), 694-714. https://doi.org/10.1080/09669582.2015.1088859

Kelly, H. (2015, November 4). Airbnb wants to turn hosts into "grassroots" activists. CNN Money. Retrieved from http://money.cnn.com/2015/11/04/technology/airbnb-after-prop-f/

Kharpal, A. (2017, April 13). Airbnb's growth is slowing because it's being hit by regulation, UBS says. $C N B C$. Retrieved from http://www.cnbc.com/2017/04/13/airbnb-growthslowing-regulation-ubs.html

King, D. (2016, April 13). Analysts elucidate the Airbnb threat to hotels. Travel Weekly. Retrieved from http://www.travelweekly.com/Travel-News/Hotel-News/Analysts-elucidateAirbnb-threat-hotels 
Kokalitcheva, K. (2015, June 17). Here's how Airbnb justifies its eye-popping \$24 billion valuation. Fortune. Retrieved from http://fortune.com/2015/06/17/airbnb-valuationrevenue/

Kokalitcheva, K. (2016, July). Airbnb Agrees To Collect Hotel Taxes In Another Huge U.S. City. Fortune. Retrieved from http://fortune.com/2016/07/18/airbnb-los-angeles-taxes/

Kubickova, M., Nusair, K., \& Hu, H.-H. "Sunny.” (2015). Does green hotel image influence guests' behavior: The case of Generation Y. Journal of Services Research, 14(2), 9-32.

Kulwin, N. (2016, June 8). Airbnb doesn't want to mess with what's working, but it is adding a few features to the service. Recode. Retrieved from http://www.recode.net/2016/6/8/11886848/airbnb-features-home-sharing-service-ipo

Kuminoff, N. V., Zhang, C., \& Rudi, J. (2010). Are travelers willing to pay a premium to stay at a "green" hotel? Evidence from an internal meta-analysis of hedonic price premia. Agricultural and Resource Economics Review, 39(3), 468-484.

Kuo, N.-W., \& Chen, P.-H. (2009). Quantifying energy use, carbon dioxide emission, and other environmental loads from island tourism based on a life cycle assessment approach. Journal of Cleaner Production, 17(15), 1324-1330. https://doi.org/10.1016/j.jclepro.2009.04.012

Lane, J., \& Woodworth, R. M. (2016). The Sharing Economy Checks In: An Analysis of Airbnb in the United States. Retrieved from http://www.cbrehotels.com/EN/Research/Pages/AnAnalysis-of-Airbnb-in-the-United-States.aspx

Leask, M. (2016). Municipal Regulation of Short Term Rental Accommodations. Retrieved April 11, 2017, from http://lbwlawyers.com/municipal-regulation-of-short-term-rentalaccomodations/

Lebour, T. (2010, January 8). Number of benefits to LEED-certified condos. The Toronto Star. Retrieved from https://www.thestar.com/life/homes/2010/01/08/number_of_benefits_to_leedcertified_cond os.html

Lee, J.-S., Hsu, L.-T. (Jane), Han, H., \& Kim, Y. (2010). Understanding how consumers view green hotels: how a hotel's green image can influence behavioural intentions. Journal of Sustainable Tourism, 18(7), 901-914. https://doi.org/10.1080/09669581003777747

Lehr, D. (2015). An Analysis of the Changing Competitive Landscape in the Hotel Industry Regarding Airbnb. Master's Theses and Capstone Projects, Paper 188. Retrieved from http://scholar.dominican.edu/masters-theses/188

Leland, J. (2012, July 21). They Can List, but They Can't Hide. The New York Times. Retrieved from http://mobile.nytimes.com/2012/07/22/nyregion/stuyvesant-town-sleuths-keep-vigilagainst-illegal-hoteliers-in-their-midst.html?_r=0

Lincoln, Y., \& Guba, E. (1985). Naturalistic Inquiry. Beverly Hills, California: Sage Publications.

Lowe, A. (1988). Small hotel survival-an inductive approach. International Journal of Hospitality Management, 7(3), 197-223. https://doi.org/10.1016/0278-4319(88)90021-7 
Lubbert, C. (2001). Tourism Ecolabels Market Research in Germany. In X. Font \& R. C. Buckley (Eds.), Tourism Ecolabelling: Certification and Promotion of Sustainable Management. New York, New York: CABI Publishing.

Manaktola, K., \& Jauhari, V. (2007). Exploring consumer attitude and behaviour towards green practices in the lodging industry in India. International Journal of Contemporary Hospitality Management, 19(5), 364-377. https://doi.org/10.1108/09596110710757534

Marowtis, R. (2016, September 15). Quebec's legislation regulating Airbnb-type rentals raises doubts. The Globe and Mail. Retrieved from http://www.theglobeandmail.com/report-onbusiness/quebecs-legislation-regulating-airbnb-type-rentals-raises-doubts/article31912028/

Mayer, F. S., \& Frantz, C. M. (2004). The connectedness to nature scale: A measure of individuals' feeling in community with nature. Journal of Environmental Psychology, 24(4), 503-515. https://doi.org/10.1016/j.jenvp.2004.10.001

McCartney, S. (2012, October 18). The Best and Worst U.S. Cities for Travel Taxes. The Wall Street Journal. Retrieved from http://www.wsj.com/articles/SB10000872396390443749204578048421344521076

Meetup. (n.d.). About Meetup. Retrieved April 7, 2016, from https://www.meetup.com/about/

Middleton, V., \& Hawkins, R. (1998). Sustainable Tourism: A Marketing Perspective. Oxford, United Kingdon: Butterworth-Heinemann.

Milfont, T. L. (2009). The effects of social desirability on self-reported environmental attitudes and ecological behaviour. Environmentalist, 29(3), 263-269. https://doi.org/10.1007/s10669-008-9192-2

Millar, M., \& Baloglu, S. (2011). Hotel guests' preferences for green guest room attributes. Cornell Hospitality Quarterly, 52(3), 302-311. https://doi.org/10.1177/1938965511409031

Miller, G. (2003). Consumerism in sustainable tourism : A survey of UK consumers. Journal of Sustainable Tourism, 11(1), 17-39.

Montgomery, K. (2014). Airbnb Thinks Greenwashing Will Clean Up All Its Bad PR. Retrieved September 16, 2016, from http://valleywag.gawker.com/airbnb-thinks-greenwashing-willclean-up-all-its-bad-pr-1614174510

Morgenstern, R., \& Pizer, W. (Eds.). (2007). Reality Check: The Nature and Performance of Voluntary Environmental Programs in the United States, Europe, and Japan. Washington, D.C.: Resources for the Future.

Murthy, R. (2016, March 23). Toronto's voluntary "hotel tax" catching most visitors by surprise. CityNews. Retrieved from http://www.citynews.ca/2016/03/23/torontos-voluntary-hotel-taxcatching-most-tourists-by-surprise/

Neuman, W. L., \& Robson, K. (2012). Basics of Social Research: Qualitative and Quantitative Approaches (2nd ed.). Toronto, Ontario: Pearson Canada.

Neuman, W. L., \& Robson, K. (2014). Basics of Social Research: Qualitative and Quantitative Approaches (3rd ed.). Toronto, Ontario: Pearson Canada. 
Newcomer, E. (2015, July 20). Airbnb Overhauls Service for Business Travelers. Bloomberg Technology. Retrieved from https://www.bloomberg.com/news/articles/2015-07-20/airbnboverhauls-service-for-business-travelers

Newcomer, E., \& Huet, E. (2016, August 5). Airbnb Files to Raise $\$ 850$ Million at $\$ 30$ Billion Valuation. Bloomberg Technology. Retrieved from http://www.bloomberg.com/news/articles/2016-08-05/airbnb-files-to-raise-850-million-at30-billion-valuation

Nowak, B., Allen, T., Rollo, J., Lewis, V., He, L., Chen, A., ... Young, E. (2015). Global Insight: Who Will Airbnb Hurt More -Hotels or OTAs? Retrieved from http://linkback.morganstanley.com/web/sendlink/webapp/f/9lf3j168-3pcc-g01h-b8bf005056013100? store $=0 \& d=U w B S Z X N 1 Y X J j a F 9 N U w B i N j V j Y z A y N i 04 N G Q 2 L T E x Z T U t$ YjFlMi03YzhmYTAzZWU4ZjQ\%3D\&user=bdvpwh9kcvqs49\&_gda_=1573813969_cf5a3761794d8651f8618fc7a544cb82

Olson, E. L. (2013). It's not easy being green: The effects of attribute tradeoffs on green product preference and choice. Journal of the Academy of Marketing Science, 41(2), 171-184. https://doi.org/10.1007/s11747-012-0305-6

Ontario Restaurant Hotel and Motel Association. (2011). Regulatory Burden in Ontario. Retrieved from https://www.orhma.com/Portals/0/PDF Files/GovtRelations/FoodSafetyNutrition/2011.02RegulatoryBurden.pdf

Park, S.-Y., \& Millar, M. (2016). The US travelers familiarity with and perceived credibility of lodging ecolabels. Journal of Vacation Marketing, 22(1), 3-12. https://doi.org/10.1177/1356766715585904

Parsons, C., \& Grant, J. (2007). Green Globe: a Global Envrionmental Certification Programme for Travel and Tourism. In R. Black \& A. Crabtree (Eds.), Quality Assurance and Certification in Ecotourism. Cambridge, Massachusetts: CABI Publishing.

Patton, M. Q. (2002). Qualitative Research \& Evaluation Methods (3rd ed.). Thousand Oaks, CA: Sage Publications.

Paulhus, D. L. (1991). Measurement and Control of Response Bias. In J. P. Robinson, P. . Shaver, \& L. S. Wrightsman (Eds.), Measures of personality and social psychological attitudes (pp. 17-59). San Diego, CA: Academic Press.

Peiro-Signes, A., Segarra-Ona, M., Verma, R., Mondejar-Jimenez, J., \& Vargas-Vargas, M. (2013). The impact of environmental certification on hotel guest ratings. Cornell Hospitality Quarterly, 55(1), 40-51. https://doi.org/10.1177/1938965513503488

Perkins, R., \& Neumayer, E. (2010). Geographic variations in the early diffusion of corporate voluntary standards: Comparing ISO 14001 and the Global Compact. Environment and Planning A, 42(2), 347-365. https://doi.org/10.1068/a4249

Podsakoff, P. M., MacKenzie, S. B., Lee, J. Y., \& Podsakoff, N. P. (2003). Common method biases in behavioral research: A critical review of the literature and recommended remedies. Journal of Applied Psychology, 88(5), 879-903. https://doi.org/10.1037/00219010.88.5.879 
Pomering, A., \& Johnson, L. W. (2009). Advertising corporate social responsibility initiatives to communicate corporate image: Inhibiting scepticism to enhance persuasion. Corporate Communications: An International Journal, 14(4), 420-439. https://doi.org/10.1108/13563280910998763

Prajogo, D., Castka, P., Yiu, D., Yeung, A. C. L., \& Lai, K.-H. (2016). Environmental audits and third party certification of management practices: Firms' motives, audit orientations, and satisfaction with certification. International Journal of Auditing, 20(2), 202-210. https://doi.org/10.1111/ijau.12068

Puhakka, R., \& Siikamaki, P. (2012). Nature tourists' response to ecolabels in Oulanka PAN Park, Finland. Journal of Ecotourism, 11(1), 56-73. https://doi.org/10.1080/14724049.2011.647917

PWC. (2015). The Sharing Economy. Retrieved from https://www.pwc.com/us/en/technology/publications/assets/pwc-consumer-intelligenceseries-the-sharing-economy.pdf

Qi, G. Y., Zeng, S. X., Tam, C. M., Yin, H. T., Wu, J. F., \& Dai, Z. H. (2011). Diffusion of ISO 14001 environmental management systems in China: Rethinking on stakeholders' roles. Journal of Cleaner Production, 19(11), 1250-1256. https://doi.org/10.1016/j.jclepro.2011.03.006

Rainforest Alliance. (2009). Partnership for Global Sustainable Tourism Criteria and Sustainable Tourism Stewardship Council Announce Merge to Form Tourism Sustainability Council. Retrieved September 26, 2016, from http://www.rainforest-alliance.org/newsroom/pressreleases/gstc-stsc-merge

Rattan, J. (2015). Is certification the answer to creating a more sustainable volunteer tourism sector? Worldwide Hospitality and Tourism Themes, 7(2), 107-126. https://doi.org/10.1108/WHATT-12-2014-0047

Rekrut, M. (n.d.). Toronto AIRBNB Hosts. Retrieved September 16, 2016, from http://www.meetup.com/Airtoronto/messages/boards/

Revell, A., \& Blackburn, R. (2007). The business case for sustainability? An examination of small firms in the UK's construction and restaurant sectors. Business Strategy and the Environment, 16(6), 404-420. https://doi.org/10.1002/bse.499

Rex, E., \& Baumann, H. (2007). Beyond ecolabels: what green marketing can learn from conventional marketing. Journal of Cleaner Production, 15(6), 567-576. https://doi.org/10.1016/j.jclepro.2006.05.013

Rezidor Hotel Group. (n.d.). Eco-labelled hotels. Retrieved January 4, 2017, from http://www.rezidor.com/phoenix.zhtml?c=205430\&p=respecolabels

Rezidor Hotel Group. (2016). Corporate Presentation - November 2016. Retrieved from http://phx.corporateir.net/External.File?item=UGFyZW50SUQ9MzA4NDkxfENoaWxkSUQ9LTF8VHlwZT0z $\& \mathrm{t}=1 \& \mathrm{cb}=635805039048146669$ 
Roberts, J. (1996). Will the socially responsible consumer please step forward. Business Horizons, 39(1), 79-84.

Rowe, T., \& Higham, J. (2007). Ecotourism Certification in New Zealand: Operator and Industry Perspectives. In R. Black \& A. Crabtree (Eds.), Quality Assurance and Certification in Ecotourism. Cambridge, Massachusetts: CABI Publishing.

Rutherfoord, R., Blackburn, R., \& Spence, L. (2000). Environmental management and the small firm: An international comparison. International Journal of Entrepreneurial Behaviour and Research, 6(6). Retrieved from http://ezproxy.lib.ryerson.ca/login?url=http://search.proquest.com/docview/212177535?acc ountid=13631

Said, C. (2012, June 10). Short-term rentals disrupting SF housing market. San Francisco Chronicle. Retrieved from http://www.sfgate.com/realestate/article/Short-term-rentalsdisrupting-SF-housing-market-3622832.php

Sampaio, A. R., Thomas, R., \& Font, X. (2012). Small business management and environmental engagement. Journal of Sustainable Tourism, 20(2), 179-193. https://doi.org/10.1080/09669582.2011.602193

Sanchez-Medina, P., Diaz-Pichardo, R., \& Cruz-Bautista, M. (2016). Stakeholder influence on the implementation of environmental management practices in the hotel industry. International Journal of Tourism Research, 18, 387-398. https://doi.org/10.1002/jtr.2056

Sandelowski, M. (2000). Whatever happened to qualitative description? Research in Nursing \& Health, 23(4), 334-340. https://doi.org/10.1002/1098-240x(200008)23:4<334::aidnur9>3.0.co;2-g

Sanders, E. (2005). Demand for Certification According to Consumer Experts and Consumer Advocacy Organizations. Retrieved from http://www.responsibletravel.org/projects/documents/certification_reports/Consumer_dema nd_experts_final_4Jan05.pdf

Schaper, M., \& Carlsen, J. (2004). Overcoming the Green Gap: Improving the Environmental Performance of Small Tourism Firms in Western Australia. In R. Thomas (Ed.), Small Firms in Tourism: International Perspectives. Oxford, United Kingdon: Elsevier Ltd.

Segarra-Ona, M., Peiro-Signes, A., Verma, R., \& Miret-Pastor, L. (2012). Does environmental certification help the economic performance of hotels?: Evidence from the spanish hotel industry. Cornell Hospitality Quarterly, 53(3), 242-256. https://doi.org/10.1177/1938965512446417

Shankman, S. (2015, February 20). Starwood's Room Growth Fell Short of Its Competitors in 2014. Skift. Retrieved from http://skift.com/2015/02/20/starwoods-room-growth-fell-shortof-its-competitors-in-2014/

Sharpley, R. (2001). The Consumer Behaviour Context of Ecolabelling. In X. Font \& R. C. Buckley (Eds.), Tourism Ecolabelling: Certification and Promotion of Sustainable Management. New York, New York: CABI Publishing. 
Sirakaya-Turk, E., Baloglu, S., \& Mercado, H. U. (2014). The efficacy of sustainability values in predicting travelers' choices for sustainable hospitality bisinesses. Cornell Hospitality Quarterly, 55(1), 115-126. https://doi.org/10.1177/1938965513499822

Sjöström, B., \& Dahlgren, L. O. (2002). Applying phenomenography in nursing research. Journal of Advanced Nursing, 40(3), 339-345. https://doi.org/10.1046/j.13652648.2002.02375.x

Snyder, B. (2014, July 31). Exclusive: Airbnb says it's saving our world with each rented room. Fortune. Retrieved from http://fortune.com/2014/07/31/exclusive-airbnb-says-its-savingour-world-with-each-rented-room/

Sommer, B., \& Sommer, R. (1991). A Practical Guide to Behavioural Research: Tools and Techniques (3rd ed.). New York, New York: Oxford University Press.

Starwood Hotels \& Resorts' Global Headquarters Earns Highest Environmental Certification. (2015, February 26). Business Wire. Retrieved from www.businesswire.com/news/home/20150226005800/en/Starwood-Hotels-Resorts'-GlobalHeadquarters-Earns-Highest

Sun, B., \& Morwitz, V. G. (2010). Stated intentions and purchase behavior: A unified model. International Journal of Research in Marketing, 27(4), 356-366. https://doi.org/10.1016/j.ijresmar.2010.06.001

Sustainability in tourism: A guide through the label jungle. (2016). Retrieved from https://www.tourism-watch.de/en/content/guide-through-tourism-label-jungle

Synergy Ltd. (2000). Tourism Certification: an analysis of Green Globe 21 and other certification programs. Retrieved from http://www.wwf.org.uk/filelibrary/pdf/tcr.pdf

TD Economics. (2015). The Market Benefits of "Green” Condos in Toronto. Retrieved from https://www.td.com/document/PDF/economics/special/GreenCondos.pdf

Tilley, F. (2000). Small firm environmental ethics: How deep do they go? Business Ethics: A European Review, 9(1), 31-42. https://doi.org/10.1111/1467-8608.00167

Ting, D. (2016, October 7). A Better Look at Airbnb's New City Hosts Program for Next-Gen Tours and Activities. Skift. Retrieved from https://skift.com/2016/10/07/airbnb-expandscity-hosts-program-as-it-prepares-to-formally-debut-magical-trips/

Top 10 hotel groups in Europe. (2016, February 18). Hospitality Think Tank. Retrieved from http://hospitality-on.com/en/news/2016/02/18/top-10-hotel-groups-in-europeinfography/\#at_pco=smlwn-1.0\&at_si=586e990504262166\&at_ab=per2\&at_pos $=0 \&$ at_tot $=1$

Toth, R. (2002). Exploring the Concepts Underlying Certification. In M. Honey (Ed.), Ecotourism \& Certification: Setting Standards in Practice. Washington, D.C.: Island Press.

Tussyadiah, I. (2015). An Exploratory Study on Drivers and Deterrents of Collaborative Consumption in Travel. In I. Tussyadiah \& A. Inversini (Eds.), Information \& Communication Technologies in Tourism 2015 (pp. 817-830). Switzerland: Springer International Publishing. https://doi.org/10.1016/S0160-7383(01)00012-3 
Tyrrell, T., Paris, C., \& Biaett, V. (2013). A quantified triple bottom line for tourism: Experimental results. Journal of Travel Research, 52(3). Retrieved from http://resolver.scholarsportal.info/resolve/00472875/v52i0003/279_aqtblfter.xml

Tzschentke, N., Kirk, D., \& Lynch, P. A. (2004). Reasons for going green in serviced accommodation establishments. International Journal of Contemporary Hospitality Management, 16(2), 116-124. https://doi.org/10.1108/09596110410520007

Tzschentke, N., Kirk, D., \& Lynch, P. A. (2008a). Ahead of their time? Barriers to action in green tourism firms. The Service Industries Journal, 28(2), 167-178. https://doi.org/10.1080/02642060701842175

Tzschentke, N., Kirk, D., \& Lynch, P. A. (2008b). Going green: Decisional factors in small hospitality operations. International Journal of Hospitality Management, 27(1), 126-133. https://doi.org/10.1016/j.ijhm.2007.07.010

urbanmetrics inc. (2017). Toronto: Economic Impact Statement. Toronto, Ontario. Retrieved from https:/www.airbnbcitizen.com/wp-content/uploads/2017/02/airbnb-Economic-ImpactStatement-Toronto-Final-released.pdf

van Haastert, M., \& de Grosbois, D. (2010). Environmental initiatives in bed and breakfast establishments in Canada: Scope and major challenges with implementation. Tourism and Hospitality Planning \& Development, 7(2), 179-193. https://doi.org/10.1080/14790531003755286

Vernon, J., Essex, S., Pinder, D., \& Curry, K. (2003). The “Greening” of tourism micro businesses: Outcome of focus group investigations in south east cornwall. Business Strategy and the Environment, 12, 49-69. https://doi.org/10.1002/bse.348

Vidovic, M., \& Khanna, N. (2007). Can voluntary pollution prevention programs fulfill their promises? Further evidence from the EPA's 33/50 Program. Journal of Environmental Economics and Management, 53(2), 180-195. https://doi.org/10.1016/j.jeem.2006.10.001

Volkmann, M. (2015, July 29). Hotel or Home-Share: Which is Greener? Sustainable City Network. Retrieved from http://www.sustainablecitynetwork.com/topic_channels/community/article_b4dccaf2-360711e5-ac7b-f7aee98b07fb.html

Walters, J. (2017, February 12). Something in the Airbnb: hosts anxious as New York begins crackdown. The Guardian. Retrieved from https://www.theguardian.com/technology/2017/feb/12/airbnb-hosts-new-york-finesgovernment-illegal

Watkins, E. B. (1994). Do guests want green hotels? Lodging Hospitality, 50(12), 70-72.

Wearing, S., Cynn, S., Ponting, J., \& McDonald, M. (2002). Converting environmental concern into ecotourism purchases: A qualitative evaluation of international backpackers in australia. Journal of Ecotourism, 1(2-3), 133-148. Retrieved from http://resolver.scholarsportal.info/resolve/14724049/v1i2-3/133_ceciepeoibia.xml 
Weaver, D. B. (2009). Reflections on Sustainable Tourism and Paradigm Change. In S. Gossling, C. Michael Hall, \& D. B. Weaver (Eds.), Sustainable Tourism Futures: Perspectives on Systems, Restructuring and Innovations (pp. 33-40). New York, NY: Routledge.

Weisleder, M. (2014, July 15). Is Airbnb legal in Ontario. The Toronto Star. Retrieved from http://www.thestar.com/business/personal_finance/2014/07/15/is_airbnb_legal_in_ontario.h tml

Wieditz, T. (2017). Squeezed Out: Airbnb's Commercialization of Home-Sharing in Toronto. Retrieved from http://fairbnb.ca/Fairbnb_Report_Feb_29.pdf

Wiengarten, F., Pagell, M., \& Fynes, B. (2013). ISO 14000 certification and investments in environmental supply chain management practices: Identifying differences in motivation and adoption levels between Western European and North American companies. Journal of Cleaner Production, 56, 18-28. https://doi.org/10.1016/j.jclepro.2012.01.021

Wiese, A., Kellner, J., Lietke, B., Toporowski, W., \& Zielke, S. (2012). Sustainability in retailing - a summative content analysis. International Journal of Retail \& Distribution Management, 40(4), 318-335. https://doi.org/10.1108/09590551211211792

Williams, P. W., \& Ponsford, I. F. (2009). Confronting tourism's environmental paradox: Transitioning for sustainable tourism. Futures, 41(6), 396-404. https://doi.org/10.1016/j.futures.2008.11.019

Winkler, R., \& MacMillan, D. (2015, June 17). The Secret Math ofAirbnb's \$24 Billion Valuation; Home-rental site's revenue projected to top more than $\$ 900$ million. The Wall Street Journal. Retrieved from https://global-factivacom.ezproxy.lib.ryerson.ca/redir/default.aspx?P=sa\&an=WSJO000020150617eb6h007k9\& cat $=$ a\&ep $=$ ASE

Wu, S. Y., Chu, P. Y., \& Liu, T. Y. (2007). Determinants of a firm's ISO 14001 certification: An empirical study of Taiwan. Pacific Economic Review, 12(4), 467-487. https://doi.org/10.1111/j.1468-0106.2007.00365.x

Yannopoulou, N., Moufahim, M., \& Bian, X. (2013). User-generated brands and social media: Couchsurfing and Airbnb. Contemporary Management Research, 9(1), 85-90. https://doi.org/10.7903/cmr.11116

Young, W., Hwang, K., McDonald, S., \& Oates, C. J. (2010). Sustainable consumption: green consumer behavior when purchasing products. Sustainable Development, 18(1), 20-31. https://doi.org/10.1177/0266242610391936

Zervas, G., Proserpio, D., \& Byers, J. (2014). The rise of the sharing economy: Estimating the impact of Airbnb on the hotel industry. Boston U. School of Management Research Paper, (2013-16). 